\title{
Hydrochemical and environmental isotope study of the geothermal water in Mae Chan (North) and Ranong (South) geothermal areas in Thailand
}

\author{
Dissertation \\ zur Erlangung des Mathematisch-Naturwissenschaftlichen Doktorgrades \\ "Doctor rerum naturalium" \\ der Georg-August-Universität zu Göttingen \\ Im Promotionsprogramm Geowissenschaften \\ der Georg-August University School of Science (GAUSS) \\ vorgelegt von \\ Monthon Yongprawat
}

aus Ratchaburi, Thailand

Göttingen 2020 


\section{Betreuungsausschuss}

Prof. Dr. Martin Sauter

Dr. Bettina Wiegand
Abteilung Angewandte Geologie, Georg-August-Universität Göttingen

Abteilung Angewandte Geologie, Georg-August-Universität Göttingen

\section{Mitglieder der Prüfungskommission Referent}
Referent Prof. Dr. Martin Sauter Abteilung Angewandte Geologie, Georg-August-Universität Göttingen

Korreferentin 1 Prof. Dr. Andreas Pack Abteilung Isotopengeologie, GeorgAugust-Universität Göttingen

weitere Mitglieder der Prüfungskommission:

Prof. Dr. Jonas Kley

Prof. Dr. Volker Thiel

Dr. Bettina Wiegand

Dr. Iulia Ghergut
Abteilung Strukturgeologie, Georg-AugustUniversität Göttingen

Abteilung Geobiologie, Georg-August-Universität Göttingen

Abteilung Angewandte Geologie, Georg-AugustUniversität Göttingen

Abteilung Angewandte Geologie, Georg-AugustUniversität Göttingen 


\section{Acknowledgements}

The work presented in this dissertation would not have been possible without my association with many people and organizations. The constant support and steady assistance from them have contributed to this achievement.

First of all, the topic of this dissertation is one of the most challenging subjects in the isotopic hydrology area for me. I wish to express my sincere appreciation to my research supervisors, Prof. Martin Sauter, and Dr. Bettina Wiegand for giving me the great opportunity to be in your research group and providing invaluable guidance in effectively operationalize my Ph.D. research. Moreover, they convincingly guided and encouraged me to be professional. Their professionalism, vision, sincerity is also the best motivator for me of all time. Without their guidance and support, the dissertation would not have materialized.

I am thankful to all doctors, colleagues, and friends at the department of applied geology in Georg-August-University Göttingen, for their excellent technical support and friendships. Especially, many thanks to Mrs. Mechthild Rittmeier for her help in the chemical analysis in the water samples. Additionally, I received generous support from Dr. Graciela Miriam Sosa. The meticulous comments and suggestions gained on petrology and mineralogy analysis are truly invaluable.

I am indebted to the staff of the Hydrology laboratory in Thailand Institute of Nuclear Technology (TINT), Thailand for their support and help in-field sampling and analyzing the chemical and the isotope concentrations in water samples in this study. I would like to recognize the invaluable assistance that they all provided during my study.

Once again, I have had the support and encouragement of the Royal Thai Government and the Office of Education Affairs, The Royal Thai Embassy, Germany for providing me the scholarship and the great opportunity to pursue my doctoral studies and supervising the living in the internationally-oriented environments in Germany.

I would like to express gratitude to Dr. Helmut Dürrast and Dr. Fongsaward Suvagonda Singharajwarapan for their guidance on the study area information. I appreciation to $\mathrm{Mr}$. Boonroong Suangarmiam and Mr. Manop Raksasakulwong from the Department of Mineral resource, Thailand, for their valuable comment and the support literature. 
I cannot forget to thanks Mr. Somboon Khositanont and Prof. Ben T. Hansen for their guidance on my research at the earlier stage.

I would like to pay my special regards to Dr. Sirinart Laoharojanapan, Napoo Wongpan, and Patcharaporn Siripravatkul for proofreading and assisted me in the English academic writing. I owe a debt of gratitude to Rucha Helmcke (Sutthasatient) and Manussawee Hengsuwan for their support in the living in Göttingen.

My sincere thanks also goes to my university office mate (Room 315) comprise of Viet, Reza, and Pengxiang. They are not only great Ph.D. friends but also make an enjoyable atmosphere and make me feel not lonely while I was studying in the office. Also, I wish to especially thank my Thai friends in Göttingen for their good memories together and their supports in any circumstance I encountered during the Ph.D. study.

Finally, I would like to thank my family and my girlfriend for their encouragement and morale that have been great contributors in the completion of the research. 


\begin{abstract}
The exploration and development of geothermal resources in Thailand have been investigated for electricity generation since 1946. In total, 112 hot springs are manifested which mostly scattered at the granite body from the north to south of Thailand. Fang and Mae Chan areas, located in the NE-SW Mae Chan fault in the northern part of the country, are among five highest potential hot springs. These areas have been continuously investigated and successfully installed the geothermal utilization facility. One the other hand, a few pieces of research have investigated low enthalpies (low temperature) hot springs such as hot springs along the Mae Chan fault and Ranong fault lines. Therefore, the hydrogeological cycle of these hot springs is still considered ambiguous as little knowledge about these systems is available.
\end{abstract}

This Ph.D. dissertation integrates the applications of natural hydrogeochemical and isotopic composition in water and rock minerals to evaluate and improve the understanding of these hydrothermal systems. The results generally reveal that these thermal waters are originated from local meteoric water, are recharged from the high elevation, flows through weathered and fractured granite and heated at the shallow reservoir $\left(\mathrm{Na}-\mathrm{HCO}_{3}\right.$ water type). These thermal waters are reliable on the conservative $\mathrm{K}-\mathrm{Mg}$ and chalcedony geothermometers. The REE concentrations in thermal water are chemically reduced by increasing temperature and pressure which has the fluoride concentration predominantly control the precipitation processes of LREE-fluoride complex during flow path in this system. The geological setting of both areas makes a difference in isotopic and chemical composition of thermal water.

-In chapter 4, based on a case study in the Mae Chan faults zone, the thermal recharges from the high elevation of the mountainous areas ranging from 740 to $1,200 \mathrm{~m}$ AMSL. The conservative $\mathrm{K}-\mathrm{Mg}$ and chalcedony subsystems state equilibrium temperatures ranging from 98 to $139{ }^{\circ} \mathrm{C}$ and provide the estimated reservoir depth ranging from 353 and $814 \mathrm{~m}$ (-405 and $150 \mathrm{~m}$ AMSL). The silica-enthalpy mixing diagram provides temperature of geothermal reservoir ranging from 129 to $168{ }^{\circ} \mathrm{C}$ and most of the samples have stream-loss during ascending to the surface and mixed with cool water from 35 to $81 \%$ by volume. During the flow part, the chemical concentration of $\mathrm{F}, \mathrm{Na}^{+}, \mathrm{K}^{+}$, and $\mathrm{SO}_{4}{ }^{2-}$ could be developed from the granitic minerals (e.g., Na-feldspar) of the local batholith granite together with decreased $\mathrm{Ca}^{2+}$ and $\mathrm{Mg}^{2+}$. The $\mathrm{Cl}^{-}$is derived from precipitation. The $\delta^{13} \mathrm{C}$ in thermal waters were mixed with three different types of carbon sources. The first group is characterized by an initial $\delta^{13} \mathrm{C}$ that remains stable from the $\delta^{13} \mathrm{C}$ surface water. The second group is probably mixed with local 
geologic gases. The third group probably mixed with biological carbon. The ${ }^{14} \mathrm{C}$ dating is specifically reliable for the first group (without external carbon contamination) that has the residence time periods ranging from 12,760 to $18,000 \mathrm{BP}$. The mixing model results of $\mathrm{Sr}$ and ${ }^{87} \mathrm{Sr} /{ }^{86} \mathrm{Sr}$ ratio in thermal water provided differently in the percentage of rock contribution ranging from 73.11 to $86.31 \%$. The hot springs closed to the fault, had $73.11 \%$ to $75.10 \% \mathrm{Sr}$ with rock origin, while the hot springs located far from the fault core had 82.50 to $86.31 \% \mathrm{Sr}$ with rock origin. This relation probably conducted with the influence of that porosity and permeability of the crystalline basement rock, which varies with the distance of the fault core from the hot springs.

-In chapter 5, based on a case study in the Ranong faults zone, thermal water recharges from the high elevation of the mountainous areas ranging from 378 to $483 \mathrm{~m}$ AMSL. The conservative $\mathrm{K}-\mathrm{Mg}$ and chalcedony subsystems state equilibrium temperatures ranging from 82 to $105^{\circ} \mathrm{C}$. Based on drilling information and $\mathrm{Mg} / \mathrm{k}$ geothermometer, the estimated reservoir depth is in the range from 327 and $640 \mathrm{~m}$ (-286 to -612 m AMSL). The silica-enthalpy mixing diagram provides the temperature of the geothermal reservoir ranging from 130 to $199{ }^{\circ} \mathrm{C}$ and most of the samples have stream-loss during ascending to the surface and mixed with cool water from 70 to $90 \%$ by volume. The main source of carbon in the thermal water is the organic-rich soil and river sediment from the southwestern coast of the country. During the flow part, the chemical concentration of $\mathrm{F}, \mathrm{Na}^{+}, \mathrm{K}^{+}, \mathrm{SO}_{4}{ }^{2-}$, and $\mathrm{Ca}^{2+}$ could be developed from the granitic minerals (e.g., Na-feldspar) of the local batholith granite together with decreased and $\mathrm{Mg}^{2+}$. The $\mathrm{Cl}^{-}$is derived from precipitation. The corrected residence time from Pearson's model ranges from 2,675 to $5,235 \mathrm{BP}$. The mixing model results of $\mathrm{Sr}$, and ${ }^{87} \mathrm{Sr} /{ }^{86} \mathrm{Sr}$ ratio in thermal water provided the narrow range in percentage of rock contribution ranging from 88.31 to 86.21 suggesting that these hot springs have similar water-rock interaction and are isotopically controlled by the granitic rock.

Theses differences in environment chemical and isotopic results can be explained by multi, small reservoirs, rather than by single, large scale reservoirs. Moreover, these can establish four conceptual models in Ranong geothermal area and five conceptual models in Mae Chan geothermal area which will be helpful for future water resources assessment and sustainable geothermal water management. 


\section{Table of contents}

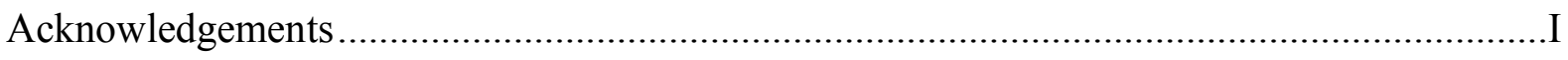

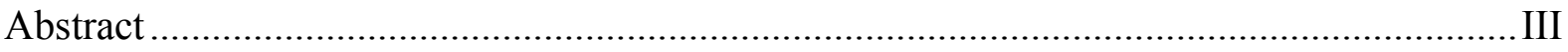

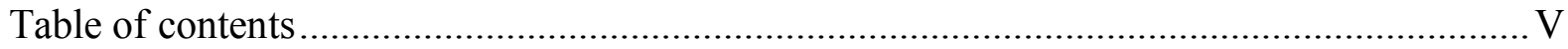

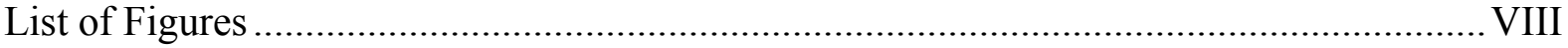

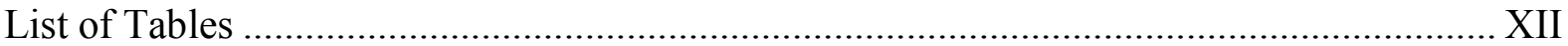

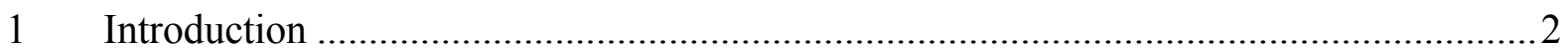

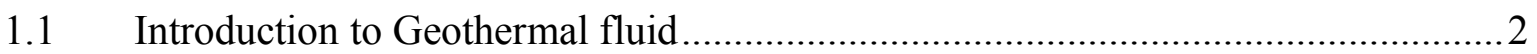

1.2 General overview - Geothermal study in Thailand ........................................... 3

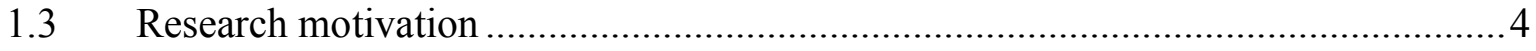

1.4 Environmental isotope and geochemistry of geothermal fluid and rock minerals ....6

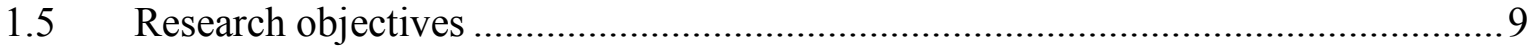

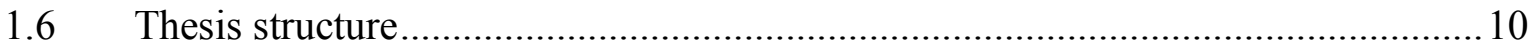

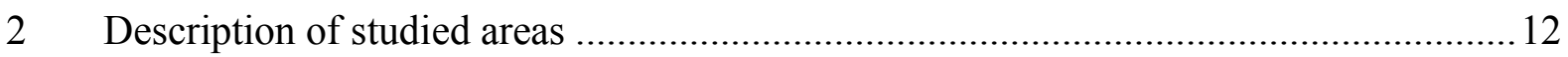

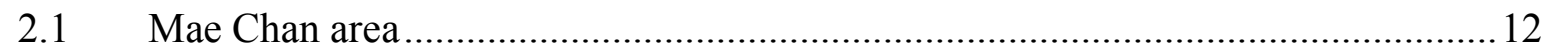

2.1.1 Geographic location and topography …................................................ 12

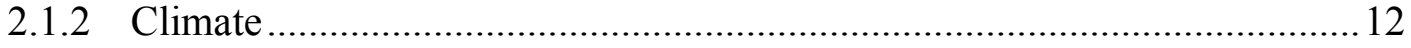

2.1.3 Regional geology and structures .............................................................. 12

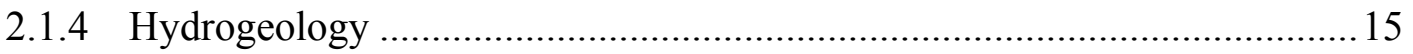

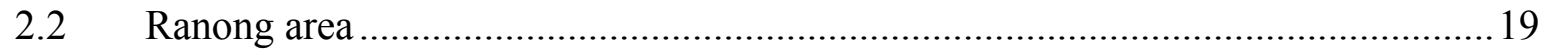

2.2.1 Geographic location and topography …................................................. 19

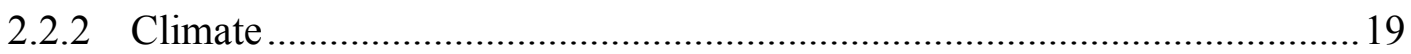

2.2.3 Regional geology and structures ........................................................ 19

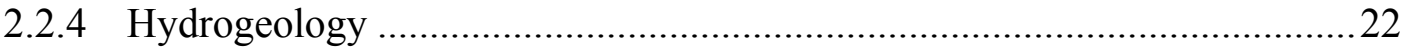

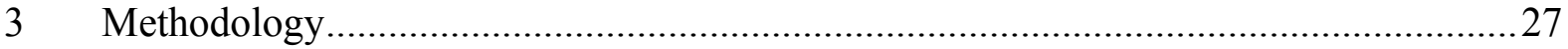

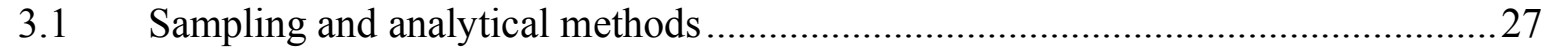

3.1.1 Measuring of field parameters …...........................................................2. 27

3.1.2 Petrology and mineralogy analysis .....................................................2

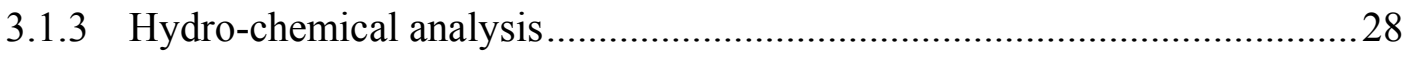

3.1.4 Radioactive and stable isotope analysis ..................................................29

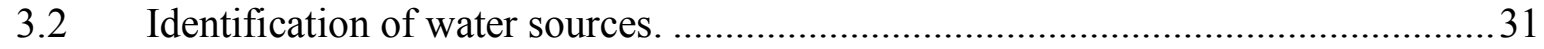

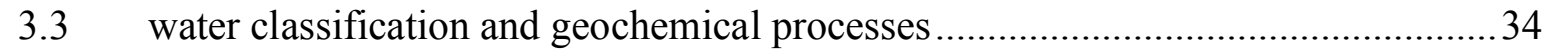

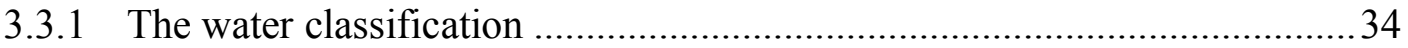


3.3.2 The geochemical processes

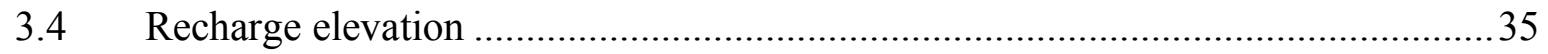

3.5 The residence time of thermal water estimation...................................................... 36

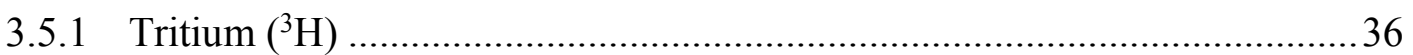

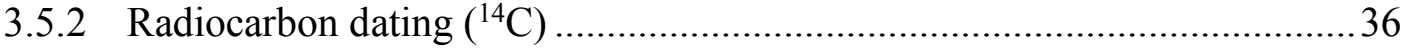

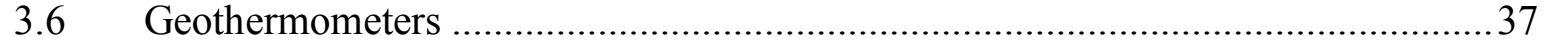

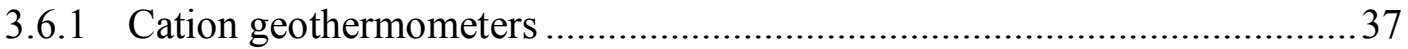

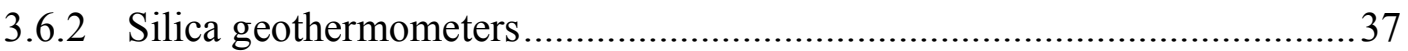

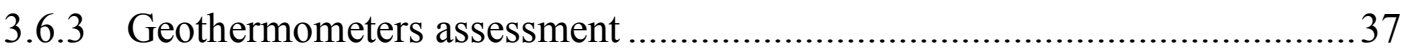

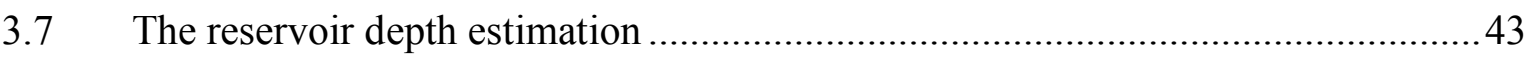

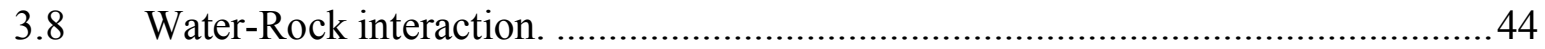

3.8.1 Rare earth elements in water and minerals ...........................................4 44

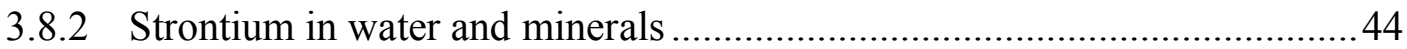

4 Characterization and evaluation of hydrochemistry, sources, and water-rock interaction

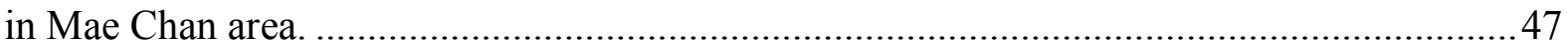

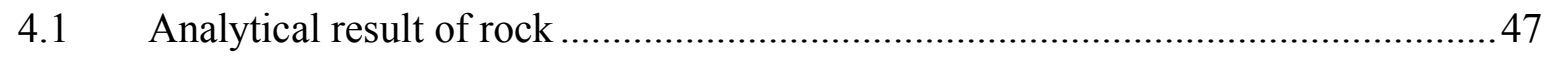

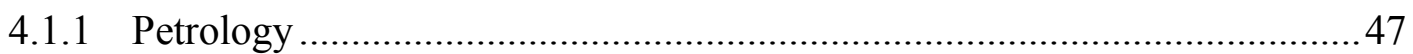

4.1.2 Rare earth elements in minerals............................................................ 48

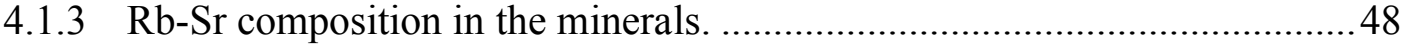

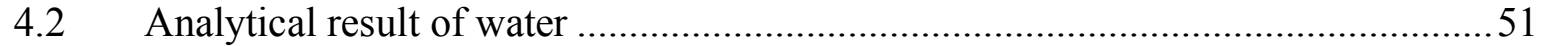

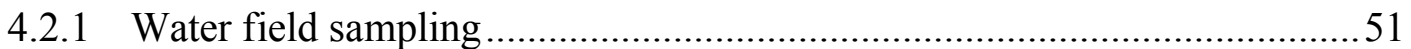

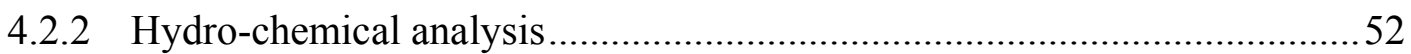

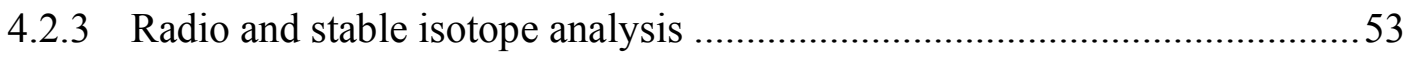

4.2.4 Geothermometer estimation. .................................................................5

4.2.5 Rare earth elements of the water............................................................61

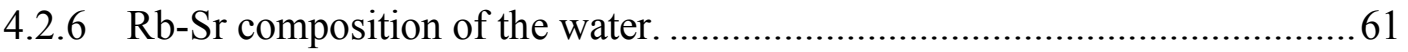

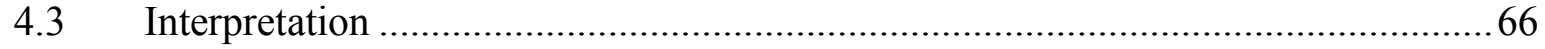

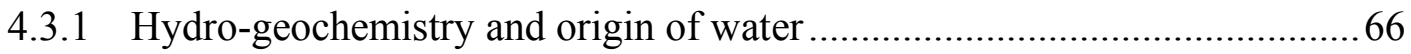

4.3.2 Geothermal assessment, geothermometer application.............................73

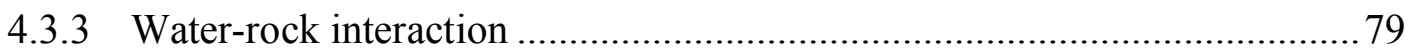

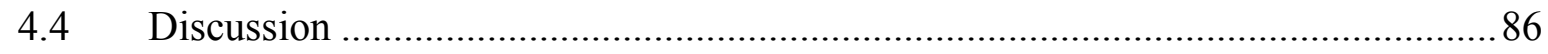

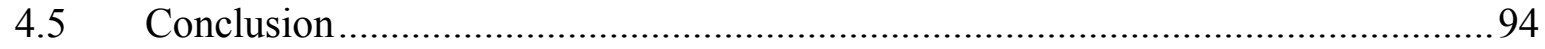

5 Characterization and evaluation of hydrochemistry, sources, and water-rock interaction in Ranong area. .98 


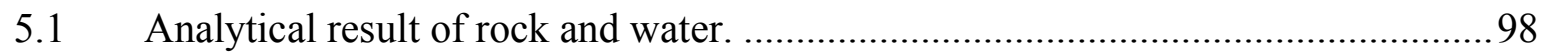

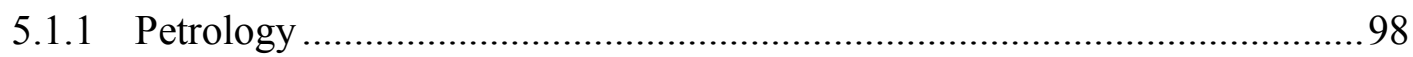

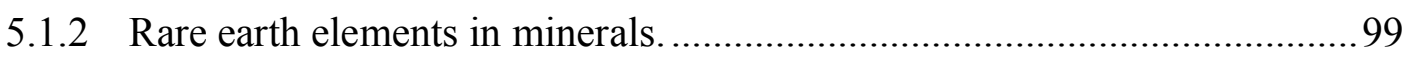

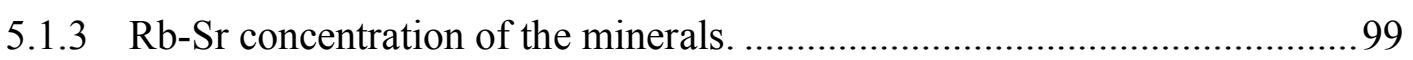

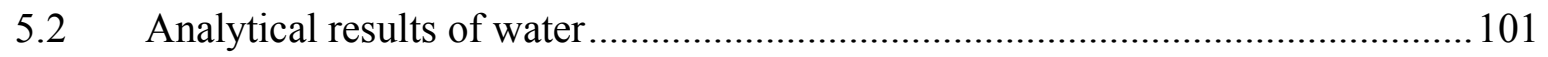

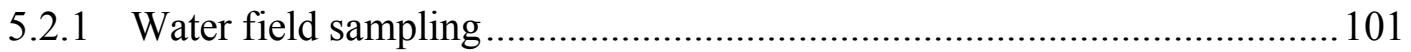

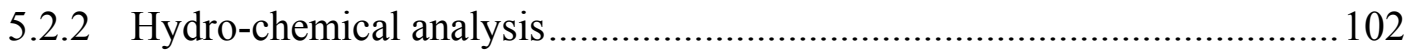

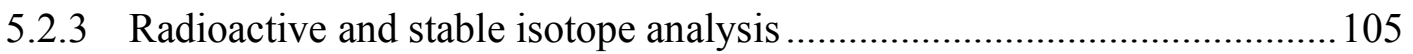

5.2.4 Geothermometer estimation............................................................... 110

5.2.5 Rare earth elements within the water.................................................. 112

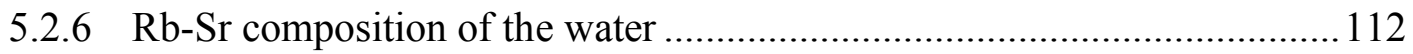

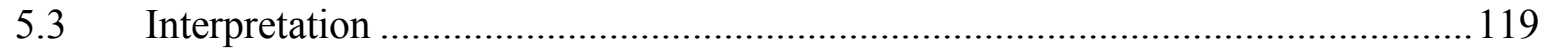

5.3.1 Hydro-geochemistry and origin of water ............................................... 119

5.3.2 Geothermal assessment, geothermometer application............................127

5.3.3 The reservoir depth estimation............................................................. 132

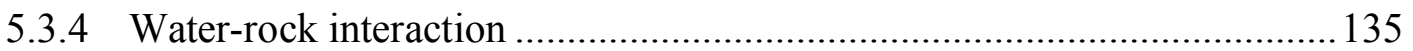

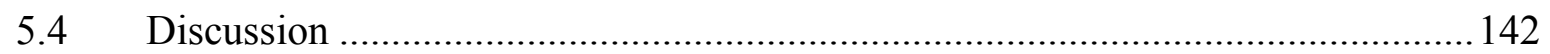

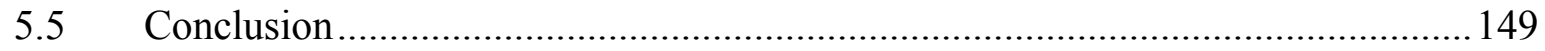

6 Comparison of Mae Chan and Ranong geothermal area......................................... 153

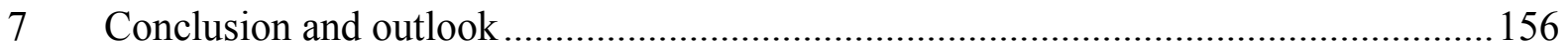

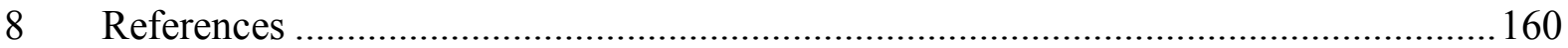

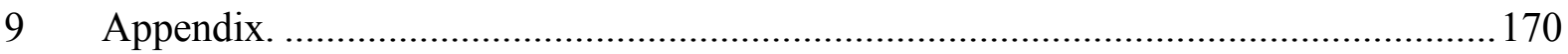

9.1 Appendix 1: The data from previous investigation are involved in the study....... 170

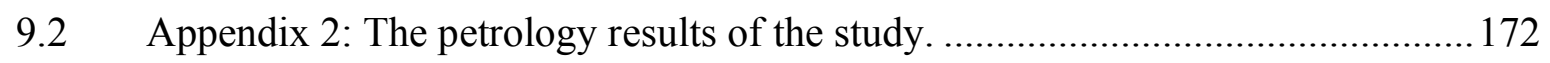




\section{List of Figures}

Figure 1.1-1: Conceptual model of Fang geothermal system from Amatyakul et al., (2016). It shows the flow path and the geothermal reservoir. 3

Figure 1.2-1: Distribution map of 112 hot springs in Thailand and the study areas, redrawn after DAEDE, (2007a) and the topographic map..... 4

Figure 2.1-1: Topographic map of the study area with sample location in Mae Chan. 12

Figure 2.1-2: Geological map of the study area along with faults line and sample location in Mae Chan. .13

Figure 2.2-1: Topographic map of the study area with sample location in Ranong. 20

Figure 2.2-2: Geological map of the study area along with faults line and sample location in Ranong (modified after Kosuwan and Nakapadungrat, (1991)). .21

Figure 3.6-1: Silica-enthalpy mixing diagram compares the results with three theoretical reference lines.

Figure 4.1-1: Chondrite-normalized REE pattern (McDonough and Sun, 1995) of the mineral samples in Mae Chan compared with the whole fresh granite data from Chiang Mai and Chiang Rai provinces (Charusiri et al., 1994). *FS = Feldspar, Bi = Biotite, and Qz = Quartz. .50

Figure 4.2-1: Triangular diagram of (a) major anions (modified from Giggenbach, 1988) and (b) major cations in water samples in post-monsoon season (2014) in Mae Chan geothermal area. .55

Figure 4.2-2: Triangular diagram of (a) major anions (modified from Giggenbach, 1988) and (b) major cations in water samples in pre-monsoon season (2016) in Mae Chan geothermal area.

Figure 4.2-3: (a) Stable isotope results in thermal water and surface water samples from postmonsoon (December 2014) and pre-monsoon seasons (March 2016), compared with LMWLs from Chiang Rai station

Figure 4.2-4: Chondrite-normalized REE patterns (McDonough and Sun, 1995) of surface and thermal water samples for location of CR-04 (a), CM-03 (b), CM-16 (d), and for CR-02, CR03, and CR-08 (c) comparing with the local rock.

Figure 4.2-5: Spatial distribution of the ${ }^{87} \mathrm{Sr} /{ }^{86} \mathrm{Sr}$ ratio in the feldspar mineral (Yellow background), the surface water (Blue background), and in the hot springs water samples (White background), are plotted with the Mae Chan geological map.

Figure 4.3-1: Correlation diagram of the major ion concentration between in the geothermal water versus in the precipitation. 
Figure 4.3-2: Na-K-Mg triangular diagram (modified from Giggenbach, 1988) for the considered thermal waters of Mae Chan area.

Figure 4.3-3: Quartz/Na-K diagram (modified from Giggenbach, 1988) and Quartz/Mg-K diagram (modified from Giggenbach et al., 1994) for the considered thermal waters of Mae Chan area.

Figure 4.3-4: Silica-enthalpy mixing diagram of Mae Chan hot spring in Post-monsoon season (a), and in pre-monsoon season (b). .76

Figure 4.3-5: Correlation between three ligands for instance; chloride $\left(\mathrm{Cl}^{-}\right)(\mathrm{a})$, sulfate $\left(\mathrm{SO}_{4}{ }^{2-}\right.$ ) (b), and fluoride $\left(\mathrm{F}^{-}\right)(\mathrm{a})$, and total REE concentration.

Figure 4.3-6: Strontium isotopic composition of surface granite samples in the Mae Chan geothermal area. 82

Figure 4.3-7: Spatial distribution of percent of $\mathrm{Sr}$ with rock origin in Mae Chan area .85

Figure 4.4-1: Topographic map along with sample location point and faults line of the study area. The yellow arrows represent the surface flow direction of each area.

Figure 4.4-2: Topographic map with major and local faults structures (a) and conceptual model (b) of Mae Chan hot spring (CR-04).

Figure 4.4-3: Topographic map with major and local faults structures (a) and conceptual model (b) of Mullika hot spring (CM-16). .91

Figure 4.4-4: Topographic map with major and local faults structures (a) and conceptual model (b) of Huy Mark lieum (CR-02) and Pha Soet (CR-03) hot springs. .92

Figure 4.4-5: Topographic map with major and local faults structures (a) and conceptual model (b) of Mullika hot spring (CM-16).

Figure 5.1-1: Chondrite-normalized REE pattern (McDonough and Sun, 1995) in the mineral samples in Ranong geothermal area compared with the whole fresh granite from Haad Som Paenn, Ranong Tin field (Imai, 2012). 100

Figure 5.2-1: Triangular diagram of (a) major anions (modified from Giggenbach, 1988) and (b) major cations in water samples in post-monsoon season (2014) in Ranong geothermal area. 106

Figure 5.2-2: Triangular diagram of (a) major anions (modified from Giggenbach, 1988) and (b) major cations in water samples in pre-monsoon season (2016) in Ranong geothermal area.

Figure 5.2-3: (a) Stable isotope results in thermal water and surface water samples from postmonsoon (December 2014) and pre-monsoon seasons (March 2016), compared with LMWLs from Ranong station. 109 
Figure 5.2-4: Chondrite-normalized REE patterns (McDonough and Sun, 1995) of surface and thermal water samples for location of RN1 (a), RN6 (b), and for RN2, RN3, and RN5 (c) comparing with the local rock.

Figure 5.2-5: Spatial distribution of ${ }^{87} \mathrm{Sr} /{ }^{86} \mathrm{Sr}$ ratio in the feldspar mineral (yellow background), the surface water (blue background), and the thermal water samples (white background), are plotted with the Ranong geological map. 118

Figure 5.3-1: Seasonal variation of amount-weighted monthly isotopic $\left(\delta^{18} \mathrm{O}\right)$ values and monthly mean precipitation amount in the Ranong station in each year from 2013 to 2015. (modified after HAII, (2016)).

Figure 5.3-2: Stable isotope results in thermal water samples from December 2014 and March 2016, compared with LMWLs from Ranong station.

Figure 5.3-3: Schoeller's diagram of the major-ion concentration between the geothermal water versus Post-ET.

Figure 5.3-4: Na-K-Mg triangular diagram of the Ranong thermal water (Giggenbach, 1988).

Figure 5.3-5: Quartz/Na-K diagram (modified from Giggenbach, 1988) and Quartz/Mg-K diagram (modified from Giggenbach et al., 1994) for the considered thermal waters of Ranong area. 130

Figure 5.3-6: Silica-enthalpy mixing diagram of Ranong hot spring in post-monsoon season (a), and in pre-monsoon season (b). 131

Figure 5.3-7: Correlation between three ligands for instance; chloride $\left(\mathrm{Cl}^{-}\right)$(a), sulfate $\left(\mathrm{SO}_{4}^{2-}\right)$ (b), and fluoride $\left(\mathrm{F}^{-}\right)(\mathrm{a})$, along with total REE concentration. 138

Figure 5.3-8: Correlation between fluoride $\left(\mathrm{F}^{-}\right)$and three major cation concentration: sodium $\left(\mathrm{Na}^{+}\right)(\mathrm{a})$, potassium $\left(\mathrm{K}^{+}\right)(\mathrm{b})$, and calcium $\left(\mathrm{Ca}^{2+}\right)(\mathrm{c})$ 138

Figure 5.3-9: Strontium isotopic composition of surface granite samples in Ranong geothermal area. 140

Figure 5.4-1: Topographic map along with sample location point of the study area. The yellow arrows represent the surface flow direction of each area.

Figure 5.4-2: Topographic map with major and local faults structures (a) and conceptual model (b) of Ban Hat Yay hot spring (RN6).

Figure 5.4-3: Topographic map with major and local faults structures (a) and conceptual model (b) of Raksawarin hot spring (RN1). 146

Figure 5.4-4: Topographic map with major and local faults structures (a) and conceptual model (b) of the Phu Lum Phi and Phorn Rung hot springs (RN2 and RN3). 147 
Figure 5.4-5: Topographic map with major and local faults structures (a) and conceptual model (b) of the Rattana Rangsan hot spring (RN5).

Figure 9.1-1: Local meteoric water line in Chiang Rai station, Thailand, based on precipitation data $(\mathrm{n}=263 \mathrm{~F})$ from 2013 to 2015 (HAII, 2016).

Figure 9.1-2: Local meteoric water line in Ranong station, Thailand, based on precipitation data $(\mathrm{n}=338)$ from 2013 to 2015 (HAII, 2016). 170

Figure 9.1-3: Temperature profiles from drilling well in the Fang shallow geothermal area (Wanakasem and Takabut, 1987).

Figure 9.2-1: Polarized light (PL) and transmitted light (Tl) microscopic analysis of thinsection and petrography in the surface granite from the Mulika hot springs (CM-16).

Figure 9.2-2: Polarized light (PL) and transmitted light $(\mathrm{Tl})$ microscopic analysis of thinsection and petrography in the surface granite from the CR-Near Malika (CM-16-2). 173

Figure 9.2-3: Polarized light (PL) and transmitted light (Tl) microscopic analysis of thinsection and petrography in the surface granite from the CR-Mae Chan (CM-04). 174

Figure 9.2-4: Polarized light (PL) and transmitted light ( $\mathrm{Tl})$ microscopic analysis of thinsection and petrography in the surface granite from the CR-Huay Mae Jai (CM-03). 175

Figure 9.2-5: Polarized light (PL) and transmitted light (Tl) microscopic analysis of thinsection and petrography in the surface granite from the Ratchagrude hot spring $(\mathrm{RN}-5) \ldots . .176$ Figure 9.2-6: Polarized light (PL) and transmitted light (Tl) microscopic analysis of thinsection and petrography in the first granite sample from Ban Hat Yay hot spring (RN-6) ... 177 Figure 9.2-7: Polarized light (PL) and transmitted light (Tl) microscopic analysis of thinsection and petrography of the second granite sample from Raksawarin hot springs (RN-1) 


\section{List of Tables}

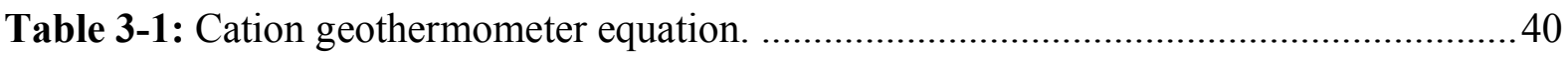

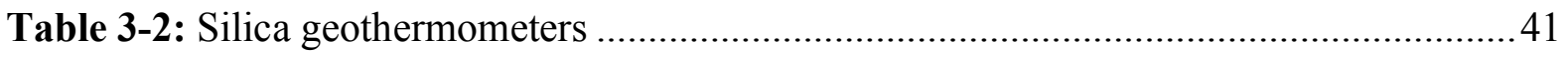

Table 4-1: Rare earth element in the rock samples in Mae Chan geothermal area................49

Table 4-2: Analytical results of $\mathrm{Rb}, \mathrm{Sr}$, and ${ }^{87} \mathrm{Sr} /{ }^{86} \mathrm{Sr}$ ratio in the rock samples in Mae Chan geothermal area.

Table 4-3: Field parameter, major ion composition, and ionic balance in water samples in Mae Chan geothermal area.

Table 4-4: Stable isotope results in thermal water and surface water samples in Mae Chan geothermal area from post-monsoon (December 2014) and pre-monsoon seasons (March 2016). .56

Table 4-5: Tritium, stable isotope of carbon, and radiocarbon results in hot springs in Mae Chan geothermal area. .59

Table 4-6: Temperature results of cation geothermal estimations ........................................60

Table 4-7: Temperature results of silica geothermometer in Mae Chan area .........................60

Table 4-8: Rare earth element in the water samples in Mae Chan area.

Table 4-9: Analytical results of $\mathrm{Rb}, \mathrm{Sr}$, and ${ }^{87} \mathrm{Sr} /{ }^{86} \mathrm{Sr}$ ratio in the water samples in Mae Chan geothermal area.

Table 4-10: Results of recharge elevation estimation from the isotopic composition of thermal water samples (Eq. (3.4)).

Table 4-11: Estimated initial reservoir temperature and initial $\mathrm{SiO}_{2}$ concentration from the Silica-enthalpy mixing diagram and mixing ratio results in pre-monsoon season and post-

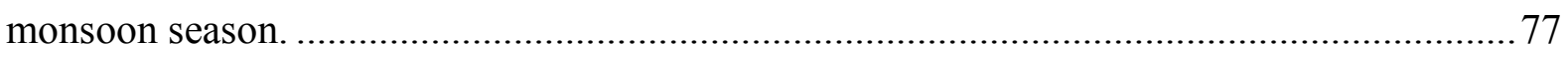

Table 4-12: Estimated depth of Mae Chan geothermal from reservoir geothermometer. ...... 78 Table 4-13: $\mathrm{Sr}$, and ${ }^{87} \mathrm{Sr} /{ }^{86} \mathrm{Sr}$ ratio dissolution results of the rock samples from the dissolution model (Négrel et al., 2001) in Mae Chan geothermal area.

Table 4-14: Mixing model results of $\mathrm{Sr}$, and ${ }^{87} \mathrm{Sr} /{ }^{86} \mathrm{Sr}$ ratio in thermal water samples in Mae Chan geothermal area.

Table 5-1: Rare earth element in the rock samples in Ranong geothermal area. 100

Table 5-2: Analytical results of $\mathrm{Rb}, \mathrm{Sr}$, and ${ }^{87} \mathrm{Sr} /{ }^{86} \mathrm{Sr}$ ratio in the rock samples in Ranong geothermal area. 101

Table 5-3: Field parameter, major ion composition, and ionic balance in water samples in Ranong geothermal area 104 
Table 5-4: Major ion concentration in Ranong meteoric water.

Table 5-5: Stable isotope results in thermal water and surface water samples in Ranong geothermal area from post-monsoon (December 2014) and pre-monsoon seasons (March 2016).

Table 5-6: Tritium, stable isotope of carbon, and radiocarbon results in hot springs in Ranong area.

Table 5-7: Temperature results of Cation geothermal estimations.

Table 5-8: Temperature results of silica geothermometer in Ranong area.

Table 5-9: Rare earth element in the water samples in Ranong area.

Table 5-10: Analytical results of $\mathrm{Rb}, \mathrm{Sr}$, and ${ }^{87} \mathrm{Sr} /{ }^{86} \mathrm{Sr}$ ratio in the water samples in Ranong geothermal area.

Table 5-11: Results of recharge elevation estimation from stable isotope composition of thermal water.

Table 5-12: Corrected resident times period of hot springs in Ranong area. 128

Table 5-13: Estimated initial reservoir temperature and initial $\mathrm{SiO}_{2}$ concentration from the silica-enthalpy mixing diagram and mixing ratio results from RN1 hot spring in the premonsoon and post-monsoon seasons.

Table 5-14: Estimated reservoir depth from spatial distribution map and from drilling information.

Table 5-15: Analytical results of $\mathrm{Rb}, \mathrm{Sr}$, and ${ }^{87} \mathrm{Sr} /{ }^{86} \mathrm{Sr}$ ratio in the rock samples in Ranong geothermal area.

Table 5-16: Mixing model results of $\mathrm{Sr}$, and ${ }^{87} \mathrm{Sr} /{ }^{86} \mathrm{Sr}$ ratio in thermal water samples in Ranong geothermal area.

Table 6-1: Comparison of the geothermal parameters and processes between two study areas. 
Chapter 1 


\section{Introduction}

\subsection{Introduction to Geothermal fluid}

Geothermal fluid is a renewable resource for developing as an energy source that provided stability energy and a friendlier to the environment system. Investments for geothermal fluid utilizations are successful and practical in many countries. Most geothermal resources can be directly used for heating, cooking, bathing, and agricultural product, however, only high geothermal systems can use for the electric generation which depending on the geological setting of each area.

The term "geothermal fluid" is used to express the type of fluid which is heated from beneath the Earth's crust and subsequently discharged at the surface or the seafloor where are located in active or recent magmatism or anomalous crustal condition, shown the example case in Figure 1.1-1.

In the hydrological cycle, the main sources of geothermal water include meteoric water, snow, and ice melt, those of which have the lowest chemical concentration compared to other kinds of natural water. These sources of water are accumulated on the earth surface then driven out by other processes for instance, surface runoff, evaporation, and vegetation. The remaining water percolate through the soils and the bedrock, thereafter, the water is heated from the geothermal reservoir. As a consequence of chemical and/or physical processes under subsurface, the concentrations of many components in the geothermal fluids are dissolved from the minerals of the host rock and soil. During ascending processes, the temperature of the geothermal fluid may be decreased by mixed with shallow cold water or the temperature gradient of the area. Subsequently, the chemical concentration in the fluids transfer to precipitating new mineral assemblages. In contrast, the minerals in the host rock are lost and are changed by the fluid in the physiochemical from the origin, which is regarded as hydrothermal alteration. The degree of these processes depends on the nature and composition of the rock and the composition of the fluid sources (Clark, 2015; Herschy, 1998; Pirajno, 2009) 


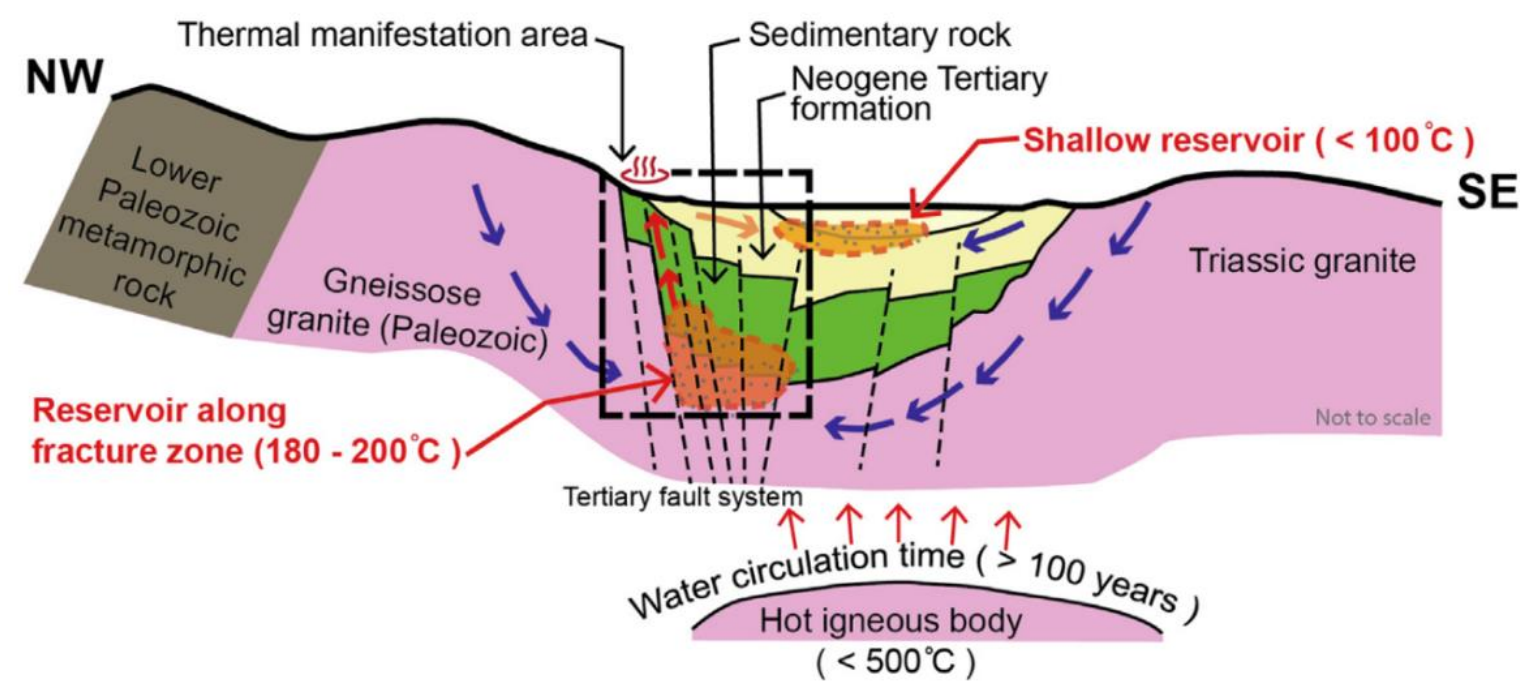

Figure 1.1-1: Conceptual model of Fang geothermal system from Amatyakul et al., (2016). It shows the flow path and the geothermal reservoir.

\subsection{General overview - Geothermal study in Thailand}

In Thailand, sustainable energy is the one issue that the government concerned for a long time. In present, the demand for electricity consumption is still rising that is increased to be $85 \%$ higher in 2017 than in 2002 (EPPO, 2018). It led to the exploration and development of geothermal resources for electricity generation since 1946 (Raksaskulwong, 2015, 2011, 2008).

Various national and international organizations investigated and evaluated the geothermal potential and the possibility of utilizing geothermal energy for electricity generation in the northern part of Thailand. (Korjedee, 2002; Raksaskulwong, 2011, 2008). The field explorations have been found in total 112 hot springs in Thailand with surface temperatures ranging from 40 to $100{ }^{\circ} \mathrm{C}$, which are manifested and scattered mostly at the granite body from the north to south of the country (DAEDE, 2007; Sanmuang, 2009). These hot springs are characterized by the geothermal enthalpy into four groups, shown in Figure 1.2-1. 


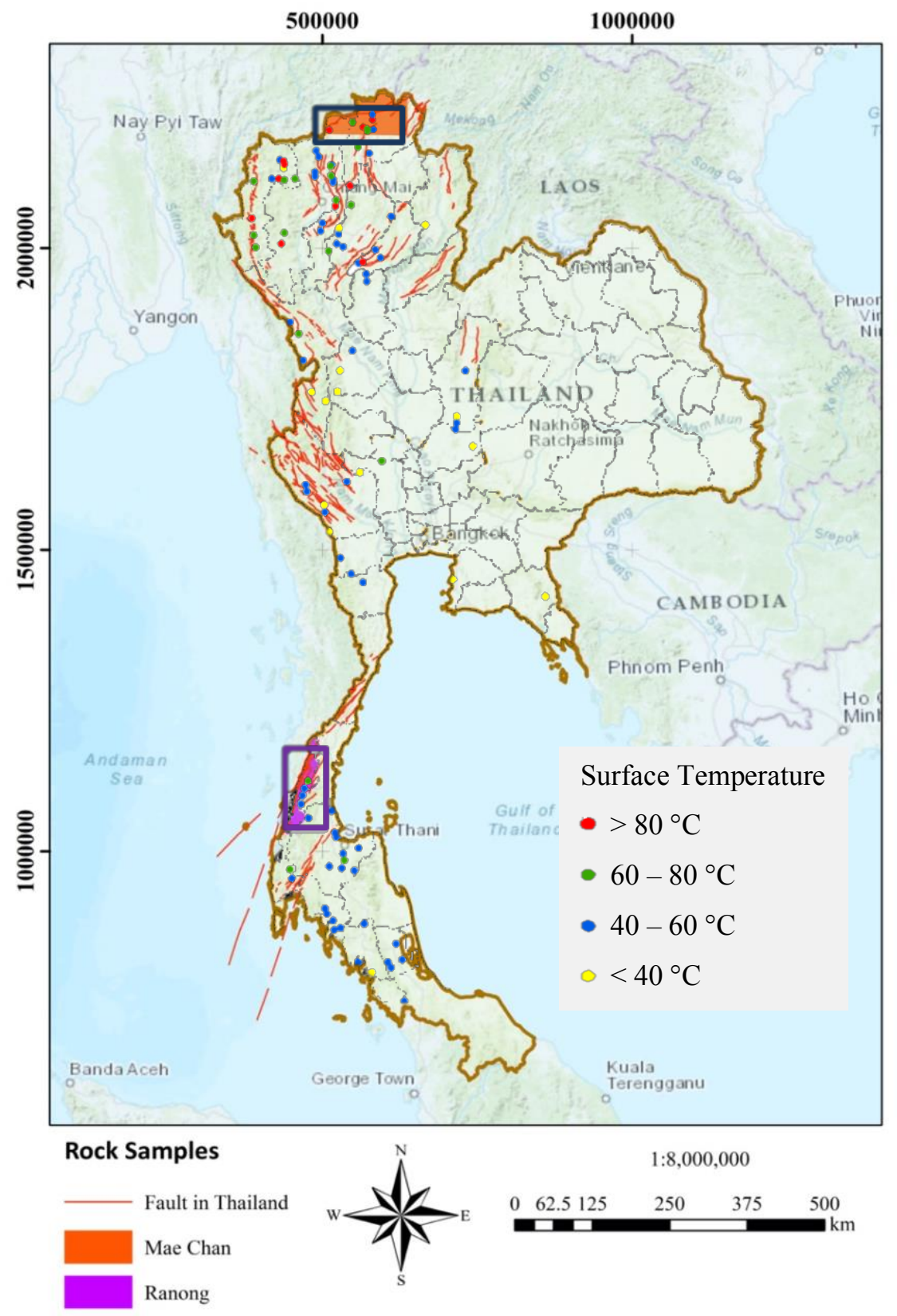

Figure 1.2-1: Distribution map of 112 hot springs in Thailand and the study areas, redrawn after DAEDE, (2007a) and the topographic map.

\subsection{Research motivation}

Most of the geothermal investigation in Thailand are focus on the higher surface temperature hot springs, are mostly located in the northern part of the country (Raksaskulwong, 2015, 2011, 2008). However, a few of high-geothermal potential area were successfully developed the pilot geothermal power plans and geothermal drilling well, for instance; Sankampaeng, Fang, and Mae Chan (Geothermica Italiana Slr., 1984; Raksaskulwong, 2015; Ratanasthein et al., 1988). 
Two high geothermal potential areas for electricity generation, called Fang and Mae Chan, are located in the NE-SW Mae Chan fault in the northern part of Thailand. These areas have been continuously investigated and successfully installed the geothermal utilization facility (DAEDE, 2007a; Sanmuang, 2009), for instance; a pilot binary power plant producing $300 \mathrm{~kW}$ of electricity in Fang area (Geothermica Italiana Slr., 1984; Raksaskulwong, 2015; Ratanasthein et al., 1988), and a demonstration agro-products cold-storage (ammonia-water absorption refrigeration system) with drying facility in Mae Chan area (DAEDE, 2007a; Singharajwarapan et al., 2012).

And once again, the recent geothermal potential investigation from DGR, (2016), these two areas are considered as the five highest potential hot springs in Thailand. However, some low potential hot springs along the Mae Chan fault line were neglected. Moreover, the repeated measurements from some investigations show that there is a high change in flow rate and outlet temperatures of thermal waters. For instance, San Kamphaeng hot springs, located in the northern part of Thailand, has been now hypothesized that these variations may be associated with natural causes such as earthquakes or human activities (Apollaro et al., 2015; Singharajwarapan et al., 2012).

On the other hand, the low enthalpy (low-temperature) hot springs in Thailand can be practically utilized for spa bathing, agriculture crop drying, and other functions (Raksaskulwong, 2004). In Ranong Province, the hot springs contain very low chemical concentrations (Chaturongkawanich and Leevongchareon, 2000; DAEDE, 2007a) and become locally tourist attractions in the southern part of the country. Because of that, the Raksawarin hot springs (RN1), and Phorn Rung hot spring (RN3), in particular, have been affected by the increasing number of seasonal tourism while the National park committee are attempting to respond to a greater public demand for access. To minimize environmental impacts within the area, it is therefore necessary to conduct a comprehensive study of the natural hydrodynamic system, which would further evaluate the availability and sustainability of groundwater resources. A few works have investigated to characterize the geological (Kosuwan and Nakapadungrat, 1992), hydrological (DAEDE, 2007a), hydrochemical (Chaturongkawanich and Leevongchareon, 2000) and the heat source (Khoonphunnarai, 2009; Sanmuang, 2009) of these hot springs. The studies found that thermal water can possibly dilute or be derived from precipitation water at the same shallow reservoir (Chaturongkawanich and Leevongchareon, 2000). However, the hydrogeological cycle of these hot springs is still considered ambiguous as little knowledge about these systems is available. 
In the present, environmental isotope and geochemistry can provide essential hydrogeological information, for instance; origin, flow part, reservoir temperature, chemical reaction, weathering process, dissolution process, mixing history, etc. However, these isotopes and geochemistry should interpret collectively with the geological data.

This Ph.D. dissertation integrated the applications of natural hydrogeochemical and isotopic composition in water and rock minerals to comprehensively evaluate and improve the understanding of these hydrothermal systems. The details are described in the further chapter.

\subsection{Environmental isotope and geochemistry of geothermal fluid and rock minerals}

Since the environmental isotope and geochemistry of geothermal fluid are controlled by the chemical and physical processes along the flow path. These composition characteristics have been used as tracers in numerous studies and have been involved in all stages of the exploration, evaluation, and monitoring of geothermal production (Nicholson, 1993). These are widely useful for determining essential hydrogeological information and reflecting the origin and history of the subsurface flow (Apollaro et al., 2015; Arnórsson, 2000; Clark, 2015; Dotsika et al., 2010; Petrini et al., 2013). The most frequently used environmental isotope and geochemistry are given below:

Major ion is a common geochemical species constitute around $95 \%$ of the total dissolved solids (TDS) in natural water, comprised of major cations and major anions. The major cations comprise of two alkaline-earths $\left(\mathrm{Ca}^{2+}\right.$ and $\left.\mathrm{Mg}^{2+}\right)$ and two alkali metals $\left(\mathrm{Na}^{+}\right.$and $\left.\mathrm{K}^{+}\right)$. The major anions comprise of the carbonate species $\left(\mathrm{HCO}_{3}{ }^{-}\right.$, and $\left.\mathrm{CO}_{3}{ }^{2-}\right)$, sulfate $\left(\mathrm{SO}_{4}{ }^{2-}\right)$, and chloride $\left(\mathrm{Cl}^{-}\right)$. These seven geochemical species are derived from the chemical reaction, weathering process, dissolution process, mixing history between natural water and the minerals from soils or host rock (Clark, 2015). Moreover, these species can also be derived from the anthropogenic origins, such as; industrial, municipal and agricultural activities. In general, these major ions consider with the other techniques, for instance, minor species, the isotope of the element.

Isotopes are atoms of the same elements that have the same number of proton but have different numbers of neutrons. It has been discovered in two types, stable isotopes, and radioactive isotopes.

Stable isotopes, such as $\delta^{2} \mathrm{H}, \delta^{18} \mathrm{O}$, and $\delta^{13} \mathrm{C}$, are no appreciable change with time, are commonly used mass dependence fractionation and mass independence fractionation for identifying the origin of that element as well as determining the processes that previously 
affected these isotopes (Battistel et al., 2016; Gat et al., 2001; Han et al., 2012; Han and Plummer, 2016; Hoefs, 2009; Négrel and Giraud, 2011). In particular, the stable isotopes ratio of water $\left(\delta^{2} \mathrm{H}\right.$ and $\left.\delta^{18} \mathrm{O}\right)$, can provides the water origin as a function of geo-hydrological and meteorological factors, the degree of water-rock interaction, groundwater mixing, and recharge elevation of the thermal water (Dotsika et al., 2010; IAEA, 1993; Wang et al., 2018). Carbon stable isotope $\left(\delta^{13} \mathrm{C}\right)$ of dissolved carbon (DC) is an identifying application of carbon source interacting with the groundwater (Han et al., 2012; Han and Plummer, 2016; Hoefs, 2009).

Radioactive isotopes have an unstable atomic nucleus that changes with time by decay processes. The nucleus emits energy and particles to a more stable form. Natural Radioactive isotopes are produced from the interaction of atmospheric gases with cosmic radiation. The precipitation obtains these unstable isotopes then infiltered to the subsurface. The water is isolated from the atmosphere. The decay process is beginning. Hence, the decay time from discharged water represents the residence time of the fluid in the subsurface. The important radioisotopes in hydrology investigation are tritium $\left({ }^{3} \mathrm{H}\right)$ and radiocarbon $\left({ }^{14} \mathrm{C}\right)$.

Radioactive hydrogen isotope or Tritium $\left({ }^{3} \mathrm{H}\right)$ has half-life 12.32 years, can estimate the travel time in the rage from 0 to 60 years before present (BP). Tritium is an important conservative tracer for groundwater dating because of this is involved in the water molecule. For the interpretation, the ${ }^{3} \mathrm{H}$ in subsurface water comparing with ${ }^{3} \mathrm{H}$ in rainfall from the atmospheric nuclear tests in the 1950s-1960s represented the input function of the system (Cartwright and Morgenstern, 2012; Clark, 2015).

Radiocarbon dating $\left({ }^{14} \mathrm{C}\right)$ can be applied to estimate the age of groundwater from dissolved inorganic carbon (DIC) and can be illustrated on the ten thousand years' timescale (approximately 0-45,000 years' timescale depending on the analytical methods) (Cartwright and Morgenstern, 2012; Han et al., 2012; Han and Plummer, 2016). Moreover, the correlation between ${ }^{14} \mathrm{C}, \delta^{13} \mathrm{C}$, and DIC in groundwater can be taken into consideration to improve the radiocarbon age and tracking-back of the carbon complex reaction (Chen et al., 2010; Han et al., 2012).

Rare earth elements (REE) or lanthanides are comprised of 14 metals from Cerium (Ce) to Lutetium $(\mathrm{Lu})$. These metals are systematically increase in the nuclear charge and decrease of ionic radius in order to $\mathrm{La}$ to $\mathrm{Lu}$. These elements have similar chemical behavior and are mostly not involved inbounding. In the geothermal system, the REE compositions are commonly derived from the dissolution and alteration of the accessory minerals in the host rocks. 
However, the pattern of these elements is sensitive to change in $\mathrm{pH}$, redox and adsorption/desorption reactions. Therefore, the variation in REE composition and pattern in water samples may be used as an indicator for understanding the fractionation mechanism during alteration of rock and fluid transport, the history of rock alteration, and the state of equilibrium in water-rock interaction (Möller, 2007).

Strontium (Sr) has four natural isotopic abundance, for instance; ${ }^{88} \mathrm{Sr}(82.58 \%),{ }^{87} \mathrm{Sr}(7 \%)$, ${ }^{86} \mathrm{Sr}(9.86 \%)$, and ${ }^{84} \mathrm{Sr}(0.56 \%)$. Sr readily substitutes for $\mathrm{Ca}$ in the minerals due to the similarity of the atomic radius. In the geological investigation, mineral crystallization generates the differences in the quantity of $\mathrm{Rb}$ and/or $\mathrm{Sr}$ of the major minerals in the granitic rock, comprised of; feldspar (plagioclase and potassium feldspars), and mica (biotite and muscovite) minerals. Moreover, the radioisotope $\mathrm{Rb}$ can substitute for potassium $(\mathrm{K})$ in the minerals and decay to ${ }^{87} \mathrm{Sr}$ over time with half-life 48.8 billion years. Therefore, the difference age of K-bearing minerals has differences in the ${ }^{87} \mathrm{Sr} /{ }^{86} \mathrm{Sr}$ ratio. Dissolved $\mathrm{Sr}$ in natural water is derived from different sources which generally represent a mixture of the atmospheric inputs and weathering products from minerals and rocks (Négrel and Giraud, 2011; Petelet-Giraud et al., 2003). In theoretically, the highest dissolution rate in the granitic minerals is plagioclase (Petelet-Giraud et al., 2003) which likely are the dominant source of radiogenic Sr in the water. However, the ${ }^{87} \mathrm{Sr} /{ }^{86} \mathrm{Sr}$ ratios in water draining granite are in between the ${ }^{87} \mathrm{Sr} /{ }^{86} \mathrm{Sr}$ ratios from the plagioclase mineral and the whole rock. Hence, the interpretation should not avoid the high Sr isotopic ratio from the other minerals (Clow et al., 1997; Lasaga, 1984; Zuddas et al., 1995). Therefore, $\mathrm{Sr}$ isotopic ratios in minerals and subsurface water can provide information on the origin of these mixing sources of solutes within the subsurface. 


\subsection{Research objectives}

The main purpose of the thesis is to increase understanding of natural hydrothermal processes and water-rock interaction in the study areas. Different hydro-geochemical and isotope techniques are applied in order to achieve these aims,

- Major ions characterize the processes controlling hydrochemistry, the reservoir temperature estimation, and reservoir depth estimation.

- The stable isotope of water $\left(\delta^{2} \mathrm{H}\right.$ and $\left.\delta^{18} \mathrm{O}\right)$ identifies the origin of geothermal water and recharge elevation.

- The stable isotope of carbon $\left(\delta^{13} \mathrm{C}\right)$ identifies the source of carbon in geothermal water.

- Radioactive isotopes (Radiocarbon and Tritium) estimate the travel time of thermal water.

- REE in thermal water and in mineral identify water-rock interaction.

- Strontium isotope in water and in mineral identify water-rock interaction. 


\subsection{Thesis structure}

This thesis presents the applications of environmental isotope and geochemistry of water that were applied and developed for understanding of natural hydrothermal systems and water-rock interaction in Mae Chan and Ranong geothermal areas. The thesis consists of seven main chapters and given below:

The current chapter (Chapter 1) introduces a general concept of the hydrothermal system and their characteristics, general overview of geothermal study in Thailand, the research motivation, the research objectives, and the structure of the thesis.

Chapter 2 is divided into two sub-chapters based on each studied area. This chapter describes a detailed geographic location and topography, climate, regional geology and structures, hydrogeology.

Chapter 3 is the methodological part of the dissertation. This chapter divided into eight subchapters belong under sampling and analytical methods, identification of water sources, water classification and geochemical processes, recharge elevation, the residence time of thermal water estimation, geothermometers, the reservoir depth estimation, water-rock interaction.

Chapter 4 and Chapter 5 are the results, interpretation, and discussion chapters from Mae Chan and Ranong areas, respectively. The rock and water results demonstrate under the parameter from methods and procedures in Chapter 3. The interpretation part focuses on characterization and evaluation of hydrochemistry and origin of water from the stable/radio isotope and chemical application, geothermal assessment from geo-thermometry application, water-rock interaction from $\mathrm{REE}$ and $\mathrm{Sr}$ isotope composition in water related to mineral. The discussion part focuses on the hydrological conceptual model in each location that obtains from isotope and hydrochemistry of the geothermal area.

Chapter 6 provided the comparison of similarity and difference between Mae Chan and Ranong geothermal area.

Chapter 7 provided a general combined conclusion regarding the results obtain from all of the application methods and procedures within this study. Moreover, the chapter presents the outlook for future perspectives and recommendations. 
Chapter 2 


\section{Description of studied areas}

\subsection{Mae Chan area}

\subsubsection{Geographic location and topography}

The study area is located within UTM zone $47 \mathrm{~N}$, from $503500 \mathrm{E}$ to $609000 \mathrm{E}$ and from $2182000 \mathrm{~N}$ to $2263000 \mathrm{~N}$, on the border of the Chiang Mai and Chiang Rai provinces in the northern part of Thailand ( $8 \mathrm{~km}$ away from Mae Chan district), covering approximately 1,175 $\mathrm{km}^{2}$ (Figure 2.1-1).

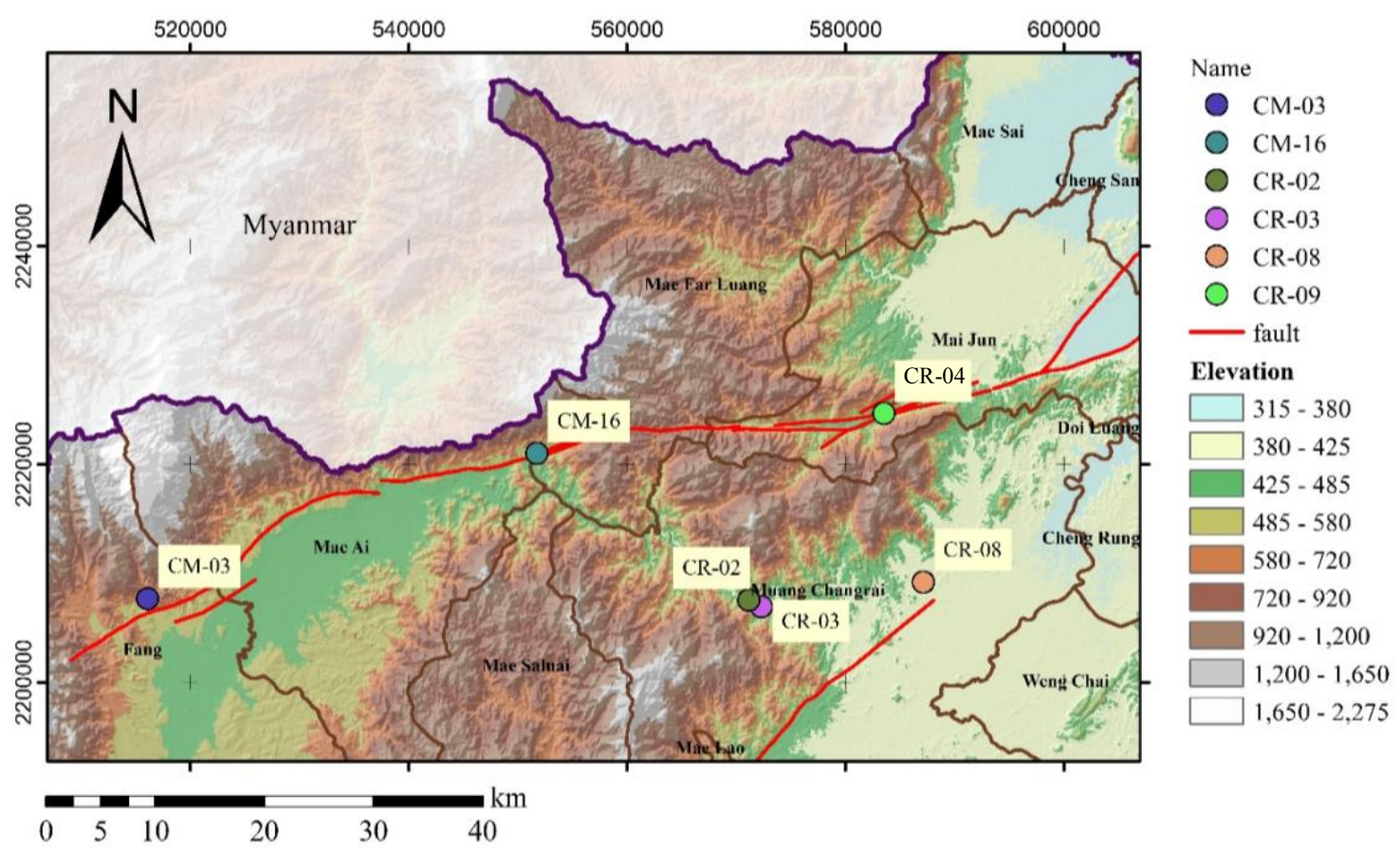

Figure 2.1-1: Topographic map of the study area with sample location in Mae Chan.

\subsubsection{Climate}

The area has a tropical monsoon climate, with an annual mean air temperature of $24.4{ }^{\circ} \mathrm{C}$, mean rainfall of $1,690 \mathrm{~mm} /$ year, mean humidity of $72-74 \%$ and mean potential evaporation of 1,269.48 mm (Thailand Meteorological Department, 2011).

\subsubsection{Regional geology and structures}

The most significant tectonic feature in the study area is the ENE-WSW-trending Mae Chan fault in the hilly and mountainous terrain. This active fault is a left-lateral strike-slip fault (Fenton et al., 2003; Wood et al., 2004). The fault line is clearly visible via satellite, extending $185 \mathrm{~km}$ from the Thai-Lao border in the east, and terminating at Fang basin in the SW direction (Morley et al., 2011). The fault is strongly linked with two tertiary extensional basins, 
composed of Mae Sai and the Fang basins (F. Ridd et al., 2011), yet the lithologic contacts are still considered ambiguous and the evidence for faults are not widely understood (von Braun and Hahn, 1981; Chaturongkawanich et al., 1980; Imsamut and Krawchan, 2005; Wood, 2018). Both basins are classified in half-graben structures, defined as the Fang basin-Mae Chan FaultMae Sai basin system (Fenton et al., 2003; Morley et al., 2011; Wood et al., 2004). The geological and tectonic setting of Mae Chan area are shown in Figure 2.1-2.

The western extent of the Mae Chan Fault bends south at the western margin of the Fang basin (Morley, 2011). The Fang basin is a fault tip basin that developed within a transtensional splay zone of the sinistral strike-slip Mae Chan fault system (Uttamo et al., 2003). West of the Fang basin is an N-S trending belt of west-dipping, folded, Paleozoic sedimentary rocks extending west beyond the Myanmar border (Wood et al., 2018). The east side of the Fang basin is mostly Triassic unfoliated porphyritic granite intruding into Carboniferous sediments and overlain by Jurassic continental sediments (von Braun and Hahn 1981; Imsamut and Krawchan 2005).

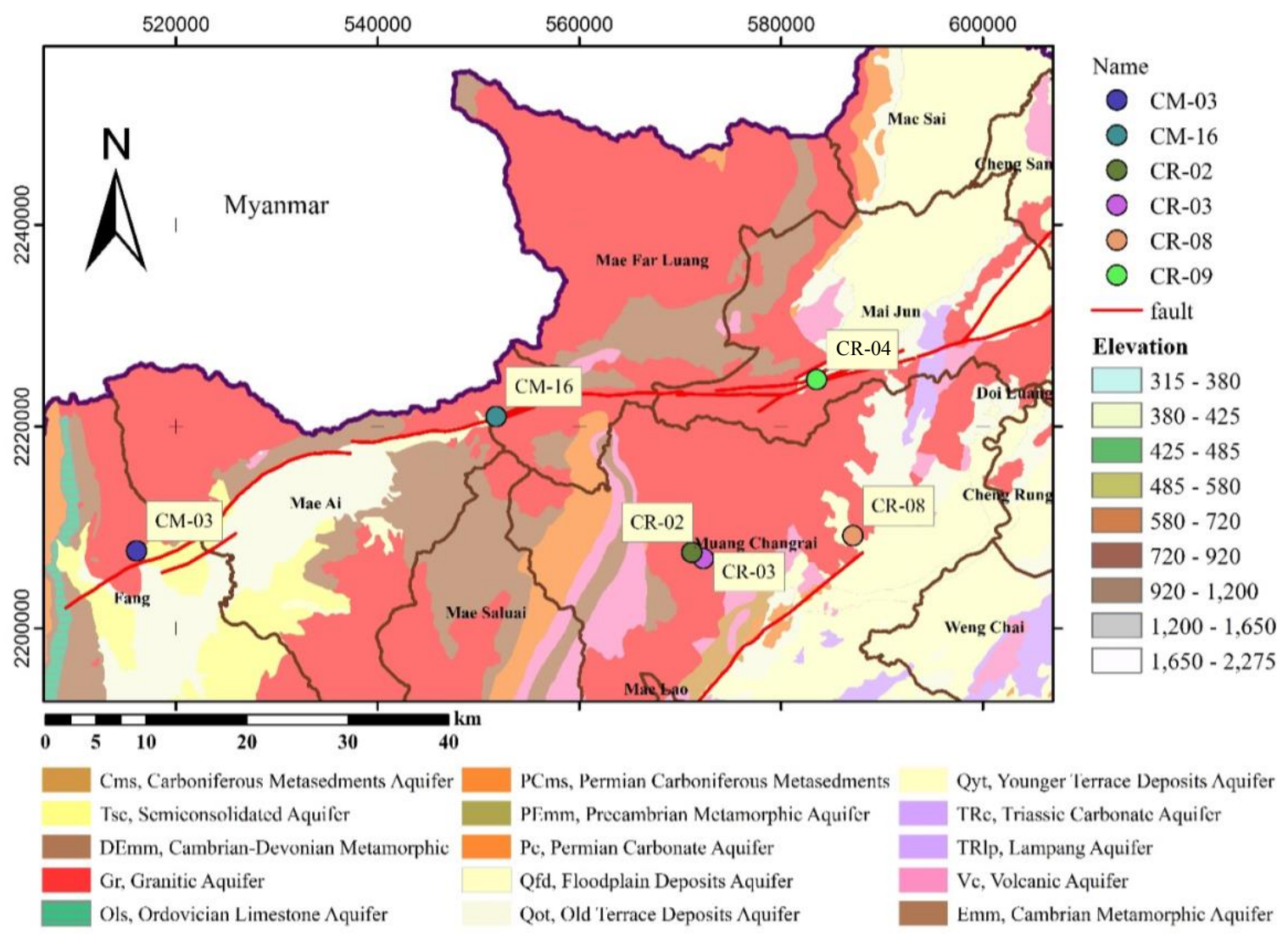

Figure 2.1-2: Geological map of the study area along with faults line and sample location in Mae Chan. 
The stratigraphy of the Fang basin area is comprised of three units. The crystalline rocks unit, which is presumably of Triassic age, features medium to high-grade metamorphic rock (mica schist and mylonite gneiss). The Paleozoic sediments units observed in outcrop are primarily thick-bedded quartz sandstone with interbeds of shale and massive limestone. The Cenozoic basin sediments create the Mae Sot formation, Mae Fang formation, and an undeformed alluvial fan and colluvium deposits (Amatyakul et al., 2016; DGR, 2017; Wood et al., 2018).

Base on three dimensional magnetotellurics (MT) data in the Fang geothermal area (Amatyakul et al., 2016) indicated that two faults are in this area. The Mae Chan Fault forms a steeply dipping contact of Paleozoic sedimentary rocks with Cenozoic alluvial fan deposits and the underlying coarse-clastic sediments of the Fang formation. The second fault, named the Doi Kia detachment fault, is a low-angle detachment fault, delineated along the Mae Chan fault in the NE-SW direction and places the Paleozoic sedimentary rocks over gneiss, foliated granite, and mylonite.

The eastern extent of the Mae Chan fault contacts the southern end of the Mae Sai basin and also bounds the southern part of the Wiang Nong Lom swamp. The Mae Sai basin developed as a pull-apart basin between the sinistral movement of the Nam Ma (NMF) and Mae Chan faults (MCF) (Uttamo et al., 2003). The regional geology of this area is comprised of PermianTriassic rhyolite, ash-flow tuff, Triassic unfoliated granitic rocks and unconsolidated Quaternary sediments that are mainly fluvial, colluvial and alluvial deposits (Amatyakul et al., 2015; Wood et al., 2004).

The stratigraphy of the Mae Chan geothermal area is described into three units from older to younger age. 1) Permian-Triassic rhyolite unit comprised of fine ash tuff, coarse ash tuff, and tuff. 2) Triassic crystalline rocks unit comprised of phenocryst coarse grained granite, equigranular granite, and foliated or stress granite. 3) Unconsolidated and poorly sorted quaternary sediments, with sizes ranging clay to well-rounded cobbles (Amatyakul et al., 2016; DGR, 2017b; Wood et al., 2018).

Recent studies have shown that the geothermal water in northern Thailand is $\mathrm{Na}-\mathrm{HCO}_{3}$ type with outlet temperatures ranging from 50 to $100^{\circ} \mathrm{C}$. These hot springs may be associated with the Triassic (?) granitic rocks (Apollaro et al., 2015; DGR, 2017a; Subtavewung et al., 2005). Two high geothermal potential hot springs, the Fang and Mae Chan, arise from shallow geothermal reservoirs less than $500 \mathrm{~m}$ below the surface (Amatyakul et al., 2016, 2015). Apollaro et al., (2015) estimated the mean residence time by applying previous tritium data, 
finding that $955 \pm 292$ before present (BP) in Fang and $507 \pm 97$ BP in Mae Chan hot springs. The water and carbon isotopic compositions of the Fang thermal water suggest that the water originated from meteoric water and the $\mathrm{CO}_{2}$ gas was derived from the volcanic $\mathrm{CO}_{2}$ (Kita et al., 1990).

\subsubsection{Hydrogeology}

The main hydrological system in the Mae Chan area is the Kok river basin. The basin covers Chiang Rai and Chiang Mai provinces in the northern part of Thailand, covering approximately $7,895 \mathrm{Km}^{2}$. The main river is Kok River originally flow from Chiang Tung mountain in the north of Burma and subsequently accumulated meteoric water belong to the several small channels from the mountain. The main in-flow of this river is in the Mae Ei, flow in the east direction through the Amphoe Mueang Chiang Rai, then flow in the north-eastern direction to Amphoe Chiang Saen and flow out to the Kong River in Tambon Ban Sew, Amphoe Chiang Saen, Chiang Rai province.

Geothermal water exploration in Thailand has been investigated since 1946. Currently, two of seven hot springs along the Mae Chan fault zone have been considered as the five highest potential hot springs in Thailand by the Department of Groundwater Resources (Amatyakul et al., 2016, 2015; DGR, 2017a). The discharge thermal waters from these seven hot springs illustrate low to medium enthalpy (between 40 and $100{ }^{\circ} \mathrm{C}$ ) and associated with Triassic (?) granitic plutons. Ratanasthein et al., (1988) described the information of these hot spring as follows;

1) Huai Mark liam hot spring (CR-02) is located near Kok riverbank at UTM 47Q, 0571177E and 2207545N, in Doy Hang Sub-district, Mueang District, and Chiang Rai Province. Approximately $20 \mathrm{~km}$ away from the city of Chiang Rai, Huai Mark Liam hot spring is administered by Lam Nam Kok National Park. The natural hot water, which flows through the fracture systems of Triassic Porphyritic granite during high-temperature and high-pressure conditions, is discharged at an elevation $420 \mathrm{~m}$ MSL into a $10 \times 12 \mathrm{~m}$ natural pool. The discharged water from the hot spring has temperatures of $67^{\circ} \mathrm{C}$ at the surface and contains a low concentration of dissolved chemical species such as fluorite, nitrate, sulfate, iodine, and bubble gas and small amounts of sinter and sulfur.

2) Pha Soet hot spring (CR-03) is located $300 \mathrm{~m}$ far from the Kok river at UTM 47Q, 0555992E and 2172634N, in Doy Hang Sub-district, Mueang District, Chiang Rai Province. The natural hot water, which flows through the fracture systems of Triassic Porphyritic granite 
during high-temperature and high-pressure conditions, is discharged to an $8 \times 12 \mathrm{~m}$ concrete hot pool. The discharged water from the hot spring has temperatures of $70-80{ }^{\circ} \mathrm{C}$ at the surface and contains many bubbles gas and small amounts of sinter, and sulfur, carbonate, and Silica.

3) Pong Phra Bath hot spring (CR-08) is situated in alluvial river terrace along with Huai Pa Sang fault and Ban Du fault line in a northwest to the southeast direction in Ban Du Subdistrict, Mueang District, Chiang Rai Province. The natural hot water, which flows through the fracture systems of fine- to-coarse grain Hornblende Biotite of Triassic granite, is discharged at an elevation $300 \mathrm{~m}$ MSL and presently covered by an $8 \mathrm{~m}$ diameter concrete pool. The discharged water from the hot spring has temperatures of $45-53{ }^{\circ} \mathrm{C}$ at the surface and contains the low concentration of dissolved chemical species such as fluorite, nitrate, sulfate, iodine, bubble gas and small amounts of sinter and sulfur.

4) Mae Chan hot spring (CR-04 and CR-09) is located on the Mae Chan Riverbank along the Mae Chan fault at UTM 47Q, 0583496E and 2224752N, in Pa Tueng Sub-district, Mae Chan District, Chiang Rai Province. The hot spring located far away from the city of Mae Chan approximately $8 \mathrm{~km}$ covering an area of approximately 2.4 hectares (F. S. Singharajwarapan et al., 2012). During 1983-1984, the Department of Mineral Resource (DMR) and the United Nations Development Programme (UNDP) initiated the geothermal research in the Northern part of Thailand, which found that the Mae Chan geothermal field exhibited high potential for electricity generation (Singharajwarapan et al., 2012). The surface temperature from natural spring ranges between $54-98{ }^{\circ} \mathrm{C}$. In 1996, the Department of Energy Development and Promotion (DEDP) was set up the utilization of hot water from the shallow system (less than $100 \mathrm{~m}$ ) for agriculture purpose projects. Two $100 \mathrm{~m}$ depth exploratory wells were drilled: PR1 and PR2. Unfortunately, PR1 well did not flow and thus had no temperature data but the water from PR2 well raised up to $15 \mathrm{~m}$ high, with a flow rate of $5.94 \mathrm{l} / \mathrm{s}$ and a temperature of $122{ }^{\circ} \mathrm{C}$ (Raksaskulwong, 2011). The head-on resistivity profile shows the temperature profile of well PR2 raises from 87 to $122{ }^{\circ} \mathrm{C}$ from 0 - $9 \mathrm{~m}$ depths, but the temperature curve was broken at a depth $57 \mathrm{~m}$. The resistivity survey in 2004 drilled a $56-\mathrm{m}$ borehole, produced $5.6 \mathrm{1} / \mathrm{s}$ of $94{ }^{\circ} \mathrm{C}$ water spouting $20 \mathrm{~m}$ into the air. This drilling well were installed a demonstration agroproducts cold-storage (ammonia-water absorption refrigeration system) and drying facility for processing the local agriculture product (Ramingwong et al., 2000). All the springs emanate from fractures in outcrops of porphyritic granite or from the alluvium in the river bed (Manoovoravong and Virapun, 1996). Amatyakul et al., (2015) used Magnetotelluric (MT) methods to assess the geothermal reservoir in this area. The results show that the geothermal 
reservoir is mostly settled less than $500 \mathrm{~m}$ below the surface and there are two conductive zones, the main heat sources, in weathered and fractured granite covered by sedimentary deposits.

5) Mallika hot spring (CM-16) is exposed from quaternary alluvial in Ban Muang Ngam, Taton subdistrict, Mae Eye District, Chiang Mai Province, $25 \mathrm{~km}$ far from Mae Eye district. This hot spring is evidently associated with porphyritic granite from the Triassic period. The discharged water from the hot spring has temperatures of $56-66.4{ }^{\circ} \mathrm{C}$ on its surface and contains the concentration of dissolved chemical species such as fluorite, carbonate, and silica. The spring exposes many gas bubbles and small amounts of sinter and sulfur. (DAEDE, 2007b)

6) Fang hot spring (CM-03) is located in UTM 47Q between 0555992E and 2172634N cover about 60,000 $\mathrm{m}^{2}$. Situated in Mon Pin subdistrict, Fang district, Chiang Mai province, approximately $140 \mathrm{~km}$ north of Chiang Mai Province, this area is administered by Doi Pha Hom Pok National Park. More than 100 hot pools manifest in this area; the surface temperature of the hot springs is above $90{ }^{\circ} \mathrm{C}$, with the highest temperature measuring $99.5^{\circ} \mathrm{C}$, and the pool vary in size from $5 \mathrm{~cm}$ to $1 \mathrm{~m}$ in diameter. Some of these hot spring are geysers that explode up to $15-30 \mathrm{~cm}$ above the surface at intervals $15-45 \mathrm{~s}$ (Geothermica Italiana Slr., 1984; Tulyatid et al., 2014).

For more than 30 years, the Thai government has focused on the highest surface temperature in the Fang region for the utilization of geothermal electric power plants. In 1982, the Fang Geothermal Development Project was established in cooperation between the Electricity Generating Authority of Thailand (EGAT) and the French Agency for Energy Management (AFME) with the aim to study the Feasibility of using hot water from the shallow reservoir (less than $100 \mathrm{~m}$ ) to install a binary cycle demonstration plant of 100-300 kWe. Twelve exploration wells (FGTE series) and eight slim holes (BH series) have been drilled and produce hot water at $105{ }^{\circ} \mathrm{C}$ and 0.4 bars at a discharge rate of up to 14 1/s (Geothermica Italiana Slr., 1984; Tulyatid et al., 2014).

From late 1985 to early 1986, the production reliability of power plant in the Fang area was confirmed by drilled two exploration wells, FGTE-14 and FGTE-15, in low-resistivity anomalous zones, EGAT decided to obtain a binary power plant of $300 \mathrm{kWe}$ capacity for the demonstration which started on, 1989. As of now, this power plant still working (Wanakasem and Takabut, 1987)

In 1990, the French Environment and Energy Management Agency (ADEME) started the Fang Deep Geothermal Development Project to define the potential of the deep reservoir. Deep wells 
(FX1- FX4) have been drilled with a target for $500 \mathrm{~m}$ deep, and electrical surveys have been carried out. These data were interpreted, the normal vertical drilling was found to have a very high risk because the geothermal reservoir was related with faults that laid down a very steep dip (Korjedee, 2002). Therefore, this project is not successful, and the geothermal utilization project no longer receive attention (Korjedee, 2002). The earlier Magnetotelluric (MT) results (Amatyakul et al., 2016) indicated the two local faults of the area and two conductivity zone. The local faults structures are N-NW trending Mae jai fault and low-angle detachment Doi kai fault. The hot springs conducted with the shallow zone $(<50 \mathrm{~m})$ interpreted as impermeable clay zone, and the surface to $500 \mathrm{~m}$ depth interpreted as the pore of sedimentary rock and altered granite fracture.

7) Wiang nong lom hot swamp (WNL) is a large swampy area about $7 \mathrm{~km}$ wide and 15 $\mathrm{km}$ long that appears to be a sag or downward from half-graben structures along the Mae Chan fault in the northwest. In the middle of a floating-grass swamp in this area found the warm springs whose surface temperatures approximately $41.1^{\circ} \mathrm{C}$ and which have an estimated flow rate of $2.1 \mathrm{~L} / \mathrm{s}$. The results from seismic reflection lines shown that the Meta-volcanic Mesozoic bedrock was covered by 130-170 m thick sediments (Wood et al., 2004; Wood and Singharajwarapan, 2015). 


\subsection{Ranong area}

\subsubsection{Geographic location and topography}

The study area is approximately $1,175 \mathrm{~km}^{2}$ located in the Ranong province in the southern part of Thailand, approximately $600 \mathrm{~km}$ from Bangkok metropolis area (Figure 2.2-1). This area lies within UTM $47 \mathrm{~N}(0450000 \mathrm{E}$ to $4750000 \mathrm{E}$ and from $1075000 \mathrm{~N}$ to $1122000 \mathrm{~N})$ and features mountainous topography. The elevation is highest (approximately $630 \mathrm{~m}$ AMSL, about $86 \%$ slope) at the eastern border of the province run and gradually decreases to the west in a narrow flat plain (approximately 20 m AM.S.L., about 14\% slope).

\subsubsection{Climate}

With a tropical monsoon climate, the study area has an annual mean air temperature of $27.1^{\circ} \mathrm{C}$, rainfall of $4,068.4 \mathrm{~mm} / \mathrm{year}$, humidity of $79.6 \%$ and potential evaporation of $1,308 \mathrm{~mm}$ (Thailand Meteorological Department, 2011).

Precipitation in Thailand is associated with a stream of warm moist air (high pressure) from the Indian Ocean calling Inter-Tropical Convergence Zone (ITCZ) which is controlled by a southwest monsoon and northeast monsoon. The southwest monsoon carries the clouds and convective precipitation of the ITCZ from the southern part of the country to southern China, causing precipitation between late April and early July. Cool and dry air (low pressure) create the northeast monsoon, driving the ITCZ southwest toward southern Thailand in September (the wettest period), staying until November.

\subsubsection{Regional geology and structures}

The oldest geological units in the area is a 2 - $3 \mathrm{~km}$ thick of Carboniferous-Permian marine sediment, which is the Kaeng Krachan Group (Figure 2.2-2; DMR, 2014; F. Ridd et al., 2011). This group is composed of gray mudstone, siliceous shale, sandstone, characteristic diamictites and conglomeratic sequences (Ueno, 2003; Watkinson et al., 2011). Quaternary aged terrace sediment (composed of gravel sand and silt), and from alluvial sediment (composed of clay and beach sand) are the youngest units, outcropping along the surface flow near the coastal area and covering the oldest units in the western part of the study area (Ueno, 2003; Watkinson et al., 2011). 


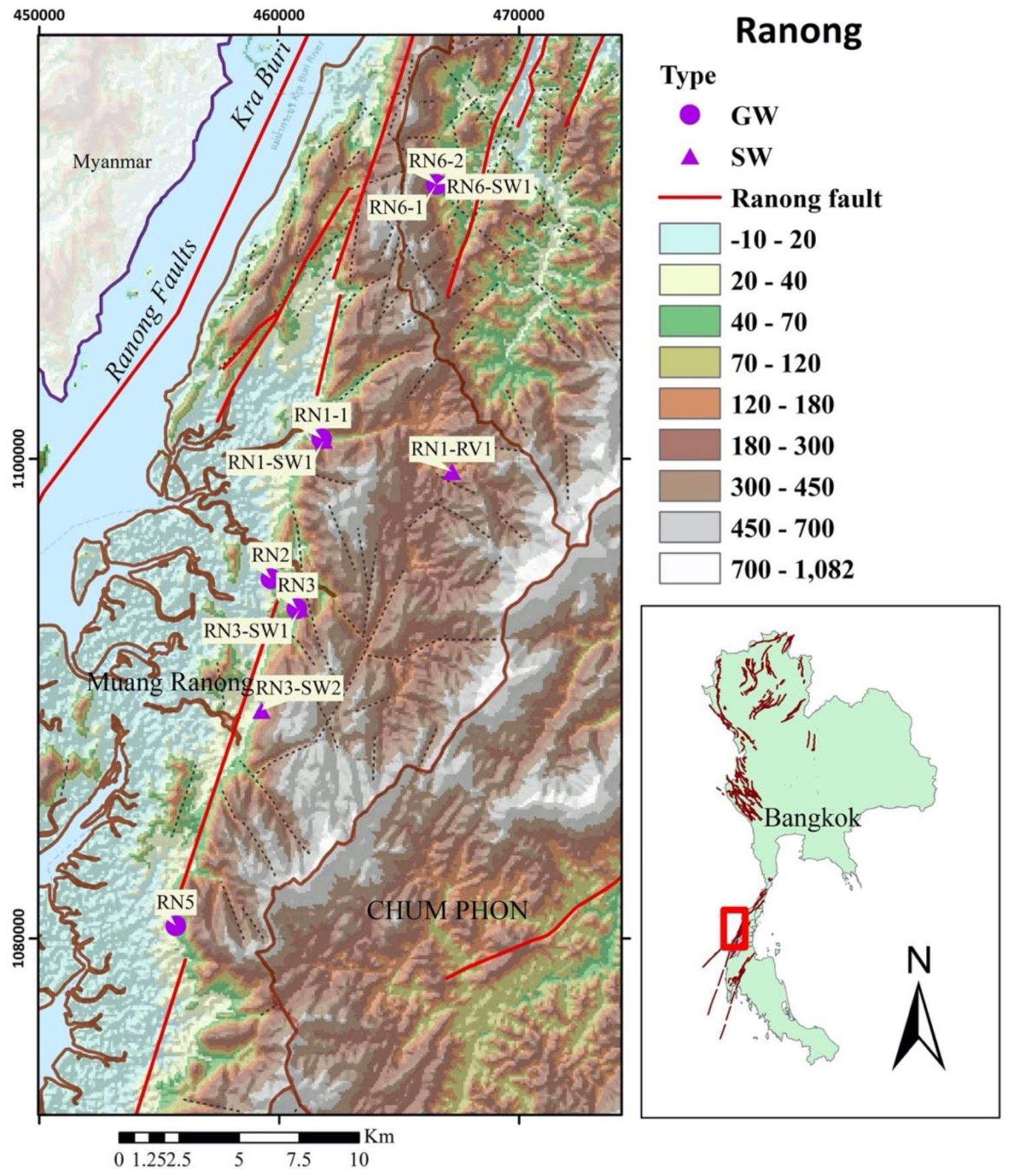

Figure 2.2-1: Topographic map of the study area with sample location in Ranong. 


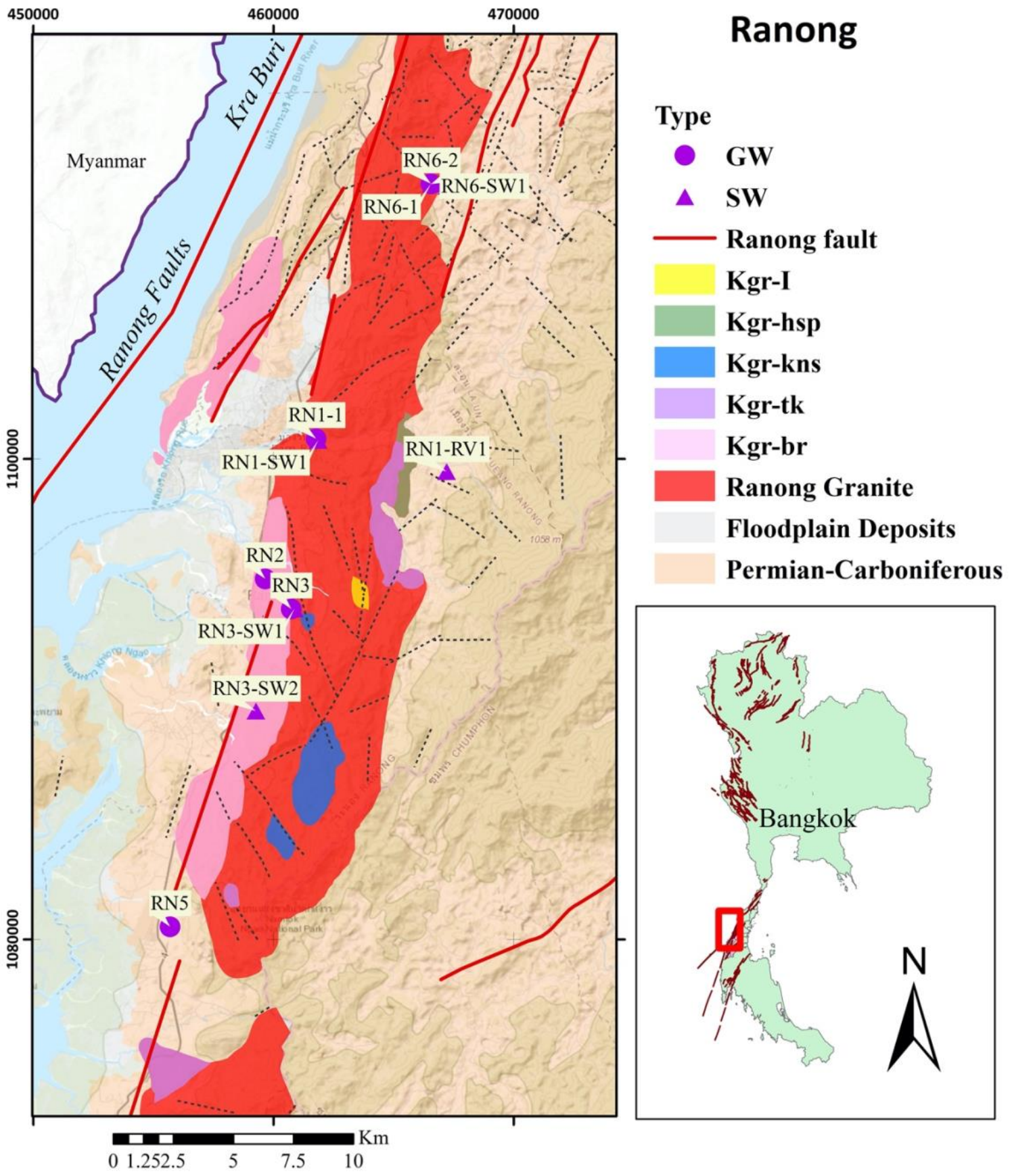

Figure 2.2-2: Geological map of the study area along with faults line and sample location in Ranong (modified after Kosuwan and Nakapadungrat, (1991)). 
The major fault in the study area is the left-lateral strike-slip Ranong fault that cuts across the Thai peninsula from northeast to southwest and links the Gulf of Thailand and the Andaman Sea (DMR, 2007; Watkinson et al., 2011). Moreover, there are several NW-SE conjugate faults line with the NE-SW Ranong fault and different direction of hundred fractures in the vicinity of the hot springs. These faults and fractures control the hot spring system (Chaturongkawanich and Leevongchareon, 2000). Undeformed medium- to high-grade metamorphic rocks intruded along the Ranong faults during the Precambrian to Carboniferous (?) age and feature amphibolite facies orthogneiss, and meta-sediments (Chaturongkawanich and Leevongchareon, 2000). The geophysical investigation results in Ranong granite by Watkinson et al., (2011) indicated that the thickness of the granite in this study area is $1.7 \mathrm{~km}$.

The intrusive Cretaceous-granite batholith in the Ranong province is part of the western province granitic belt group, which has been interpreted as predominantly S-type and I-type granitic rocks (F. Ridd et al., 2011). Kosuwan and Nakapadungrat, (1991) classified the intrusive granite into six categories (Figure 2.2-2): Khlong Ban Rin (Kgr-br), Khlong Ngao (Kgr-ng), Leucocratic (Kgr-1), Thung Ka (Kgr-tk), Khao Nom Sao (Kgr-ns), and Haad Som Pan (Kgr-hsp).

The largest pluton, Kgr-br, passes from the northern part to the southern part of the area and is described as porphyritic biotite-muscovite granite with a maximum phenocryst size of $2-5$ $\mathrm{cm}$.

The second-largest pluton is Kgr-ng, which formed the crystal foliation from the tectonic force until the shape of the feldspar changed to augen shape. The mineral compositions of both these granites are similar. The major mineral compositions are K-feldspar, plagioclase, quartz, and biotite; only, Kgr-br contains muscovite (Kosuwan and Nakapadungrat, 1991).

The discharged temperature of the thermal waters varies between $36{ }^{\circ} \mathrm{C}-66{ }^{\circ} \mathrm{C}$. These thermal waters discharge along the two regional intrusive batholiths.

\subsubsection{Hydrogeology}

The surface flow system is accumulated from the precipitation at high elevation and flows through several small streams about 20 to $30 \mathrm{~km}$ long to the Kraburi River and eventually the Andaman Sea at the western part of Ranong province (Department of Mineral Resources [DMR], 2007). 
In total six hot springs have been located along the regional intrusive batholith, namely: Raksawarin hot spring (RN1), Phu Lum Phi hot spring (RN2), Phorn Rung hot spring (RN3), Khlong Bang Rin hot spring (RN4), Rattana Rangsan hot spring (RN5), and Hatyay hot spring (RN6).

1) Raksawarin Hot spring (RN1), also called Wat Thapotharam hot spring, actually encompasses three hot springs; Por hot spring (RN1-1), Mae hot spring (RN1-2) and Lok Saw hot spring (RN1-3). These hot springs located near the canal area of Khlong Had Som Paen at UTM 47Q, 0461805E and 1100853N, in Muang district, approximately $2 \mathrm{~km}$ away from the city of Ranong. Up to the present time, these Raksawarin hot springs have been administered and developed by the Ranong Municipality for spa facilities to stimulate local tourism industries and related businesses such as spa, shops, restaurants, and recreations.

- Por hot spring (RN1-1) is exposed in the middle of Khlong Had Som Paen) and has the highest geothermal potential in this area. At the surface, this spring is a $2.8 \mathrm{~m}$ diameter circular concrete pool rising, one meter above the ground surface.

- Mae hot spring (RN1-2) and Lok Saw hot spring (RN1-3) are artificial circular concrete pools that are $1.5 \mathrm{~m}$ and $2 \mathrm{~m}$ in diameter, respectively. Both are approximately one meter above the ground surface. Both springs are located on the east side of Khlong Had Som Paen river.

The discharged waters from these hot springs have an estimated flow rate of $600 \mathrm{~m}^{3}$ per day with a range of temperatures from $40{ }^{\circ} \mathrm{C}$ to $65^{\circ} \mathrm{C}$ at the surface, contain rather low concentrations of dissolved chemical species, and are slightly alkaline ( $8.4 \mathrm{pH})$. The springs release little $\mathrm{CO}_{2}$ gas, little steam, and exhibit no algae or $\mathrm{H}_{2} \mathrm{~S}$ smell. The alteration minerals of cryptocrystalline calcite are present. These hot springs appear to be associated with Triassic porphyritic granite (144-65 Ma) along the Ranong fault direction (Chaturongkawanich and Leevongchareon, 2000; DAEDE, 2007b).

2) Phu Lum Phi hot spring (RN2) is located near an abandoned tin mine at UTM 47Q, 459678E and 1094986N, approximately 600 m from Khlong Bang Rin River in Bang Rin subdistrict, Mueang district, Ranong province. The naturally hot water discharges at an elevation $15 \mathrm{~m}$ above MSL that and covered by colluvium. The administrative organizations of the Bang Rin sub-district have built an octagonal artificial concrete pool (approximately $19 \mathrm{~m}^{2}$, and 0.8 $\mathrm{m}$ above ground surface) at the surface of RN2. The naturally warm water from this pool has a temperature of $40{ }^{\circ} \mathrm{C}$ at the surface, a $\mathrm{pH}$ of 8.3 , and contains low concentrations of dissolved 
chemical species such as $\mathrm{CO}_{2}$. This spring has no $\mathrm{H}_{2} \mathrm{~S}$ smell, algae, alteration minerals, and is slightly alkaline. RN2 is geologically associated with north-south oriented lenses of porphyritic Ngao-granite, situated in the western part of Bang-Rin granite (Chaturongkawanich and Leevongchareon, 2000; Office of Development Tourism, 2006; Office of Natural Resources and Environmental Policy and Planning, 2014).

3) Phorn Rung hot spring (RN3), consists of, three hot springs located in the east bank of Phorn Rung River at UTM 47Q, 0460779E and 1093733N, at the Khao Cheng Plu area in Bang Rin sub-district, Muang District, Ranong Province. The temperatures of the warm water from these three hot springs vary between $38{ }^{\circ} \mathrm{C}$ and $40{ }^{\circ} \mathrm{C}$ at the surface. This water contains the low concentrations of dissolved chemical species (such as $\mathrm{CO}_{2}$ ), has no $\mathrm{H}_{2} \mathrm{~S}$ smell, little yellow algae, is slightly alkaline with a $\mathrm{pH}$ of 8.4 , and has a low flow rate (less than $1 \mathrm{l} / \mathrm{sec}$ in each pool). This water discharges at an elevation of about 60 AMSL and is covered by three concrete pools; the two circular pools have 1.5 diameters and the third, oval pool is $4 \times 6 \mathrm{~m}$ diameter. All three pools have approximately $1.2 \mathrm{~m}$ above the ground surface. These hot springs are geologically associated with Triassic porphyritic granite (144-65 Ma) along the Ranong fault. Up to the present time, the Ngao Waterfall National Park Committee has administered the hot springs, building soaking hot pools and guest houses to strengthen the tourism sectors (Chaturongkawanich and Leevongchareon, 2000; Office of Development Tourism, 2006; Office of Natural Resources and Environmental Policy and Planning, 2014).

4) Khlong Bang Rin hot spring area (RN4) was discovered below Khlong Ban Rin within fractured rocks ranging from one centimeter to one meter in diameter. The hot water is $50{ }^{\circ} \mathrm{C}$ at the surface with clear water, little $\mathrm{CO}_{2}$, no $\mathrm{H}_{2} \mathrm{~S}$ smell, and no algae (Office of Development Tourism, 2006). The present, the study did not collect the water samples for chemistry data at this site.

5) Rattana Rangsan hot spring (RN5), which is located close to an abandoned tin mine near the base of the mountain at UTM 47Q, 0455870E and $1080669 \mathrm{~N}$, is located in the area of Fort Rattana Rangsan, Ratcha Grute sub-district, Muang district, Ranong province. Three circular concrete pools with diameters of $1.5 \mathrm{~m}$ cover the naturally hot water to a height of 0.3 $\mathrm{m}$ above the ground surface. This water was later utilized for consumption inside the fort. This hot spring has an estimated flow rate of approximately $4.14 \mathrm{~m}^{3}$ per hour, with a range of temperatures from $43{ }^{\circ} \mathrm{C}$ to $45^{\circ} \mathrm{C}$ at the surface and contains low concentrations of dissolved chemical species such as little $\mathrm{CO}_{2}$. No $\mathrm{H}_{2} \mathrm{~S}$ smell is present, but there is a small amount of 
whitish and greenish algae, as well as alteration minerals. This hot spring geologically inclines, relating to the granite of Cretaceous age (Office of Development Tourism, 2006).

6) Ban Hat Yay hot spring (RN6) is located in Lam Nam Kra Buri National Park Protection Unit, administered by Kra Buri National Park Committee, and includes four hot springs, two of which are covered by $1.5 \mathrm{~m}$ diameter concrete pools. The third hot spring is covered by a $3 \mathrm{~m}$ long artificial concrete weir, and the fourth hot spring is covered by an artificial soil pool ( $1.5 \mathrm{~m}$ in diameter and at $0.3 \mathrm{~m}$ depth below the ground surface). These four natural springs presumably associate with porphyritic-phaneritic-granite of Cretaceous age with a temperature of about $40{ }^{\circ} \mathrm{C}$ at the surface (Office of Natural Resources and Environmental Policy and Planning, 2014). 
Chapter 3 


\section{Methodology}

\subsection{Sampling and analytical methods}

This study attempts to evaluate the natural hydrothermal systems and water-rock interaction in the study areas by applying the hydro chemical and isotope data from water and rock. According to tropical monsoon climate, the studied area has highly variable in the annual rainfall which may affected on the shallow aquifer and surface water. Hence, hot water from hot spring surface discharges (surface manifestations) and cold water from surface waters (streams and lakes) along the sampling locations were carried out on seasonal basis, namely post-monsoon seasons (December 2014) and pre-monsoon seasons (March 2016). In total, eight hot water and six surface waters are sampled in Mae Chan, shown in Figure 2.1. In total, twelve hot water and six surface waters are sampled in Ranong area, shown in Figure 2.2. Moreover, seven meteoric water samples were collected from the Ranong area in 2014 for investigating the geochemical processes in these areas. The rock samples were collected from surrounding hot springs in March 2016 (four rock samples for Mae Chan and three rock samples for Ranong). The sample details in each study area are explained in the results chapter (Chapter 4 for the Mae Chan area and Chapter 5 for the Ranong area).

\subsubsection{Measuring of field parameters}

The water field parameters, comprised of; dissolved oxygen (DO), $\mathrm{pH}$, temperature, and electrical conductivity (EC), were measured on-site with portable instruments from WTW $\mathrm{GmbH}$. These instruments contained an Oxi 3205 electrode (standard deviation (SD) $\pm 0.5 \%$ ) to measure $\mathrm{DO}$ and temperature, a $\mathrm{pH} 3110$ electrode $(\mathrm{SD} \pm 0.005)$ to measure $\mathrm{pH}$, a Cond 3210 electrode ( $\mathrm{SD} \pm 0.5 \%$ ) to measure EC and temperature ( $\mathrm{SD} \pm 0.1{ }^{\circ} \mathrm{C}$ ). Alkalinity (reported as $\mathrm{HCO}_{3}$ ) was analyzed through titration with $0.1 \mathrm{~N} \mathrm{HSO}_{4}$ using a $\mathrm{HACH}$ Digital titrator.

\subsubsection{Petrology and mineralogy analysis}

The rock samples were transferred to Geoscience Centre, University of Göttingen, Germany for rock sampling preparation. In total, seven granitic rock samples from both study areas prepared to $30 \mu \mathrm{m}$ thin sections for polarization microscopic analysis. The granitic rocks were crushed and were optically separated each major mineral (e.g., feldspar, and biotite) for the $\mathrm{REE}$ and $\mathrm{Sr}$ analysis. It should be noted that it is not possible to separate the K-feldspar and plagioclase from the granite rock. Hence, the analytical results of REE, Sr and ${ }^{87} \mathrm{Sr} /{ }^{86} \mathrm{Sr}$ ratios 
in the feldspar minerals contain a mixture of both plagioclase and k-feldspar which were considered together.

\subsubsection{Hydro-chemical analysis}

\subsubsection{Major cations and anions analysis}

According to International Atomic Energy Agency (IAEA) sampling procedure (IAEA, 2010), for major cations and anions analysis $\left(\mathrm{Na}^{+}, \mathrm{K}^{+}, \mathrm{Ca}^{2+}, \mathrm{Mg}^{2+}, \mathrm{Cl}^{-}\right.$, and $\left.\mathrm{SO}_{4}^{2-}\right)$, the water samples were filtered through a $0.45 \mu \mathrm{m}$ (Millipore filter) in the field. These filtered water samples were separated into the $50 \mathrm{~mL}$ polyethylene bottles for anions and $125 \mathrm{ml}$ polyethylene bottles for cation analysis. Moreover, the water samples for the cation analysis were acidified by concentrated nitric acid $\left(\mathrm{HNO}_{3}\right)$ to a $\mathrm{pH}$ of less than 2 .

The analyses of major ion chemistry in thermal and surface water samples were performed by ion chromatography (IC) at the Geosciences Centre, Georg-August-University of Göttingen, Germany. The major cations were separated and determined by the Dionex AQUION system (Thermo scientific) with conductometric detection and the CG12-5 $\mu$ m precolumn with a $\mathrm{CS} 12 \mathrm{~A}-5 \mu \mathrm{m}$ column. The separation was performed at $44{ }^{\circ} \mathrm{C}$ with $18 \mathrm{mM}$ methanesulfonic acid as eluent. For the separation and the determination of major anions were conducted on an ion chromatography system (Dionex) with conductometric detection using an IonPac AG11$\mathrm{HC}$ precolumn and IonPac AS1-HC column. The separation was performed at $30{ }^{\circ} \mathrm{C}$ with $23 \mathrm{mM} \mathrm{KOH}$ as eluent. The ion chromatography system consisting of a Dionex IP25 Isocratic Pump, a Dionex IC25 Ion Chromatography module, Dionex EG50 Eluent generator module, and a Dionex AD20 absorbance detector module (used in special cases).

\subsubsection{Rare earth element (REE) and Strontium concentration (Sr)}

The rock and water samples were determined the Rare earth element (REE) and Strontium concentration (Sr) by using ICP-MS on a PerkinElmer DRC II (Sciex, Canada) at the department of Geochemistry (Geoscience Centre, University of Göttingen, Germany).

\subsubsection{Silicon concentration $\left(\mathrm{SiO}_{2}\right)$}

The $\mathrm{SiO}_{2}$ in water samples was determined in the form of a blue molybdate-silica-complex by following a DIN 38405 Part 21 procedure. During the sample preparation, the plastic containers and plastic equipment are recommended to avoid silica contamination. Two sets of $1 \mathrm{ml}$ water samples are diluted with $25 \mathrm{ml}$ distilled water and $25 \mathrm{ml}$ boric acid. The first set is 
prepared for titration of sulfuric acid to $\mathrm{pH} 1.1$. The second set is prepared for the measurement, add the sulfuric acid from the titration volume, add $2 \mathrm{ml}$ ammonium molybdate, add $2 \mathrm{ml}$ tartaric acid, and add $2 \mathrm{ml}$ ascorbic acid. Then filled up with distilled water to a total volume of $100 \mathrm{ml}$. The solution allowed to stand 5 minutes for each additional chemistry. The blue molybdate-silica-complex in the solution is measured by a Photometry "Varian Cary 50 Scan UV-Vis" by $50 \mathrm{~mm}$ cuvette and in the condition of 0.5 seconds, the wavelength of $\lambda=810$ $\mathrm{mm}, 5$ replicates. Calibration of the photometer was performed with 9 reference solutions. All furtherments are carried out with the resulting calibration curve.

\subsubsection{Radioactive and stable isotope analysis}

\subsubsection{Stable isotope of water}

For isotopic analysis of hydrogen, oxygen, and carbon, sampling protocols followed the IAEA sampling recommendations (IAEA, 2010). All of the sampling containers were pre-cleaned by weak hydrochloric acid and dried before sampling. The hot water samples were stored in $50 \mathrm{ml}$ glass bottles and cool waters were stored in $50 \mathrm{ml}$ polyethylene bottles. Sample bottles were filled with water and then closed and wrapped by parafilm to reduce evaporation and weight loss before transport to the laboratory at the Thailand Institute of Nuclear Technology (TINT), Ongkarak, Thailand. The water isotopic ratios were determined using a laser spectrometer for liquid water analysis (Picarro, L2310-i) at TINT, using the Vienna Standard Mean Ocean

Water (VSMOW) as a reference standard. The results are reported as $\delta^{2} \mathrm{H}$ and $\delta^{18} \mathrm{O}$ values in permil (\%o) deviations from SMOW. The analytical precision of the reported $\delta^{2} \mathrm{H}$ and $\delta^{18} \mathrm{O}$ values are $\leq 0.2 \%$ and $\leq 2 \%$, respectively.

\subsubsection{Tritium isotope}

Tritium concentration $\left({ }^{3} \mathrm{H}\right)$ in modern precipitation in Thailand decreased to $<5$ tritium units $\left(1 \mathrm{TU}=1 \mathrm{~atm}\right.$ of tritium per $10^{18}$ atom of hydrogen $\left.=0.11919+0.00021 \mathrm{~Bq} / \mathrm{l}\right)($ Yongprawat et al., 2012). At such levels, the ${ }^{3} \mathrm{H}$ in water samples was measurable using a low-level background liquid scintillation counter with the tritium electrolytic enrichment unit in the TINT laboratory. The hot and cool water samples were collected into the $1 \mathrm{~L}$ PE bottles and transferred to the laboratory. All samples were distilled prior to electrolysis (primary distillation) until the EC were less than $30 \mu \mathrm{S}$. In each enrichment run, 15 distilled water samples, three spikes (known ${ }^{3} \mathrm{H}$ activity), and two backgrounds (without ${ }^{3} \mathrm{H}$ activity) were prepared into 20 electrolytic cells of $500 \mathrm{ml}$ volume. During electrolysis, the cells were 
contained in a freezer/refrigerator controlling temperature between $0{ }^{\circ} \mathrm{C}$ and $-4{ }^{\circ} \mathrm{C}$. The total amount of energy charge in a cell is $1423 \mathrm{Ah}$ for 8 days. The initial volume of $500 \mathrm{ml}$ in each cell was electrolytically enriched to approximately $22 \mathrm{ml}$. After secondary distillation, the 20 enriched waters, and 6 original standards (two "backgrounds", two "spike" and two reference standard) were then mixed with UltimaGold LLT scintillator ( $8 \mathrm{ml}$ of water :12 $\mathrm{ml}$ scintillator). Beta particles $(\beta)$ in the cocktail samples were measured in 10 cycles, 50 min each by a liquid scintillation counting device (LSC) (Packard Tricarb 3180 TR/SL). The minimum detectable activity (MDA) of this method (detection limit) is $0.02 \mathrm{~Bq} / 1 .{ }^{3} \mathrm{H}$ concentrations are calculated and expressed in tritium units (TU) with a standard uncertainty (one sigma level) in the order of 0.3-0.4 Tritium Units (TU).

\subsubsection{Radioactive and stable isotope of carbon}

To determine the stable isotopic composition of carbon $\left(\delta^{13} \mathrm{C}\right)$ and radiocarbon $\left({ }^{14} \mathrm{C}\right)$, the study precipitated all inorganic carbon species from 40- and 60-liters thermal water in the field. The water was store in the special container, which was sealed to avoid atmospheric carbon contamination. Adding $50 \mathrm{ml}$ of carbonate-free sodium hydroxide $\left(\mathrm{NaOH}_{(1)}\right)$ and approximately $5 \mathrm{~g}$ of iron sulfate (s) for increasing $\mathrm{pH}$ to about 11 . Then, adding $150 \mathrm{~g}$ of barium chloride $\left(\mathrm{BaCl}_{2(\mathrm{~s})}\right)$ and $40 \mathrm{ml}$ of praestol solution for precipitating the dissolved carbon species in the form of barium carbonate $\left(\mathrm{BaCO}_{3(\mathrm{~s})}\right)$. After the precipitation reactions were completed, the solid carbonate samples are transferred to $1 \mathrm{~L}$ polyethylene bottles for transportation to the TINT laboratory, where they were separated into pre-measured containers for $\delta^{13} \mathrm{C}$ and ${ }^{14} \mathrm{C}$ measurement.

${ }^{14} \mathrm{C}$ measurement was performed by direct absorption. The precipitated carbonate samples were acidified with concentrated $\mathrm{HCl}_{(\mathrm{g})}$ to release $\mathrm{CO}_{2(\mathrm{~g})}$ under the vacuum system. The released gas was purified and incorporated as a carbomate in a 1:1 mixture of absorber (Carbo-Sorb E) and scintillation cocktail (Permafluor E). The mixing cocktail measured beta particles $(\beta)$ with a liquid scintillation counting device (LSC) (Quantulus ${ }^{\mathrm{TM}}$ 1220). The minimum detectable activity (MDA) of this method (detection limit) is $6 \mathrm{~Bq} / \mathrm{kg} \mathrm{C}$. The results from LSC (counts per minute: CPM) were statistically evaluated into units of percent modern carbon (PMC) (precision \pm 3 to $\pm 10 \% \mathrm{PMC}$ ).

For $\delta^{13} \mathrm{C}$ measurement, precipitated samples were acidified to convert from solid carbonates $\left(\mathrm{BaCO}_{3(\mathrm{~s})}\right)$ to $\mathrm{CO}_{2}$ gas and transferred to the Picarro G2101-I for carbon isotopic determination. 
This instrument is based on Picarro's unique Wavelength-Scanned Cavity Ring Down Spectroscopy (WS-CRDS). Pee Dee Belemnite (PDB) was used as a reference standard. The uncertainties of this measurement are less than $0.4 \%$.

\subsubsection{Strontium isotope}

Preparation of ${ }^{87} \mathrm{Sr} /{ }^{86} \mathrm{Sr}$ analysis by evaporated $10 \mathrm{~mL}$ of water samples to dryness and dissolved in $1 \mathrm{~mL}$ of $2.5 \mathrm{~N}$ hydrochloric acids. It was transferred to ion-chromatography columns using BioRad AG 50x8 (200-400 mesh) cation-exchange resin and 2.5 N hydrochloric acid as eluent for $\mathrm{Sr}$ separation from other ions. Strontium was purified by loaded onto outgassed Re filaments (double- filament technique) with $0.25 \mathrm{~N}$ ultrapure phosphoric acid $\left(\mathrm{H}_{3} \mathrm{PO}_{4}\right)$, A Finnigan MAT 262 thermal ionization mass spectrometer (TIMS) measured $\mathrm{Sr}$ isotopes ratios. The instrumental fractionation of the measured ${ }^{87} \mathrm{Sr} /{ }^{86} \mathrm{Sr}$ ratios is normalized to a constant ${ }^{88} \mathrm{Sr} /{ }^{86} \mathrm{Sr}$ ratio of $8.375209\left({ }^{88} \mathrm{Sr} /{ }^{86} \mathrm{Sr}=0\right)$. All ${ }^{87} \mathrm{Sr} /{ }^{86} \mathrm{Sr}$ values were adjusted to a certified NBS987 value of $0.71039 \pm 0.00001$. The precision of this measurement is $0.003 \%$ $(2 \sigma)$ or less.

Preparation of ${ }^{87} \mathrm{Sr} /{ }^{86} \mathrm{Sr}$ analysis in mineral samples, the separated minerals were digested in a mixture of $\mathrm{HF}-\mathrm{NO}_{3}-\mathrm{HClO}_{4}$ at $120{ }^{\circ} \mathrm{C}$ overnight. After complete dissolution and evaporation, the sample residues were dissolved in $6 \mathrm{~N} \mathrm{HCl}$ at $120{ }^{\circ} \mathrm{C}$ and again evaporated. Thereafter, the sample residues were measured following the same procedure of ${ }^{87} \mathrm{Sr} /{ }^{86} \mathrm{Sr}$ analysis in water samples.

\subsection{Identification of water sources.}

The stable isotope data from laboratory results expressed as the abundance ratio of the two most abundant isotopes of a given element (for instance; ${ }^{2} \mathrm{H} / \mathrm{H},{ }^{18} \mathrm{O} /{ }^{16} \mathrm{O}$, and ${ }^{13} \mathrm{C} /{ }^{12} \mathrm{C}$ etc.). Due to the slightly differences in the number of isotope abundance ratios in various natural reservoirs and the dissimilarity of different laboratory results, the isotopic compositions are normally expressed in terms of absolute abundance ratios in $\delta$-notation (delta). The $\delta$-notation represent as deviations of sample isotopic ratios from measurement reported relative to international standard reference material which known isotopic composition in a unit of parts per thousand or per mil (\%), 


$$
\delta=\left(\frac{R_{\text {sample }}-R_{\text {standard }}}{R_{\text {standard }}}\right) \times 1000
$$

where $R_{\text {sample }}$ represents the measured isotope ratio from water sample, $R_{\text {standard }}$ represents the measured isotope ratio from standard, $\delta$ represents the deviations of sample isotopic ratios from measurement reported relative to standard.

Hence, the samples have more isotopic ratios than isotopic ratios from reference standard or positive value of $\delta$-notation of that element $\left(\delta^{2} \mathrm{H}\right.$ and $\left.\delta^{18} \mathrm{O}\right)$ are called "enriched" or "heavy", In contrast, the samples have less isotopic ratios than isotopic ratios from reference standard or negative value of $\delta$-notation of that element $\left(\delta^{2} \mathrm{H}\right.$ and $\left.\delta^{18} \mathrm{O}\right)$ are called "depleted" or "light".

Stable isotope composition of water $\left(\delta^{\mathbf{2}} \mathbf{H}\right.$ and $\left.\delta^{\mathbf{1 8}} \mathbf{O}\right)$. A water molecule $\left(\mathrm{H}_{2} \mathrm{O}\right.$ or di-hydrogen oxide) has a possibility to discover a different isotopic combination of one atom of oxygen $\left({ }^{16} \mathrm{O},{ }^{17} \mathrm{O}\right.$ and ${ }^{18} \mathrm{O}$ isotope $)$ and two atoms of hydrogen $\left({ }^{1} \mathrm{H},{ }^{2} \mathrm{H}\right.$ and $\left.{ }^{3} \mathrm{H}\right)$. The most second abundance of the hydrogen atom and oxygen atoms, comprised of deuterium $\left({ }^{2} \mathrm{H}: 0.015 \%\right.$ of hydrogen atom) and oxygen-18 ( ${ }^{18} \mathrm{O}: 0.038 \%$ of oxygen atom) (Deshpande, 2011).

The stable isotopic composition of $\delta^{2} \mathrm{H}$ and $\delta^{18} \mathrm{O}$ is relatively conservative in reaction with the material in the subsurface system. However, these are varied by different parameters such as temperature effect, altitude effect, latitude effect, continental effect, and amount effect (Clark, 2015; Kendall et al., 2004).

Theoretically, geothermal fluid can derive from five sources, 1) meteoric water, 2) Seawater, 3) Conate water, 4) Metamorphics water, 5) Juvenile or magmatic water (Clark, 2015; Pirajno, 2009). The previous investigation in the study areas (Chaturongkawanich and Leevongchareon, 2000; DAEDE, 2007a) demonstrated that most of the water chemistry results have low electrical conductivity (EC) which is in the range of surface water and groundwater (EC $<700 \mu \mathrm{S} / \mathrm{cm}$; U.S. Geological Survey, 2019). Thus, meteoric water should be an important recharge source for the geothermal fluid. To prove this hypothesis and to determine the water source and to understand the hydrologic cycle within these study areas, the stable isotopic ratios of samples are plotted between $\delta^{2} \mathrm{H}$ and $\delta^{18} \mathrm{O}$ with the primary magmatic water area from Giggenbach, (1992), the global meteoric water line (GMWL) $\left(\delta^{2} \mathrm{H}=8 \delta^{18} \mathrm{O}+10 \%\right.$; Craig, 1961), and local meteoric water line (LMWL) of each study area. 
For Mae Chan area, the LMWL was obtained from the stable isotope data of daily precipitation $(\mathrm{n}=263)$ from 2013 to 2015 in the Chiang Rai precipitation monitoring station (Hydro and Agro Informatics Institute (HAII), 2016), which is considered the nearest station to the study area. The equation for the LMWL is $\delta^{2} \mathrm{H}=7.83 \delta^{18} \mathrm{O}+7 \%$, with -47.99 weight mean average $\delta^{2} \mathrm{H}$ and -7.07 weight mean average $\delta^{18} \mathrm{O}$. The isotopic correlation graph is shown in Figure 9.1-1 in Appendix 1.

For Ranong area, the LMWL was obtained from the stable isotopic data in daily precipitation samples $(\mathrm{n}=338)$ from 2013 to 2015 at the Ranong monitoring station (HAII, 2016). This station, located in Tambon Bang Yai, Amphoe Kra Buri, Chang Wat Ranong, is the closest station to the Raksawarin hot spring about $40 \mathrm{~km}$ northeast, at $21 \mathrm{~m} \mathrm{AMSL}$ ). The isotopic correlation graph is shown in Figure 9.1-2 in Appendix 1.

The $\delta^{18} \mathrm{O}$ ratio from the high thermal geothermal water is often enriched and thus deviates from the LMWL which is often described as "oxygen isotope shift" or " $\delta^{18} \mathrm{O}$-shifted". Due to the fact that the rock has higher oxygen (approximately $50 \%$ by mass) to hydrogen ( $1 \%$ by mass). The isotopic exchange mechanism between initial water (e.g., meteoric water) and the heavy isotopic composition of the surrounding rock is controlled by the temperature of the geothermal reservoir. Hence, this isotope shift can identify in oxygen and is a good indicator for investigating the water-rock interaction in the geothermal study (Aggarwal et al., 2005; Hoefs, 2009; Nicholson, 1993). The $\delta^{18} \mathrm{O}$-shifted in each thermal water sample is calculated by the equation.

$$
\delta^{18} \mathrm{O} \text {-shifted }=\delta^{18} \mathrm{O}_{\text {thermal }}-\delta^{18} \mathrm{O}_{\text {LMwL }}
$$

where $\delta^{18} \mathrm{O}$-shifted represents the $\delta^{18} \mathrm{O}$ value of oxygen isotope shift (\%o); $\delta^{18} \mathrm{O}_{\text {thermal }}$ represents the $\delta^{18} \mathrm{O}$ value of the thermal water (\%o); and $\delta^{18} \mathrm{O}_{\mathrm{LMwL}}$ represents the $\delta^{18} \mathrm{O}$ value of the average precipitation which derived from LMWL.

Stable isotope of carbon can provide the carbon source in thermal water investigating by comparing the $\delta^{13} \mathrm{C}$ results with the $\delta^{13} \mathrm{C}$ range from Hoefs, (2009). 


\subsection{Water classification and geochemical processes}

\subsubsection{The water classification}

To better understand the water classification in the geothermal area, the major ion results were interpreted graphically by plotting the chemical data in the triangular diagrams modified from Giggenbach, (1988).

\subsubsection{The geochemical processes}

In hydrological cycle, the precipitation water regards as the major source in most of the subsurface system and naturally has low chemical concentrations. During the rainwater infiltration under the unsaturated zone or from the water table, solutes in the water become increasingly concentrated under the influence of evapotranspiration. Afterward, under the saturated zone, the chemical concentration has changes by additional chemical and other geochemical processes.

The study considered that the possible concentration in the unsaturated zone derived under influenced on evapotranspiration losses (Post-ET). This would be calculated from the maximum concentration in seven Ranong precipitation samples multiply by an evapotranspiration concentration factor (ETF) in each study area (Giggenbach, 1988; Saad and Thorstenson, 1998; Petelet-Giraud et al., 2003). The analytical results and computed results of the major-ion compositions in Post-ET shown in Chapter 5 in Table 5-4.

For visual identification of the geochemical processes, the major-ion compositions in thermal waters and the major-ion compositions in Post-ET are plotted in a Schoeller's diagram. The diagram can indicate the major grouping or trends of the data, which will show and explain in the results chapter of each area (Chapter 4 for Mae Chan and Chapter 5 for Ranong).

ETF is calculated from the mean rainfall divided by the difference in between mean rainfall and mean potential evapotranspiration in that area, described as

$$
E T F=\frac{P}{P-E T}
$$

where $E T F$ is the evapotranspiration concentration factor; $P$ is the mean rainfall; and $E T$ is the mean potential evapotranspiration in that area. 
From Chapter 2, the ETF in each area can computed from the climate referent data (Thailand Meteorological Department, 2011), as follows

The Mae Chan area has a mean rainfall of 1,690 mm/year and means potential evaporation of $1,269.48 \mathrm{~mm}$. Therefore, the ETF in the Mae Chan area is 4.02 .

The Ranong area has a mean rainfall of $4,068.4 \mathrm{~mm} /$ year and means potential evaporation of $1,308 \mathrm{~mm}$. Therefore, the ETF in the Ranong area is 1.5.

\subsection{Recharge elevation}

The altitude effect is an important parameter on the variation of stable isotope composition. Due to the fact that the atmospheric temperature is decreased with increasing elevation. It drives rainout and distillation, changing the isotopic composition in precipitation. After the water penetrates into the subsurface, the isotopic composition of groundwater remains stable from the recharge area. Hence, the groundwater recharged from a higher elevation would reflect the depleted isotopic composition. In this study, the recharge elevation of thermal water can be estimated based on the altitude effect of stable isotope in the equation

$$
H=H_{g}+\frac{\left(O_{p}-O_{g}\right)}{g r a d-O}
$$

where $H$ and $H_{g}$ are the altitude of the recharge elevation and sampling elevation (m AMSL), respectively; $O_{g}$ and $O_{p}$ are the $\delta^{18} \mathrm{O}$ value of the thermal water and the average precipitation near the sampling site $(\%)$; $\operatorname{grad}-O$ is the altitude- $\delta^{18} \mathrm{O}$ gradient in the study area. Remarkably, the $\delta^{18} \mathrm{O}$ of thermal water can be disturbed by water-rock interaction at high temperatures, hence, the $\delta^{18} \mathrm{O}$ results from thermal water do not represent the isotope composition from the recharge area. In contrast, the basement rock has an extremely small amount of hydrogen. The shifts in $\delta^{2} \mathrm{H}$ by water-rock interaction do not take place. Therefore, $\delta^{18} \mathrm{O}$ value of the thermal water is replaced by the calculated $\delta^{18} \mathrm{O}$ at the recharge area from $\delta^{2} \mathrm{H}$ results by the LMWL equation. The altitude- $\delta^{18} \mathrm{O}$ gradient in Thailand from Doi Inthanon reported (TINT, 2012) that is $-0.22 \%$ / $/ 100 \mathrm{~m}$, was used for calculation. 


\subsection{The residence time of thermal water estimation}

The residence time is an important parameter for evaluating the quantity of the hydrological system, for instance, circulation and renewability. This can estimate from common radioactive decay law equation and is defined as

$$
N=N_{0} \cdot e^{-\lambda t}
$$

where $\lambda$ is the decay constant, $N_{0}$ and $N$ are the numbers of particles from initial and after decay processes, $t$ is the residence time from the decay processes.

\subsubsection{Tritium $\left({ }^{3} \mathbf{H}\right)$}

Tritium is a conservative tracer in water that can indicate travel times through radioactive decay and has a half-life of 12.32 years. The tritium dating is investigated by comparing ${ }^{3} \mathrm{H}$ results with the peak concentration of ${ }^{3} \mathrm{H}$ in rainfall (the input function) from the atmospheric nuclear tests of the 1950s-1960s (Cartwright et al., 2013; Cartwright and Morgenstern, 2012; Clark, 2015).

\subsubsection{Radiocarbon dating $\left({ }^{14} \mathrm{C}\right)$}

The residence time from Radiocarbon dating $\left({ }^{14} \mathrm{C}\right)$ is commonly investigated by the common decay law (Eq 3.5). The ${ }^{14} \mathrm{C}$ of DIC is measured with a half-life 5,730 years and can be illustrated on the ten thousand years' timescale ranging from modern to longer than 45,000 BP (Han et al., 2012; Han and Plummer, 2016). The common decay law equation (3.2) can generate to equation (3.6), is defined as

$$
t=-\frac{5730}{\ln 2}\left(\frac{{ }^{14} C_{D I C}}{{ }^{14} C_{0}}\right)=-\frac{1}{\lambda_{14}} \ln \left(\frac{{ }^{14} C_{D I C}}{{ }^{14} C_{0}}\right)
$$

where $\lambda_{14}$ is the decay constant, ${ }^{14} \mathrm{C}$ DIC is the measured ${ }^{14} \mathrm{C}$ value of dissolved inorganic carbon, ${ }^{14} \mathrm{C}_{0}$ is the initial ${ }^{14} \mathrm{C}$ value derived from atmosphere $(100 \mathrm{pMC}), t$ represents the fluid residence time of ${ }^{14} \mathrm{C}$.

However, these radiocarbon results may be disturbed by varieties of physical and geochemical processes which occurred along the flow part, such as; calcite dissolution, dolomite dissolution, oxidation of organic matter, exchange with the aquifer matrix, diffusion into the matrix, sulfate reduction, methanogenesis, and mixing of geogenic $\mathrm{CO}_{2}$ (Cartwright and Morgenstern, 2012; Clark, 2015). Therefore, for an understanding of these processes and improving the fluid 
residence time estimation in the study areas, the ${ }^{14} \mathrm{C}$ results are investigated cooperating with $\delta^{13} \mathrm{C}$ results. It will be explained in detail in the results from Chapter 4 and Chapter 5.

\subsection{Geothermometers}

The reservoir temperatures can be estimated by the comprehensive geothermometrical methods, comprised of, two most widely used chemical geothermometers, which are congregated and summarized by Arnórsson, (2000). The first one is cation geothermometers and the second is silica geothermometers.

\subsubsection{Cation geothermometers}

Some cations composition in thermal water, which are developed from the thermal dependent reaction between the minerals in host rock and solution in the equilibrium state, are widely applied for reservoir temperature estimation (Arnórsson, 2000). Na-K, K-Mg, and Na-K-Ca geothermometer equations from many studies are applied for temperature estimation in these study areas. The details of geothermometer equations are shown in Table 3-1.

\subsubsection{Silica geothermometers}

Silica geothermometers are widely applied for estimating the reservoir temperature. It has been several experimentally investigations, which mostly based on Chalcedony and Quartz solubility, this equation and detail have shown in Table 3-2. These geothermometers can estimate the realistic reservoir temperature in the range of 120 and $180{ }^{\circ} \mathrm{C}$ (Arnórsson et al., 1983). Chalcedony geothermometer can also be utilized if the temperature of the geothermal system below $190^{\circ} \mathrm{C}$, while Quartz geothermometer can apply at higher temperature. shown in Table 3-1.

\subsubsection{Geothermometers assessment}

Different geothermometers would provide different ranges of temperature results. Moreover, if the system has not reached the water-rock equilibrium state and/or has been mixed with cooled water while rising to the surface, a straightforward temperature estimation from these geothermometers would not provide reliable temperature results. This study recognizes three graphical tools for validating these geothermometers in hot springs: $\mathrm{Na}-\mathrm{K}-\mathrm{Mg}$ triangular diagram, the quartz/Na-K diagrams and quartz/Mg-K diagrams, and the silica-enthalpy mixing model. 


\subsubsection{The Na-K-Mg triangular diagram.}

The Na-K-Mg triangular diagram was proposed by Giggenbach, (1988), and was utilized for evaluating the degree of water-rock equilibrium at a given temperature, based on two theories between the rapid rock-water equilibrium reaction of the $\mathrm{K}-\mathrm{Mg}$ geothermometer and the slow rock-water equilibrium reaction of the Na-K geothermometer. The state of water-rock equilibrium is classified as three equilibrate states; 1) fully equilibrated, 2) partially equilibrated, and 3) immature water.

\subsubsection{The Quartz/Na-K diagram and Quartz/Mg-K diagram.}

The temperatures from these geothermometers may be disturbed by dilution processes, cooling effect, equilibration with amorphous silica, and acidity of the system. The Quartz/Na-K diagram (Giggenbach, 1988) and the Quartz/Mg-K diagram (Giggenbach et al., 1994) compare the logarithm of chemical concentration from hot springs and theoretical geothermometer lines. These theoretical lines represent the maximum $\mathrm{Na} / \mathrm{K}$ ratio, $\mathrm{Mg}-\mathrm{K}$ ratio and silica content at a given temperature, obtained from the geothermometer equation in Table 3.6-1. and 3.6-2, comprised of; amorphous silica geothermometer, chalcedony geothermometer, and Quatz geothermometer (no steam loss and maximum steam loss) equations from Giggenbach et al., (1994) and Fournier and Rowe, (1977).

\subsubsection{The silica-enthalpy mixing model}

The chemical composition of the original thermal water can be modified by the chemical concentration of cold surface water. In this case, chemical geo-thermometers would probably obtain an incorrect estimated temperature result (mixed temperature).

Fournier and Rowe, (1977) proposed a model for evaluating the reservoir temperature before mixing with cold surface waters during the surface ascending processes. This model assumes that the ascending thermal water is mixed from two water sources that have distinct temperature and are chemically controlled by quartz solubility. The silica concentration in the water should not have been disturbed before or after mixing by other processes, such as silica deposition and conductive cooling. However, the combined temperature from two water sources is not conserved in this model. The heat content (enthalpy), which can be estimated from steam table (Wagner and Hans-Joachim, 2007), is a better representatively parameter than temperature. 
As proposed by Founier, (1989), another silica phase is applied to replace the quartz solubility equation. Therefore, in this study, the chalcedony equation and chalcedony steam-loss geothermometer from Arnórsson, (1983) in Table 3-2 are applied instead of the quartz solubility.

The average dissolved silica concentrations of thermal water and cold water are plotted against the corresponding enthalpies from hot springs along with the results, to compares with three theoretical reference lines (Figure 3.6-1).

The model is considered in two scenarios. In the first scenario, the enthalpy of mixing water remains stable (does not lost) during ascension to the surface. So that is the mixing process occurs after boiling, and the total amount of steam is condensed in the cold water. In the second scenario, the warm water loses enthalpy from the steam leakage before the mixing process at atmospheric pressure. 
Table 3-1: Cation geothermometer equation.

\begin{tabular}{|c|c|c|c|}
\hline Type & Equation & $\begin{array}{l}\text { Range } \\
\left({ }^{\circ} \mathrm{C}\right)\end{array}$ & References \\
\hline \multirow[t]{7}{*}{$\mathrm{Na} / \mathrm{K}$} & $T=\frac{1217}{1.438-\log (\mathrm{Na} / \mathrm{K})}-273.15$ & & Fournier (1979) \\
\hline & $T=\frac{933}{0.933-\log (\mathrm{Na} / \mathrm{K})}-273.15$ & $25-250$ & $\begin{array}{l}\text { (Han et al., 2012; } \\
\text { Han and } \\
\text { Plummer, 2016) }\end{array}$ \\
\hline & $T=\frac{1319}{1.699-\log (\mathrm{Na} / \mathrm{K})}-273.15$ & $250-350$ & $\begin{array}{l}\text { Arnórsson et al., } \\
\qquad(1983)\end{array}$ \\
\hline & $T=\frac{1178}{1.470-\log (\mathrm{Na} / \mathrm{K})}-273.15$ & \multirow{4}{*}{$0-350$} & $\begin{array}{l}\text { Nieva \& Nieva } \\
\quad(1987)\end{array}$ \\
\hline & $T=\frac{1390}{1.750-\log (\mathrm{K} / \mathrm{Na})}-273.15$ & & $\begin{array}{l}\text { Giggenbach, } \\
\text { (1988) }\end{array}$ \\
\hline & $\begin{aligned} T=733.6+ & (-770.551(\log (N a / K)) \\
& +\left(378.189(\log (N a / K))^{2}\right) \\
& +\left(-95.753(\log (N a / K))^{3}\right) \\
& +\left(9.5444\left((\log (N a / K))^{4}\right)\right.\end{aligned}$ & & $\begin{array}{l}\text { Arnórsson, } \\
\text { (2000) }\end{array}$ \\
\hline & $T=\frac{1052}{1+\mathrm{e}^{0.252+\left(1.714 * \log \left((\mathrm{Na} / \mathrm{K})^{4}\right)\right.}+76}$ & & Can, (2002) \\
\hline \multirow[t]{4}{*}{$\mathrm{K} / \mathrm{Mg}$} & $T=\frac{2330}{7.35-\log \left(\mathrm{K}^{2} / \mathrm{Mg}\right)}-273.15$ & & Fournier (1991) \\
\hline & $T=\frac{1077}{7.35-\log \left(\mathrm{K}^{2} / \mathrm{Mg}\right)}-273.15$ & & $\begin{array}{l}\text { Fournier }(1991) \\
\text { (Adiabatic } \\
\text { cooling) }\end{array}$ \\
\hline & $T=\frac{4410}{14.0-\log \left(\mathrm{K}^{2} / \mathrm{Mg}\right)}-273.15$ & & $\begin{array}{l}\text { Giggenbach, } \\
\text { (1988) }\end{array}$ \\
\hline & $T=\frac{4630}{14.6-\log \left(\mathrm{K}^{2} / \mathrm{Mg}\right)}-273.15$ & & $\begin{array}{l}\text { Giggenbach, } \\
\text { (1988) (Adiabatic } \\
\text { cooling) }\end{array}$ \\
\hline $\mathrm{Na}+\mathrm{K}+\mathrm{Ca}$ & $T=\frac{1647}{\log \left(\frac{\mathrm{Na}}{\mathrm{K}}\right)+\beta \log \left(\frac{\sqrt{\mathrm{Ca}}}{\mathrm{K}}\right)+2.24}-273.15$ & & $\begin{array}{c}\text { Fournier and } \\
\text { Truesdell, (1973) }\end{array}$ \\
\hline
\end{tabular}


Table 3-2: Silica geothermometers.

\begin{tabular}{|c|c|c|c|}
\hline Type & Equation & $\begin{array}{c}\text { Range } \\
\left({ }^{\circ} \mathrm{C}\right)\end{array}$ & References \\
\hline Chalcedony & $T=\frac{1032}{4.69-\log S}-273.15$ & $0-250$ & Fournier(1977) \\
\hline $\begin{array}{l}\text { Quartz } \\
\text { (no steam loss) }\end{array}$ & $T=\frac{1309}{5.19-\log S}-273.15$ & $25-250$ & Fournier(1977) \\
\hline $\begin{array}{l}\text { Quartz } \\
\text { (max. steam } \\
\left.\text { loss at } 100^{\circ} \mathrm{C}\right)\end{array}$ & $T=\frac{1522}{5.79-\log S}-273.15$ & $25-250$ & Fournier(1977) \\
\hline Quartz & $\begin{aligned} \mathrm{T}=(- & 42.2)+0.28831 \mathrm{~S} \\
& +\left(-3.6686 \times 10^{-4} \mathrm{~S}^{2}\right) \\
& +\left(3.1665 \times 10^{-7} \mathrm{~S}^{3}\right) \\
& +77.034 \operatorname{logS}\end{aligned}$ & $50-900$ & $\begin{array}{l}\text { Fournier and } \\
\text { Potter(1982) }\end{array}$ \\
\hline Quartz $^{\mathrm{a}}$ & $\begin{aligned} \mathrm{T}=( & -53.5)+0.11236 \mathrm{~S} \\
& +\left(-0.5559 \times 10^{-4} \mathrm{~S}^{2}\right) \\
& +\left(0.1772 \times 10^{-7} \mathrm{~S}^{3}\right) \\
& +88.370 \log \mathrm{S}\end{aligned}$ & & $\begin{array}{l}\text { Fournier and } \\
\text { Potter(1982) }\end{array}$ \\
\hline Chalcedony & $T=\frac{1112}{4.91-\log S}-273.15$ & & $\begin{array}{l}\text { Arnoorsson } \\
\text { (1983) }\end{array}$ \\
\hline Quartz & $\begin{array}{c}\mathrm{T}=(-55.3)+0.3659 \mathrm{~S}+ \\
\left(-5.3954 \times 10^{-4} \mathrm{~S}^{2}\right)+ \\
\left(5.5132 \times 10^{-7} \mathrm{~S}^{3}\right)+74.360 \operatorname{logS}\end{array}$ & $0-350$ & $\begin{array}{l}\text { Arnoorsson } \\
\text { (1988) }\end{array}$ \\
\hline Quartz $^{\mathrm{a}}$ & $\begin{array}{c}\mathrm{T}=(-66.9)+0.1378 \mathrm{~S}+ \\
\left(-4.9727 \times 10^{-5} \mathrm{~S}^{2}\right)+ \\
\left(1.0468 \times 10^{-8} \mathrm{~S}^{3}\right)+87.841 \operatorname{logS}\end{array}$ & $0-350$ & $\begin{array}{l}\text { Arnoorsson } \\
\text { (1988) }\end{array}$ \\
\hline Quartz & $T=\frac{1175}{4.88-\log S}-273.15$ & & Verma (2000) \\
\hline
\end{tabular}

where $\mathrm{S}=$ Silicon concentration in ppm

$\mathrm{a}=$ Silicon concentration in thermal water which initially boiling in equilibrium with quartz after adiabatic boiling to $100{ }^{\circ} \mathrm{C}$ 


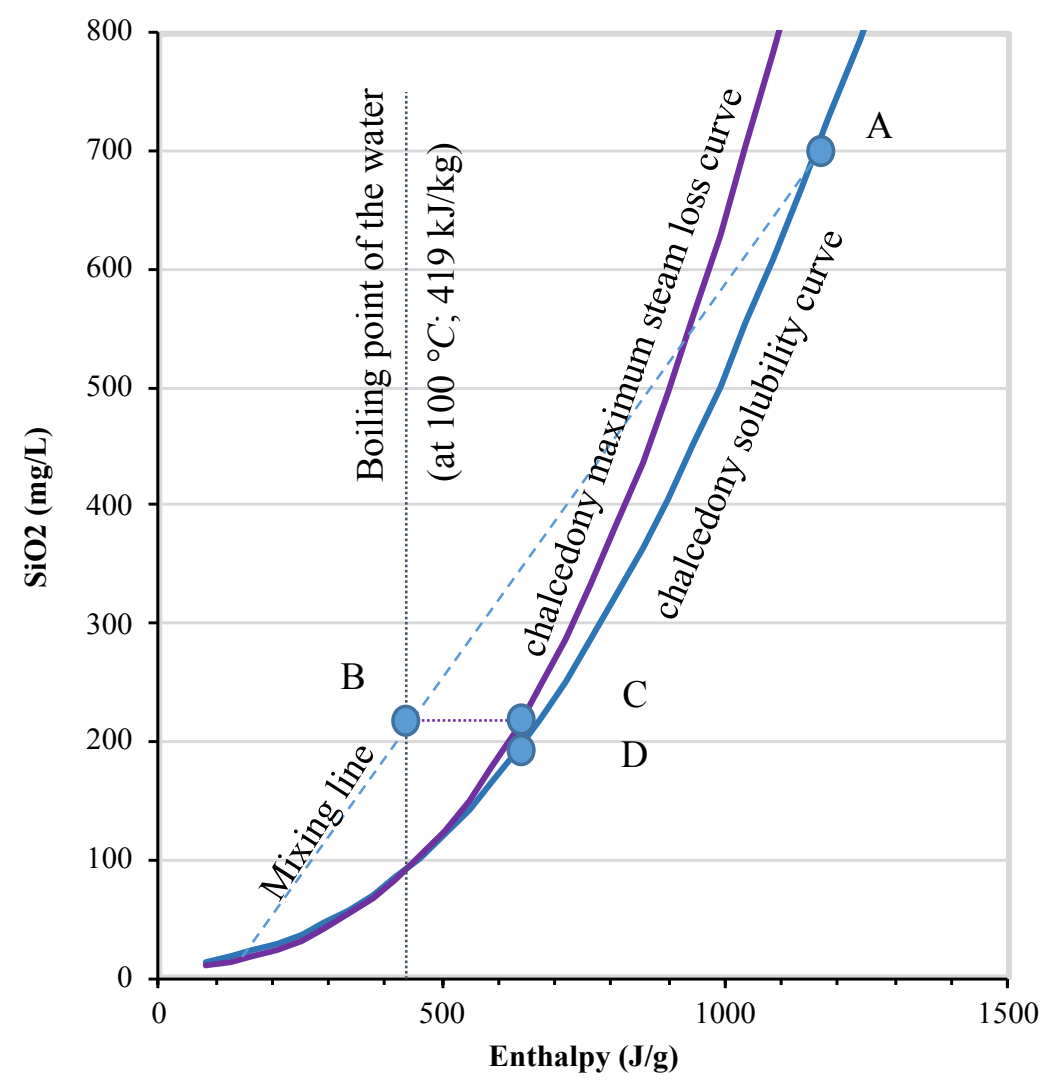

Figure 3.6-1: Silica-enthalpy mixing diagram compares the results with three theoretical reference lines; The first line (blue line) is the chalcedony solubility curve, and the second line (purple line) is the chalcedony maximum steam loss curve. Both curves estimated from the equation of chalcedony and chalcedony steam-loss geothermometer from Arnórsson et al., (1983). The third line (vertical gray line) refers to the boiling point of the water (at $100{ }^{\circ} \mathrm{C}$ ) which have been assumed equal to $419 \mathrm{~kJ} / \mathrm{kg}$ of the enthalpy at saturation state (Wagner and Hans-Joachim, 2007).

In the first scenario, a mixing line extends from the cold-water results (assumed to be initial water) to the thermal water results (assumed to be mixed water) until it converges on the chalcedony solubility curve at point $\mathrm{A}$. This point refers to the initial silicon condition and enthalpy of the hot water component in the reservoir before mixing.

In the second scenario, the crossing point at which the vertical gray line and the mixing line (point B) is assumed to be the water boiling point. Then, a horizontal line is drawn from point $\mathrm{B}$ to the maximum steam loss line at point $\mathrm{C}$, which is assumed to be the water lost the enthalpy at this point. A vertical line is then drawn from point $\mathrm{C}$ to the chalcedony solubility line at point $\mathrm{D}$, which represents the initial point of the water that loses enthalpy during the mixing 
processes (in scenario 2). The two end members from the graph, the cold water, and the initial reservoir water can be expressed by the following equations:

$$
\begin{gathered}
H=\alpha H_{A}+(1-\alpha) H_{B} \\
S=\alpha S_{A}+(1-\alpha) S_{B}
\end{gathered}
$$

where $H$ is the enthalpy of the shallow geothermal water; $H_{A}$ is the enthalpy of the cold water; $H_{B}$ is the enthalpy of the initial reservoir water; $S$ is the $\mathrm{SiO}_{2}$ concentration in the shallow geothermometer water, $S_{A}$ is the $\mathrm{SiO}_{2}$ concentration in the cold water; $S_{B}$ is the $\mathrm{SiO}_{2}$ concentration in the initial reservoir water; and $\alpha$ is the mixing ratio of the cold water and initial reservoir water.

\subsection{The reservoir depth estimation}

Identifying the fluid circulation depth is thus critical to understand the dynamic behavior of the geothermal system. The reservoir depths in this study are estimated from reservoir temperature results from the suitable geothermometers and the temperature gradients in hot springs which is a site-specific variable. In the Mae Chan area, the temperature gradient has been estimated from temperature profiles of the Fang shallow geothermal wells (Wagner and Hans-Joachim, 2007); for instance, FGTE-6, FGTE-8, and FGTE-10 are shown in Figure 9.1-3., in Appendix 1. The calculation details are illustrated in Chapter 4.

In contrast, the geothermal gradient in the Ranong area has not been observed. The spatial distribution map of heat flow in south-eastern Asia (Hall, 2002) and drilling information from Ponrunk hot springs are applied for the estimated temperature gradients in the Ranong area. The geothermal gradient in the spatial distribution map of heat flow in south-east Asia represents the temperature gradients of the system. It can be estimated from the spatial distribution map of heat flow in south-east Asia through the simple heat transfer equation and is defined as

$$
Q=k \nabla T
$$

where, $\mathrm{Q}$ is the heat flow of the hot spring area $\left(\mathrm{W} / \mathrm{m}^{2}\right), \mathrm{k}$ is the thermal conductivity $\left(\mathrm{W} / \mathrm{m}^{\circ} \mathrm{C}\right)$, $\nabla \mathrm{T}$ is the geothermal gradients $\left({ }^{\circ} \mathrm{C} / \mathrm{m}\right)$.

The geothermal gradient in Ranong geothermal area can be calculated from a difference in altitudes and temperatures from three Phorn Rung hot springs, comprised of two natural hot 
springs (RN-3 and RN3-1) and a pumping well (RN3-2). The calculation details and results are illustrated in Chapter 5.

\subsection{Water-Rock interaction.}

\subsubsection{Rare earth elements in water and minerals}

The REE compositions in the geothermal fluids are derived from the dissolution and alteration of the accessory minerals in the host rocks. The variation in REE composition and pattern in water samples can be used as an indicator for understanding the fractionation mechanism during alteration of rock and fluid transport, the history of rock alteration, and the state of equilibrium in water-rock interaction.

The REE contents in the minerals and water samples are normalized to the composition of chondrite (McDonough and Sun, 1995). For the rock investigation, the REE results in the minerals are plotted with respect to each rock sample and comparing with the reported REE of whole fresh granite from the literature. For the water investigation, the REE results in the surface water and thermal water are plotted to compare with the local rock.

Cerium (Ce) and Europium (Eu) behavior in water REE can provide a good information for the understanding of the complexation of chemical reaction under subsurface. Cerium $(\mathrm{Ce})$ and Europium (Eu) anomaly are defined after De Baar et al. (1985) as;

$$
\begin{gathered}
C e / C e^{*}=2 C e_{\text {norm }} /\left(L a_{\text {norm }}+P r_{\text {norm }}\right) \\
E u / E u^{*}=2 E u_{\text {norm }} /\left(S m_{\text {norm }}+G d_{\text {norm }}\right)
\end{gathered}
$$

where $\mathrm{Ce}_{\text {norm, }} \mathrm{La} a_{\text {norm}}, \mathrm{Pr}_{\text {norm }}, \mathrm{Eu}_{\text {norm}}, \mathrm{Sm}_{\text {norm}}$, and $\mathrm{Gd}_{\text {norm }}$ correspond to the chondrite normalized concentration.

\subsubsection{Strontium in water and minerals}

According to the manifestation of the hot spring in both areas are dominantly associated with the granitic basement rock. The Sr concentration in thermal water would be originated from the mixture of atmospheric inputs and weathering products. The present study applies the mixing model from Wiegand, (2009) assuming that the mixing process of these sources occurs at the steady-state condition (the recharge and discharge rates are constant), following the mixing model in equation 


$$
{ }^{87} S r /{ }^{86} S r_{W}=\frac{\left({ }^{87} S r /{ }^{86} S r_{m} \times S r_{m}\right)-\left({ }^{87} S r /{ }^{86} S r_{r} \times S r_{r}\right)}{S r_{W}}
$$

where ${ }^{87} \mathrm{Sr} /{ }^{86} \mathrm{Sr}_{w}$ is the ${ }^{87} \mathrm{Sr} /{ }^{86} \mathrm{Sr}$ ratios of the weathering minerals phase; $S r_{W}$ is the $\mathrm{Sr}$ concentration of the weathering minerals phases; ${ }^{87} \mathrm{Sr} /{ }^{86} \mathrm{Sr}$ is the ${ }^{87} \mathrm{Sr} /{ }^{86} \mathrm{Sr}$ ratios of the thermal water; $S r_{m}$ is the $\mathrm{Sr}$ concentration of the thermal water; ${ }^{87} \mathrm{Sr} /{ }^{86} \mathrm{Sr}_{r}$ is the ${ }^{87} \mathrm{Sr} /{ }^{86} \mathrm{Sr}$ ratios of the atmospheric water; $\mathrm{Sr}_{r}$ is the $\mathrm{Sr}$ concentration of the atmospheric water.

For the model input (or atmospheric water), according to the $\mathrm{Sr}$ isotope ratio and $\mathrm{Sr}$ concentration in precipitation in both areas, this study applies the ${ }^{87} \mathrm{Sr} /{ }^{86} \mathrm{Sr}$ ratios $(0.71)$ and $\mathrm{Sr}$ concentration in precipitation $(0.3 \mu \mathrm{g} / \mathrm{l})$ at the Bangkok metropolis from Klaus, Hansen, \& Buapeng, (2007). Due to the fact that the ETF can influence to the Sr concentration in recharge water. From the ETF calculation, the Chiang rai province has an ETF of 4.02 and Ranong province has an ETF of 1.5. Therefore, the Sr concentration of recharged water in Chiang rai province and in Ranong province are $1.206 \mu \mathrm{g} / \mathrm{l}$ and $4.5 \mu \mathrm{g} / 1$, respectively.

For the weathering minerals phase $\left({ }^{87} S r /{ }^{86} S r_{w}\right)$, the granite dissolution model (Négrel et al., 2001; Petelet-Giraud et al., 2003), based on the hypothesis that most of the Sr composition, are derived from the dissolution of three mineral phases (e.g. plagioclase feldspar, potassium feldspar, and biotite) at equilibrium condition following equation.

$$
{ }^{87} S r /{ }^{86} S r_{W}=\frac{\sum\left({ }^{87} S r /{ }^{86} S r_{m x} \times S r_{m x} \times \%_{m x} \times W_{m x}\right)}{\sum\left(S r_{m x} \times \%_{m x} \times W_{m x}\right)}
$$

where ${ }^{87} \mathrm{Sr} /{ }^{86} \mathrm{Sr}_{m x}$ is the ${ }^{87} \mathrm{Sr} /{ }^{86} \mathrm{Sr}$ ratios of the three minerals phase (plagioclase feldspar, potassium feldspar, and biotite); $S r_{m x}$ is the $\mathrm{Sr}$ concentration of the three minerals phase; $\%_{m x}$ is the proportion of each mineral in rocks which obtained from the petrology analysis of the surface granite rock; $W_{m x}$ is the weatherability of each minerals phase taking that of plagioclase as 1 , is 0.25 for biotite and 0.1 for potassium feldspar (Négrel et al., 2001; PeteletGiraud et al., 2003).

According to the petrology analysis and minerals separation, it is not possible to separate the K-feldspar and plagioclase from the granite rock. Hence, the $\mathrm{Sr}$ concentration and ${ }^{87} \mathrm{Sr} /{ }^{86} \mathrm{Sr}$ ratios of the feldspar contain a mixture of both plagioclase and k-feldspar which are considered together. 
Chapter 4 


\section{Characterization and evaluation of hydrochemistry, sources, and water-rock interaction in Mae Chan area.}

\subsection{Analytical result of rock}

\subsubsection{Petrology}

The four granitic samples are prepared thin sections for polarization and transmitted microscopic analysis. The proportion of major minerals in each granite samples are estimated by evaluating the areas of visible major minerals in each thin section, shown in Appendix 2 and described as follows.

CM-16 (Mulika) thin-section is a granitic rock from the Mulika hot spring in Northern Thailand, composed of quartz (approximately 30\%), alkali-feldspar (microcline) (approximately 30\%), plagioclase (approximately 30\%), and biotite (approximately 10\%) (Figure 9.2-1 in Appendix 2). Plagioclase shows polysynthetic twinning and is the second most abundant mineral in the thin section examined. Quartz, the predominant mineral phase, shows undulose extinction and is polycrystalline. Both features testify to metamorphic overprinting. Biotite, too, occasionally displays signs of ductile deformation. Plagioclase crystals exhibit incipient sericitization of their more Ca-rich cores. Biotite and quartz may contain small zircon grains. This thin-section results shown in CM-16-2 (CR-Near Malika) or thin-section is compositionally very similar to Mulika granite samples but displays significantly more alteration and deformation (Figure 9.22 in Appendix 2). It may be classified as a gneiss. In addition to quartz, alkali feldspar, plagioclase, and biotite, the rock contains some muscovite - probably as an alteration product.

CM-04 (CR-Mae Chan) thin-section from Mae Chan hot spring area shows a mixed-grained granite or granitic gneiss. The vast majority of quartz (approximately 25\%) has been recrystallized and constitutes a fine-grained "matrix" (Figure 9.2-3 in Appendix 2). Feldspar (approximately 45\%) crystals are often very large and repeatedly show very heterogeneous perthitic textures. Plagioclase (approximately 25\%) cores display incipient alteration (sericitization). Minor amounts of muscovite and biotite are also present. Biotite (approximately 5\%) exhibits chloritization. Hematite and possibly other oxides have been observed as accessory minerals.

CM-03 (CR-Huay Mae Jai) thin-section from Huy Mae Jai area is a mixed-grained granite or granitic gneiss, displaying clear signs of deformation and alteration (Figure 9.2-4 in Appendix 2). It is composed of deformed quartz (polycrystalline and elongated) (approximately 30\%), 
pervasively altered feldspar (alteration is less prominent for alkali feldspar (approximately $25 \%$ ), i.e., microcline and perthitic feldspar (approximately 40\%)), and interstitial biotite (approximately 5\%). Biotite has been partially transformed into chlorite. Occasionally, altered amphibole is present.

\subsubsection{Rare earth elements in minerals.}

REE compositions of the separated minerals in four Mae Chan granite rocks are given in the Table 4-1. The $\Sigma$ REE contents of feldspar mineral in the Mae Chan granite range between 59.7 and $365.5 \mathrm{mg} / \mathrm{kg}$. The lowest $\Sigma \mathrm{REE}$ contents of feldspar are found in the CR-04 samples (59.7 $\mathrm{mg} / \mathrm{kg}$ ). The $\Sigma \mathrm{REE}$ contents of biotite mineral range between 405.4 and $1,120.9 \mathrm{mg} / \mathrm{kg}$. The biotite minerals indicate the highest $\Sigma$ REE content $(1,120.9 \mathrm{mg} / \mathrm{kg})$. All of samples are relatively enriched in LREE, resulting in LREE/HREE ratio more than 9.5. The highest LREE/HREE contents shown in the CR-04 (38.8).

The REE contents in these minerals are normalized to the composition of chondrite (McDonough and Sun, 1995), are plotted with respect to each sample and comparing with the reported REE of whole fresh granite from Chiang Mai and Chiang Rai provinces (Charusiri et al., 1994) in Figure 4.1-1. The mineral samples illustrate an enriched pattern in LREE relative to the HREE. Although the REE pattern in biotite minerals in most of the samples are higher than the REE pattern in feldspar minerals, CM-16 sample illustrates the relatively narrow width range of the REE pattern between these minerals. Moreover, feldspar minerals samples indicate moderate positive Eu anomalies and biotite minerals indicated moderate negative Eu anomalies.

All of the separated mineral samples do not illustrate $\mathrm{Ce}$ anomaly with $\mathrm{Ce} / \mathrm{Ce}$ * ranging from 0.85 to 1.09 . Biotite mineral samples show similar negative $\mathrm{Eu}$ anomaly with $\mathrm{Eu} / \mathrm{Eu}^{*}$ ranging from 0.23 to 0.43 . Contrarily, feldspar minerals show similar positive Eu anomaly with $\mathrm{Eu} / \mathrm{Eu}^{*}$ ranging from 1.27 to 10.27 and the strongest positive Eu anomaly are shown in CR-04 feldspar (10.27).

\subsubsection{Rb-Sr composition in the minerals.}

$\mathrm{Rb}$ concentrations, $\mathrm{Sr}$ concentrations, $\mathrm{Rb} / \mathrm{Sr}$ ratios, and ${ }^{87} \mathrm{Sr} /{ }^{86} \mathrm{Sr}$ ratios in each separated mineral of all four bedrocks were analyzed (Table 4-2). The Sr isotopic ratios range between 0.7230 and 0.7418 for feldspar, and range between 0.7710 and 1.2520 for biotite. The $\mathrm{Rb}$ concentrations range between 72 and $781 \mathrm{mg} / \mathrm{kg}$ for feldspar, and range between 23 and 1,495 $\mathrm{mg} / \mathrm{kg}$ for biotite. The $\mathrm{Sr}$ concentrations range between 24 and 1,063 mg/kg for feldspar and 
range between 22 and $169 \mathrm{mg} / \mathrm{kg}$ for biotite. The $\mathrm{Rb} / \mathrm{Sr}$ ratios range between 0.10 and 33.12 for feldspar, and range between 0.29 and 68.85 for biotite. The ${ }^{87} \mathrm{Sr} /{ }^{86} \mathrm{Sr}$ ratios of the biotite are higher than that in feldspar. On the other hand, the ${ }^{87} \mathrm{Sr} /{ }^{86} \mathrm{Sr}$ ratios and $\mathrm{Rb}$ concentrations of the biotite in the Mae Chan hot spring sample are similar to the feldspar within the same sample.

Table 4-1: Rare earth element in the rock samples in Mae Chan geothermal area.

\begin{tabular}{|c|c|c|c|c|c|c|c|c|c|}
\hline \multirow{4}{*}{$\begin{array}{c}\text { Name } \\
\text { Location } \\
\text { Type of the rock } \\
\text { Type of Minerals }\end{array}$} & \multirow{3}{*}{\multicolumn{2}{|c|}{$\begin{array}{l}\text { CM-16 } \\
\text { Mulica } \\
\text { Granite }\end{array}$}} & \multirow{3}{*}{\multicolumn{2}{|c|}{$\begin{array}{c}\text { CM-16-2 } \\
\text { CR-NearMalica } \\
\text { Granite/gniss }\end{array}$}} & \multirow{3}{*}{\multicolumn{2}{|c|}{$\begin{array}{c}\text { CR-04 } \\
\text { CR-Mae Chan } \\
\text { Granite }\end{array}$}} & \multirow{2}{*}{\multicolumn{3}{|c|}{$\begin{array}{c}\text { CM-03 } \\
\text { CR-Huay Mae Jai }\end{array}$}} \\
\hline & & & & & & & & & \\
\hline & & & & & & & \multirow[b]{2}{*}{$\mathrm{Bi}$} & \multicolumn{2}{|c|}{ Granite } \\
\hline & $\mathrm{Bi}$ & FS & $\mathrm{Bi}$ & FS & \multirow{2}{*}{$\mathrm{Bi}$} & FS & & FS & Qz \\
\hline $\mathrm{La}$ & 88.2 & 82.5 & 216.7 & 86.3 & & 16.1 & 247.3 & 43.6 & 7.0 \\
\hline $\mathrm{Ce}$ & 176.2 & 144.9 & 491.7 & 164.0 & 215.2 & 25.2 & 493.1 & 77.3 & 15.2 \\
\hline $\operatorname{Pr}$ & 19.4 & 16.6 & 56.3 & 17.7 & 26.7 & 2.6 & 51.8 & 8.5 & 1.5 \\
\hline $\mathrm{Nd}$ & 71.6 & 61.1 & 205.9 & 62.8 & 108.7 & 8.7 & 184.7 & 29.3 & 5.3 \\
\hline $\mathrm{Sm}$ & 14.9 & 11.3 & 37.9 & 10.4 & 26.8 & 1.4 & 28.1 & 5.2 & 0.8 \\
\hline $\mathrm{Eu}$ & 1.0 & 5.7 & 1.6 & 4.2 & 3.1 & 3.6 & 4.4 & 2.1 & 0.1 \\
\hline $\mathrm{Gd}$ & 11.4 & 7.3 & 31.9 & 9.3 & 25.1 & 0.6 & 34.8 & 2.9 & 0.9 \\
\hline $\mathrm{Tb}$ & 1.8 & 1.2 & 3.9 & 1.2 & 3.4 & 0.1 & 5.1 & 0.5 & 0.1 \\
\hline Dy & 9.7 & 6.7 & 19.9 & 5.8 & 19.8 & 0.6 & 30.9 & 2.6 & 0.7 \\
\hline Ho & 1.7 & 1.2 & 3.1 & 0.9 & 4.0 & 0.1 & 5.9 & 0.4 & 0.1 \\
\hline Er & 4.4 & 2.8 & 6.8 & 1.8 & 11.0 & 0.3 & 16.2 & 1.0 & 0.3 \\
\hline $\mathrm{Tm}$ & 0.6 & 0.4 & 0.8 & 0.2 & 1.5 & 0.0 & 2.2 & 0.1 & 0.0 \\
\hline $\mathrm{Yb}$ & 3.9 & 2.2 & 4.3 & 1.0 & 10.6 & 0.3 & 14.5 & 0.7 & 0.3 \\
\hline $\mathrm{Lu}$ & 0.5 & 0.3 & 0.5 & 0.1 & 1.7 & 0.0 & 1.8 & 0.1 & 0.0 \\
\hline$\Sigma \mathrm{REE}$ & 405.4 & 344.1 & 1081.2 & 365.5 & 546.8 & 59.7 & 1120.9 & 174.5 & 32.4 \\
\hline LREE & 382.7 & 329.4 & 1042.0 & 354.6 & 494.8 & 58.2 & 1044.2 & 169.1 & 30.8 \\
\hline HREE & 22.6 & 14.7 & 39.2 & 10.9 & 52.0 & 1.5 & 76.6 & 5.4 & 1.6 \\
\hline LREE/HREE & 16.9 & 22.3 & 26.6 & 32.4 & 9.5 & 38.8 & 13.6 & 31.2 & 19.0 \\
\hline$\left(\mathrm{Eu} / \mathrm{Eu}^{*}\right) \mathrm{cn}$ & 0.23 & 1.80 & 0.14 & 1.27 & 0.35 & 10.27 & 0.43 & 1.48 & 0.35 \\
\hline$\left(\mathrm{Ce} / \mathrm{Ce}^{*}\right) \mathrm{cn}$ & 0.99 & 0.90 & 1.05 & 0.96 & 1.06 & 0.86 & 1.00 & 0.91 & 1.09 \\
\hline
\end{tabular}

*FS = Feldspar, $\mathrm{Bi}=$ Biotite, and $\mathrm{Qz}=$ Quartz. 


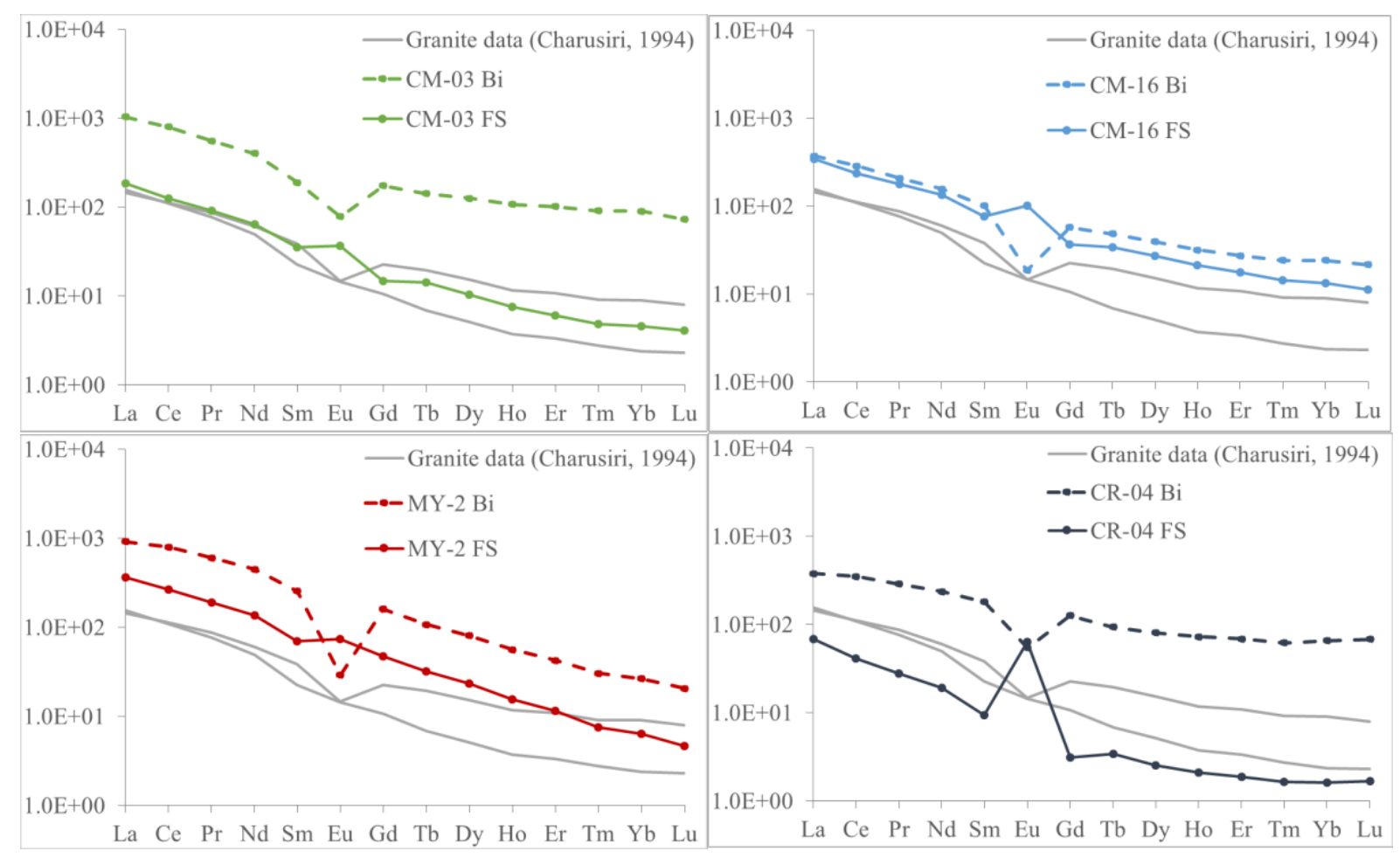

Figure 4.1-1: Chondrite-normalized REE pattern (McDonough and Sun, 1995) of the separated mineral samples in Mae Chan compared with the whole fresh granite data from Chiang Mai and Chiang Rai provinces (Charusiri et al., 1994). *FS = Feldspar, Bi $=$ Biotite, and $Q z=$ Quartz.

Table 4-2: Analytical results of $\mathrm{Rb}, \mathrm{Sr}$, and ${ }^{87} \mathrm{Sr} /{ }^{86} \mathrm{Sr}$ ratio in the rock samples in Mae Chan geothermal area.

\begin{tabular}{|c|c|c|c|c|c|c|c|c|}
\hline Code & $\begin{array}{c}\text { Rock } \\
\text { samples }\end{array}$ & $\begin{array}{l}\text { Rock } \\
\text { type }\end{array}$ & $\begin{array}{l}\text { Type of } \\
\text { Mineral }\end{array}$ & ${ }^{87} \mathrm{Sr} /{ }^{86} \mathrm{Sr}$ & $\mathrm{SD}$ & $\begin{array}{c}\mathrm{Rb} \\
\mathrm{mg} / \mathrm{kg}\end{array}$ & $\begin{array}{c}\mathrm{Sr} \\
\mathrm{mg} / \mathrm{kg}\end{array}$ & $\mathrm{Rb} / \mathrm{Sr}$ \\
\hline \multirow{2}{*}{ CM16 } & \multirow{2}{*}{ CR-Malika } & \multirow{2}{*}{ Granite } & $\mathrm{Bi}$ & 1.1747 & 0.00005 & 1,495 & 22 & 68.85 \\
\hline & & & FS & 0.7364 & 0.00002 & 72 & 695 & 0.10 \\
\hline \multirow{2}{*}{ CM16-2 } & \multirow{2}{*}{$\begin{array}{c}\text { CR-Malica- } \\
2\end{array}$} & \multirow{2}{*}{$\begin{array}{l}\text { Granite } \\
\text { /gneiss }\end{array}$} & $\mathrm{Bi}$ & 1.2520 & 0.00003 & 23 & 78 & 0.29 \\
\hline & & & FS & 0.7389 & 0.00002 & 781 & 24 & 33.12 \\
\hline \multirow{2}{*}{ CR-04 } & \multirow{2}{*}{$\begin{array}{c}\text { CR-Mae } \\
\text { Chan }\end{array}$} & \multirow{2}{*}{ Granite } & $\mathrm{Bi}$ & 0.7710 & 0.00003 & 338 & 63 & 5.36 \\
\hline & & & FS & 0.7230 & 0.00002 & 340 & 1,063 & 0.32 \\
\hline \multirow{3}{*}{$\mathrm{CM}-03$} & \multirow{3}{*}{$\begin{array}{l}\text { CR-Huay } \\
\text { Mae Jai }\end{array}$} & \multirow{3}{*}{ Granite } & $\mathrm{Bi}$ & 0.8659 & 0.00002 & 48 & 169 & 0.29 \\
\hline & & & FS & 0.7418 & 0.00002 & 459 & 549 & 0.84 \\
\hline & & & $\mathrm{Qz}$ & 0.7454 & 0.00005 & 13 & 4 & 3.55 \\
\hline
\end{tabular}

$* \mathrm{FS}=$ Feldspar which are contained plagioclase and $\mathrm{K}$-feldspar, $\mathrm{Bi}=$ Biotite, and $\mathrm{Qz}=$ Quartz. 


\subsection{Analytical result of water}

Field parameters and chemical compositions of the major ions in thermal and surface water samples were recorded (Table 4-3). According to the quality-assurance check of the chemical analyze, the ionic balance error in most case was found within 5\% limit. The stable isotope in thermal and surface water samples represent a summary of the isotopic data for both the premonsoon season and post-monsoon seasons (Table 4-4). It should be noted that the isotopes of $\delta^{13} \mathrm{C},{ }^{14} \mathrm{C}$, and ${ }^{3} \mathrm{H}$ in thermal water were determined only in the post-monsoon season samples (Table 4-5).

\subsubsection{Water field sampling}

The field parameters and chemicals in the thermal waters are higher variables relative to the surface water. Variation of $\mathrm{pH}$ and $\mathrm{Cl}^{-}$from thermal waters are slightly higher than those from surface water. Moreover, all of the water results are generally characterized by a neutral $\mathrm{pH}$.

The surface water samples illustrate the seasonal variation of the field parameters (Table 4-3), which are characterized by a neutral $\mathrm{pH}$ during the pre-monsoon season and slightly increased to a weak base during the post-monsoon season. EC values range from 56.80 to $110.60 \mu \mathrm{S} / \mathrm{cm}$ in the post-monsoon season and range from 77.00 to $136.20 \mu \mathrm{S} / \mathrm{cm}$ in pre-monsoon season. The temperatures range from 21.2 to $24.0^{\circ} \mathrm{C}$ in the post-monsoon season and range from 25.6 to $29.7^{\circ} \mathrm{C}$ in the pre-monsoon season.

The field parameters in the thermal water samples display similar values during both seasons (Table 4-3). These thermal water samples are generally characterized by medium temperatures with a weak base (temperatures range 50.9 to $92.0{ }^{\circ} \mathrm{C}$, $\mathrm{pH}$ range from 8.24 to 8.97 , and $\mathrm{EC}$ range from 433 to $670 \mu \mathrm{S} / \mathrm{cm}$ ). The alkalinity analysis by using a $\mathrm{HACH}$ Digital titrator indicates that the DIC in all of water are in the bicarbonate ion form $\left(\mathrm{HCO}_{3}^{-}\right)$, ranging between 39.6 and $67.2 \mathrm{mg} / \mathrm{l}$, shown in Table 4-3. Notably, Wiang Nong Lom Swamp (WNL) is an outlier compared to the other thermal water samples, characterized by low values for all field parameters (EC: $477 \mu \mathrm{S} / \mathrm{cm}$, temperature: $38.8^{\circ} \mathrm{C}, \mathrm{pH}: 6.23$ ). 


\subsubsection{Hydro-chemical analysis}

Overall, the results from field parameters and chemical composition of water samples are shown in Table 4-3. The ionic balance error in most case was found within 5\% limit.

The surface waters samples indicate the seasonal variations in major ion concentration. The major ions concentrations in pre-monsoon season are slightly higher than those in the postmonsoon season. Most of the cations in surface water are at concentrations lower than $10 \mathrm{mg} / \mathrm{l}$, such as, $\mathrm{Ca}^{2+}$ (1.01 to $\left.10.93 \mathrm{mg} / \mathrm{l}\right), \mathrm{Na}^{+}$(3.15 to 9.64$), \mathrm{K}^{+}$(2.07 to $\left.3.20 \mathrm{mg} / \mathrm{l}\right)$, and $\mathrm{Mg}^{2+}(1.56$ to $3.26 \mathrm{mg} / \mathrm{l})$. Moreover, surface water samples usually have low anions concentrations as well (lower than $5 \mathrm{mg} / \mathrm{l})$, such as $\mathrm{SO}_{4}{ }^{2-}(1.39$ to $3.04 \mathrm{mg} / \mathrm{l})$, and $\mathrm{Cl}^{-}(0.31$ to $2.60 \mathrm{mg} / \mathrm{l})$. However, the bicarbonate ions $\left(\mathrm{HCO}_{3}{ }^{-}\right)$concentrations are predominantly higher than the other anions, ranging between 39.6 and $67.2 \mathrm{mg} / \mathrm{l}$ in both seasons. The chemical concentrations in reservoir water (RV-CM03) are predominantly higher than that on the other surface water but are lower than that in thermal water.

In comparison, the chemical concentrations of major ions in the thermal water are not radically different between the pre- and post-monsoon seasons, in contrast, the chemical concentrations from pre-monsoon season are slightly lower than those from the post-monsoon season. Individual cation concentrations in the thermal water are mostly less than $8 \mathrm{mg} / \mathrm{l}$, such as, $\mathrm{Ca}^{2+}$ (0.16 to $1.4 \mathrm{mg} / \mathrm{l}), \mathrm{Mg}^{2+}(0.04$ and $0.14 \mathrm{mg} / \mathrm{l})$, and $\mathrm{K}^{+}$(3.07 to $\left.15.95 \mathrm{mg} / \mathrm{l}\right)$. However, the $\mathrm{Na}^{+}$ concentrations range between 99.01 and $261.1 \mathrm{mg} / 1$. Individual anion concentrations in thermal water display different range for each parameter: $\mathrm{Cl}^{-}$(5.27 to $\left.20.06 \mathrm{mg} / \mathrm{l}\right)$; $\mathrm{SO}_{4}^{2-}$ (28.21 to 90.75 $\mathrm{mg} / \mathrm{l})$; and $\mathrm{HCO}_{3}^{-}$(124.8 to $\left.252.0 \mathrm{mg} / \mathrm{l}\right)$.

The $\mathrm{SiO}_{2}$ concentrations in the thermal water were analyzed during both seasons (Table 4-7.), ranging from the lowest value of $70.66 \mathrm{mg} / \mathrm{l}$ to the highest value of $184.80 \mathrm{mg} / \mathrm{l}$, with an average of $118.06 \mathrm{mg} / \mathrm{l}$. The $\mathrm{SiO}_{2}$ concentrations in the hot spring water in the post-monsoon seasons are slightly higher than in the post-monsoon season.

To better understand the water classification in the geothermal area, these major ion results were interpreted graphically by plotting the chemical data in the triangular diagrams modified from Giggenbach, (1988) (Figures 4.2-1 and 4.2-2). The triangular diagrams illustrate both the thermal and surface water contain $\mathrm{Na}^{+}$and $\mathrm{K}^{+}$(Figures 4.2-1(b) and 4.2-2(b)), and $\mathrm{HCO}_{3}{ }^{-}$as the dominant anion (Figure 4.2-1(a) and 4.2-2(a)). Although the cations in water clearly display the $\mathrm{Na}+\mathrm{K}$ type in the triangular diagram graph, $\mathrm{Na}^{+}$has greater relative abundance than $\mathrm{K}^{+}$, since the $\mathrm{Na} / \mathrm{K}$ ratio varies from 14.61 to 32.59 in thermal water and from 1.65 to 4.39 in the 
surface water. Therefore, thermal waters are predominantly the $\mathrm{Na}-\mathrm{HCO}_{3}$ type (immature sodium-bicarbonate water). The surface water is the $\mathrm{Na}-\mathrm{K}-\mathrm{HCO}_{3}$ type.

\subsubsection{Radio and stable isotope analysis}

\subsubsection{Water isotopic characterization}

Stable isotopic ratios (deuterium: $\delta^{2} \mathrm{H}$ and oxygen 18: $\delta^{18} \mathrm{O}$ ) of the thermal and surface water were analyzed during both seasons (Table 4-4). The $\delta^{2} \mathrm{H}$ isotopic compositions of the surface waters in the post-monsoon season range from -57.26 to $-37.94 \%$, and $\delta^{18} \mathrm{O}$ range from -8.45 to $-4.09 \%$. During the pre-monsoon season, $\delta^{2} \mathrm{H}$ range from -54.24 to $-47.70 \%$ and $\delta^{18} \mathrm{O}$ range from -8.03 to $-6.88 \%$. The post-monsoon season is depleted in heavy isotope compared to the pre-monsoon season. Nevertheless, the isotopic values of the thermal water measured in each sample during both seasons remained relatively constant $\left(\delta^{2} \mathrm{H}\right.$ range between -59.79 to $53.65 \%$ and $\delta^{18} \mathrm{O}$ range between -8.20 to $-6.88 \%$ ), with $\delta^{2} \mathrm{H}$ isotopic variation from -0.76 to $0.23 \%$ and a $\delta^{18} \mathrm{O}$ variation from -0.21 to $0.03 \%$.

To determine the water source and to understand the hydrologic cycle within the area, these stable isotopic ratios are plotted against the global meteoric water line (GMWL) (Clark, 2015) and local meteoric water line (LMWL) (Figure 4.2-3(a)). The LMWL is referenced from the stable isotopic data in daily precipitation samples $(n=263)$ from 2013 to 2015 at the Chiang Rai monitoring station (HAII, 2016). Moreover, these isotopic ratios are plotted with the stable isotopic data of magmatic water, having a $\delta^{2} \mathrm{H}$ of $-20 \pm 10 \%$ and a $\delta^{18} \mathrm{O}$ of $+10 \pm 2 \%$ (Giggenbach, 1992) (Figure 4.2-3(b)).

According to the $\delta^{18} \mathrm{O}$ and $\delta^{2} \mathrm{H}$ diagrams during both seasons (Figure 4.2-3), the isotopic distribution in most thermal and surface water samples are located in the range of the isotopic data for daily precipitation. They plot closely below the LMWL with some small $\delta^{18} \mathrm{O}$ shifts in the geothermal water. 
Table 4-3: Field parameter, major ion composition, and ionic balance in water samples in Mae Chan geothermal area.

\begin{tabular}{|c|c|c|c|c|c|c|c|c|c|c|c|c|c|c|c|c|c|c|c|c|c|c|c|}
\hline \multirow{3}{*}{ Location } & \multicolumn{7}{|c|}{ Field parameters } & \multicolumn{8}{|c|}{ Cations } & \multicolumn{6}{|c|}{ Anions } & \multirow{2}{*}{\multicolumn{2}{|c|}{$\begin{array}{l}\text { IB } \\
(\%)\end{array}$}} \\
\hline & \multirow[t]{2}{*}{$\begin{array}{l}\text { Altitude } \\
\text { (m) }\end{array}$} & \multicolumn{2}{|c|}{$\begin{array}{l}\text { Temp. } \\
\left({ }^{\circ} \mathrm{C}\right)\end{array}$} & \multicolumn{2}{|c|}{$\mathrm{pH}$} & \multicolumn{2}{|c|}{$\begin{array}{c}\mathrm{EC} \\
(\mu \mathrm{S} / \mathrm{cm})\end{array}$} & \multicolumn{2}{|c|}{$\begin{array}{c}\mathrm{Ca}^{2+} \\
(\mathrm{mg} / \mathrm{l})\end{array}$} & \multicolumn{2}{|c|}{$\begin{array}{c}\mathrm{Na}^{+} \\
(\mathrm{mg} / \mathrm{l})\end{array}$} & \multicolumn{2}{|c|}{$\begin{array}{c}\mathrm{K}^{+} \\
(\mathrm{mg} / \mathrm{l})\end{array}$} & \multicolumn{2}{|c|}{$\begin{array}{l}\mathrm{Mg}^{2+} \\
(\mathrm{mg} / \mathrm{l})\end{array}$} & \multicolumn{2}{|c|}{$\begin{array}{l}\mathrm{HCO}_{3}{ }^{-} \\
(\mathrm{mg} / \mathrm{l})\end{array}$} & \multicolumn{2}{|c|}{$\begin{array}{c}\mathrm{Cl}^{-} \\
(\mathrm{mg} / \mathrm{l})\end{array}$} & \multicolumn{2}{|c|}{$\begin{array}{l}\mathrm{SO}_{4}{ }^{2-} \\
(\mathrm{mg} / \mathrm{l})\end{array}$} & & \\
\hline & & 2014 & 2016 & 2014 & 2016 & 2014 & 2016 & 2014 & 2016 & 2014 & 2016 & 2014 & 2016 & 2014 & 2016 & 2014 & 2016 & 2014 & 2016 & 2014 & 2016 & 2014 & 2016 \\
\hline $\mathrm{CM}-03$ & 550 & 80.40 & 76.00 & 8.60 & 8.51 & 530.0 & 549.0 & 0.16 & 0.94 & 183.9 & 98.49 & 12.59 & 3.84 & 0.12 & 0.06 & 218.4 & 188.4 & 11.66 & 6.39 & 54.65 & 28.21 & -1.80 & -4.18 \\
\hline CM-16 & 474 & 65.50 & 62.00 & 8.51 & 8.36 & 442.0 & 460.0 & 1.00 & 0.95 & 114.6 & 99.90 & 3.81 & 3.07 & 0.09 & 0.07 & 222.0 & 184.8 & 5.27 & 5.78 & 30.44 & 36.62 & 0.86 & -4.30 \\
\hline CR-02 & 409.4 & 53.90 & 55.50 & 8.64 & 8.49 & 466.0 & 481.0 & 1.40 & 1.11 & 148.3 & 98.98 & 6.71 & 4.01 & 0.12 & 0.04 & 181.2 & 156.0 & 7.54 & 6.47 & 45.19 & 39.08 & 1.93 & -4.72 \\
\hline CR-03 & 413 & 74.80 & 75.20 & 8.35 & 8.24 & 433.0 & 449.0 & 1.13 & 0.67 & 115.3 & 116.4 & 4.79 & 7.49 & 0.10 & 0.07 & 198.0 & 188.4 & 6.16 & 9.04 & 31.11 & 26.10 & 3.00 & -1.68 \\
\hline CR-08 & 399 & 50.90 & 52.90 & 8.88 & 8.97 & 456.0 & 469.0 & 1.02 & 0.78 & 126.9 & 100.6 & 4.33 & 3.09 & 0.09 & 0.05 & 156.0 & 165.6 & 9.05 & 8.80 & 43.73 & 43.16 & -1.29 & 1.28 \\
\hline CR-04 & 437.5 & 92.00 & 91.10 & 8.59 & 8.37 & 559.0 & 615.0 & 0.60 & 0.46 & 261.1 & 130.7 & 15.95 & 7.77 & 0.14 & 0.05 & 223.2 & 252.0 & 20.06 & 12.95 & 90.75 & 45.45 & -3.40 & -4.21 \\
\hline CR-09 & 438 & - & 55.10 & - & 8.94 & - & 670.0 & - & 0.62 & - & 144.2 & - & 7.94 & - & 0.07 & - & 256.8 & - & 13.51 & - & 48.71 & - & -3.65 \\
\hline WNL & - & - & 38.80 & - & 6.23 & - & 477.0 & - & 0.60 & - & 99.01 & - & 3.10 & - & 0.06 & - & 124.8 & - & 11.61 & - & 90.20 & - & 1.38 \\
\hline SW-CM-03 & 545 & 22.10 & 25.60 & 7.08 & 8.10 & 56.80 & 77.00 & 5.89 & 7.17 & 4.61 & 4.97 & 2.07 & 1.82 & 1.56 & 1.77 & 42.00 & 43.20 & 1.57 & 0.31 & 2.62 & 1.46 & 8.78 & 20.44 \\
\hline SW-CR-09 & 436 & 24.00 & 29.70 & 7.50 & 7.40 & 95.00 & 111.9 & 7.51 & 7.85 & 9.60 & 6.25 & 2.80 & 2.48 & 2.41 & 2.67 & 64.80 & 67.20 & 2.60 & 1.09 & 3.04 & 2.09 & 4.66 & 1.49 \\
\hline SW-CR-03 & 410 & 21.20 & - & 7.50 & - & 73.00 & - & 5.13 & - & 5.77 & - & 2.41 & - & 2.31 & - & 39.60 & & 1.18 & - & 1.39 & - & 2.49 & - \\
\hline SW-01 & - & 22.40 & 28.10 & 7.50 & 8.35 & 110.6 & 136.2 & 10.93 & 8.56 & 5.28 & 9.64 & 3.20 & 2.20 & 3.26 & 2.71 & 66.00 & 67.20 & 2.09 & 0.85 & 2.63 & 2.71 & -5.15 & -8.95 \\
\hline RV-CM- 03 & 531 & 24.00 & - & 7.60 & - & 585.0 & - & 53.27 & - & 18.41 & - & 5.03 & - & 26.37 & - & 176.4 & - & 3.81 & - & 175.5 & - & 12.43 & - \\
\hline SW-WNL & - & - & 32.80 & - & 7.52 & - & 26.80 & - & 1.01 & - & 3.15 & - & 1.30 & - & 0.65 & - & 14.40 & - & 0.86 & - & 0.34 & - & 9.58 \\
\hline
\end{tabular}

IB; Ionic Balance (\%) 
(a)

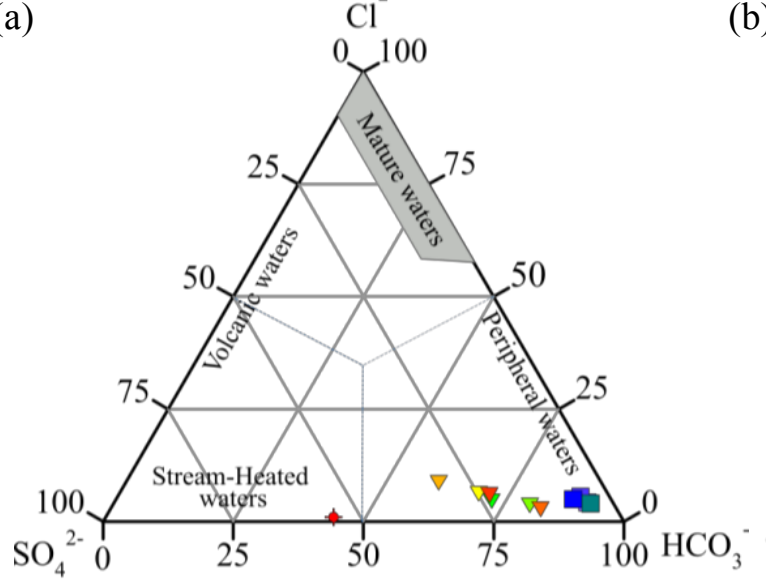

(b)

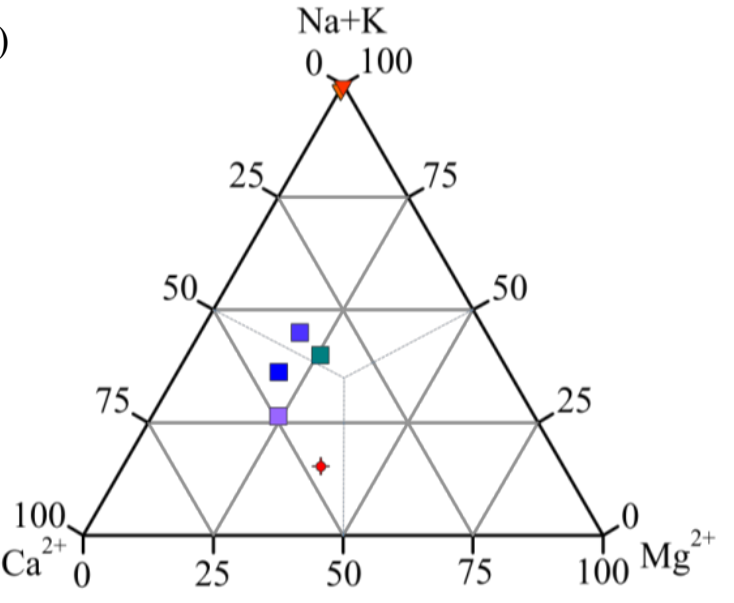

SW-01

SW-CR-09
SW-CM-03

SW-CR-03

$\nabla^{\mathrm{CR}-02}$
$\nabla^{\mathrm{CR}-03}$

$\nabla \mathrm{CR}-08$

$\nabla \mathrm{CR}-09$
RV-CM-03

Figure 4.2-1: Triangular diagram of (a) major anions (modified from Giggenbach, 1988) and (b) major cations in water samples in post-monsoon season (2014) in Mae Chan geothermal area.

(a)

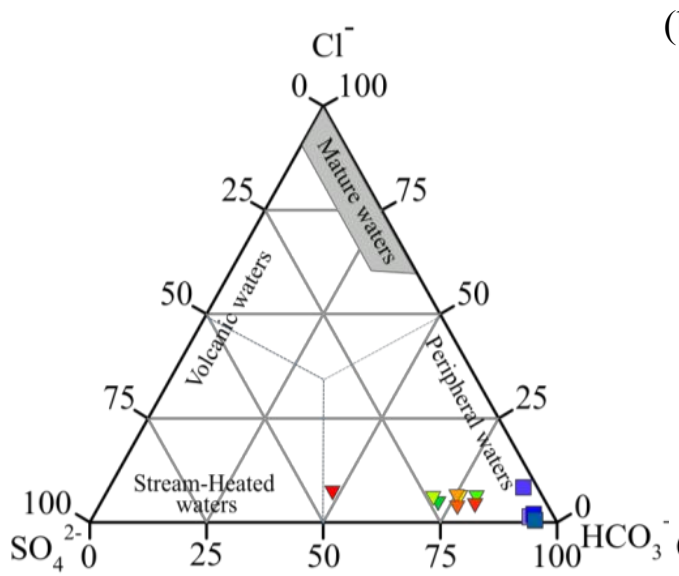

(b)

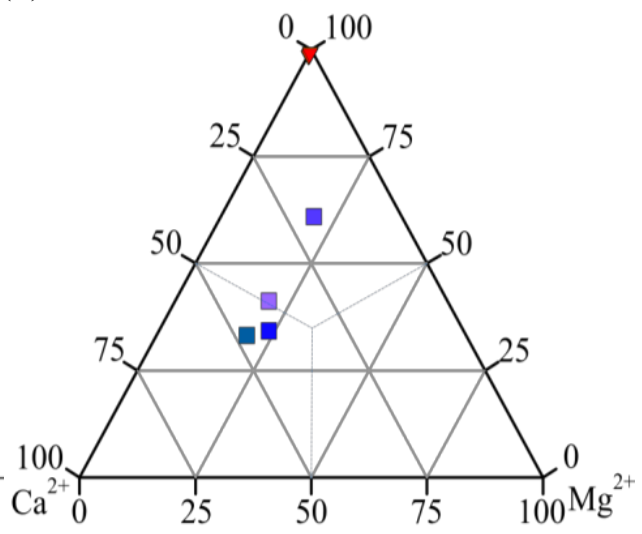

Figure 4.2-2: Triangular diagram of (a) major anions (modified from Giggenbach, 1988) and (b) major cations in water samples in pre-monsoon season (2016) in Mae Chan geothermal area. 
Moreover, the surface water samples show a seasonal variation that fluctuated along the LMWL. Meanwhile, there is an insignificant seasonal variation in the thermal water, and this variation is lower than the uncertainty of the measurement $\left(\delta^{18} \mathrm{O}<0.2 \%\right.$ and $\delta^{2} \mathrm{H}<2 \%$ ) (Table 4-4). The surface water (SW-WNL) and thermal water (WNL) from Wiang Nong Lom Swamp have isotopic values more enriched than other areas, which could be caused by an evaporation effect. In Figure 4.2-3(b), thermal water does not have a correlation with the magmatic water area.

Most of the $\delta^{18} \mathrm{O}$-shifted results in thermal waters are higher than the analytical precision for $\delta^{18} \mathrm{O}$ while most of the $\delta^{18} \mathrm{O}$-shifted results in surface waters are lower than the analytical precision $\left(0.2 \%\right.$ ) (Table 4-4). However, the ranges of the $\delta^{18} \mathrm{O}$-shifted results in thermal water for the pre-monsoon season ( 0.24 to $0.69 \%$ ) are slightly higher than that for the pre-monsoon season $(0.12$ to $0.63 \%)$ as well indicating that a small seasonal effect on the interaction between water and rock (water-rock interaction) is present.

Table 4-4: Stable isotope results in thermal water and surface water samples in Mae Chan geothermal area from post-monsoon (December 2014) and pre-monsoon seasons (March 2016).

\begin{tabular}{ccccccccc}
\hline & \multicolumn{3}{c}{$\begin{array}{c}\text { post-monsoon season } \\
\text { Lecember 2014) }\end{array}$} & \multicolumn{2}{c}{$\begin{array}{c}\text { pre-monsoon seasons } \\
\text { (March 2016) }\end{array}$} & \multicolumn{2}{c}{ Seasonal variation } \\
\cline { 2 - 9 } & $\delta^{2} \mathrm{H}$ & $\delta^{18} \mathrm{O}$ & $\begin{array}{c}\delta^{18} \mathrm{O}- \\
\text { shift }\end{array}$ & $\delta^{2} \mathrm{H}$ & $\delta^{18} \mathrm{O}$ & $\begin{array}{c}\delta^{18} \mathrm{O}- \\
\text { shift }\end{array}$ & $\delta^{2} \mathrm{H}_{\text {diff }}$ & $\delta^{18} \mathrm{O}_{\text {diff }}$ \\
\hline CM-03 & -59.79 & -7.89 & 0.63 & -59.51 & -7.81 & 0.69 & -0.27 & -0.09 \\
CM-16 & -58.43 & -8.2 & 0.16 & -58.25 & -8.08 & 0.25 & -0.18 & -0.11 \\
CR-02 & -54.34 & -7.3 & 0.53 & -54.04 & -7.17 & 0.63 & -0.3 & -0.13 \\
CR-03 & -57.32 & -8.09 & 0.12 & -56.56 & -7.88 & 0.24 & -0.76 & -0.21 \\
CR-08 & -55.07 & -7.55 & 0.38 & -55.3 & -7.58 & 0.37 & 0.23 & 0.03 \\
CR-04 & -57.45 & -7.84 & 0.39 & -57.27 & -7.79 & 0.42 & -0.19 & -0.05 \\
CR-09 & - & - & - & -53.65 & -6.88 & 0.87 & - & - \\
WNL & - & - & - & -25.24 & -2.16 & 1.96 & - & - \\
\hline SW-01 & -52.41 & -7.51 & 0.08 & -48.41 & -6.8 & 0.28 & -4 & -0.71 \\
SW-CM-03 & -57.26 & -8.45 & -0.24 & -54.24 & -8.03 & -0.21 & -3.02 & -0.42 \\
SW-CR-09 & -54.4 & -7.83 & 0.02 & -48.27 & -6.77 & 0.29 & -6.13 & -1.05 \\
SW-WNL & - & - & - & -47.7 & -6.01 & 0.97 & - & - \\
SW-CR-03 & -52.24 & -7.68 & -0.11 & - & - & - & - & - \\
RV-CM-03 & -37.94 & -4.09 & 1.65 & - & - & - & - & - \\
\hline
\end{tabular}


(a)

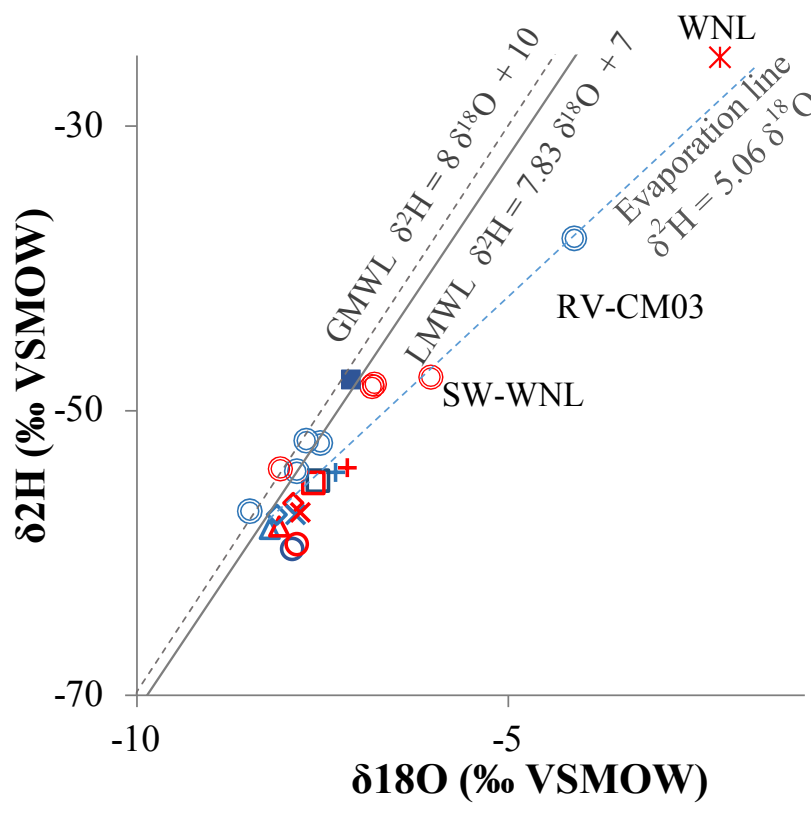

(b)

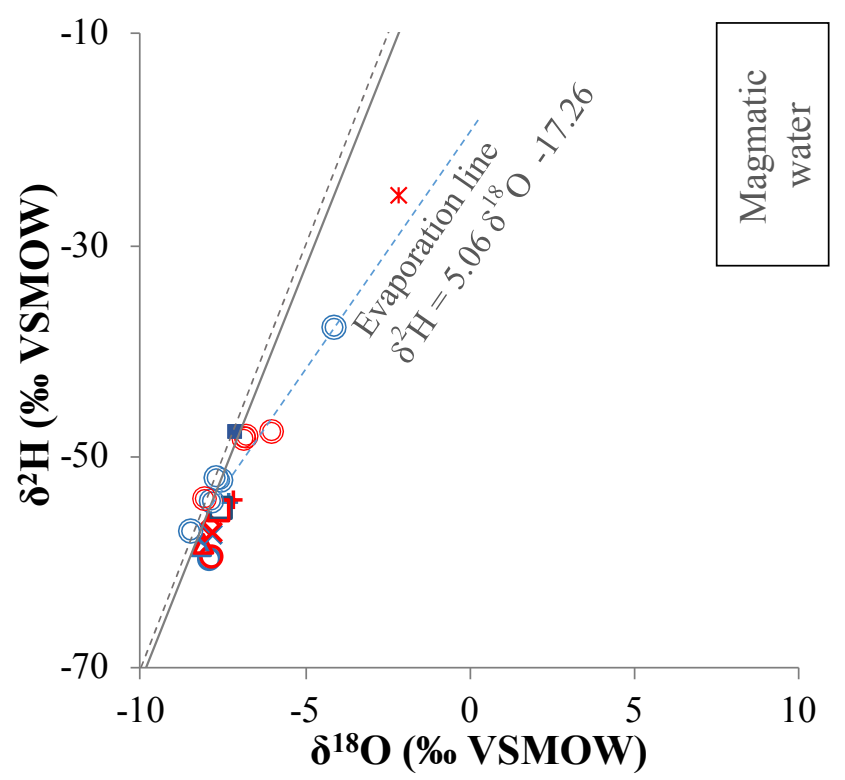

○ CM-03-2014

○ CM-03-2016

$\triangle$ CM-16-2014

$\Delta$ CM-16-2016

$+\quad$ CR-02-2014

+ CR-02-2016

$\diamond$ CR-03-2014

$\diamond \quad$ CR-03-2016

ㄷ CR-08-2014

다-08-2016

$\times \quad$ CR-09-2014

$\times \quad$ CR-09-2016

* WNL-2016

(C) Surface water-2014

(O) Surface water-2016

- LW Avg

- . - - Linear (GMWL)

_ Linear (LMWL)

Figure 4.2-3: (a) Stable isotope results in thermal water and surface water samples from postmonsoon (December 2014) and pre-monsoon seasons (March 2016), compared with LMWLs from Chiang Rai station. The blue symbols represent the samples, collected in December 2014, while red symbols represent the samples, collected in March 2016. The gray dot line represents the linear from the LMWL equation. The navy blue-square symbol represents the average rainfall from three-year weighted mean data. The blue-dot line represents the linear from the local evaporation. (b) these results comparing with the magmatic water area was plotted according to Giggenbach, (1992). 
4.2.3.2 Carbon stable isotope $\left(\delta^{13} \mathrm{C}\right)$, radiocarbon $\left({ }^{14} \mathrm{C}\right)$, and tritium $\left({ }^{3} \mathrm{H}\right)$

The analytical results of $\delta^{13} \mathrm{C},{ }^{14} \mathrm{C}$, and ${ }^{3} \mathrm{H}$ in the thermal waters are shown in Table 4-5. The thermal water ${ }^{3} \mathrm{H}$ concentrations are below the detection limit $(<0.3 \mathrm{TU})$, while the surface water ${ }^{3} \mathrm{H}$ concentrations range from 1.5 to $2.0 \mathrm{TU}$. The results of $\delta^{13} \mathrm{C}$ indicate the wide variation for both the thermal and surface water, range from -4.35 to $-32.27 \%$ oPDB, and the ${ }^{14} \mathrm{C}$ activities vary between 0 to $20.42 \mathrm{pMC}$. The calculated fluid resident times from ${ }^{14} \mathrm{C}$ by Eq. (3.6) range from 12,760 to longer than $30,000 \mathrm{BP}$.

As the $\delta^{13} \mathrm{C}$ and dissolved inorganic carbon (DIC) can identify the complex geochemical processes which disturbing the ${ }^{14} \mathrm{C}$. The alkalinity analysis in chapter 4.2.1, shown in Table 43 , indicates that the DIC in all of water are in the bicarbonate ion form $\left(\mathrm{HCO}_{3}{ }^{-}\right)$. Therefore, these parameters are integrated with the ${ }^{14} \mathrm{C}$ interpretation to understand the geochemical processes of carbon and to improve the fluid residence time estimation in the Mae Chan thermal springs. The details are described in the further chapter (Chapter 4.3).

\subsubsection{Geothermometer estimation.}

\subsubsection{Cation geothermometer}

The estimated reservoir temperatures from cation geothermometers range from 97.7 to $381.3{ }^{\circ} \mathrm{C}$, are shown in Table 4-6. The estimated reservoir temperatures from $\mathrm{Na}-\mathrm{K}-\mathrm{Ca}$ geothermometer $\left(261-381.3{ }^{\circ} \mathrm{C}\right)$ are higher than that from the $\mathrm{Na}-\mathrm{K}$ and $\mathrm{K}-\mathrm{Mg}$ geothermometers, ranging from 99.1 to $215.4^{\circ} \mathrm{C}$, and 97.7 to $295.8^{\circ} \mathrm{C}$, respectively. Moreover, these temperature results from adiabatic cooling and conductive cooling of the $\mathrm{K}-\mathrm{Mg}$ geothermometer mostly have similar values, implying that the conductive cooling may not occur.

\subsubsection{Silica geothermometers}

The estimated reservoir temperature results from the silica geothermometers range from $90.1{ }^{\circ} \mathrm{C}$ to $176.5^{\circ} \mathrm{C}$, (Table 4-7) and, consistent previous results from DAEDE, (2007b) and DGR, (2016). Temperature results from the quartz geothermometer $\left(105-176.5^{\circ} \mathrm{C}\right)$ are higher than those from the chalcedony geothermometer $\left(90.1-152.7{ }^{\circ} \mathrm{C}\right)$, while the quartz geothermometer results from maximum steam loss are mostly similar as the results from the no steam loss. 
Table 4-5: Tritium, stable isotope of carbon, and radiocarbon results in hot springs in Mae Chan geothermal area.

\begin{tabular}{|c|c|c|c|c|c|c|c|c|c|c|}
\hline \multirow{2}{*}{ Location } & \multirow{2}{*}{ Name } & \multicolumn{2}{|c|}{ Tritium } & \multirow{2}{*}{$\frac{\mathrm{DIC}^{*}}{\mathrm{mg} / \mathrm{l}}$} & \multicolumn{2}{|c|}{$\delta^{13} \mathrm{C}$} & \multicolumn{2}{|c|}{ Measured ${ }^{14} \mathrm{C}$} & \multicolumn{2}{|c|}{ Estimated resident times } \\
\hline & & $\mathrm{TU}$ & error & & $\begin{array}{c}\text { Permil } \\
(\%)\end{array}$ & error & $\mathrm{pMC}$ & error & $\mathrm{BP}$ & error \\
\hline CM-03 & Fang Hot spring & 0 & 0.2 & 218.4 & $-4.35^{* *}$ & $0.19^{* *}$ & $19.63^{* *}$ & $1.24^{* *}$ & 13,080 & 520 \\
\hline CM-16 & Mullika Hot spring & 0.1 & 0.1 & 222.0 & -32.27 & 1.073 & 11.41 & 0.42 & 17,440 & 30 \\
\hline CR-02 & Huy Mark lieum Hot spring & 0.1 & 0.2 & 181.2 & -10.58 & 0.079 & 20.42 & 1.25 & 12,760 & 510 \\
\hline CR-03 & Par Sert Hot spring & 0.1 & 0.1 & 198.0 & -16.58 & 0.118 & n.d. & n.d. & n.d. & n.d. \\
\hline CR-08 & Pong Pra Bath Hot spring & 0 & 0.1 & 156.0 & -10.11 & 0.312 & 10.48 & 0.51 & 18,120 & 400 \\
\hline CR-04 & Mae Chan Hot spring & 0 & 0.1 & 223.2 & $-7.05^{* *}$ & $0.49^{* *}$ & 0 & 0 & $>30,000$ & n.d. \\
\hline WNL & Wiang nong lom Hotspring & 0.3 & 0.2 & 218.4 & - & - & - & - & - & - \\
\hline Sw-CR-09 & River near Mae Chan & 1.5 & 0.2 & 64.80 & $-10.47^{* *}$ & $0.23^{* *}$ & 83.86 & 5.22 & 1410 & 520 \\
\hline Sw-01 & Kok River & 2.0 & 0.2 & 66.00 & - & - & - & - & - & - \\
\hline SW-WNL & Wiang nong lom Surface water & 2.2 & 0.2 & - & - & - & - & - & - & - \\
\hline
\end{tabular}

n.d.; not detect from the laboratory

*DIC data obtained from the alkalinity analysis in 2014 which all of water shown in the bicarbonate ion form $\left(\mathrm{HCO}_{3}{ }^{-}\right)$

**The data obtained from (DGR, 2017a) 
Table 4-6: Temperature results of cation geothermal estimations.

\begin{tabular}{|c|c|c|c|c|c|c|c|c|c|c|c|c|c|c|c|c|c|c|c|c|c|c|}
\hline \multirow{3}{*}{ Location } & \multicolumn{14}{|c|}{$\mathrm{Na}-\mathrm{K}$} & \multicolumn{6}{|c|}{$\mathrm{Mg} / \mathrm{K}$} & \multirow{2}{*}{\multicolumn{2}{|c|}{$\begin{array}{c}\mathrm{Na}+\mathrm{K}+\mathrm{Ca} \\
\text { Fournier and } \\
\text { Truesdell } \\
\text { (1973) }\end{array}$}} \\
\hline & \multicolumn{2}{|c|}{$\begin{array}{c}\text { Fournier } \\
\text { (1979) }\end{array}$} & \multicolumn{2}{|c|}{$\begin{array}{c}\text { Arnorsson } \\
\text { (1983) }\end{array}$} & \multicolumn{2}{|c|}{$\begin{array}{l}\text { Arnorsson } \\
\text { (1983) et al2 }\end{array}$} & \multicolumn{2}{|c|}{$\begin{array}{c}\text { Nieva \& } \\
\text { Nieva (1987) }\end{array}$} & \multicolumn{2}{|c|}{$\begin{array}{l}\text { Giggenbach } \\
\text { (1988) }\end{array}$} & \multicolumn{2}{|c|}{$\begin{array}{c}\text { Arnorson } \\
(2000)\end{array}$} & \multicolumn{2}{|c|}{ Can 2002} & \multicolumn{2}{|c|}{ Fournier (1991) } & \multicolumn{2}{|c|}{$\begin{array}{l}\text { Giggenbach } \\
\text { (1988) } \\
\text { (Adiabatic } \\
\text { cooling) }\end{array}$} & \multicolumn{2}{|c|}{$\begin{array}{c}\text { Giggenbach } \\
\text { (1994) } \\
\text { (Conductive } \\
\text { cooling) }\end{array}$} & & \\
\hline & $1 \mathrm{st}$ & 2nd & $1 \mathrm{st}$ & 2nd & $1 \mathrm{st}$ & 2 nd & $1 \mathrm{st}$ & 2nd & $1 \mathrm{st}$ & 2nd & $1 \mathrm{st}$ & 2nd & $1 \mathrm{st}$ & 2 nd & $1 \mathrm{st}$ & 2nd & $1 \mathrm{st}$ & 2nd & $1 \mathrm{st}$ & 2nd & $1 \mathrm{st}$ & 2nd \\
\hline CM-03 & 194 & 154 & 159 & 115 & 187 & 151 & 174 & 136 & 204 & 167 & 215 & 169 & 176 & 144 & 277 & 200 & 132 & 108 & 130 & 107 & 381 & 280 \\
\hline CM-16 & 144 & 139 & 104 & 99 & 142 & 138 & 126 & 122 & 157 & 153 & 157 & 152 & 137 & 134 & 179 & 172 & 100 & 98 & 100 & 98 & 270 & 261 \\
\hline CR-02 & 164 & 157 & 126 & 118 & 160 & 154 & 145 & 138 & 176 & 169 & 180 & 171 & 152 & 146 & 215 & 214 & 113 & 113 & 112 & 112 & 298 & 281 \\
\hline CR-03 & 158 & 190 & 120 & 154 & 155 & 183 & 140 & 169 & 171 & 199 & 173 & 210 & 147 & 172 & 193 & 253 & 105 & 125 & 105 & 123 & 286 & 334 \\
\hline CR-08 & 146 & 139 & 106 & 99 & 143 & 137 & 128 & 122 & 159 & 153 & 159 & 152 & 138 & 134 & 191 & 187 & 105 & 103 & 104 & 103 & 274 & 264 \\
\hline CR-04 & 186 & 184 & 150 & 147 & 180 & 178 & 166 & 164 & 196 & 194 & 205 & 202 & 169 & 167 & 296 & 268 & 137 & 129 & 135 & 127 & 358 & 336 \\
\hline CR-09 & - & 178 & - & 141 & - & 173 & - & 159 & - & 189 & - & 196 & - & 163 & - & 260 & - & 127 & - & 125 & - & 327 \\
\hline WNL & - & 141 & - & 101 & - & 139 & - & 123 & - & 154 & - & 153 & - & 135 & - & 183 & - & 102 & - & 101 & - & 268 \\
\hline
\end{tabular}

Table 4-7: Temperature results of silica geothermometer in Mae Chan area.

\begin{tabular}{|c|c|c|c|c|c|c|c|c|c|c|c|c|c|c|c|c|c|c|c|c|c|c|}
\hline \multirow{3}{*}{ Location } & \multirow{2}{*}{\multicolumn{2}{|c|}{$\begin{array}{c}\text { Surface } \\
\text { temperature } \\
{ }^{\circ} \mathrm{C}\end{array}$}} & \multirow{2}{*}{\multicolumn{2}{|c|}{$\begin{array}{l}\mathrm{SiO}_{2} \\
\mathrm{mg} / 1\end{array}$}} & \multicolumn{6}{|c|}{ Fournier (1977) } & \multicolumn{4}{|c|}{ Fournier and Potter (1982) } & \multicolumn{2}{|c|}{$\begin{array}{c}\text { Arnorsson } \\
(1983)\end{array}$} & \multicolumn{4}{|c|}{ Arnorsson (1988) } & \multicolumn{2}{|c|}{$\begin{array}{l}\text { Verma } \\
(2000)\end{array}$} \\
\hline & & & & & \multicolumn{2}{|c|}{ Chalcedony } & \multicolumn{2}{|c|}{$\begin{array}{l}\text { Quartz (no } \\
\text { steam loss) }\end{array}$} & \multicolumn{2}{|c|}{$\begin{array}{c}\text { Quartz (max. } \\
\text { steam loss at } \\
100^{\circ} \mathrm{C} \text { ) }\end{array}$} & \multicolumn{2}{|c|}{ Quartz } & \multicolumn{2}{|c|}{ Quartz $^{\mathrm{a}}$} & \multicolumn{2}{|c|}{ Chalcedony } & \multicolumn{2}{|c|}{ Quartz } & \multicolumn{2}{|c|}{ Quartz $^{\mathrm{a}}$} & \multicolumn{2}{|c|}{ Quartz } \\
\hline & $1 \mathrm{st}$ & 2nd & $1 \mathrm{st}$ & 2nd & $1 \mathrm{st}$ & 2nd & $1 \mathrm{st}$ & 2nd & $1 \mathrm{st}$ & 2nd & $1 \mathrm{st}$ & 2nd & $1 \mathrm{st}$ & 2nd & $1 \mathrm{st}$ & 2nd & $1 \mathrm{st}$ & 2nd & $1 \mathrm{st}$ & 2nd & $1 \mathrm{st}$ & 2nd \\
\hline CM-03 & 80.40 & 76.00 & 140.4 & 148.5 & 129 & 139 & 154 & 162 & 147 & 154 & 154 & 163 & 148 & 155 & 126 & 135 & 143 & 152 & 137 & 145 & 153 & 163 \\
\hline CM-16 & 65.50 & 62.00 & 76.13 & 70.66 & 93 & 90 & 121 & 119 & 119 & 117 & 121 & 119 & 120 & 118 & 93 & 90 & 108 & 106 & 107 & 105 & 117 & 115 \\
\hline CR-02 & 53.90 & 55.50 & 114.9 & 105.1 & 119 & 114 & 145 & 140 & 139 & 135 & 145 & 140 & 141 & 136 & 117 & 112 & 133 & 128 & 129 & 125 & 143 & 138 \\
\hline CR-03 & 74.80 & 75.20 & 107.8 & 99.06 & 114 & 110 & 140 & 137 & 135 & 132 & 140 & 137 & 137 & 133 & 112 & 108 & 128 & 125 & 125 & 122 & 138 & 134 \\
\hline CR-08 & 50.90 & 52.90 & 110.0 & 100.8 & 115 & 110 & 141 & 137 & 136 & 132 & 142 & 137 & 138 & 133 & 113 & 108 & 130 & 125 & 126 & 122 & 140 & 134 \\
\hline CR-04 & 92.00 & 91.10 & 156.5 & 154.5 & 127 & 139 & 152 & 163 & 145 & 154 & 152 & 163 & 146 & 156 & 124 & 136 & 141 & 153 & 135 & 146 & 151 & 164 \\
\hline CR-09 & - & 55.10 & - & 184.8 & - & 153 & - & 175 & - & 164 & - & 175 & - & 166 & - & 148 & - & 166 & - & 156 & - & 176 \\
\hline WNL & - & 38.80 & - & 83.7 & - & 100 & - & 127 & - & 125 & - & 128 & - & 125 & - & 99 & - & 115 & - & 113 & - & 124 \\
\hline
\end{tabular}




\subsubsection{Rare earth elements of the water.}

The REE compositions in the water samples are given in Table 4-8. The $\Sigma$ REE contents in surface water samples and the thermal water samples range from 0.43 to $4.54 \mu \mathrm{g} / \mathrm{l}$, and from 0.024 to $0.372 \mu \mathrm{g} / \mathrm{l}$, respectively. Most of the water samples indicate the negative Eu anomalies with $\mathrm{Eu} / \mathrm{Eu}^{*}$ ranging from 0.30 to 1.69 , as well as positive $\mathrm{Ce}$ anomalies with $\mathrm{Ce} / \mathrm{Ce}$ * ranging from 0.82 to 1.51 . In contrast, the RV-CM-03 indicates a positive Eu anomaly $\left(\mathrm{Eu} / \mathrm{Eu}^{*}=1.69\right)$ and $\mathrm{Ce}$ anomaly $\left(\mathrm{Ce} / \mathrm{Ce}^{*}=0.99\right)$

The REE contents in water samples are normalized to the composition of chondrite (McDonough and Sun, 1995) and plotted for each location in the Figure 4.2-4. There is considerably higher REE concentration pattern in the surface water than the thermal water. The highest REE concentration is demonstrated in SW-CR-04 in Figure 4.2-4 (a). Most of the surface water samples are slightly enriched in LREE relative to the HREE with moderate negative Eu anomalies. In contrast, the RV-CM-03 sample has weak positive Eu anomaly in Figure 4.2-4(b).

The REE concentration pattern from the highest temperature water $\left(92^{\circ} \mathrm{C}\right)$ in $\mathrm{CR}-04$ in Figure 4.2-4(a) demonstrate a depleted pattern in the HREE. Low-thermal water samples $\left(<70{ }^{\circ} \mathrm{C}\right.$; CM-16 and CR-02) indicate a relatively flat REE pattern comparing with the REE patterns from surface water and rock samples at the same location. However, the high-temperature thermal waters $\left(>70{ }^{\circ} \mathrm{C} ; \mathrm{CM}-03\right.$, and CR-03) in each area show a depleted pattern in the LREE relative to HREE, which indicated remarkably in $\mathrm{Pr}, \mathrm{Nd}$ and $\mathrm{Sm}$ elements. The Eu anomalies probably are in the negative value which less than the detection limit. Remarkably, CR-08 samples in Figure 4.2-4 (c), which have the lowest temperature, illustrate show depleted pattern in the LREE relative to HREE.

\subsubsection{Rb-Sr composition of the water.}

The $\mathrm{Rb}$ contents, $\mathrm{Sr}$ contents and $\mathrm{Sr}$ isotopic ratio of surface water and thermal waters are shown in Table 4-9. The surface water has lower concentrations of both $\mathrm{Rb}$ and $\mathrm{Sr}$ than the thermal waters. The surface water results range from 4.17 to $15.61 \mu \mathrm{gL}^{-1}$ for $\mathrm{Rb}$ and from 22.18 to $186.18 \mu \mathrm{gL}^{-1}$ for $\mathrm{Sr}$. In thermal waters, $\mathrm{Rb}$ contents range between 49.06 and $170.05 \mu \mathrm{gL}^{-1}$ and $\mathrm{Sr}$ contents range between 43.27 and $90.97 \mu \mathrm{gL}-1$. The measured ${ }^{87} \mathrm{Sr} /{ }^{86} \mathrm{Sr}$ ratios range between 0.7121 and 0.7347 in surface waters and between 0.7179 and 0.7364 in thermal waters. Sample CR-08 has the lowest ${ }^{87} \mathrm{Sr} /{ }^{86} \mathrm{Sr}$ ratio, while the highest ${ }^{87} \mathrm{Sr} /{ }^{86} \mathrm{Sr}$ ratio is in CM-16. 
Table 4-8: Rare earth element in the water samples in Mae Chan area.

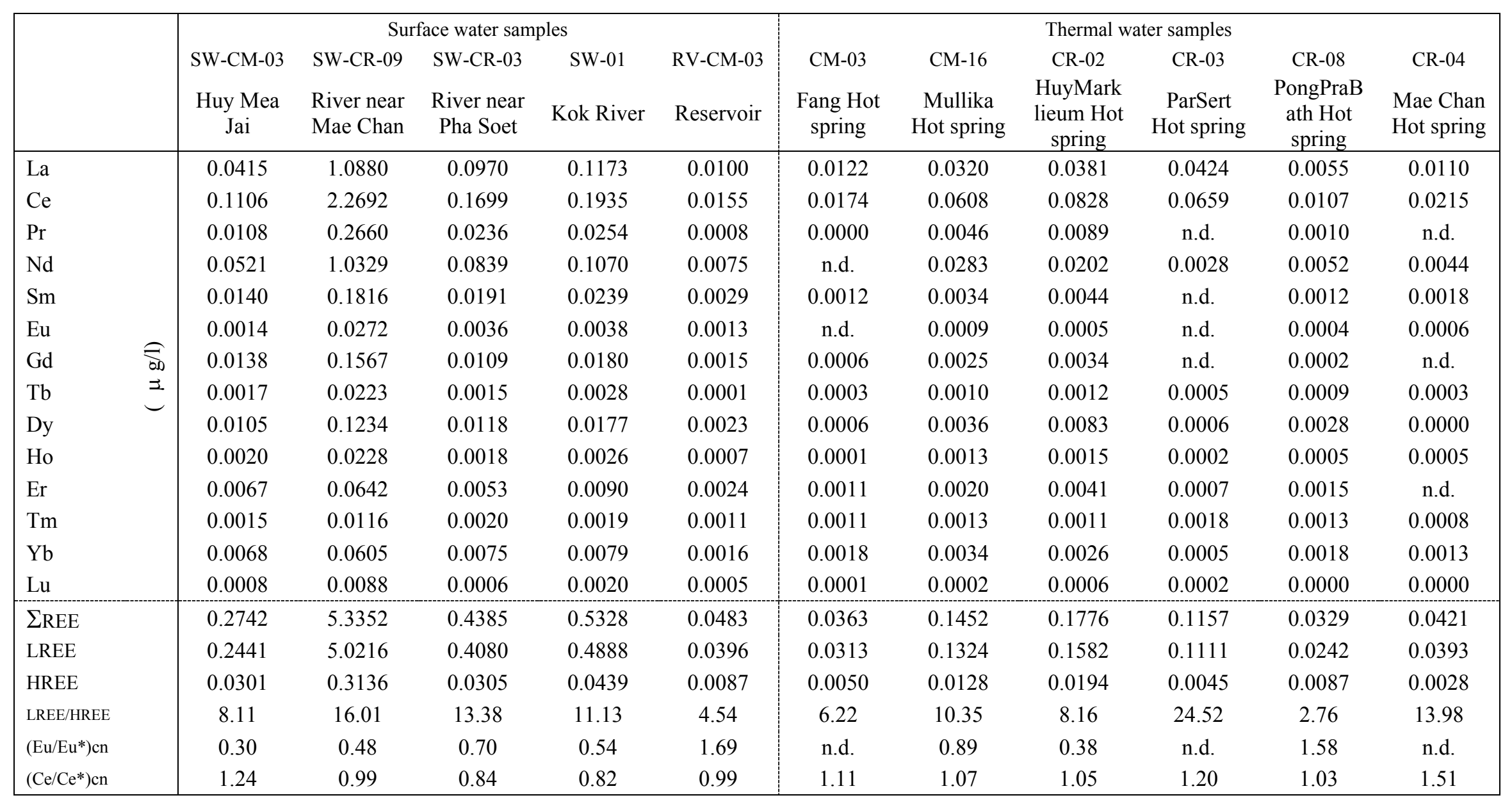

n.d.; not detect from the laboratory 


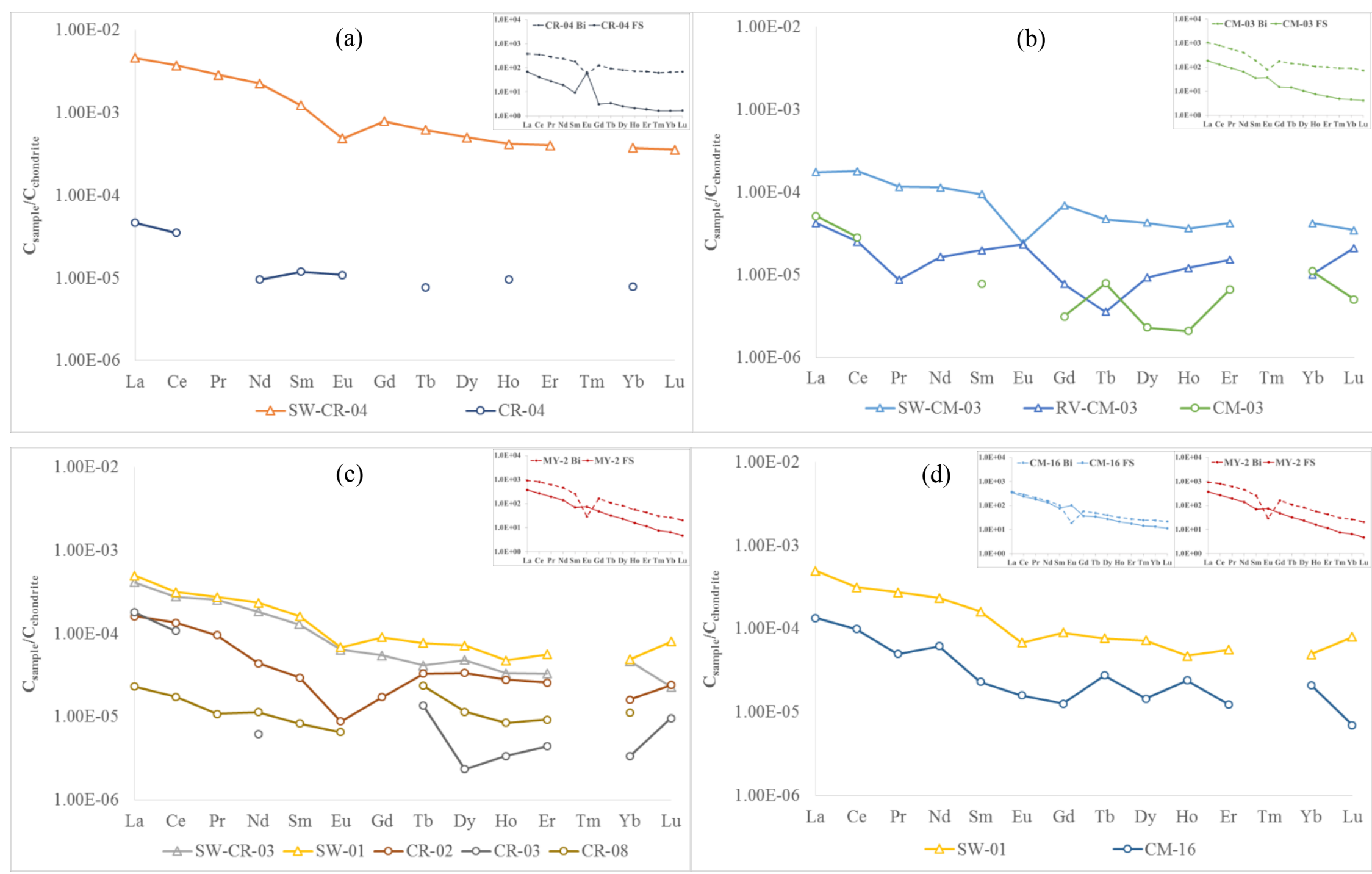

Figure 4.2-4: Chondrite-normalized REE patterns (McDonough and Sun, 1995) of surface and thermal water samples for location of CR-04 (a), CM-03 (b), CM-16 (d), and for CR-02, CR-03, and CR-08 (c) comparing with the local rock. 
Table 4-9: Analytical results of $\mathrm{Rb}, \mathrm{Sr}$, and ${ }^{87} \mathrm{Sr} /{ }^{86} \mathrm{Sr}$ ratio in the water samples in Mae Chan geothermal area.

\begin{tabular}{lcccccc}
\hline Location & ${ }^{87} \mathrm{Sr} /{ }^{86} \mathrm{Sr}$ & $\mathrm{SD}$ & $\begin{array}{c}\mathrm{Rb} \\
(\mu \mathrm{g} / \mathrm{l})\end{array}$ & $\begin{array}{c}\mathrm{Sr} \\
(\mu \mathrm{g} / \mathrm{l})\end{array}$ & $\mathrm{Rb} / \mathrm{Sr}$ & $1 / \mathrm{sr}$ \\
\hline $\mathrm{CM}-03$ & 0.7197 & 0.00003 & 156.41 & 50.26 & 3.11 & 0.020 \\
$\mathrm{CM}-16$ & 0.7364 & 0.00002 & 55.21 & 46.67 & 1.18 & 0.021 \\
$\mathrm{CR}-02$ & 0.7278 & 0.00002 & 113.86 & 64.99 & 1.75 & 0.015 \\
$\mathrm{CR}-03$ & 0.7275 & 0.00002 & 100.33 & 68.44 & 1.47 & 0.015 \\
CR-08 & 0.7179 & 0.00002 & 49.06 & 90.97 & 0.54 & 0.011 \\
CR-04 & 0.7258 & 0.00002 & 170.05 & 43.27 & 3.93 & 0.023 \\
\hline SW-CM-03 & 0.7347 & 0.00001 & 4.17 & 22.18 & 0.19 & 0.045 \\
SW-CR-09 & 0.7267 & 0.00002 & 10.40 & 46.19 & 0.23 & 0.022 \\
SW-CR-03 & 0.7275 & 0.00002 & 4.80 & 41.26 & 0.12 & 0.024 \\
SW-01 & 0.7279 & 0.00002 & 5.10 & 41.93 & 0.12 & 0.024 \\
RV-CM-03 & 0.7121 & 0.00002 & 15.61 & 186.18 & 0.08 & 0.005 \\
\hline
\end{tabular}

The ${ }^{87} \mathrm{Sr} /{ }^{86} \mathrm{Sr}$ ratio of the feldspar minerals, the surface water, and the thermal water from the Mae Chan geothermal area are plotted by local against geological map (Figure 4.2-5). In general, the ${ }^{87} \mathrm{Sr} /{ }^{86} \mathrm{Sr}$ ratios in the geothermal and surface water are significantly lower than the ${ }^{87} \mathrm{Sr} /{ }^{86} \mathrm{Sr}$ ratio from the granitic host rock samples. Apart from that, the ${ }^{87} \mathrm{Sr} /{ }^{86} \mathrm{Sr}$ ratios in CM03, RV-CM-03, and CR-08 water samples are significantly lower than ${ }^{87} \mathrm{Sr} /{ }^{86} \mathrm{Sr}$ ratios in the feldspar samples (lower than 0.72). 


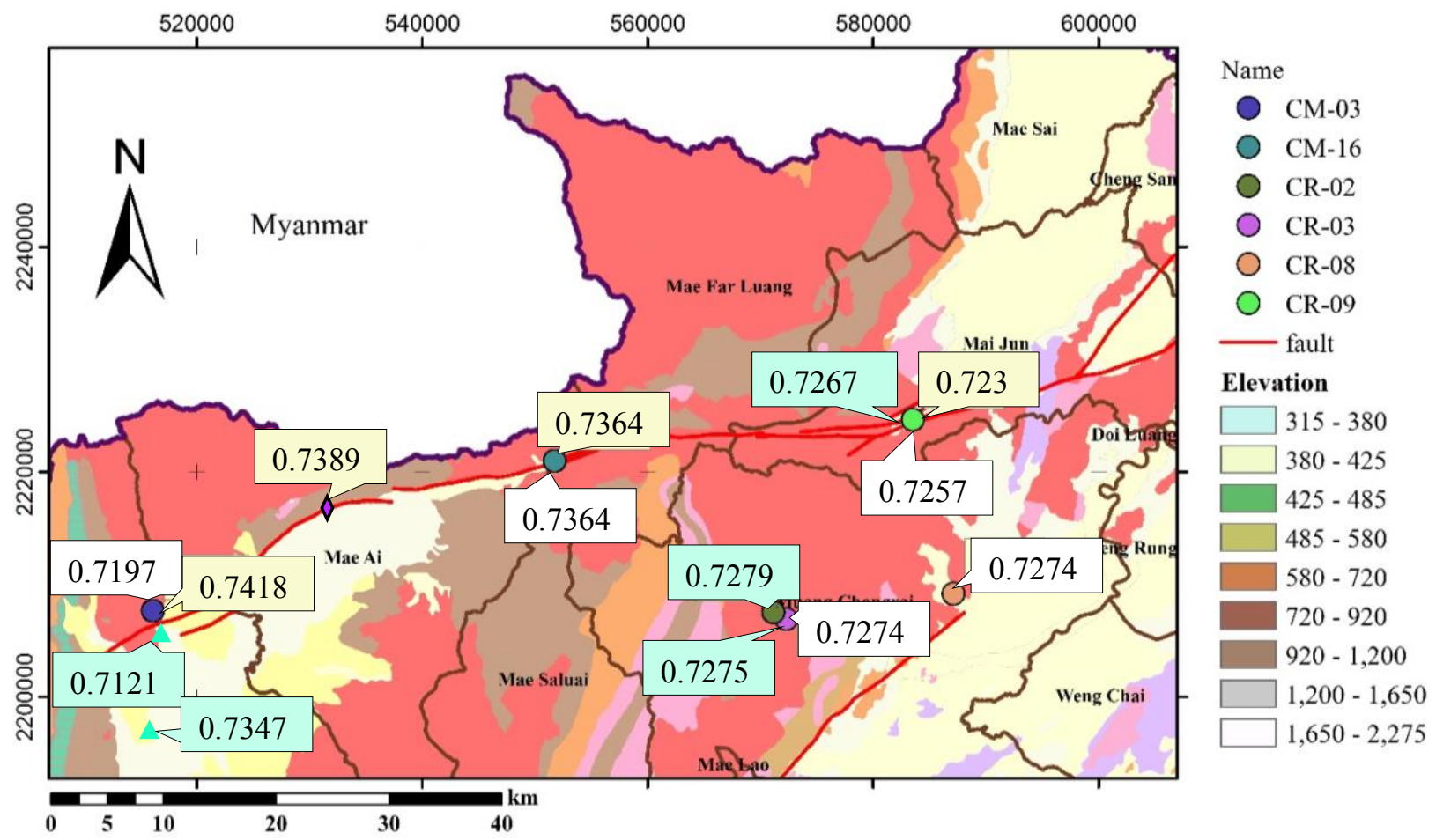

Figure 4.2-5: Spatial distribution of the ${ }^{87} \mathrm{Sr} /{ }^{86} \mathrm{Sr}$ ratio in the feldspar mineral (Yellow background), the surface water (Blue background), and in the hot springs water samples (White background), are plotted with the Mae Chan geological map. 


\subsection{Interpretation}

\subsubsection{Hydro-geochemistry and origin of water}

\subsubsection{The origin of thermal water}

In hydrological cycles, the meteoric water is the primary source of geothermal water. The isotopic composition of hydrogen and oxygen in thermal water reflects a combination of isotopic effects that occur in locally infiltrated meteoric water, for instance: temperature effects, altitude effects, continental effects, amount effects, and source effects (Dansgaard, 1964; Rozanski et al., 1993).

The LMWL of the Chiang Rai station (HAII, 2016) is consistent with previous results that obtain from surface water samples (Kita et al., 1990), and is also in agreement with the GMWL (Clark, 2015), $\delta^{2} \mathrm{H}=8 \delta^{18} \mathrm{O}+10$. All three meteoric water lines are slightly difference in the slope and the deuterium excesses of these equations.

$\delta^{2} \mathrm{H}$ and $\delta^{18} \mathrm{O}$ results of Mae Chan thermal water and surface water samples, which plot close to the LMWL in the stable isotope relationship diagram (Figure 4.2-3(a)) and does not correlate with the magmatic water area from Giggenbach, (1992) (Figure 4.2-3(b)). Therefore, these indicate that the main source of thermal and surface water only derives from local meteoric water without magmatic sources. This is in good agreement with the previous study from Kita et al., (1990) demonstrating that the Fang thermal water originates from the local meteoric water.

The isotopic compositions of thermal water samples are more depleted than the surface water and the mean weight isotopic composition of precipitation. The decrease in isotope values for precipitation varies according to a function of increasing elevation since isotopic fractionation occurs from the cooling and condensation of water vapor as it rises over the mountain (Rowley et al., 2001; Rowley and Garzione, 2007). Therefore, the recharge areas of thermal water are located at the higher elevations and can be estimated by using the Eq. (3.4) with the altitude$\delta^{18} \mathrm{O}$ gradient in Thailand from Doi Inthanon reported, $-0.22 \% / 100 \mathrm{~m}$ (TINT, 2012). The results of the recharge elevation range from 740 to 1,200 m AMSL and are shown in Table 4-10.

The $\delta^{18} \mathrm{O}$ values in the thermal waters from the pre-monsoon seasons are slightly higher than that those from the post-monsoon seasons. In addition, most of the thermal waters have shifted $\delta^{18} \mathrm{O}$ values in both seasons and indicate a small seasonal effect on the interaction between 
water and rock (water-rock interaction). Amatyakul et al. (2016, 2015) suggested that the heat source for the Fang and Mae Chan thermal springs are derived from convective flows through weathered and fractured granite in a shallow system (less than $500 \mathrm{~m}$ below the surface). This shallow system may be sensitive to seasonal changes, for instance, less recharge water during the pre-monsoon season could contribute to increasing the rock-water ratios in the system. This would increase the isotopic exchange mechanism between the initial $\delta^{18} \mathrm{O}$ of the water and the heavy $\delta^{18} \mathrm{O}$ of the surrounding rock mineral. Therefore, it can be implied that the Mae Chan thermal water interacted with the surrounding rock and/or at low-temperature conditions, and the degree of interaction probably relies on the seasonal effects.

Table 4-10: Results of recharge elevation estimation from the isotopic composition of thermal water samples (Eq. (3.4)).

\begin{tabular}{cccc}
\hline \multirow{2}{*}{ Location } & $\begin{array}{c}\text { Altitude } \\
\text { (m AMSL) }\end{array}$ & \multicolumn{2}{c}{$\begin{array}{c}\text { Recharge elevation } \\
\text { (m AMSL) }\end{array}$} \\
\cline { 2 - 4 } & & 1 st & 2nd \\
\hline CM-03 & 550 & $1,213.42$ & $1,197.51$ \\
CM-16 & 474 & $1,058.61$ & $1,048.05$ \\
CR-02 & 409.4 & 756.61 & 739.34 \\
CR-03 & 413 & 933.17 & 889.23 \\
CR-08 & 399 & 788.69 & 802.09 \\
CR-04 & 437.5 & 965.53 & 954.78 \\
CR-09 & 435 & - & 742.07 \\
\hline
\end{tabular}

Apart from RV-CM-03, WNL and SW-WNL, the value range of field parameters and chemical composition of these samples match each other samples. However, in Figure 4.2-3 (a)., the isotopic composition of these samples deviated significantly to the right of the LMWL. These samples are collected from a reservoir (RV-CM-03), a swamp-grass area (SW-WNL and WNL). These areas probably have high evaporation in the pre-monsoon seasons then mixing with the meteoric water in the post-monsoon seasons. Our results are higher in temperature and EC compared to the previous WNL hydro-chemical results from S.H. Wood, (2015), collected in May 2014 (during the monsoon season). It can be implied that a shift of isotopic composition could be derived from the evaporation effect during the pre-monsoon season. Therefore, the correlation of these surface water should represent the evaporation effect of this area, which is evaluated in the equation $\delta^{2} \mathrm{H}=5.06 \delta^{18} \mathrm{O}-17.26 \%$. 


\subsubsection{Geochemical processes}

Groundwater geochemistry is controlled by the chemical and physical processes of subsurface systems such as cation exchange, dissolution of silicate minerals and the dissolution and/or precipitation of carbonates and gypsum (Cartwright and Morgenstern, 2012). In the Mae Chan geothermal area, thermal waters provided a higher chemical concentration relative to surface water and meteoric water. From the triangular diagram, the water samples are dominated by $\mathrm{Na}-\mathrm{HCO}_{3}$ type which commonly characterized in the shallow condensate zone from the margins of the geothermal fields (Nicholson, 1993). This is consistent with the previous hydrogeochemical and geophysical results from Magnetotelluric (MT) data and drilling profile in the Fang and Mae Chan hot springs. This indicates that those reservoirs are located above a depth within only a few hundred meters (Amatyakul et al., 2016, 2015). Moreover, the isotopic compositions in thermal water indicate the precipitation origin. These would reflect the development of chemical concentration from rainwater and surface water to the subsurface geothermal system.

As aforementioned in Chapter 3.3, for visual identification of the geochemical processes, the analytical major-ion compositions in thermal waters samples and the major-ion compositions in Post-ET (Table 5-4) are plotted in the Schoeller's diagram in Figure 4.3-1.

In Figure 4.3-1, most of the major ion concentrations in thermal water $\left(\mathrm{F}^{-}, \mathrm{Na}^{+}, \mathrm{K}^{+}\right.$, and $\left.\mathrm{SO}_{4}^{-}\right)$ are increased from major-ion compositions in Post-ET. The geological setting of these thermal water is the granitic basement rock, which mainly composes of plagioclase (Na-feldspar), Kfeldspar, and Biotite. These minerals can provide major-ion compositions to the water at the higher temperature and long residence time. This implies that the concentration of $\mathrm{F}^{-}, \mathrm{Na}^{+}, \mathrm{K}^{+}$, and $\mathrm{SO}_{4}^{-}$could be attributed to the water-rock interaction after the water flow through the undersaturated zone. 


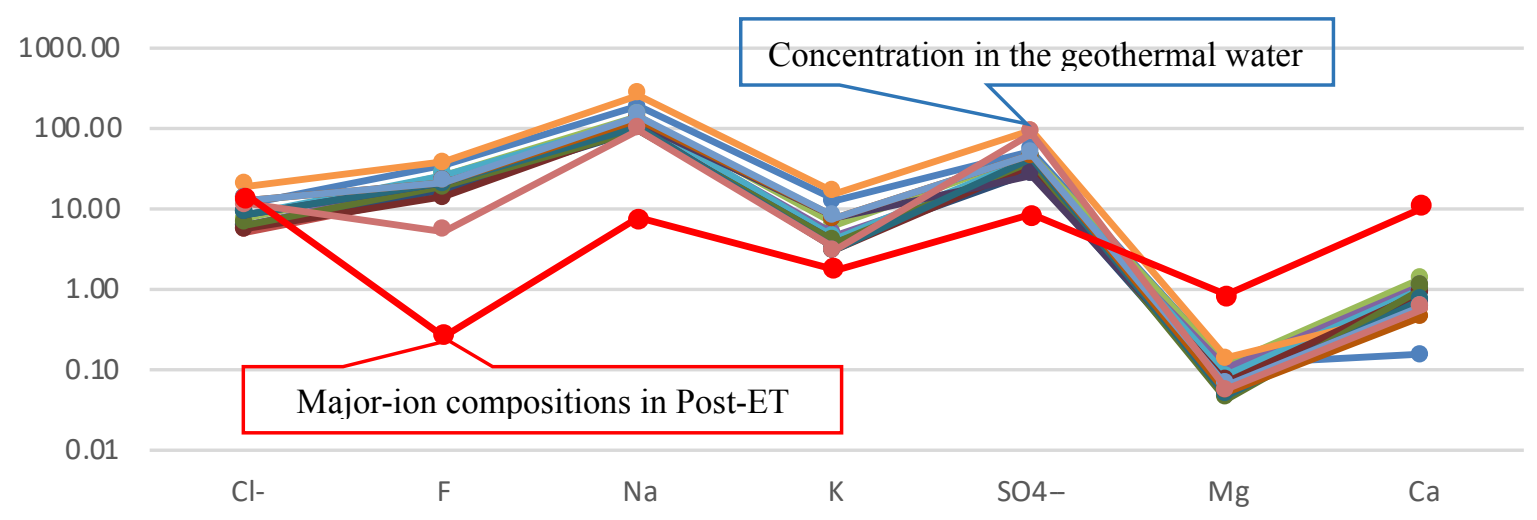

Figure 4.3-1: Correlation diagram of the major ion concentrations between in the geothermal water versus in the precipitation.

In contrast, $\mathrm{Ca}^{2+}$ and $\mathrm{Mg}^{2+}$ concentrations in thermal water are clearly lower than that in the meteoric water. According to Nicholson, (1993), $\mathrm{Ca}^{2+}$ and $\mathrm{Mg}^{2+}$ can precipitate in the form of carbonates, gypsum, or siliceous sinter at high temperature. This precipitation is in good agreement with field exploration results from our and Singharajwarapan et al., (2012) that illustrate the silica sinter and silica encrustation at the surface thermal water. Moreover, $\mathrm{Mg}^{2+}$ is easily absorbed into these secondary alteration minerals; such as illite and chlorite (Nicholson, 1993). These secondary minerals also investigated in a drilled well profile in the Fang geothermal area (Wood et al., 2018). Therefore, these imply that $\mathrm{Ca}^{2+}$ and $\mathrm{Mg}^{2+}$ were decreased by precipitation processes after the water flow through the undersaturated zone.

$\mathrm{Cl}^{-}$is a conservative element in the hydrological cycle, and is a useful chemical tracer for indicating sources, atmospheric input, and the flow part of the subsurface. The main sources in hydrological system are derived from marine salt, human activity, and rock (halite) (Clark, 2015; Nicholson, 1993; Petelet-Giraud et al., 2003). However, the $\mathrm{Cl}^{-}$concentrations in the thermal water samples are in a small range from 2 to $20 \mathrm{mg} / \mathrm{l}$ and are located close to the chemical concentration of the precipitation (Post-ET) in Figure 4.3-1. These can be indicating that $\mathrm{Cl}$ in thermal water was assigned to the precipitation origin.

4.3.1.3 Source of dissolved inorganic carbon and residence time of thermal water

The residence time is an important parameter for evaluating the quantity of the hydrological system. This study investigates the residence time of Mae Chan hot springs through tritium and radiocarbon dating. 
The residence time estimation from tritium concentration, surface water and precipitation are represented as the present input function of the groundwater system. The ${ }^{3} \mathrm{H}$ in surface water (1.5 to $2.0 \mathrm{TU})$ in the Mae Chan geothermal area correlate fairly well with modern precipitation in the Nakhon Nayok Province in Thailand, ranging from 2.5 to 3.0 TU (Yongprawat et al., 2012).

On the other hand, all thermal water samples in Mae Chan have a low tritium content ranging between 0 and $0.1 \mathrm{TU}$. These results are lower than the standard uncertainty of the referenced measurement (one sigma level = 0.3-0.4 TU). Geothermica Italiana Slr., (1984) reported 0.7 TU in Fang and 1.3 TU in Mae Chan hot springs. These results are applied in calculating the ${ }^{3} \mathrm{H}$ concentration in 2014 in Mae Chan and Fang geothermal areas by common Radioactive decay law (Eq. (3.5)), giving 0.11 and 0.20 TU, respectively. In addition to Apollaro et al., (2015), the maximum mean residence time by applying the well mixed reservoir model indicated $955 \pm 292$ BP in the Fang hot spring and $507 \pm 97$ BP in the Mae Chan hot spring. Therefore, these can suggest that these hot springs have the moderate flowing rate and the residence time in thermal springs is older than 60 years.

For carbon sources and residence time estimation, the thermal fluids in the Mae Chan geothermal area have a narrow range of DIC values in the bicarbonate ion form $\left(\mathrm{HCO}_{3}^{-}\right)$at $\mathrm{pH}$ $8.3-8.9$, which a wide range of $\delta^{13} \mathrm{C}$ isotopic composition values. This would indicate the presence of complex carbon processes from various carbon sources in the study area.

The surface water sample Sw-CR-04 contains low DIC, $-10.47 \%$ of $\delta^{13} \mathrm{C}$, and a young water age (from ${ }^{3} \mathrm{H}$ and carbon dating). This sample was collected during the post-monsoon season from a small stream beside the Mae Chan area, where is topographically considered as the upstream river. In fact, the gas exchange with the atmosphere and groundwater inputs seem to play an important role in $\delta^{13} \mathrm{C}$-DIC in small rivers at the upstream river (Finlay, 2003; Roach et al., 2016). This $\delta^{13} \mathrm{C}$ ratio in the surface sample probably derived from the unsaturated zone (subsurface flow). However, there is a noticeable difference between this $\delta^{13} \mathrm{C}$ value and the

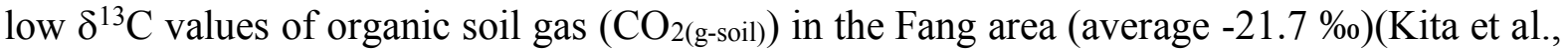
1990). According to Wood et al., (2018), the field exploration in the Fang area, the massive gray limestones from the Paleozoic sediments are exposed in some area at the Doi Kia fault contact. However, the $\mathrm{HCO}_{3}^{-}$results in surface and thermal waters indicate low concentration. Hence, this can imply that these waters have less/no contact with the geologic limestone. The different isotopic compositions of the $\delta^{13} \mathrm{C}$ are probably associated with the evolution of 
carbon in the local shallow groundwater. Under the open-system condition, if the recharge water slowly infiltrates and dissolves $\mathrm{CO}_{2}$ (g-soil). The dissolved $\mathrm{CO}_{2}$ (aq) evolves to $\mathrm{HCO}_{3}{ }^{-}$in the equilibrium condition. The changed chemical state of this $\mathrm{CO}_{2}$ associated with an estimated $\delta^{13} \mathrm{C}$ fractionation of around $+1 \%$ and its equilibrium transition form associated with estimated $\delta^{13} \mathrm{C}$ fractionation from +9 to $+11 \%$ (Clark, 2015; Mook et al., 1974; Myrttinen et al., 2012; Szaran, 1998). Therefore, the $\delta^{13} \mathrm{C}$ from the surface water sample probably derived from the

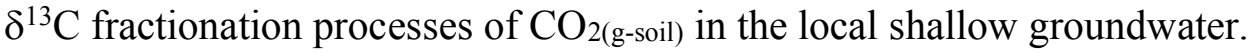

A wide range of $\delta^{13} \mathrm{C}$ isotopic compositions is demonstrated in the geothermal water (from 4.35 to $-32.27 \%$ ), indicating a variety of carbon sources in the system. As the thermal water discharge from fractures in outcrops of the granitic basement. The primary carbon source of thermal water would be derived from $\mathrm{CO}_{2}$ (g-soil) of surface water. For this reason, the carbon sources in the geothermal system can be distinguished into three differential isotopic groups based on the $\delta^{13} \mathrm{C}$ isotopic compositions of the surface water.

The first group comprises of CR-02 and CR-08. This group has the detected ${ }^{14} \mathrm{C}$ activity and the $\delta^{13} \mathrm{C}$ ratio in the range of the $\delta^{13} \mathrm{C}$ ratio from Sw-CR-04. It can imply that this system has no additional carbon during the flow part. The ${ }^{14} \mathrm{C}$ decay process probably occurred after filtering into the closed system before arising to discharge area. Therefore, the age of ${ }^{14} \mathrm{C}$ dating in this group would indicate the residence time of the system.

The second group comprises of CM-03 and CR- 04 . The $\delta^{13} \mathrm{C}$ ratio of this group is more enriched than the $\delta^{13} \mathrm{C}$ ratio from $\mathrm{Sw}-\mathrm{CR}-04$. This group displays lower ${ }^{14} \mathrm{C}$ activity and slightly higher DIC than from the first group. This data may indicate that additional carbon was introduced by inorganic matter and the additional carbon is more enriched in $\delta^{13} \mathrm{C}$ than the

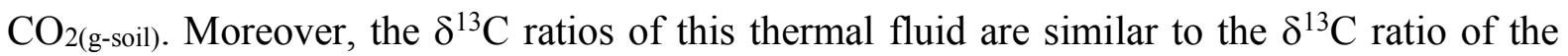
Fang hot spring gases (Kita et al., 1990). These can imply that this geothermal fluid $\delta^{13} \mathrm{C}$ ratio may react with the enriched $\delta^{13} \mathrm{C}$ ratio of geologic gases. The estimated residence time from ${ }^{14} \mathrm{C}$ dating is longer than a realistic residence time.

The third group comprises of CR-03 and CM-16. This group has a more depleted $\delta^{13} \mathrm{C}$ ratio and has high ${ }^{14} \mathrm{C}$ age than the surface water (Sw-CR-04). These depleted $\delta^{13} \mathrm{C}$ ratios may have been influenced by organic matter and/or other carbon sources which are more depleted in $\delta^{13} \mathrm{C}$

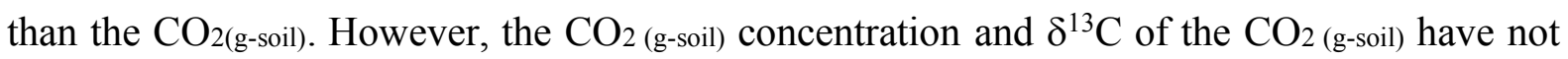
been observed in this area, and the ${ }^{14} \mathrm{C}$ of CR-03 was not detected. Therefore, the source of 
DIC in this group is still not clear. The CM-16 sample had the most depleted $\delta^{13} \mathrm{C}$ ratio of $32.27 \%$. It is in line with previous results from Stute, (1989) and Thomas, (2018), and were interpreted as the result of methane oxidation by sulfate reduction (Eq. (4.1)). This hot spring is geologically located in Paleozoic sedimentary rock along the Mae Chan fault line, where interbeds of shale are exposed (Imsamut and Krawchan, 2005). As reported by Wood et al., (2018), Fang basin discovered oil seeps and developed 240 petroleum production wells for many years. Therefore, this area has a possibility for methane emissions. Moreover, this hot spring indicates the sulfate reduction evidence from field exploration, such as strong rotten egg odor and an abundance of fine black particulates, which presumably are sulfide mineral precipitates. For these reasons, this thermal water probably undergoes methane oxidation by sulfate reduction processes.

$$
\mathrm{CH}_{4}+\mathrm{SO}_{4}^{2-} \rightarrow \mathrm{HCO}_{3}^{-}+\mathrm{HS}^{-}+\mathrm{H}_{2} \mathrm{O}
$$




\subsubsection{Geothermal assessment, geothermometer application.}

Different geothermometers provide a different range of temperature results. On the other hand, if the system has not reached the water-rock equilibrium state and/or has been mixed with cooled water while rising to the surface, a straightforward temperature estimation from these geothermometers would not provide reliable temperature results. This study recognizes three graphical tools for validating these geothermometers in Mae Chan hot springs: $\mathrm{Na}-\mathrm{K}-\mathrm{Mg}$ triangular diagram, the quartz/Na-K diagrams and quartz/Mg-K diagrams, and the silicaenthalpy mixing model.

\subsubsection{The Na-K-Mg triangular diagram.}

All of the Mae Chan thermal waters are in the partial equilibrium water in the regime of the $\mathrm{Na}-\mathrm{K}-\mathrm{Mg}$ triangular diagram (Figure 4.3-2) indicating that these waters are not reached in equilibrium condition with host rock and/or mixed with cold water. Moreover, water samples are classified into two groups. The first group is in the higher temperature (CR-04, CR-09, CR02, and CM-03) and the second group is in the lower temperature (CM-16, CR-08, and CR$03)$.

\subsubsection{The Quartz/Na-K diagram and Quartz/Mg-K diagram}

The graphical correlation between the silica geothermometer and two cation geothermometers (Na-K and $\mathrm{Mg}-\mathrm{K}$ ) with the different rates of equilibrium reactions has been applied to check the validity of each aforementioned geothermometer.

The Quartz/Na-K diagram (Giggenbach, 1988) and the Quartz/ Mg-K diagram (Giggenbach et al., 1994) compare the logarithm of chemical concentrations from Mae Chan hot springs and theoretical geothermometer lines (Figure 4.3-3(a), and 4.3-3(b) respectively). These theoretical lines represent the maximum $\mathrm{Na} / \mathrm{K}$ ratio, $\mathrm{Mg}-\mathrm{K}$ ratio and silica content at a given temperature obtained from the equation in Table 3-1. and Table 3-2., which comprised of amorphous silica geothermometer, chalcedony geothermometer, quartz geothermometer (no steam loss and maximum steam loss) equations from Giggenbach et al., (1994) and Fournier and Rowe, (1977). 


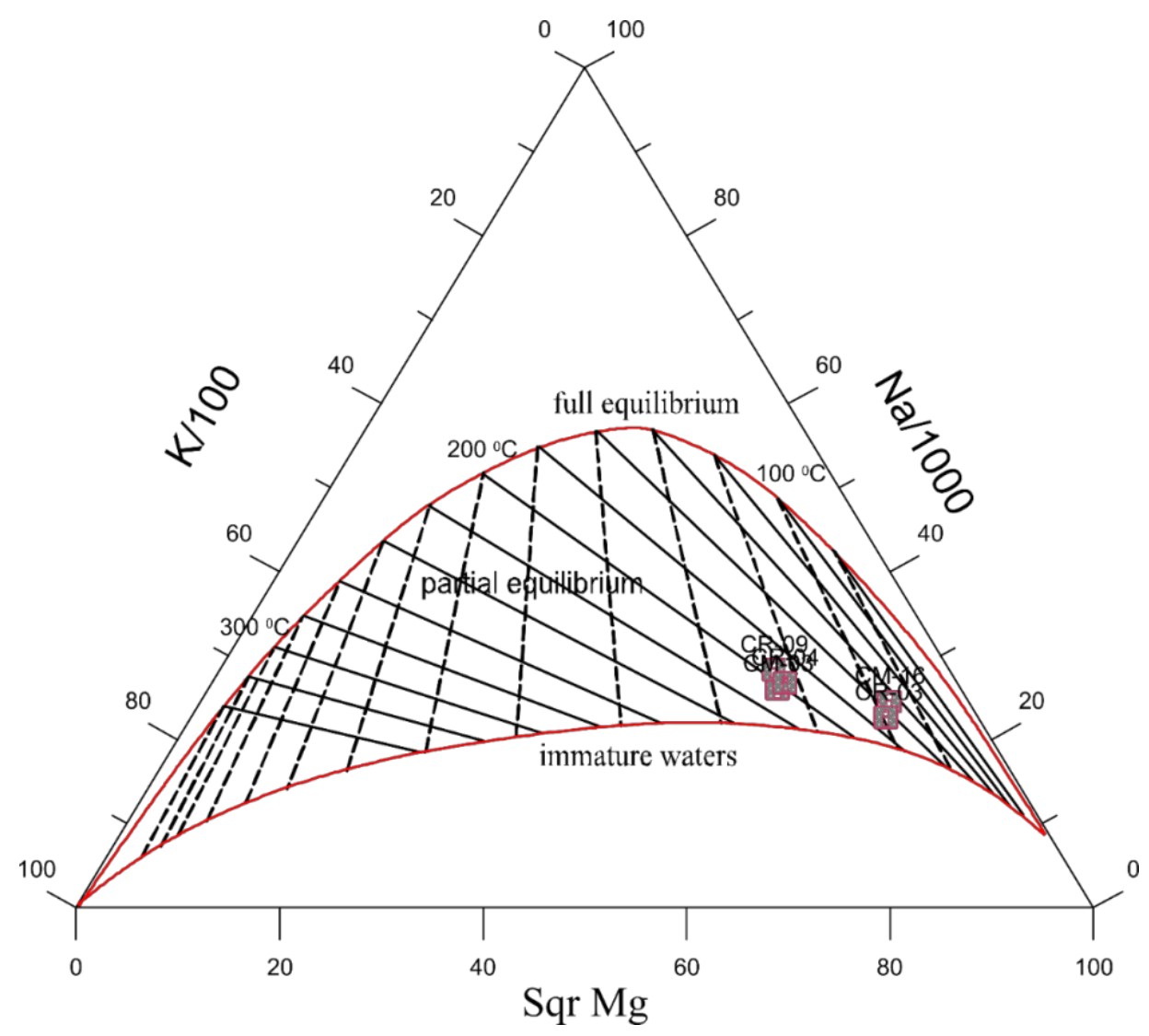

Figure 4.3-2: Na-K-Mg triangular diagram (modified from Giggenbach, 1988) for the considered thermal waters of Mae Chan area.

In Figure 4.3-3(a), the quartz/Na-K diagram results illustrate that all of the thermal waters are located below the theoretical line. For this reason, albite and K-feldspar minerals (which are represented by $\mathrm{Na}^{+}$and $\mathrm{K}^{+}$), are probably not present as hydrothermal minerals also the thermal water is probably not reached to the equilibrium condition.

In Figure 4.3-3(b), the quartz/Mg-K diagram results demonstrate that most of the thermal water are located close to the chalcedony, the quartz adiabatic cooling and conductive cooling lines in the lower part of the graph $\left(<150{ }^{\circ} \mathrm{C}\right)$. CR-08, CR-02, CR-04, and WNL are located in the chalcedony equilibrium line, indicating that these hot springs are reliable on the conservative $\mathrm{K}-\mathrm{Mg}$ and chalcedony subsystem. CR-03 and CM-16 are located in the quartz adiabatic cooling and quartz conductive cooling lines, showing that these hot springs are reliable on the conservative $\mathrm{K}-\mathrm{Mg}$ and quartz subsystem. Therefore, these diagrams can suggest that most of thermal water are reliable on the conservative $\mathrm{K}-\mathrm{Mg}$ and chalcedony subsystems, which are rapid rock-water equilibrium reaction at low temperature $\left(<150{ }^{\circ} \mathrm{C}\right)$. 


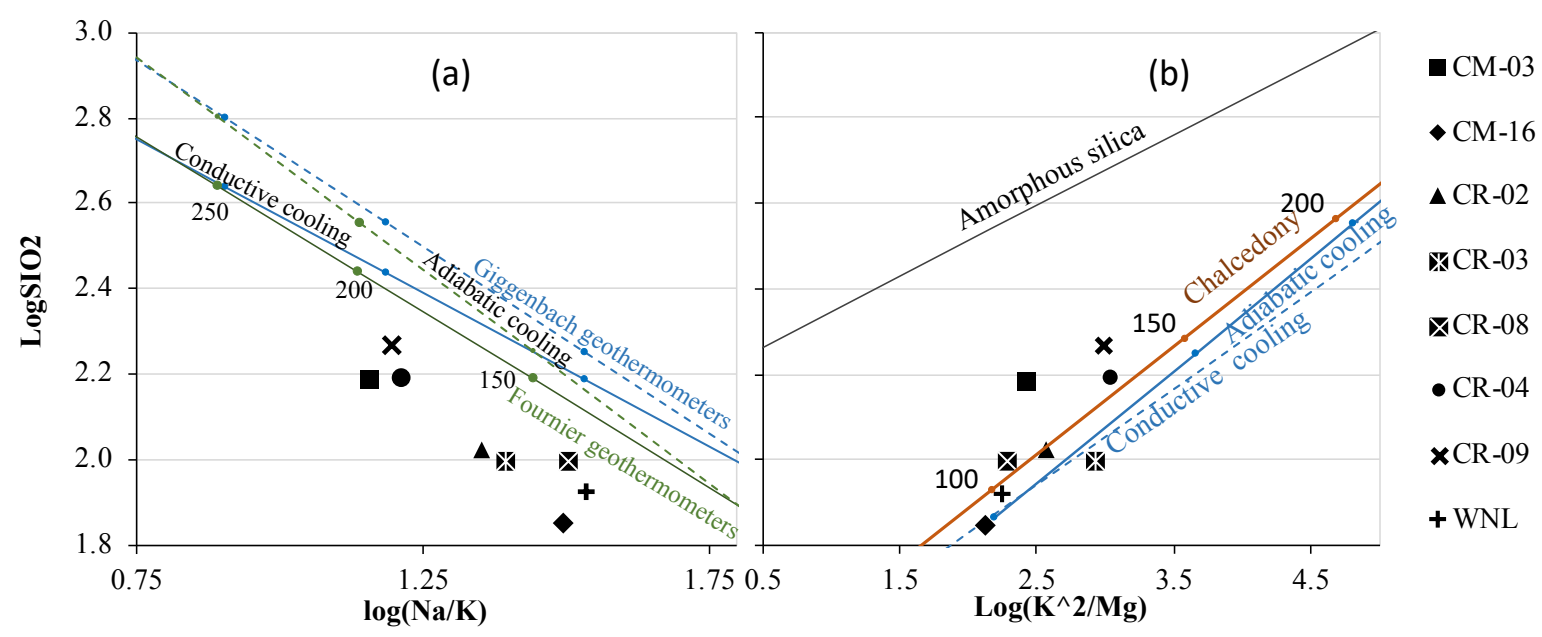

Figure 4.3-3: Quartz/Na-K diagram (modified from Giggenbach, 1988) and Quartz/Mg-K diagram (modified from Giggenbach et al., 1994) for the considered thermal waters of Mae Chan area.

\subsubsection{The Silica-enthalpy mixing model}

The results of the triangular diagram and the quartz/Cation-ratio diagram from Mae Chan hot springs can imply that all of the samples contain partially equilibrated water, and most of the thermal water are controlled by the rapidly equilibrium reaction of chalcedony and $\mathrm{Mg}-\mathrm{K}$ geothermometers. As proposed by Founier, (1989), another silica phase can be used to replace the quartz solubility equation. Therefore, in this study, the chalcedony equation and chalcedony steam-loss geo-thermometer from Arnórsson et al., (1983) are applied instead of the quartz solubility.

The average dissolved silica concentrations of thermal water and cold water are plotted against the corresponding enthalpies from Mae Chan hot springs along with the results, comparing with three theoretical reference lines (Figure 4.3-4(a) and 4.3-4(b)).

The results in the first scenario illustrated that both graphs can draw a mixing line converge on the chalcedony solubility curve. Except for CR-02 and CR-08 in post-monsoon season, the enthalpy from the convergent point (at point A) is higher than the limitation of the chalcedony geothermometer i.e., more than 1085.32 J/g (at $250{ }^{\circ} \mathrm{C}$ ) (Arnórsson, 2000; Fournier and Rowe, 1977). Therefore, it can be roughly implied that this model and the estimation of the mixing ratio from the first scenario is not suitable for the CR-02 and the CR-08 hot springs in postmonsoon season, shown in Table 4-11. The dilution ratios from enthalpy $(\mathrm{H})$ and $\mathrm{SiO}_{2}(\mathrm{~S})$ in this scenario range from 0.56 to 0.91 and the reservoir temperature ranging from 166 to $274{ }^{\circ} \mathrm{C}$. 


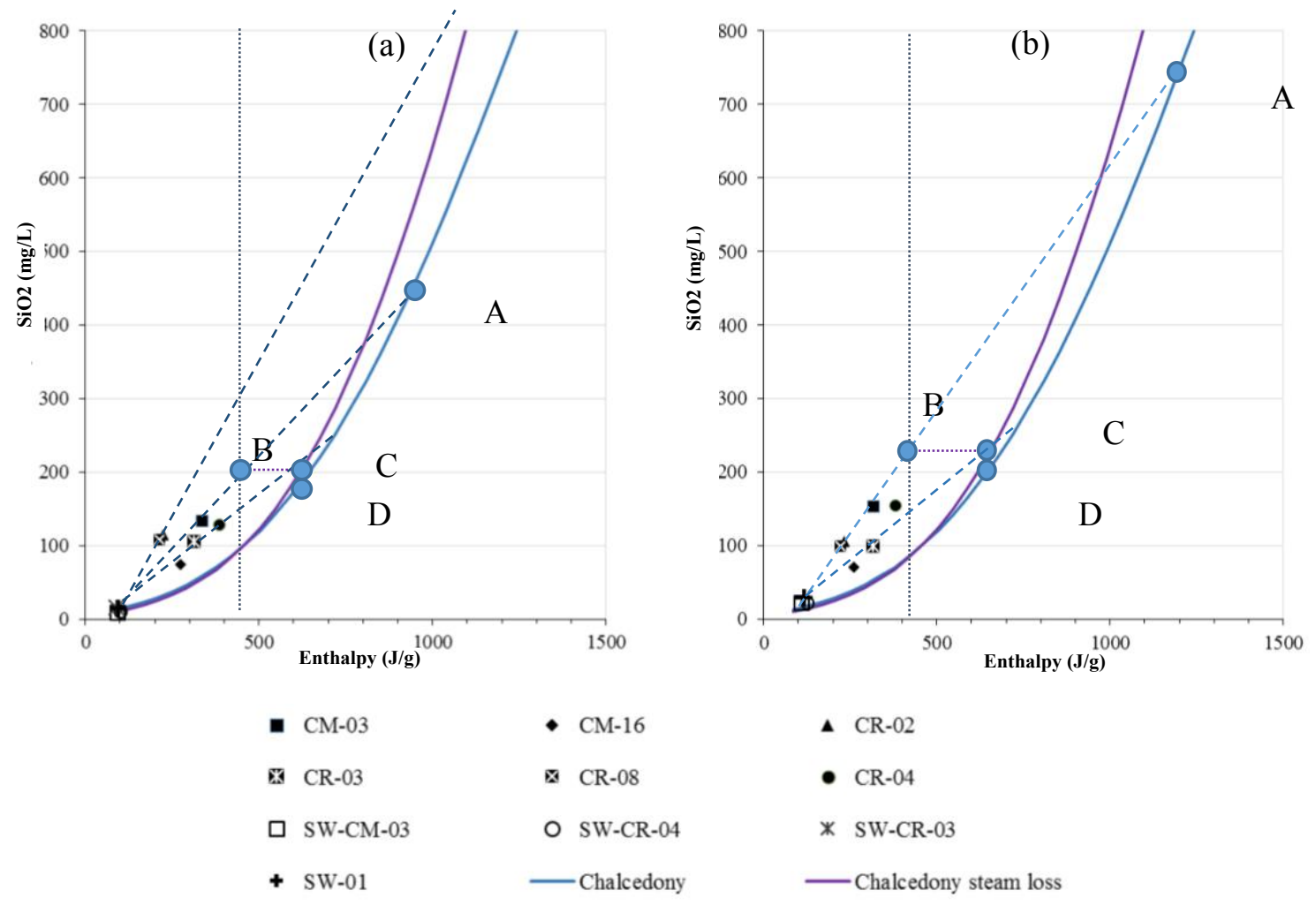

Figure 4.3-4: Silica-enthalpy mixing diagram of Mae Chan hot spring in Post-monsoon season (a), and in pre-monsoon season (b). The results compare with three theoretical reference lines; The first line (blue line) is the chalcedony solubility curve, and the second line (purple line) is the chalcedony maximum steam loss curve. Both curves estimated from the equation of chalcedony and chalcedony steam-loss geothermometer from Arnórsson et al., (1983). The third line (vertical gray line) refers to the boiling point of the water (at $100{ }^{\circ} \mathrm{C}$ ) which has been assumed equal to $419 \mathrm{~J} / \mathrm{g}$ of the enthalpy at saturation state (Wagner and Hans-Joachim, 2007).

The results on second scenario (Table 4-11) show that: the initial $\mathrm{SiO}_{2}$ concentrations range from 225 to $355 \mathrm{mg} / \mathrm{L}$, the corresponding reservoir temperatures range from 132 to $199{ }^{\circ} \mathrm{C}$, enthalpy dilution ratio $(\mathrm{H})$ range from 0.80 to 0.93 , and dilution ratio $\mathrm{SiO}_{2}(\mathrm{~S})$ range from 0.73 to 0.83 . Apart from that, the results of $\mathrm{CR}-04$ indicate lower value relative to the other hot springs.

This model shows that if thermal water has been mixed with cool water during the discharging process, the geothermal reservoir would have a high temperature (approximately ranging from 129 to $168^{\circ} \mathrm{C}$ ). Most of the samples indicate stream-loss during ascension to the surface and mixed with cool water from 35 to $81 \%$ by volume. 
Table 4-11: Estimated initial reservoir temperature and initial $\mathrm{SiO}_{2}$ concentration from the Silica-enthalpy mixing diagram and mixing ratio results in pre-monsoon season and postmonsoon season.

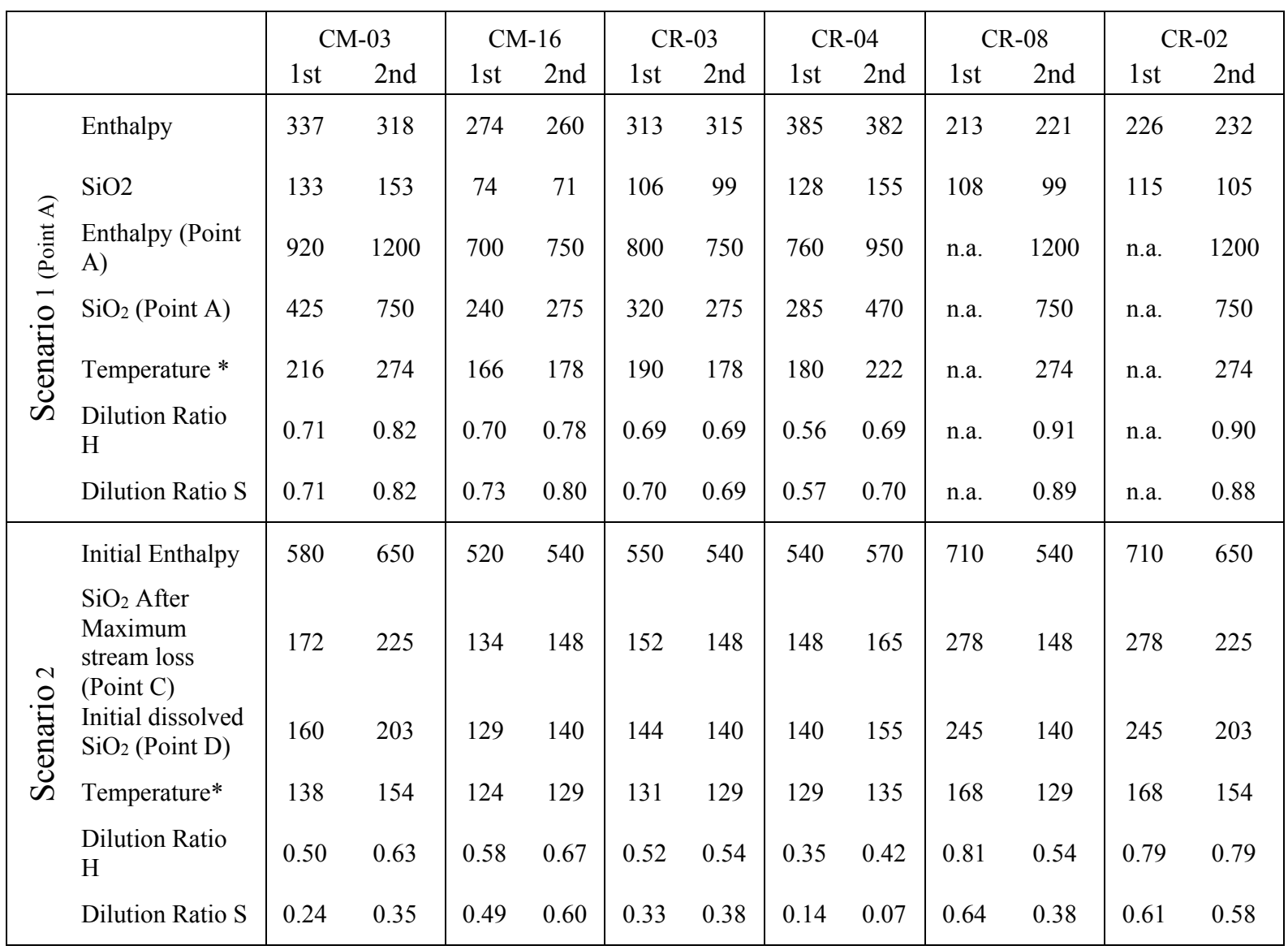

*Temperature and enthalpy of geothermal reservoir determines from international steam table at saturation state (Wagner and Hans-Joachim, 2007).

\subsubsection{The reservoir depth estimation.}

Identifying the fluid circulation depth is thus critical to understand the dynamic behavior of the Mae Chan geothermal system. The high geothermal potential of Fang and Mae Chan hot springs have been continuously investigated and the geothermal potential for utilizing geothermal energy has also been evaluated (DAEDE, 2007a; Geothermica Italiana S1r., 1984; Raksaskulwong, 2015; Ratanasthein et al., 1988). Wanakasem and Takabut, (1987) provided the information on temperature profiles of the Fang shallow geothermal wells; for instance, FGTE-6, FGTE-8, and FGTE-10 are shown in Figure 9.1-3 in Appendix 1. The estimated temperature gradients of these shallow wells range from 31 to $78{ }^{\circ} \mathrm{C} / \mathrm{km}$ (average $55.6^{\circ} \mathrm{C} / \mathrm{km}$, $\mathrm{n}=3$ ). Wood et al., (2018) suggested that these wells are influenced by the up-flow zone of hydrothermal convection system in crystalline rock at Fang. Moreover, the stable isotope 
results in thermal water are not associated with volcanic or underlying magma systems. Thus, thermal springs are heated by local temperature anomaly.

For the geothermal reservoir depth estimation, the highest range of the temperature gradient in Fang $\left(78{ }^{\circ} \mathrm{C} / \mathrm{km}\right)$ was selected as the representative anomaly heat flow at hot springs that changing temperature from the geothermal reservoir to the surface. Since, the quartz/Na-K diagram and quartz/Mg-K diagram, most of these hot springs rely on the conservative $\mathrm{K}-\mathrm{Mg}$ and chalcedony subsystem. The estimated depths of geothermal results in these thermal springs are shown in Table 4-12.

Table 4-12: Estimated depth of Mae Chan geothermal from reservoir geothermometer.

\begin{tabular}{|c|c|c|c|c|c|c|c|c|}
\hline \multirow[t]{2}{*}{ Location } & \multicolumn{2}{|c|}{$\begin{array}{c}\text { Water } \\
\text { temperature } \\
\left({ }^{\circ} \mathrm{C}\right)\end{array}$} & \multicolumn{2}{|c|}{$\begin{array}{l}\mathrm{Mg} / \mathrm{K} \\
(\mathrm{m})\end{array}$} & \multicolumn{2}{|c|}{$\begin{array}{l}\text { Chalcedony } \\
\text { (m) }\end{array}$} & \multicolumn{2}{|c|}{$\begin{array}{l}\text { Quartz } \\
\text { (m) }\end{array}$} \\
\hline & $1 \mathrm{st}$ & 2nd & $\min$ & $\max$ & $\min$ & $\max$ & $\min$ & $\max$ \\
\hline CM-03 & 80.4 & 76 & 410 & 662 & 679 & 751 & 1,000 & 1,046 \\
\hline CM-16 & 65.5 & 62 & 462 & 442 & 359 & 353 & 731 & 712 \\
\hline CR-02 & 53.9 & 55.5 & 745 & 737 & 771 & 814 & 1,104 & 1,147 \\
\hline CR-03 & 74.8 & 75.2 & 387 & 638 & 451 & 497 & 797 & 831 \\
\hline CR-08 & 50.9 & 52.9 & 681 & 642 & 758 & 796 & 1,104 & 1,129 \\
\hline CR-04 & 92 & 91.1 & 460 & 577 & 460 & 614 & 781 & 910 \\
\hline CR-09 & - & 55.1 & - & 992 & - & 1,255 & - & 1,537 \\
\hline WNL & - & 38.8 & - & 810 & - & 785 & - & 1,105 \\
\hline
\end{tabular}

According to CR-08, CR-02, CR-04, and WNL, they rely on the conservative $\mathrm{K}-\mathrm{Mg}$ and chalcedony subsystem, which has the expected geothermal reservoir depth ranging from 460 to $814 \mathrm{~m}$ from the surface. CR-03 and CM-16 are reliable on the conservative K-Mg and Quartz subsystem, has the expected geothermal reservoir depth ranging from 353 to $831 \mathrm{~m}$ from the surface. In addition, the geothermal reservoir depth estimation in Fang (CM-03) and Mae Chan hot springs (CR-04) from $\mathrm{Mg} / \mathrm{K}$ are consistent with the thermal fluid reservoir depth results from 3-D magnetotelluric survey and 3-D resistivity model by Amatyakul et al., (2016, 2015). The model provided that the reservoir locates within the five hundred meters below the surface in the sedimentary deposits and weathered and fractured granite. 


\subsubsection{Water-rock interaction}

\subsubsection{The REE in Mae Chan granite.}

In Figure 4.1-1, the distribution of REE results from biotite minerals indicated higher concentration relative to whole fresh granite in Chiang Mai and Chiang Rai provinces (Charusiri et al., 1994). In contrast, feldspar minerals indicate highly variable REE concentration.

According to Alderton, (1980), the REE concentration of the rock varies by the proportion of accessory phases which are contributed to the degree of alteration and deformation. Plagioclase minerals have the high potential alteration to the mineral sericite, which is a fine-grained white mica and has higher REE concentration. Biotite minerals are altered to chlorite, which can accommodate HREE released from the minerals. These are in good agreement with our petrology evidence that illustrates sericitization in feldspar and chloritization in biotite samples. For instance, the feldspar samples from CM-16 and CM-16-2, which has highly replaced by sericite, indicated significantly high REE concentration. Moreover, the biotite sample from CR-04, which has highly replaced by minor chlorite and muscovite, indicated the lowest LREE/HREE ratio (9.5). These can suggest that the degree of alteration and deformation in CM-16 and CM-16-2 feldspar minerals are stronger than that in CR-04 and CM-03 feldspar mineral. In contrast, the degree of alteration of biotite minerals in CR-04 is higher than the other samples.

\subsubsection{The REE in the fluid phase.}

According to the REE compositions in the geothermal fluids are derived from the dissolution and alteration of the accessory minerals in the host rocks. The variation in REE composition and pattern in water samples may use as an indicator for understanding the fractionation mechanism during alteration of rock and fluid transport, the history of rock alteration, and the state of equilibrium in water-rock interaction.

The chondrite normalized REE concentration patterns in Figure 4.2-4 show that the REE patterns in surface waters are similar to the REE patterns in the mineral samples and the degree of enriched LREE in surface waters is less than that from the mineral samples. Conversely, the thermal water results indicate completely different from REE concentration patterns and lower compositions relative to those of rocks and surface water. These results are generally consistent with the conceptual model. It states that the REE in surface waters at atmospheric pressure 
would be leached from the host rock. After the water passes other permeable rock to the thermal system, the REE in thermal water is commonly regenerated by the rock minerals and is chemically reduced by increasing temperature and pressure (Migdisov et al., 2016; Möller, 2007).

The REE concentration patterns in low-temperature waters $\left(<70^{\circ} \mathrm{C}\right.$; e.g., $\mathrm{CR}-2$ and $\left.\mathrm{CM}-16\right)$ demonstrate the flat pattern which may be derived from the surface water. Moreover, based on the results, it illustrates markedly depleted LREE pattern (especially in $\mathrm{Pr}, \mathrm{Nd}$, and $\mathrm{Sm}$ elements) relative to HREE in high-thermal water samples $\left(>70^{\circ} \mathrm{C}\right.$; e.g., CM-03, and CR-03 shown in Figure 4.2-4 (b), and (c), respectively). According to Möller, (2007), this evidence points to chemical complexation of various strengths (e.g., $\mathrm{OH}^{-}, \mathrm{F}^{-}, \mathrm{HCO}^{3-}, \mathrm{H}_{2} \mathrm{PO}^{4-}$, etc.) which plays an important role in the behavior of REE in the hydrothermal system.

For more detail, the experimental data from Migdisov et al., (2016) points out that chloride $\left(\mathrm{Cl}^{-}\right.$ ) and sulfate $\left(\mathrm{SO}_{4}{ }^{2-}\right)$ are the main ligands responsible for $\mathrm{REE}$ transportation, while fluoride $\left(\mathrm{F}^{-}\right.$ ) is the main ligand responsible for REE deposition. These ligands can be used to evaluate the REE behavior in the Mae Chan hydrothermal area. The concentrations in These ligands are plotted against total REE concentration in Figure 4.3-5.

From Figure 4.3-5, these ligands indicate negative correlations with total REE content. These total REE relationships with $\mathrm{Cl}^{-}$and with $\mathrm{SO}_{4}{ }^{2-}$ ions (Figure 4.3-5 (a), and (b)) do not support the conclusion of Migdisov et al., (2016) who state that these ligands are REE vehicles, which increases the mobility of REE complexes. This would lead to the release of the REE complexes to the discharge water.

Conversely, the high negative correlation between $\mathrm{F}^{-}$and total REE concentrations (Figure 4.35 (c)) is in line with the aforementioned conclusion. Leached $\mathrm{F}^{-}$in groundwater leads to the crystallization of solid REE-fluoride complexes along the flow path. The LREE-fluoride complexes, which have lower solubility relative to the HREE-fluoride complex, were precipitated at veinlet before discharging to the outflow. Therefore, these can indicate that the total REE concentrations in the Mae Chan geothermal area are chemically controlled by the variation of $\mathrm{F}^{-}$ions. Furthermore, the depleted LREE patterns in thermal water are likely associated with the precipitation processes of LREE-fluoride complexes along the flow path. The lowest temperature water sample in CR-08 also indicates the depleted LREE pattern relative to HREE. Although, it is not clearly complete, this may originate as the same processes as the high temperature water, however, the temperature may be reduced during discharge. 
Remarkably, the highest temperature water sample in CR-04 indicates the depleted HREE pattern relative to LREE and indicates significant high $\mathrm{Cl}^{-}$and $\mathrm{SO}_{4}{ }^{2-}$ concentration $(20$ and $90.7 \mathrm{mg} / \mathrm{L}$, respectively) in Figure 4.3-5. As suggested by Migdisov et al., (2016), these evidence point to $\mathrm{Cl}^{-}$and $\mathrm{SO}_{4}{ }^{2-}$ ligands may increase the mobility and solubility of the LREE complex in CR-04.

(a)

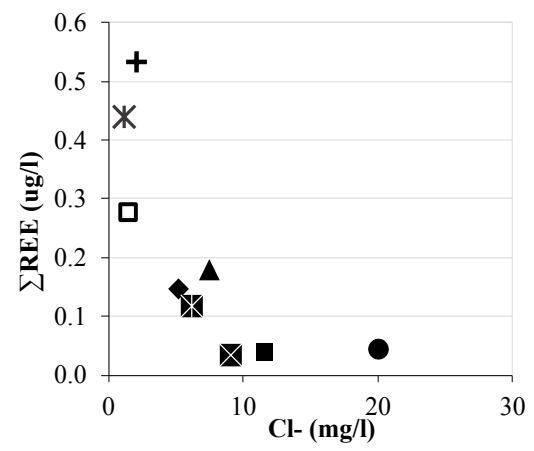

(b)

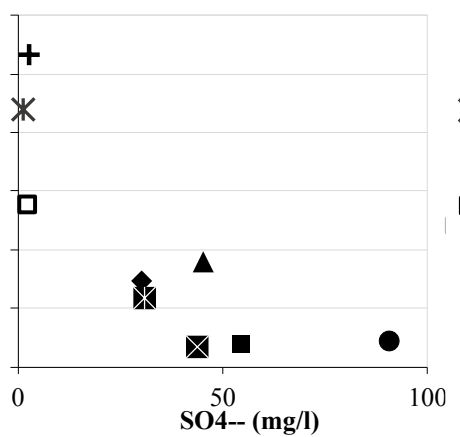

(c)

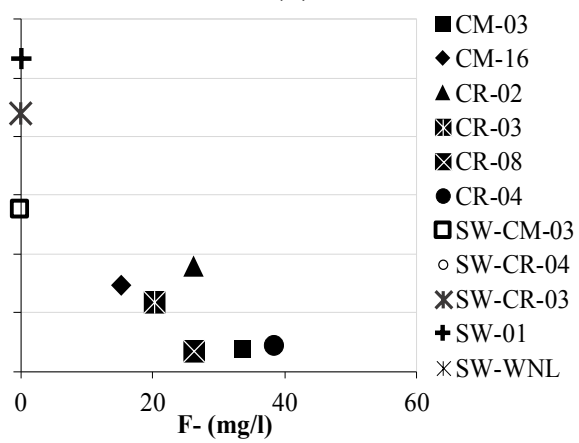

Figure 4.3-5: Correlation between three ligands for instance; chloride $\left(\mathrm{Cl}^{-}\right)(\mathrm{a})$, sulfate $\left(\mathrm{SO}_{4}{ }^{2-}\right.$ ) (b), and fluoride $\left(\mathrm{F}^{-}\right)(\mathrm{a})$, and total REE concentration.

4.3.3.3 Strontium isotopic ratio and chemical concentration in the solid phase.

According to F. Ridd et al., (2011) and DMR, (2014), they have been conducted on $\mathrm{Sr}$ geochronology of whole granite in this area. Our rock sampling area is in the central-province granitic belt group (S-type) in northern Thailand, where are shown the Sr isotopic ratio, ranging from 0.722 to 0.733 and regarded as Permo-Triassic age (210-220 Ma). The results in the feldspar minerals correlate fairly well with the ${ }^{87} \mathrm{Sr} /{ }^{86} \mathrm{Sr}$ ratio in Fang batholith $0.7295+0.0020$ $(224+16 \mathrm{Ma})$.

From the geological information (Imsamut and Krawchan, 2005; Wood et al., 2018), the Triassic (?) granite on the north side of Fang basin is described as unfoliated biotite granite and the Triassic (?) granite on the right side of the map is described as unfoliated porphyritic granite, while the Mae Chan fault line contact with foliated granitic rock and Paleozoic sedimentary rocks. Moreover, our thin-section analysis indicates minerals alteration. The Mae Chan geological map (Figure 4.2-5) demonstrates that the feldspar minerals have $\mathrm{Sr}$ isotopic heterogeneity. Including, the pattern of the spatial distribution of ${ }^{87} \mathrm{Sr} /{ }^{86} \mathrm{Sr}$ ratio varies from the low value in the east (CR-04) to the higher value further west (CM-03) of the map.

As results of the ${ }^{87} \mathrm{Sr} /{ }^{86} \mathrm{Sr}$ ratio and the $\mathrm{Rb} / \mathrm{Sr}$ ratio in the granitic mineral samples were plotted in the $\mathrm{Rb} / \mathrm{Sr}$ isochron diagram (Figure 4.3-6). All of the biotite samples indicate high radiogenic 
compositions relative to the feldspar mineral. Conversely, some results of our granite analysis indicate significantly low $\mathrm{Rb}$ content in biotite and low $\mathrm{Sr}$ content in feldspar, for instance, CM-03 and CM-16-2. Additionally, CM-04, the ${ }^{87} \mathrm{Sr} /{ }^{86} \mathrm{Sr}$ ratio and the $\mathrm{Rb} / \mathrm{Sr}$ ratio in the biotite are not radically different than these from feldspar. Theoretically, the mineral crystallization and decay processes are responsible for the significant amount of $\mathrm{Rb}$ and $\mathrm{Sr}$ content in each mineral. Mica minerals (biotite and muscovite) have higher $\mathrm{Rb} / \mathrm{Sr}$ and ${ }^{87} \mathrm{Sr} /{ }^{86} \mathrm{Sr}$ ratios compared to feldspar minerals (plagioclase and potassium feldspars). The alteration minerals in this area, which demonstrated chlorite, and sericite in the thin-section results, may change the rock geochemistry.

During chloritization, the biotite is broken down in the alteration zone and loses $\mathrm{K}-\mathrm{Rb}$ elements to the fluid, explained by Glodny and Grauert, (2009). Meanwhile, the plagioclase feldspar loses $\mathrm{Ca}-\mathrm{Sr}$ elements to the fluid during sericitization. Therefore, biotite minerals in the CM03, CM-16-2, and CM-04, which are indicated alteration minerals in the petrology results, show low $\mathrm{Rb} / \mathrm{Sr}$ ratios and low radiogenic compositions, while the CM-16-2 feldspar minerals show high $\mathrm{Rb} / \mathrm{Sr}$ ratios.

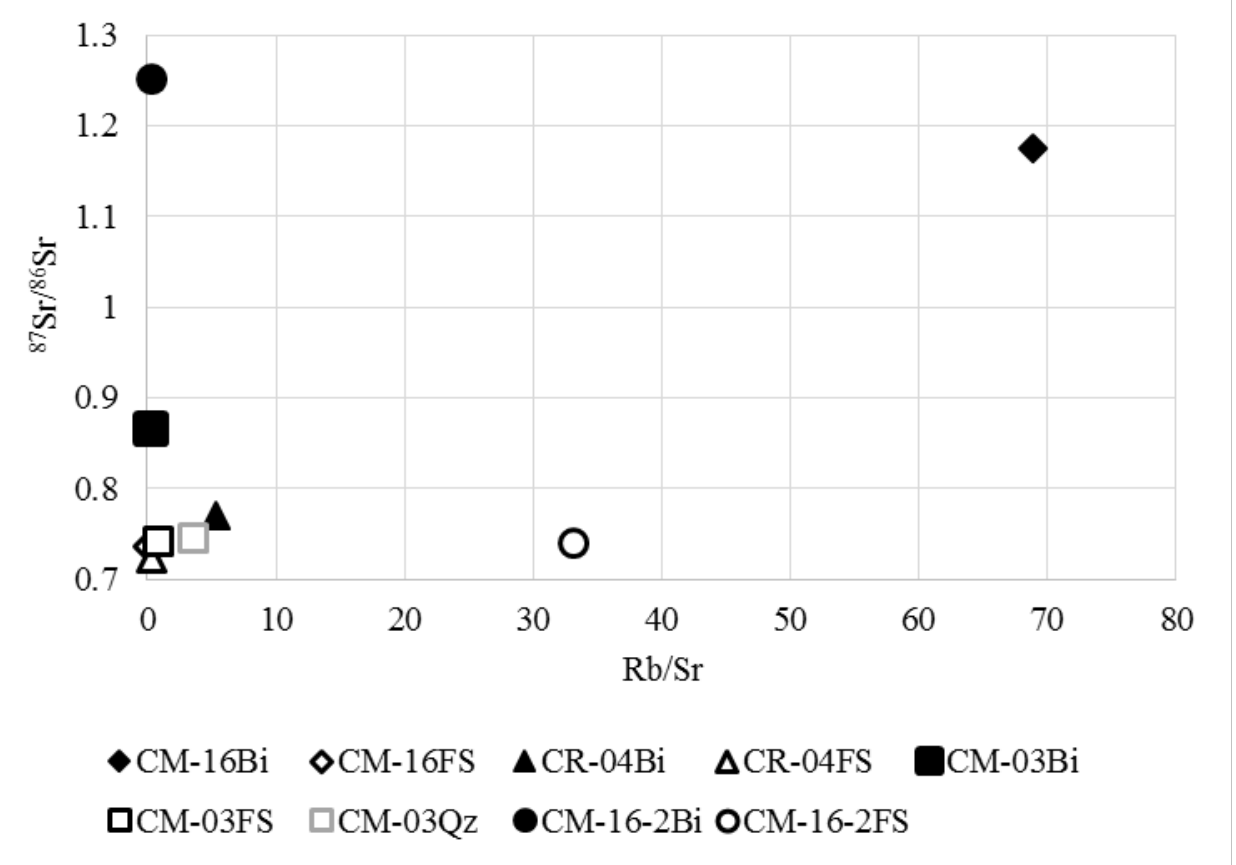

Figure 4.3-6: Strontium isotopic composition of surface granite samples in the Mae Chan geothermal area. 
4.3.3.4 The strontium isotopic ratio and concentration in the fluid phase.

Dissolved $\mathrm{Sr}$ in natural water is derived from different sources which are generally the atmospheric inputs and weathering products from minerals and rocks. Sr isotopic ratios can provide information on the origin of these solute sources within the water.

As aforementioned in the Chapter 3, the present study applies the mixing model from Wiegand, (2009) (Eq. (3.12)) and the granite dissolution model (Négrel et al., 2001; Petelet-Giraud et al., 2003) (Eq. (3.13)) to investigate the water-rock interaction. The calculating parameters and results of the granite dissolution model are shown in Table 4-13. For the reason that the granite cannot be sampled from every water sampling area, the calculation of the mixing model is computed from the most representative parent rock of thermal groundwater, as follows; The CM-03 rock sample represents the parent rock from CM-03 hot spring. The CM-16 rock sample represents the parent rock from CM-16 hot spring. The CR-04 rock sample represents the parent rock from CR-02, CR-03, CR-02, CR-08, and CR-04 hot springs. The mixing model results are shown in Table 4-14.

The mixing model regarding of $\mathrm{Sr}$ and ${ }^{87} \mathrm{Sr} /{ }^{86} \mathrm{Sr}$ ratio indicated that the dissolved $\mathrm{Sr}$ concentrations in thermal waters are mostly derived from rock ranging from 73.11 to $86.31 \%$, are plotted by local against geological map (Figure 4.3-7). The percent of Sr with rock origin can be explained by the distance between the fault core and the hot springs. Mitchell and Faulkner, (2012) show that long-distance results in low porosity of granite rock, for example, low water storage in the granite rock. CR-02, CR-03, and CR-08 are located at a far distance from the fault core, compared to CM-03, CM-16, and CR-04. Therefore, the influence of dissolved Sr from rock contribution in CR-02, CR-03, and CR-08 (82.50 to 86.31\%) is higher than that in CM-03, CM-16, and CR-04 (73.11 to 75.10\%). 
Table 4-13: $\mathrm{Sr}$, and ${ }^{87} \mathrm{Sr} /{ }^{86} \mathrm{Sr}$ ratio dissolution results of the rock samples from the dissolution model (Négrel et al., 2001) in Mae Chan geothermal area.

\begin{tabular}{|c|c|c|c|c|c|c|c|}
\hline Location & Rock samples & $\begin{array}{l}\text { Type of } \\
\text { Mineral }\end{array}$ & ${ }^{87} \mathrm{Sr} /{ }^{86} \mathrm{Sr}$ & $\begin{array}{c}\mathrm{Sr} \\
\mathrm{mg} / \mathrm{kg}\end{array}$ & $\begin{array}{c}\text { minerals } \\
\text { composition }\end{array}$ & $\begin{array}{c}\text { Model } \\
\mathrm{Sr} \\
\mathrm{mg} / \mathrm{kg}\end{array}$ & $\begin{array}{c}\text { Model } \\
{ }^{87} \mathrm{Sr} /{ }^{86} \mathrm{Sr}\end{array}$ \\
\hline \multirow{2}{*}{$\mathrm{CM}-16$} & \multirow{2}{*}{ CR-Malika } & $\mathrm{Bi}$ & 1.1747 & 22 & 10 & \multirow{2}{*}{101.1} & \multirow{2}{*}{0.7376} \\
\hline & & FS & 0.7364 & 695 & $30+30$ & & \\
\hline \multirow{2}{*}{ CM-16-2 } & \multirow{2}{*}{ CR-Malica-2 } & $\mathrm{Bi}$ & 1.2520 & 78 & 10 & \multirow{2}{*}{4.4} & \multirow{2}{*}{0.8533} \\
\hline & & FS & 0.7389 & 24 & $30+30$ & & \\
\hline \multirow{2}{*}{ CR-04 } & \multirow{2}{*}{$\begin{array}{c}\text { CR-Mae } \\
\text { Chan }\end{array}$} & $\mathrm{Bi}$ & 0.7710 & 63 & 5 & \multirow{2}{*}{123.6} & \multirow{2}{*}{0.7233} \\
\hline & & FS & 0.7230 & 1,063 & $45+25$ & & \\
\hline \multirow{3}{*}{ CM-03 } & \multirow{3}{*}{$\begin{array}{c}\text { CR-Huay } \\
\text { Mae Jai }\end{array}$} & $\mathrm{Bi}$ & 0.8659 & 169 & 5 & \multirow{3}{*}{68.5} & \multirow{3}{*}{0.7456} \\
\hline & & FS & 0.7418 & 549 & $40+25$ & & \\
\hline & & $\mathrm{Qz}$ & 0.7454 & 4 & 30 & & \\
\hline
\end{tabular}

$* \mathrm{FS}=$ Feldspar which are contained plagioclase and $\mathrm{K}$-feldspar, $\mathrm{Bi}=$ Biotite, and $\mathrm{Qz}=$ Quartz.

Table 4-14: Mixing model results of $\mathrm{Sr}$, and ${ }^{87} \mathrm{Sr} /{ }^{86} \mathrm{Sr}$ ratio in thermal water samples in Mae Chan geothermal area.

\begin{tabular}{lcccc}
\hline Location & ${ }^{87} \mathrm{Sr} /{ }^{86} \mathrm{Sr}$ & $\mathrm{Sr}$ & $\begin{array}{c}\mathrm{Sr} \text { from } \\
\text { rock } \\
\mu \mathrm{g} / \mathrm{l}\end{array}$ & $\begin{array}{c}\% \text { Sr from } \\
\text { rock } \\
\%\end{array}$ \\
\hline $\mathrm{CM}-03$ & 0.7197 & 50.26 & 37.08 & 73.79 \\
$\mathrm{CM}-16$ & 0.7364 & 46.67 & 35.05 & 75.10 \\
$\mathrm{CR}-02$ & 0.7278 & 64.99 & 53.61 & 82.50 \\
$\mathrm{CR}-03$ & 0.7275 & 68.44 & 57.05 & 83.36 \\
$\mathrm{CR}-08$ & 0.7179 & 90.97 & 78.52 & 86.31 \\
$\mathrm{CR}-04$ & 0.7258 & 43.27 & 31.63 & 73.11 \\
\hline
\end{tabular}




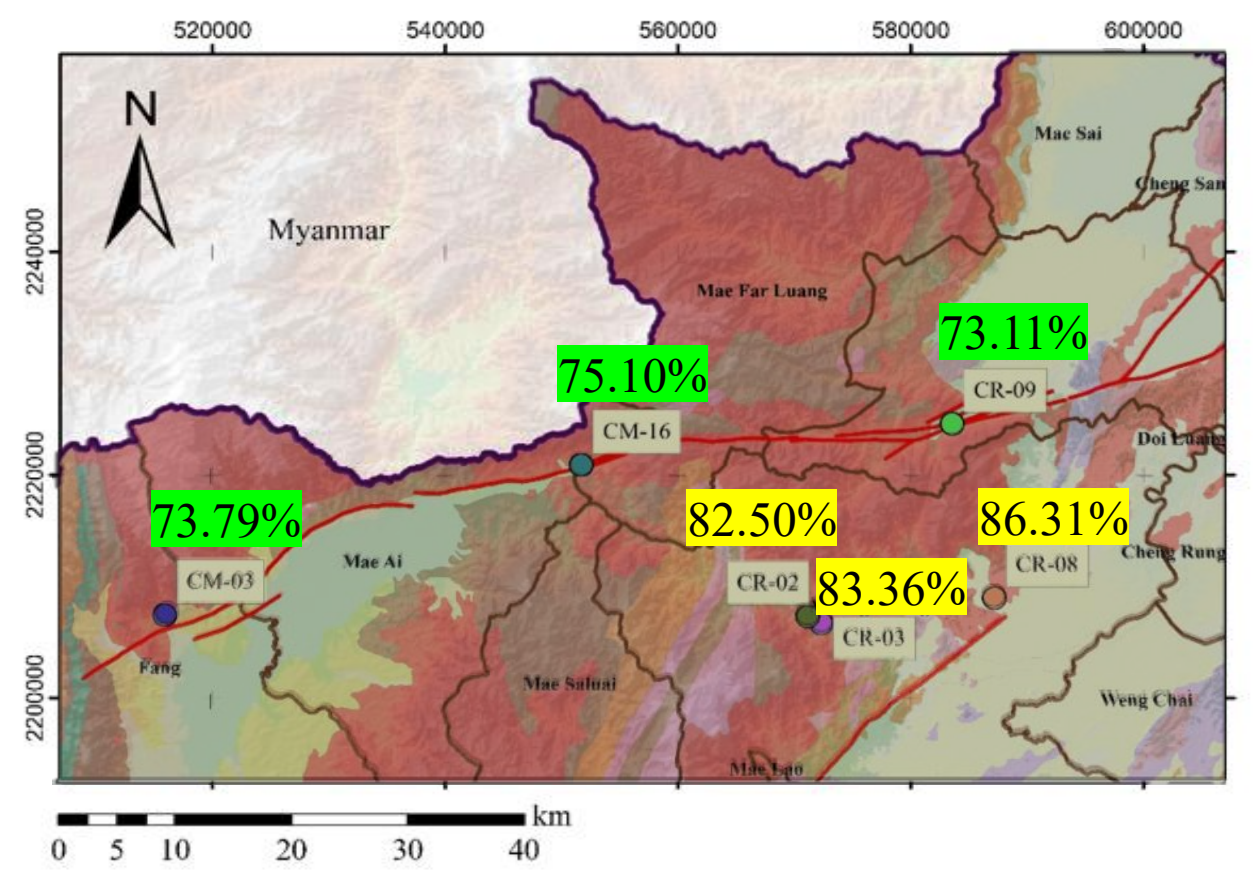

Figure 4.3-7: Spatial distribution of percent of Sr with rock origin in Mae Chan area, indicating that the hot springs are located close to the fault (CM-03, CM-16, and CR-04) have 73.11 to $75.10 \% \mathrm{Sr}$ with rock origin (Green background) while the hot springs are located far from the fault core (CR-02, CR-03, and CR-08) have 82.50 to $86.31 \%$ Sr with rock origin (Yellow background). 


\subsection{Discussion}

Geothermal fluids are generally controlled by the geological setting of the area and conduct with the surface hydrological system. Six hot springs in Mae Chan geothermal area manifest along the intrusive Triassic (?)-granite batholith, which is featured mountainous topography and commonly associated with the ENE-WSW-trending Mae Chan Fault. In general, geothermal fluids are controlled by physical boundary of the region, hence, the groundwater flow is marked by the elevation of the major watershed that obtained from a Digital Elevation Model (DEM) in ArcGIS v.10.3 (ESRI C), 1999-2018) from the ASTER 30 m resolution dataset (USGS Earth Explorer, 2017), shown in Figure 4.4-1.

The regional conceptual model can hydrologically explain the local flow direction that the precipitation accumulates and flows from the high mountainous area to the lower elevation. Moreover, the surface flow directions from each hot spring location are different reflecting different watershed.

The geochemical and isotopic composition results in Mae Chan thermal water are distinctively different from that of the surface water (in Chapter 4.2). The stable isotopic composition and $\mathrm{Cl}^{-}$concentration results can clearly suggest that the local precipitations are the main recharge source of thermal water and surface water without magmatic contact. However, the thermal water is recharged from the higher elevation compared with the surface water. Including, the chemical concentration, temperature, and EC in geothermal water are higher than that in the surface water. The thermal fluid obtains the chemical composition along the flow part that is described in the $\mathrm{Na}-\mathrm{HCO}_{3}$ type. Tritium and radiocarbon in thermal waters indicated that the residence time ranged from 12,760 to $18,000 \mathrm{BP}$. The wide range of $\delta^{13} \mathrm{C}$ data indicated that carbon in thermal water had (i) no external carbon contamination along the flow path, (ii) was mixed with local geologic gases, and biological carbon. After the water passes the local permeable rock to the thermal system, total REE concentrations are chemically reduced by increasing temperature and pressure. 


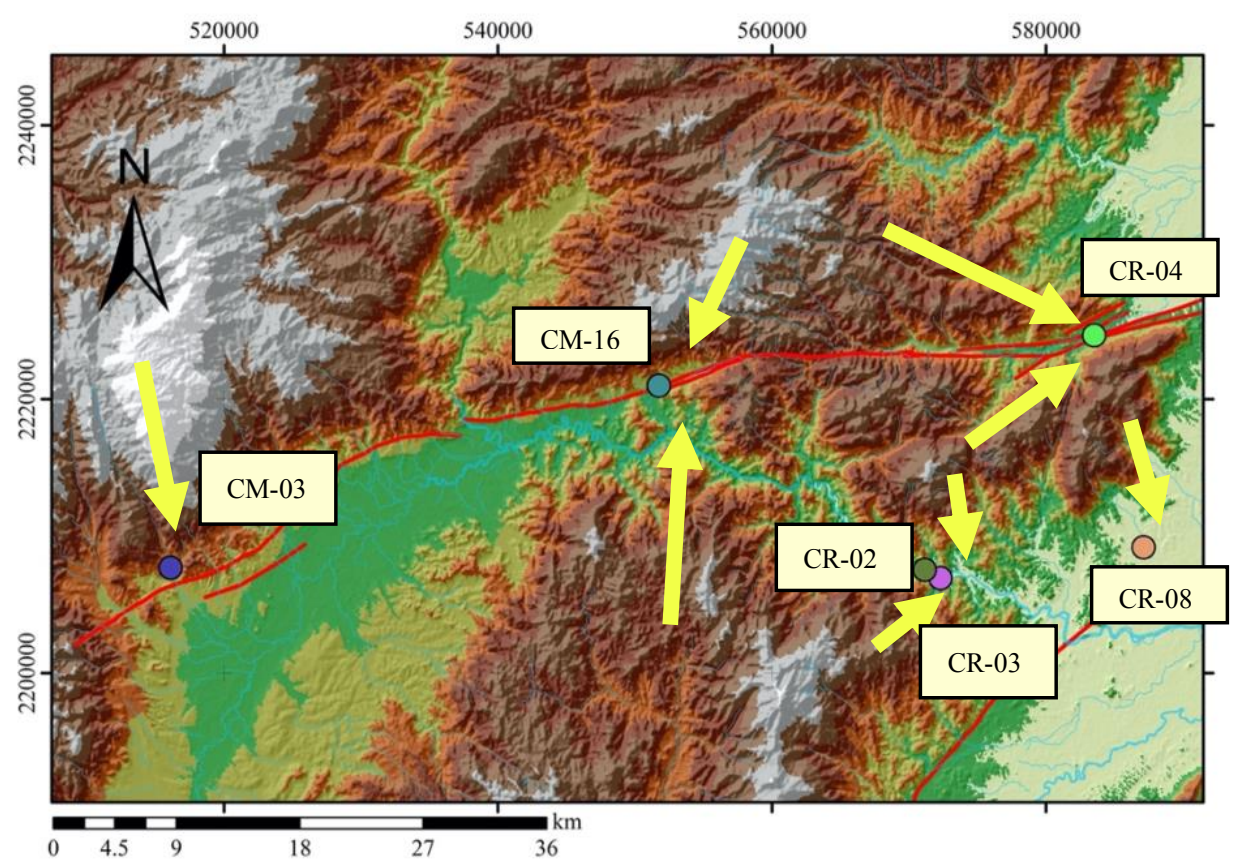

Figure 4.4-1: Topographic map along with sample location point and faults line of the study area. The yellow arrows represent the surface flow direction of each area.

Thermal water in different areas shown a close range of chemical concentration and isotopic composition. However, the characterization and evaluation of hydrochemistry indicated that the amount of precipitation infiltrates from faults and fractures of the granite with the recharge elevations between 740 and 1,200 m AMSL into the underground. This is in agreement with the elevation of the area in the ASTER 30 m resolution dataset (USGS Earth Explorer, 2017).

Based on drilling information and $\mathrm{Mg} / \mathrm{k}$ geothermometer, the fluid is trapped and heated at the reservoir depth between 353 and $814 \mathrm{~m}$ (-405 to $150 \mathrm{~m} \mathrm{AMSL}$ ) before ascending to the surface. This reservoir depth is in agreement with the earlier Magnetotelluric (MT) results (Amatyakul et al., 2016, 2015) interpreted that the pressurized hot fluid in Fang and Mae Chan hot springs derived from the fractures in the damage zone of the fault at depths of up to $500 \mathrm{~m}$. Moreover, the possible heat source in these areas is originated from the batholith granite lying beneath, however, the depth and location from the Mae Chan fault line are different, Fang located in the northwest of the faults at 2,000 $\mathrm{m}$ depth and Mae Chan located in the southwest of the faults at 1,000 m depth. Moreover, the Sr mixing model provided that the hot springs closed to the fault, had $73.11 \%$ to $75.10 \% \mathrm{Sr}$ from the rock, while the hot springs located far from the fault core had 82.50 to $86.31 \% \mathrm{Sr}$ from the rock. Therefore, these hot springs can explain by total six reservoirs, rather by single, large scale reservoirs. 
For more specific interpretation, five conceptual models in these geothermal hot springs are established by considering the surface flow direction from the topographic map, the previous geophysical investigation, and our results, 1) CM-03, 2) CR-04, 3) CM-16, 4) CR-02 and CR03

Remarkably, the topographic map is created from a Digital Elevation Model (DEM) using the ASTER 30 m resolution dataset (USGS Earth Explorer, 2017) on top of the online topographic layer which was embedded in ArcGIS v.10.3 (ESRI C), 1999-2018).

1) Fang hot spring (CM-03)

The CM-03 hot spring is located in $1 \mathrm{~km}$ north of the Mae Chan fault zone. The previous investigations (Amatyakul et al., 2016; Wood et al., 2018) indicated that the hot spring area conducts with the two local faults and two conductivity zone, shown in Figure 4.4-2(a). The local faults structures are N-NW trending Mae Jai fault and low-angle detachment Doi kai fault. The hot springs conducted with the shallow zone $(<50 \mathrm{~m})$ interpreted as impermeable clay zone, and the surface to a depth of $500 \mathrm{~m}$ interpreted as the pore of sedimentary rock and altered granite fracture. This deeper zone is in good agreement with our reservoir depth estimation which obtained 400 to $750 \mathrm{~m}$ depth. Therefore, these results and the topographic of CM-03 can suggest that surface flow is directed towards the high mountainous area in the north to the lower elevation in the south (Figure 4.4-2(a)). The precipitation water infiltered from the granitic fracture at the high mountainous area (1,200 m AMSL) in the north of the Mae Chan fault. The water flows through the fractured and weathered granite and the sedimentary rock at the 400 to $750 \mathrm{~m}$ depth of geothermal reservoir (150 m to $-200 \mathrm{~m}$ AMSL). The heat source of the system heated the fluid from 108 to $135{ }^{\circ} \mathrm{C}$. The thermal fluid rises from reservoir depth (400 to $750 \mathrm{~m}$ depth) to the shallow zone $(<50 \mathrm{~m})$ by Mae Jai fault and Doi kai fault. The travel time period is more than $60 \mathrm{BP}$. The thermal fluid obtains the chemical composition along the flow part that is described in the $\mathrm{Na}-\mathrm{HCO}_{3}$ type. The conceptual model of CM-03 hot spring shown in Figure 4.4-2(b).

In addition, the reservoir water in this area (RV-CM03), located lower elevation comparing with $\mathrm{CM}-03$, have a low strontium isotopic ratio with high $\mathrm{Sr}$ concentration. Moreover, the stable isotope composition indicate a high evaporation effect in the pre-monsoon seasons, these would be implied that the reservoir water probably derived from the mixing process between CM-03 thermal water and rainwater then evaporated to increased $\mathrm{Sr}$ composition. This case 
applied binary a mixing model to identify the primary $\mathrm{Sr}$ concentration before evaporation. The primary $\mathrm{Sr}$ concentration is $53.78 \mathrm{ug} / 1$ and has been evaporated to 3.46 times.

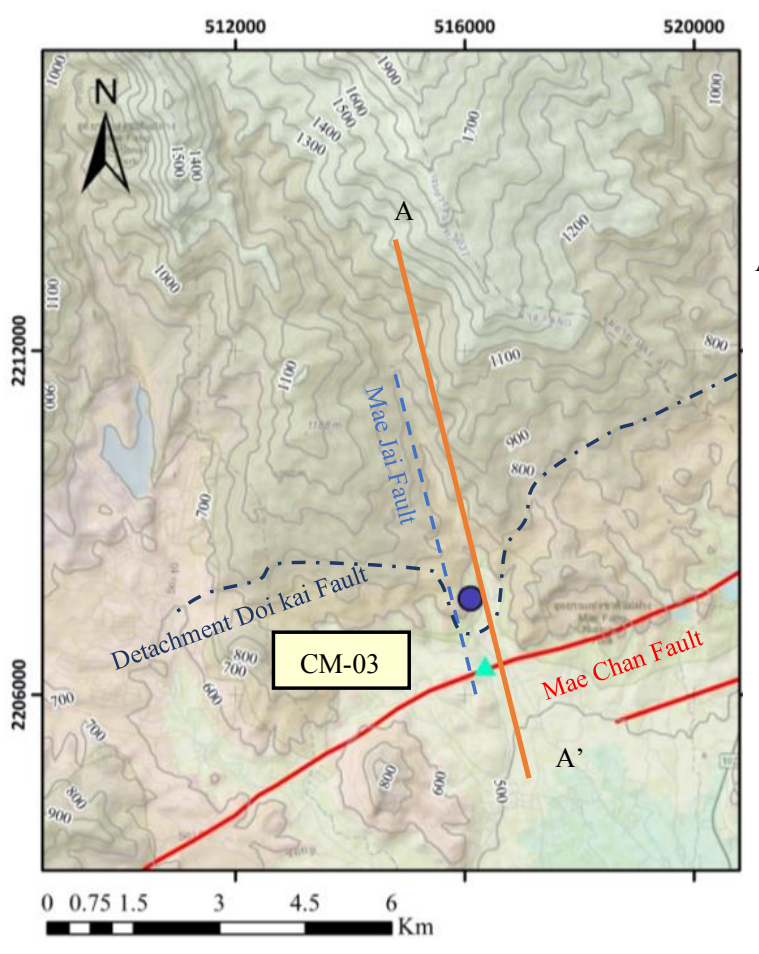

(a)

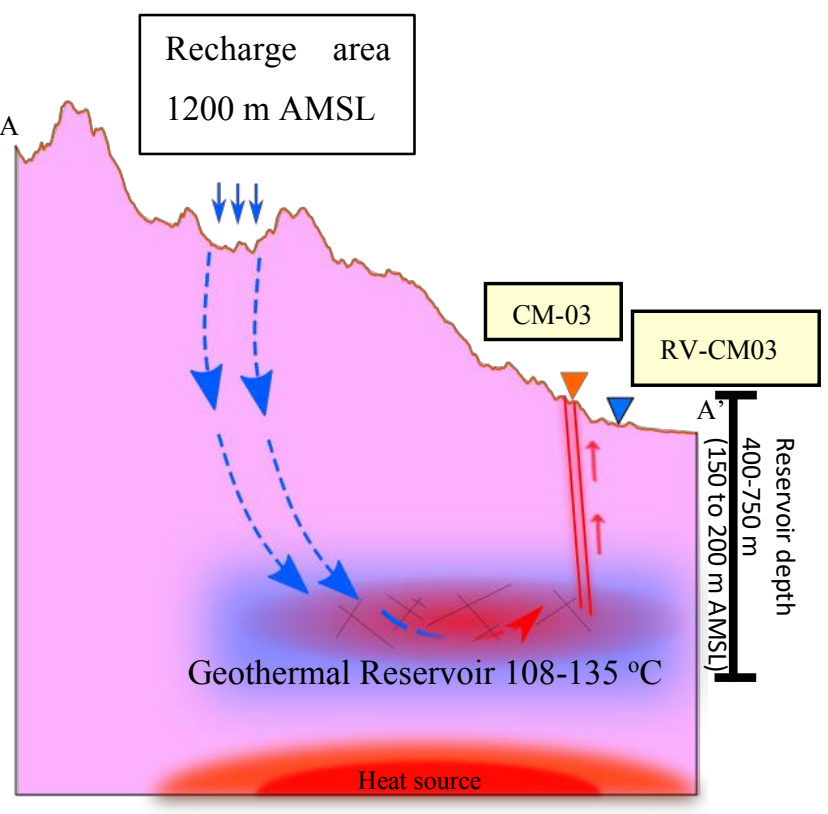

(b)

Figure 4.4-: Topographic map with major and local faults structures (a) and conceptual model (b) of Fang hot spring (CM-03). The purple circle represents the water sample location. Detachment Doi Kai and Mae Jai faults drawn according to a recent survey (Amatyakul et al., 2016; Wood et al., 2018). The red line is the estimated orientation Mae Chan Fault. The orange line (cross-section line; A-A') represents the location of the conceptual model generated from our geochemical and isotopic investigation.

2) Mae Chan hot spring (CR-04)

The surface flow is directed towards the south and the north of the fault. As our reservoir depth estimation in CR-04 is in good agreement with the magnetotelluric survey in Mae Chan hydrothermal system from (Amatyakul et al., 2015) that the surface hot fluid is ascended from the storage identified by two conductivity zone at 250 depth and $500 \mathrm{~m}$ depth. These conductivity zones are located in the north-west direction from Mae Chan fault, while the high resistivity zone of deeper granitic batholith located in the south of the fault (Figure 4.4-3. (a)). Based on these and our results can suggest that the precipitation water infiltered from the high mountainous area (750-950 m AMSL) in the north-west of the faults to the 460 to $600 \mathrm{~m}$ depth 
of geothermal reservoir (-22.76 to $-165.06 \mathrm{~m}$ AMSL) which comprised of fractured and weathered granite and the sedimentary rock. The heat source of the system should be from the great depth of the granitic batholith in the south of the map and warmed the fluid to 127 to 137 ${ }^{\circ} \mathrm{C}$. Then, the thermal fluid rises up to the surface along the fault's core direction which has the travel time period more than $60 \mathrm{BP}$. The thermal fluid obtains the chemical composition along the flow part that is described in the $\mathrm{Na}-\mathrm{HCO}_{3}$ type. The conceptual model of CR-04 hot spring shown in Figure 4.4-3 (b).

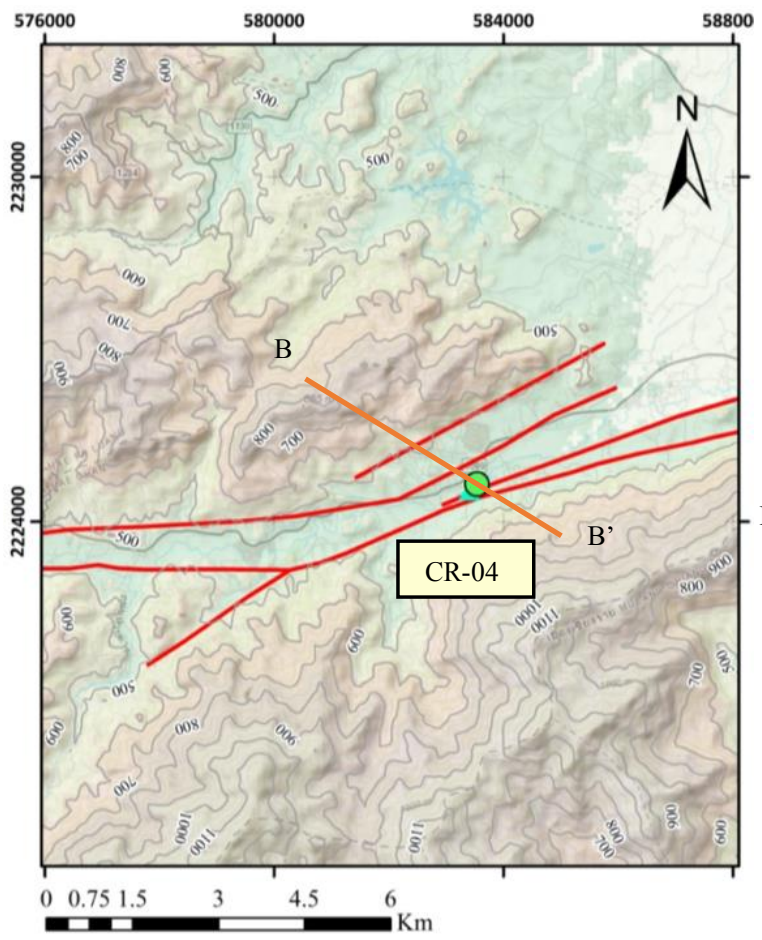

(a)

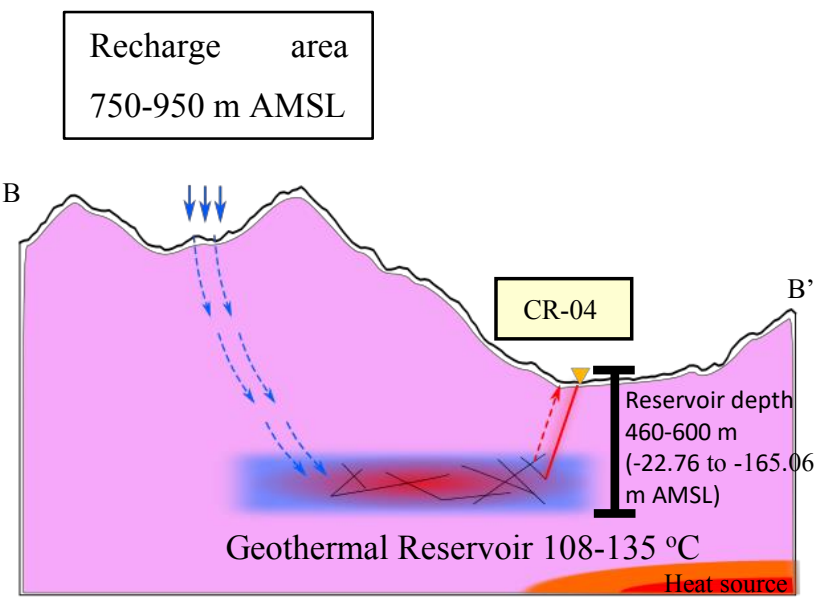

(b)

Figure 4.4-2: Topographic map with major and local faults structures (a) and conceptual model (b) of Mae Chan hot spring (CR-04). The green circle represents the water sample location. The red line is the estimated orientation of Mae Chan fault. The orange line (cross-section line; B-B') represents the location of the conceptual model generated from our geochemical and isotopic investigation.

3) Mullika hot spring (CM-16)

The topographic of CM-16 indicates that surface flow is directed towards the high mountainous area in the north to the lower elevation of the fault line (Figure 4.4-4. (a)). The hydro-chemical and isotope results demonstrate that the precipitation water infiltered from the high mountainous area (1050 m AMSL) in the north of the fault to the 350 to $450 \mathrm{~m}$ depth of the 
geothermal reservoir (12 to $121 \mathrm{~m} \mathrm{AMSL).} \mathrm{The} \mathrm{heat} \mathrm{source} \mathrm{of} \mathrm{the} \mathrm{system} \mathrm{should} \mathrm{be} \mathrm{from} \mathrm{the}$ great depth of the granitic batholith in the south of the map and heat the fluid to 98 to $100{ }^{\circ} \mathrm{C}$. Then, the thermal fluid rises up to the surface along the fault's core direction which has the travel time period more than $60 \mathrm{BP}$. The thermal fluid obtains the chemical composition along the flow part that is described in the $\mathrm{Na}-\mathrm{HCO}_{3}$ type. The conceptual model of CM-16 hot spring shown in Figure 4.4-4. (a).

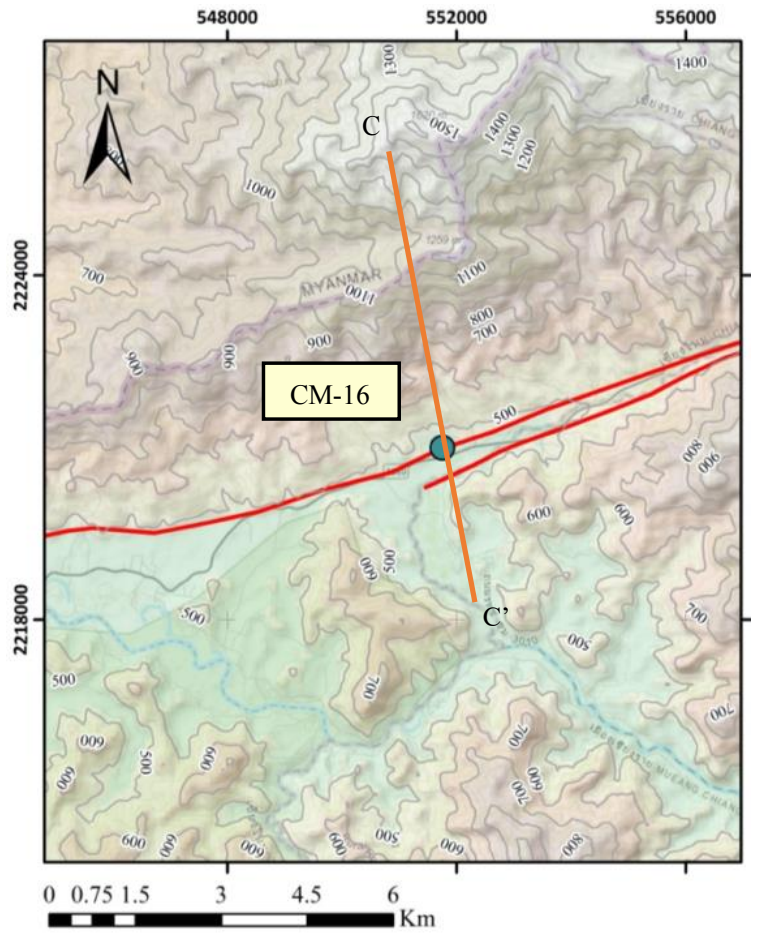

(a)

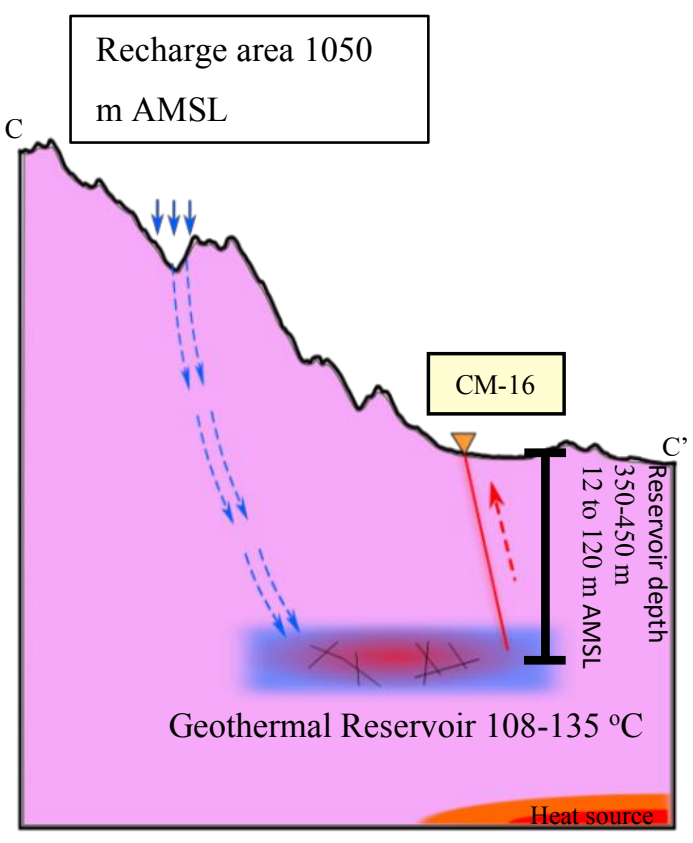

(b)

Figure 4.4-3: Topographic map with major and local faults structures (a) and conceptual model (b) of Mullika hot spring (CM-16). The green circle represents the water sample location. The red line is the estimated orientation Mae Chan fault. The orange line (cross-section line; C-C') represents the location of the conceptual model generated from our geochemical and isotopic investigation.

4) Huy Mark lieum hot spring (CR-02) and Pha Soet hot spring (CR-03) hot springs

These hot springs are geologically located in the same location, shown in Figure 4.4-5. (a). However, the stable isotope and geothermometer results from these hot springs provide different ranges suggesting that these hot springs ascend from different systems. The conceptual model of CR-02 and CR-03 hot springs shown in Figure 4.4-5 (b) and explain below. 
The topographic of CR-02 indicates that surface flow is directed towards the high mountainous area in the north to the lower elevation in the south. The hydro-chemical and isotope results can suggest that the precipitation water infiltered from the high mountainous area (740 to 750 $\mathrm{m}$ AMSL) and infiltered towards a geothermal reservoir at 737 to $814 \mathrm{~m}$ depth (-335.5 to 404.7 $\mathrm{m}$ AMSL). The heat source of the system heated the fluid to $112{ }^{\circ} \mathrm{C}$. Then, the thermal fluid rises up to the surface along the fault or fracture direction which has the travel time period $12,760 \mathrm{BP}$. The thermal fluid obtains the chemical composition along the flow part that is described in the $\mathrm{Na}-\mathrm{HCO}_{3}$ type.

The topographic of CR-03 indicates that surface flow is directed towards from the high mountainous area in the south to the lower elevation in the north. The hydro-chemical and isotope results interpreted that the precipitation water infiltered from the high mountainous area (890 to $940 \mathrm{~m} \mathrm{AMSL}$ ) and infiltered towards the geothermal reservoir at 387 to $638 \mathrm{~m}$ depth (26 to $-225 \mathrm{~m}$ AMSL). The heat source of the system heated the fluid to $105-123{ }^{\circ} \mathrm{C}$. Then, the thermal fluid rises up to the surface along the fault or fracture direction which has the travel time period more than $60 \mathrm{BP}$. The thermal fluid obtains the chemical composition along the flow part that is described in the $\mathrm{Na}-\mathrm{HCO}_{3}$ type.

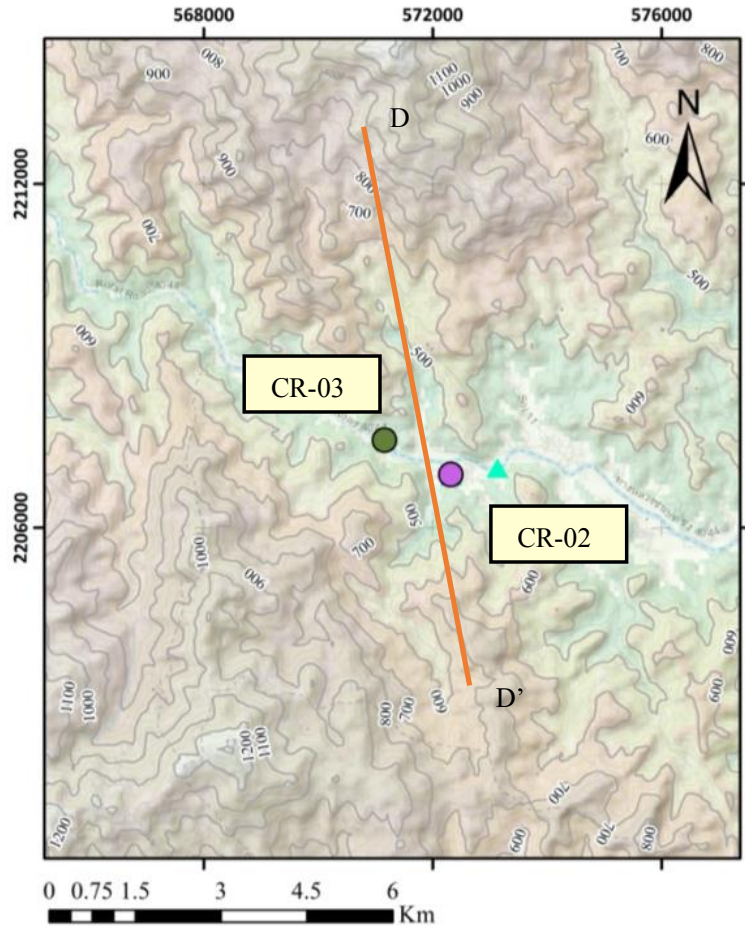

(a)

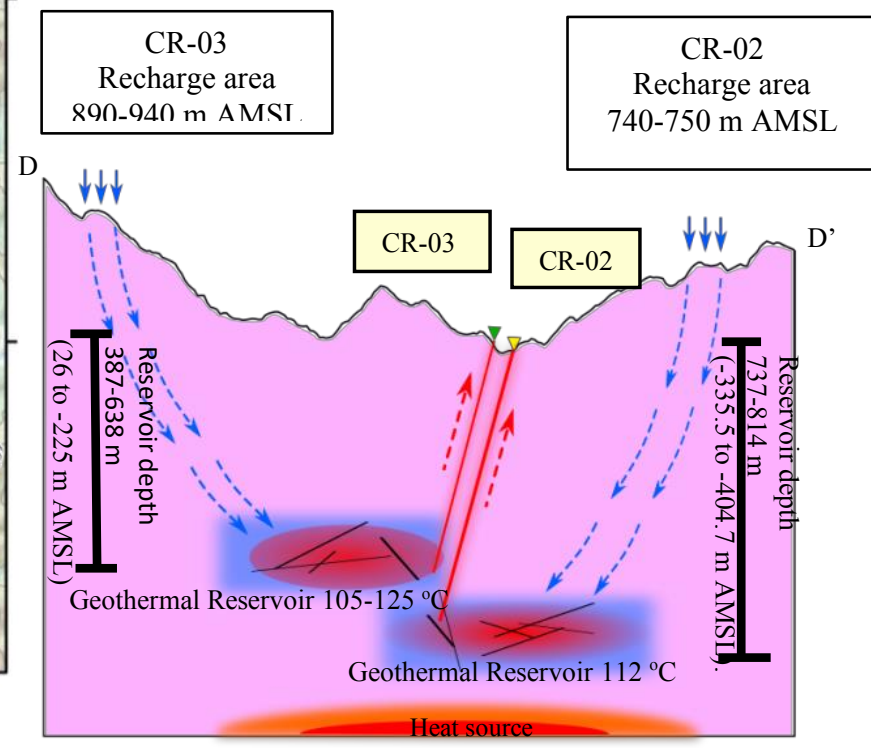

(b)

Figure 4.4-4: Topographic map with major and local faults structures (a) and conceptual model (b) of Huy Mark lieum (CR-02) and Pha Soet (CR-03) hot springs. The green and purple circles 
represent the water sample locations from CR-02 and CR-03, respectively. The orange line (cross-section line; D-D') represents the location of the conceptual model generated from our geochemical and isotopic investigation.

\section{5) CR-08}

The topographic of CR-08 indicates that surface flow is directed towards the high mountainous area in the north-west to the lower elevation in the south-east Figure 4.4-6 (a). The hydrochemical and isotope results can suggest that the precipitation water infiltered from the high mountainous area (800 m AMSL) and infiltered towards the geothermal reservoir at 642 to 796 $\mathrm{m}$ depth (-243 to $-397 \mathrm{~m}$ AMSL). The heat source of the system heated the fluid to $105{ }^{\circ} \mathrm{C}$. Then, the thermal fluid rises up to the surface along the fault or fracture of the local granite, and manifest to the alluvium deposit which has a travel time period 18,120 BP. The thermal fluid obtains the chemical composition along the flow part that is described in the $\mathrm{Na}-\mathrm{HCO}_{3}$ type. The conceptual model of CR-08 hot spring shown in Figure 4.4-6 (b).

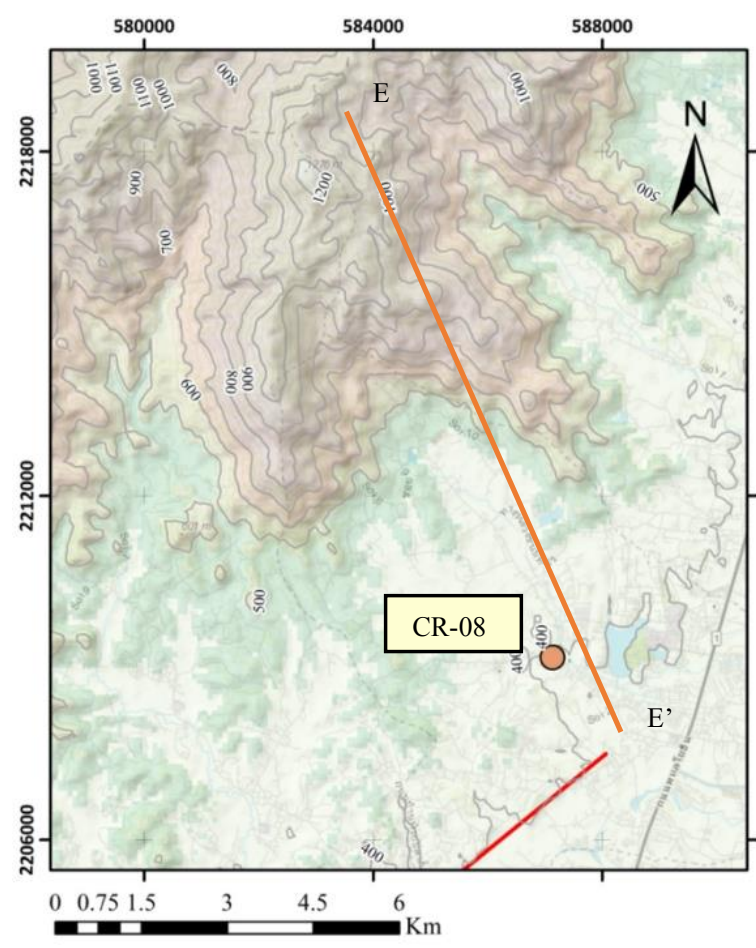

(a)

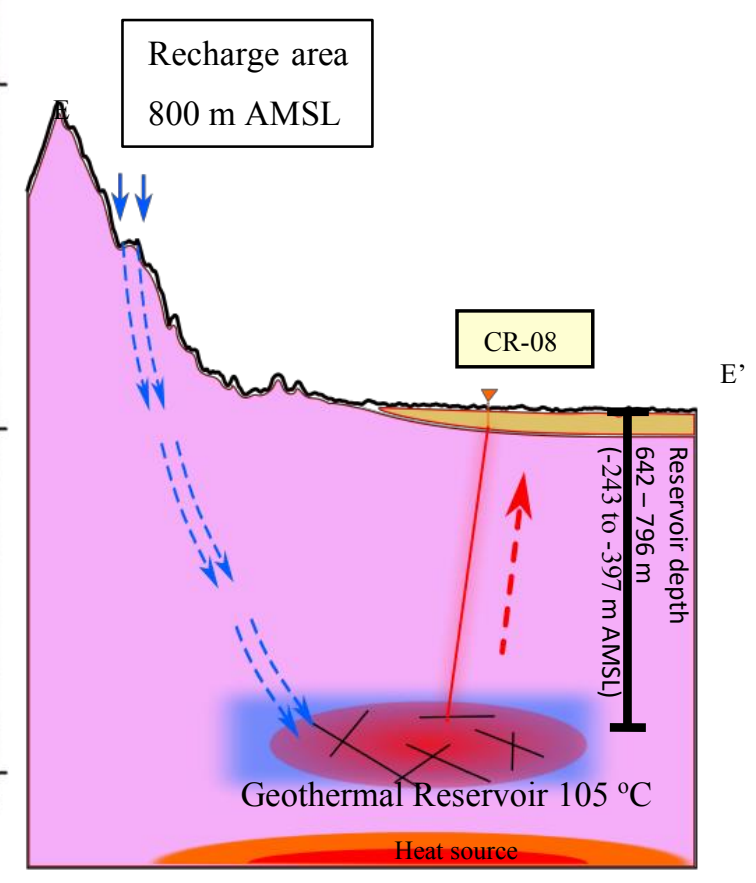

(b)

Figure 4.4-5: Topographic map with major and local faults structures (a) and conceptual model (b) of Mullika hot spring (CM-16). The orange circle represents the water sample location. The orange line (cross-section line; E-E') represents the location of the conceptual model (b) generated from our geochemical and isotopic investigation. 


\subsection{Conclusion}

The NE-SW Mae Chan fault in the northern part of the country manifests two among five highest potential hot springs in Thailand. These hot springs have been continuously investigated and successfully installed the geothermal utilization facility. One the other hand, there have been few published investigations of low enthalpy (low temperature) hot springs along the Mae Chan fault.

The integration of hydro-geochemical concentration together with the isotope composition of the thermal water provides valuable information about the meteoric origin, chemical processes, travel time, geothermal reservoir, and water-rock interaction. These can help to evaluate and understand the granitic hydrothermal system of the Mae Chan area in the northern part of Thailand.

-Measured stable isotopic ratios $\left(\delta^{2} \mathrm{H}\right.$ and $\left.\delta^{18} \mathrm{O}\right)$ of thermal water from the pre- and post-monsoon seasons point out a shallow-circulating meteoric origin and recharge from the high elevation of the mountainous area ranging from 740 to $1200 \mathrm{~m}$ AMSL. Moreover, $\delta^{18} \mathrm{O}-$ shifted of thermal water varies under seasonal change.

-The chemical composition of the thermal water is characterized as $\mathrm{Na}-\mathrm{HCO}_{3}$ type and is derived from the plagioclase (Na-feldspar) dissolution of the local batholith granite together with the precipitation of $\mathrm{Ca}^{2+}$ and $\mathrm{Mg}^{2+}$ in the secondary minerals or sinter minerals (e.g. carbonates, gypsum, or siliceous sinter). The $\mathrm{Cl}^{-}$is derived from precipitation.

-The conservative tracer tritium indicated that the surface water samples are in agreement with modern precipitation in Thailand, while thermal water samples have an undetectable amount of tritium. This can state that the travel time of the thermal water is longer than $60 \mathrm{BP}$.

-The $\delta^{13} \mathrm{C}$ results that $\mathrm{HCO}_{3}{ }^{-}$in the surface water probably derived from subsurface flow, was associated with the carbon isotope fractionation between dissolved organic soil gas $\left(\mathrm{CO}_{2 \text { (g-soil) }}\right)$ and bicarbonate $\left(\mathrm{HCO}_{3}{ }^{-}\right)$during equilibrium conditions. The wide range of $\delta^{13} \mathrm{C}$ ratio in the discharged thermal waters were divided into three different types of carbon sources by considering the $\delta^{13} \mathrm{C}$ from surface water as an input function of the thermal water. The first group is characterized by an initial $\delta^{13} \mathrm{C}$ that remains stable without external carbon contamination along the flow path. The radiocarbon ages in this group refer to the water residence time. In the second group, the $\delta^{13} \mathrm{C}$ of the discharged thermal water is more enriched 
than the initial $\delta^{13} \mathrm{C}$ and probably mixed with local geologic gases. Therefore, these calculated radiocarbon ages are longer than realistic residence times. The third group is characterized by a depleted discharged thermal water $\delta^{13} \mathrm{C}$ value compared to the initial $\delta^{13} \mathrm{C}$. This group probably mixed with biological carbon. The most depleted $\delta^{13} \mathrm{C}$ ratio (from sample $\mathrm{CM}-16$ ) has been interpreted as the result of methane oxidation by sulfate reduction.

-The ${ }^{14} \mathrm{C}$ dating provided long residence time periods. Based on the $\delta^{13} \mathrm{C}$ results, the first group (without external carbon contamination) demonstrates the residence time periods ranging from 12,760 to $18,000 \mathrm{BP}$. Two rest groups illustrate the evidence of contaminated carbon from geologic gases and from methane oxidation by sulfate reduction processes, therefore, the residence time periods of these groups are not reliable.

-The geothermometer application provides a different range of temperature results. The verification of the geothermometers application suggests that the thermal waters in Mae Chan geothermal area have not reached in equilibrium condition with host rock and/or mixed with cold water, and are reliable on the conservative $\mathrm{K}-\mathrm{Mg}$ and chalcedony subsystems, which state equilibrium temperatures ranging from 98 to $139^{\circ} \mathrm{C}$. The estimated reservoir depth is in the range between 353 and $814 \mathrm{~m}$ (-405 and $150 \mathrm{~m}$ AMSL). Moreover, if thermal water sample has been mixed with cold water in the silica-enthalpy mixing diagram, the geothermal reservoir would have high temperature approximately ranging from 129 to $168{ }^{\circ} \mathrm{C}$ and most of the samples have stream-loss during ascending to the surface and mixed with cool water from 35 to $81 \%$ by volume

-The water-rock interaction in the Mae Chan geothermal area is evaluated by applying the REE and strontium isotopic compositions in minerals of surface rock and thermal water.

-The petrology results indicate the mineral alteration, e.g., chloritization and the sericitization in the granitic rocks in Mae Chan.

-The REE concentration pattern results are generally accepted that REE in surface waters would be leached from the host rock. After the water passes the local permeable rock to the thermal system, total REE concentrations are chemically reduced by increasing temperature and pressure. The results illustrate markedly depleted LREE patterns (especially in $\mathrm{Pr}, \mathrm{Nd}$, and $\mathrm{Sm}$ elements) relative to HREE in high-thermal water samples $\left(>70^{\circ} \mathrm{C}\right)$, e.g., CM-03, and CR-03. Moreover, the results suggest that the fluoride concentration from the biotite and muscovite mineral dissolution predominantly control the precipitation processes of 
LREE-fluoride complex during flow path in this system. This contributes to the LREE depletion in thermal water.

-The mixing model regarding of $\mathrm{Sr}$ and ${ }^{87} \mathrm{Sr} /{ }^{86} \mathrm{Sr}$ ratio indicated that the $\mathrm{Sr}$ concentrations in thermal waters are mostly derived from rock ranging from 73.11 to $86.31 \%$. The hot springs are located close to the fault (CM-03, CM-16, and CR-04) have 73.11 to $75.10 \% \mathrm{Sr}$ with rock origin while the hot springs are located far from the fault core (CR-02, CR-03, and CR-08) have 82.50 to $86.31 \% \mathrm{Sr}$ with rock origin. These suggest that the porosity and permeability of the crystalline basement rock, which vary with the distance of the fault core from the hot springs, significantly control the amount of $\mathrm{Sr}$ in thermal water.

-Theses environment chemical and isotopic results in Mae Chan geothermal hot springs can establish five conceptual models by considering the surface flow direction from the topographic map, the previous geophysical investigation, and our results, for instance: 1) CM-03, 2) CR-04, 3) CM-16, 4) CR-02 and CR-03. 
Chapter 5 


\section{Characterization and evaluation of hydrochemistry, sources, and water-rock interaction in Ranong area.}

\subsection{Analytical result of rock and water.}

\subsubsection{Petrology}

The three granitic samples are prepared thin sections for polarization and transmitted microscopic analysis. The proportion of major minerals in each granite samples are estimated by evaluating the areas of visible major minerals in each thin section, shown in Appendix 2 and described as follows.

The first granite sample from Ban Hat Yay hot spring (RN-6) is a very coarse-grained granite, composed dominantly of quartz (approximately 25-30\%), alkali feldspar (approximately 40\%), and plagioclase (approximately 15\%), together with subordinate biotite (5\%) (Figure 9.2-5 in Appendix 2). It compositionally resembles the porphyritic biotite granite of Khlong Ngao granite (Kgr-ng) (Kusuwan and Nakapadungrat, 1992). However, the alteration minerals are displayed as completely chloritized of biotite and minor sericitized of plagioclase.

The second granite sample from Raksawarin hot springs ( $\mathrm{RN}-1)$ is a fine-grained granite, composed dominantly of deformed quartz (approximately 40\%), alkali feldspar (approximately $35 \%$ ), and plagioclase (approximately 15\%) with subordinate muscovite (approximately 5\%) (Figure 9.2-6 in Appendix 2). Accessory phases include altered amphibole and small zircon grains. The feldspar shows the signs of alteration that is often incipient but, sometimes progressed. The muscovite sometime formed veins (fine-grained sericite) or euhedral grains. It compositionally resembles Khlong Ban Rin granite (Kgr-br).

The third granite sample exposed near the Ratchagrude hot spring (RN-5) at the Heo lom waterfall, is relatively coarse-grained granite or granitic gneiss dominantly composed of quartz, alkali feldspar, and plagioclase with subordinate biotite (Figure 9.2-7 in Appendix 2). Large feldspar (plagioclase and some alkali feldspars) and quartz crystals are embedded in an oriented matrix of fine-grained polycrystalline quartz. Biotite crystals are elongated and oriented as well. Deformation and incipient chloritization are omnipresent. Some muscovite veinlets are present. It likely correlates with Khlong Ban Rin granite (Kgr-br) or Khlong Ngao granite (Kgr-ng). 


\subsubsection{Rare earth elements in minerals.}

REE compositional of the separated minerals in all three Ranong granite samples are given in Table 5-1. The RREE contents of feldspar mineral in the Ranong granite range between 46.04 and $212.97 \mathrm{mg} / \mathrm{kg}$. The lowest $\Sigma$ REE content of feldspar is found in the RN5 samples (46.04 $\mathrm{mg} / \mathrm{kg}$ ). The biotite minerals indicate the highest $\Sigma$ REE content of 3,355.2 mg/kg. All samples are relatively enriched in LREE, resulting in a LREE/HREE ratio of more than 10. The highest LREE/HREE ratio presents in RN5 (21.8).

The REE contents in these minerals are normalized to the composition of chondrite (McDonough and Sun, 1995) and are plotted compared to the REE of the whole fresh granite from Haad Som Paenn, Ranong tin field (Imai et al., 2013) in Figure 5.1-1. Most of the separated mineral samples are enriched in LREE relative to the HREE with negative Eu anomalies. In contrast, the RN5 sample shows the higher slope pattern with a positive Europium (Eu) anomaly.

Most of the separated mineral samples shown similar negative $\mathrm{Eu}$ and $\mathrm{Ce}$ anomalies with $\mathrm{Ce} / \mathrm{Ce}^{*}$ values ranging from 1.3 to 1.4 and $\mathrm{Eu} / \mathrm{Eu}^{*}$ values ranging from 0.03 to 0.44 . In contrast, RN5 had a positive Eu anomaly (6.07) and slightly a negative Ce anomaly (2.0).

\subsubsection{Rb-Sr concentration of the minerals.}

The $\mathrm{Rb}$ concentrations, $\mathrm{Sr}$ concentrations, $\mathrm{Rb} / \mathrm{Sr}$ ratios and ${ }^{87} \mathrm{Sr} /{ }^{86} \mathrm{Sr}$ ratios in each separated mineral of three bedrocks were analyzed (Table 5-2). The $\mathrm{Sr}$ isotopic ratios range between 0.7601 and 0.8737 for feldspar and 0.7782 for biotite. The $\mathrm{Rb}$ concentrations range between 355 and $1,334 \mathrm{mg} / \mathrm{kg}$ for feldspar and $39 \mathrm{mg} / \mathrm{kg}$ for biotite. The $\mathrm{Sr}$ concentrations range between 5 and $78 \mathrm{mg} / \mathrm{kg}$ for feldspar and $532 \mathrm{mg} / \mathrm{kg}$ for biotite. The $\mathrm{Rb} / \mathrm{Sr}$ ratios range between 14.58 and $74.90 \mathrm{mg} / \mathrm{kg}$ for feldspar and $0.07 \mathrm{mg} / \mathrm{kg}$ for biotite. The ${ }^{87} \mathrm{Sr} /{ }^{86} \mathrm{Sr}$ ratio of the biotite in the Ban Hat Yay hot spring sample is similar to the feldspar within the same sample, however, the $\mathrm{Rb}$ concentration is higher in the feldspar more than in the biotite. 
Table 5-1: Rare earth element in the rock samples in Ranong geothermal area.

\begin{tabular}{|c|c|c|c|c|c|}
\hline \multirow{3}{*}{$\begin{array}{l}\text { Sample } \\
\text { Rock Sample } \\
\text { Type of Mineral }\end{array}$} & & \multirow{3}{*}{$\begin{array}{c}\text { RN5 } \\
\text { Heo Lom } \\
\text { waterfall } \\
\text { FS* }\end{array}$} & \multicolumn{2}{|c|}{ RN6 } & \multirow{3}{*}{$\begin{array}{c}\text { RN1 } \\
\text { Raksawarin } \\
\text { River } \\
\text { FS }\end{array}$} \\
\hline & & & \multicolumn{2}{|c|}{ Ban Hat Yay hot spring } & \\
\hline & & & $\mathrm{Bi}^{*}$ & FS & \\
\hline $\mathrm{La}$ & & 11.8 & 682.4 & 25.2 & 42.5 \\
\hline $\mathrm{Ce}$ & & 19.0 & 1481.0 & 51.1 & 93.8 \\
\hline $\mathrm{Pr}$ & & 1.9 & 163.7 & 5.2 & 10.8 \\
\hline $\mathrm{Nd}$ & & 6.4 & 547.8 & 16.8 & 36.3 \\
\hline $\mathrm{Sm}$ & & 1.2 & 107.5 & 4.0 & 9.1 \\
\hline $\mathrm{Eu}$ & & 2.5 & 1.1 & 0.5 & 0.1 \\
\hline $\mathrm{Gd}$ & $\stackrel{00}{*}$ & 1.3 & 112.9 & 3.1 & 6.4 \\
\hline $\mathrm{Tb}$ & $\stackrel{60}{\Xi}$ & 0.2 & 18.3 & 0.7 & 1.1 \\
\hline Dy & & 1.0 & 104.6 & 4.0 & 6.0 \\
\hline Но & & 0.2 & 17.8 & 0.7 & 0.9 \\
\hline Er & & 0.4 & 48.8 & 1.9 & 2.3 \\
\hline $\mathrm{Tm}$ & & 0.0 & 7.5 & 0.3 & 0.4 \\
\hline $\mathrm{Yb}$ & & 0.2 & 54.5 & 2.0 & 2.9 \\
\hline $\mathrm{Lu}$ & & 0.0 & 7.3 & 0.3 & 0.4 \\
\hline$\Sigma$ REE & & 46.04 & $3,355.2$ & 115.8 & 212.97 \\
\hline LREE & & 44.0 & $3,096.4$ & 106.0 & 199.0 \\
\hline HREE & & 2.0 & 258.7 & 9.8 & 14.0 \\
\hline LREE/HREE & & 21.8 & 12.0 & 10.8 & 14.2 \\
\hline$\left(\mathrm{Eu} / \mathrm{Eu}^{*}\right) \mathrm{cn}$ & & 6.07 & 0.03 & 0.44 & 0.04 \\
\hline$\left(\mathrm{Ce} / \mathrm{Ce}^{*}\right) \mathrm{cn}$ & & 0.88 & 1.04 & 1.03 & 1.04 \\
\hline
\end{tabular}

*FS $=$ Feldspar minerals that contains plagioclase and $\mathrm{K}$-feldspar, $\mathrm{Bi}=$ Biotite.

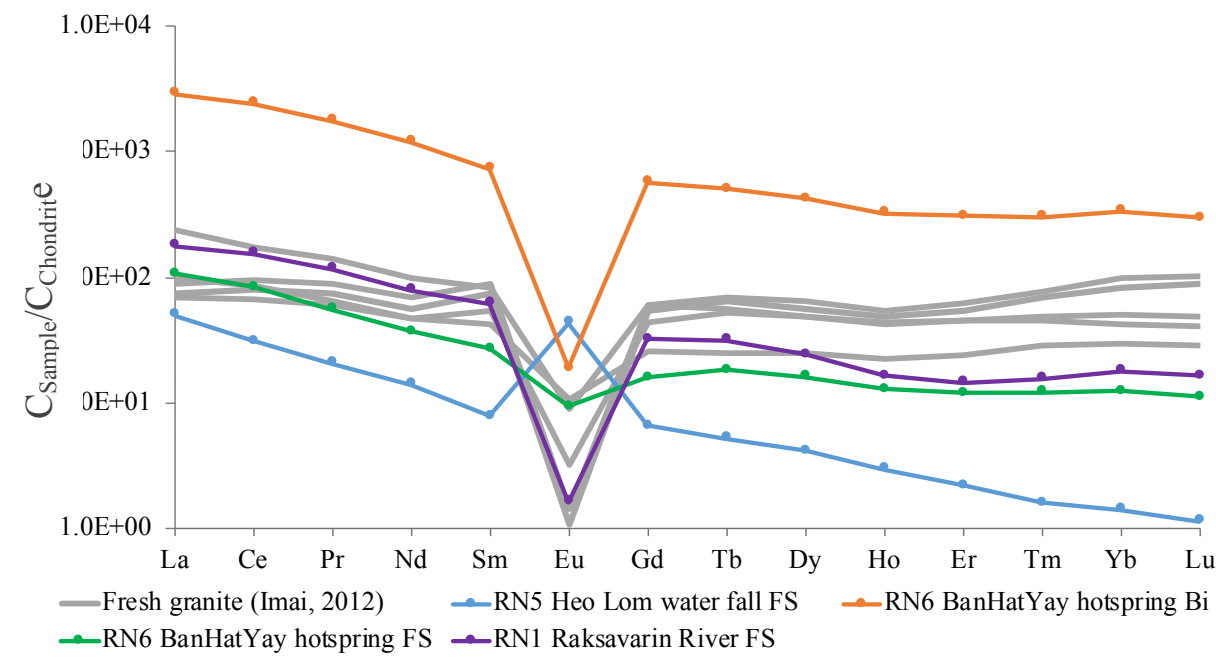

Figure 5.1-1: Chondrite-normalized REE pattern (McDonough and Sun, 1995) in the mineral samples in Ranong geothermal area compared with the whole fresh granite from Haad Som Paenn, Ranong Tin field (Imai, 2012). 
Table 5-2: Analytical results of $\mathrm{Rb}, \mathrm{Sr}$, and ${ }^{87} \mathrm{Sr} /{ }^{86} \mathrm{Sr}$ ratio in the rock samples in Ranong geothermal area.

\begin{tabular}{ccccccccc}
\hline Code & $\begin{array}{c}\text { Rock } \\
\text { Sample }\end{array}$ & $\begin{array}{c}\text { Rock } \\
\text { type }\end{array}$ & $\begin{array}{c}\text { Type of } \\
\text { Mineral }\end{array}$ & ${ }^{87} \mathrm{Sr} /{ }^{86} \mathrm{Sr}$ & $\mathrm{SD}$ & $\mathrm{Rb}$ & $\mathrm{Sr}$ & $\mathrm{Rb} / \mathrm{Sr}$ \\
\hline \multirow{2}{*}{ RN6 } & $\begin{array}{c}\text { Ban Hat } \\
\text { Yay }\end{array}$ & Granite & $\mathrm{Bi}$ & 0.7782 & 0.00003 & 39 & 532 & 0.07 \\
& $\mathrm{FS}$ & 0.7892 & 0.00003 & 1134 & 78 & 14.58 \\
\hline \multirow{2}{*}{$\mathrm{RN1}$} & $\begin{array}{c}\text { Raksawarin } \\
\text { river }\end{array}$ & Granite & $\mathrm{Bi}$ & - & - & - & - & - \\
& FS & 0.8737 & 0.00003 & 1334 & 32 & 41.54 \\
\hline \multirow{2}{*}{ RN5 } & $\begin{array}{c}\text { Heo Lom } \\
\text { Waterfall }\end{array}$ & $\begin{array}{c}\text { Foliate } \\
\text { granite }\end{array}$ & Bi & - & - & - & - & - \\
& FS & 0.7601 & 0.00002 & 355 & 5 & 74.90 \\
\hline
\end{tabular}

*FS $=$ Feldspar minerals that contains plagioclase and $\mathrm{K}$-feldspar, $\mathrm{Bi}=$ Biotite.

Note that, the results from biotite mineral are illustrated only in Ban Hat Yay hot spring. Due to the petrology investigation, the igneous biotite was often replaced by chlorite. These minerals often associated with one another. The biotite sample was insufficient, making it impossible to purify for Sr isotope analysis. Therefore, $\mathrm{Rb}-\mathrm{Sr}$ content and ${ }^{87} \mathrm{Sr} /{ }^{86} \mathrm{Sr}$ ratio for biotite are shown only in Ban Hat Yay hot spring.

\subsection{Analytical results of water}

Field parameters and chemical compositions of the major ions in the thermal and surface water samples were recorded (Table 5-3). According to the quality-assurance check of the chemical analyze, the ionic balance error in most case was found within 5\% limit. The major ions in seven meteoric water samples from Ranong monitoring station represent the chemical atmospheric input of the subsurface system (Table 5-4). The stable isotopes in thermal and surface water samples represent a summary of the isotopic data for both the pre-monsoon and post-monsoon seasons (Table 5-5). It should be noted that the isotopes of $\delta^{13} \mathrm{C},{ }^{14} \mathrm{C}$, and ${ }^{3} \mathrm{H}$ in thermal water were determined only for the post-monsoon season samples (Table 5-6).

\subsubsection{Water field sampling}

The field parameters and chemicals in the thermal waters are higher variables relative to the surface water. Variation of $\mathrm{pH}, \mathrm{Cl}^{-}$, and $\mathrm{Mg}^{+}$from thermal waters are slightly higher than those from surface water. Moreover, all of the water results are generally characterized by a neutral $\mathrm{pH}$. Notably, RN6-SW1 is an extreme case which contains the highest value of field parameters and chemical concentration in surface water (EC: $213 \mu \mathrm{S} / \mathrm{cm}$, temperature: $35.5^{\circ} \mathrm{C}, \mathrm{pH}: 7.6$, 
and chemical concentration: $>10 \mathrm{mg} / \mathrm{l}$ ). This anomaly will be explained in the discussion section.

The surface water samples show seasonal variations of the field parameters (Table 5-3). The $\mathrm{pH}$ values in the surface water are in the range of neutral values between 6.72 and 7.62. EC values range from 14.2 to $35.4 \mu \mathrm{S} / \mathrm{cm}$ in the post-monsoon season and range from 18.4 to 213 $\mu \mathrm{S} / \mathrm{cm}$ in the pre-monsoon season. Temperatures range from 25.9 to $35.5^{\circ} \mathrm{C}$ in the postmonsoon season and range from 26 to $34.6{ }^{\circ} \mathrm{C}$ in the pre-monsoon season. The alkalinity analysis by using a HACH Digital titrator indicates that the DIC in all of water samples are in the bicarbonate ion form $\left(\mathrm{HCO}_{3}{ }^{-}\right)$, ranging between 98.4 and $167.5 \mathrm{mg} / \mathrm{l}$. The field parameters in the thermal water samples displayed similar values during both seasons (Table 5-3). These samples are characterized by medium temperatures in the range of 36 to $66.8{ }^{\circ} \mathrm{C}$ (the highest temperature is RN1-1), EC in the range of 256 to $339 \mu \mathrm{S} / \mathrm{cm}$, and $\mathrm{pH}$ values in the range of 6.97 to 7.84 .

\subsubsection{Hydro-chemical analysis}

During both seasons, each major ion concentration from the surface water samples is less than $10 \mathrm{mg} / 1$ (Table 5-3). Most of the cations are at concentrations lower than $1 \mathrm{mg} / \mathrm{l}$, such as, $\mathrm{Ca}^{2+}$ (0.17 to $17.47 \mathrm{mg} / \mathrm{l}), \mathrm{K}^{+}(0.75$ to $3.50 \mathrm{mg} / \mathrm{l})$, and $\mathrm{Mg}^{2+}(0.12$ to $1.10 \mathrm{mg} / \mathrm{l})$. The sodium ions $\left(\mathrm{Na}^{+}\right)$concentrations are predominantly higher than the other cations, ranging between 1.67 and $3.17 \mathrm{mg} / 1$ in the post-monsoon season and between 3.16 and $45.65 \mathrm{mg} / \mathrm{l}$ during the premonsoon season. Surface water samples usually had low concentrations of anions as well (but more than $1 \mathrm{mg} / \mathrm{l})$, like $\mathrm{SO}_{4}{ }^{2-}(1.28$ to $7.15 \mathrm{mg} / \mathrm{l}), \mathrm{HCO}_{3}{ }^{-}(6.00$ to $91.2 \mathrm{mg} / \mathrm{l})$, and $\mathrm{Cl}^{-}(2.84$ to $3.17 \mathrm{mg} / \mathrm{l})$.

The major ion concentrations from seven meteoric water samples are less than $5 \mathrm{mg} / \mathrm{l}$ in each parameter. The chloride ions $\left(\mathrm{Cl}^{-}\right)$ranges between 0.34 and $3.48 \mathrm{mg} / \mathrm{l}$. For investigating the geochemical processes, multiply the maximum major-ion concentration in these meteoric water samples by ETF to calculate the major-ion compositions in Post-ET, which is explained in the chapter 3. The analytical and calculated results shown in Table 5-4.

The $\mathrm{SiO}_{2}$ concentrations in the thermal water were analyzed during both seasons (Table 5-8.), ranging from the lowest value of $73.06 \mathrm{mg} / \mathrm{l}$ to the highest value of $103.77 \mathrm{mg} / \mathrm{l}$, with an average of $87.80 \mathrm{mg} / \mathrm{l}$. The $\mathrm{SiO}_{2}$ concentrations in the hot spring water in the post-monsoon seasons are slightly higher than in the post-monsoon season. 
In comparison, the chemical concentrations of major ions in the thermal water are not radically different between the pre- and post-monsoon seasons, however, the chemical concentrations from the pre-monsoon season are slightly higher (Table 5-3). Individual cation concentrations in the thermal water are mostly more than $2 \mathrm{mg} / \mathrm{l}$, such as, $\mathrm{Ca}^{2+}(9.20$ to $22.60 \mathrm{mg} / \mathrm{l}), \mathrm{Na}^{+}(29.29$ to $81.00 \mathrm{mg} / \mathrm{l}), \mathrm{K}^{+}$(2.09 to $\left.5.66 \mathrm{mg} / \mathrm{l}\right)$, yet the $\mathrm{Mg}^{2+}$ concentrations range from 0.05 to 0.15 $\mathrm{mg} / \mathrm{l}$. Similarly, individual anions concentrations in thermal water are mostly more than $2 \mathrm{mg} / \mathrm{l}$, like of; $\mathrm{SO}_{4}{ }^{2-}$ (4.24 to $\left.46.35 \mathrm{mg} / \mathrm{l}\right), \mathrm{HCO}_{3}^{-}(98.4$ to $167.5 \mathrm{mg} / \mathrm{l})$, and $\mathrm{Cl}^{-}(2.74$ to $4.90 \mathrm{mg} / \mathrm{l})$.

To better understand the water classification in the geothermal area, these major ion results were interpreted graphically by plotting the chemical data in the triangular diagrams modified from Giggenbach, (1988) (Figure 5.2-1 and 5.2-2.)

The triangular diagrams illustrate both the thermal and surface waters contain $\mathrm{Na}^{+}$and $\mathrm{K}^{+}$as the dominant cations (Figure 5.2-1 (b) and 5.2-2 (b)), and $\mathrm{HCO}_{3}{ }^{-}$as the dominant anion (Figure 5.2-1 (a) and 5.2-2 (a)). Although the cations in water clearly display the $\mathrm{Na}+\mathrm{K}$ type in the triangular diagram graph, $\mathrm{Na}^{+}$has greater relative abundance than $\mathrm{K}^{+}$, since the $\mathrm{Na} / \mathrm{K}$ ratio varies from 12.17 to 20.80 in thermal water and from 1.83 to 13.05 in the surface water. Therefore, these waters are predominantly the $\mathrm{Na}-\mathrm{HCO}_{3}$ type (immature sodium-bicarbonate water). 
Table 5-3: Field parameter, major ion composition, and ionic balance in water samples in Ranong geothermal area

\begin{tabular}{|c|c|c|c|c|c|c|c|c|c|c|c|c|c|c|c|c|c|c|c|c|c|c|c|}
\hline \multirow{3}{*}{ Location } & \multicolumn{7}{|c|}{ Field parameters } & \multicolumn{8}{|c|}{ Cations } & \multicolumn{6}{|c|}{ Anions } & & \\
\hline & \multirow[t]{2}{*}{$\begin{array}{l}\text { Altitude } \\
\text { (m) }\end{array}$} & \multicolumn{2}{|c|}{$\begin{array}{l}\text { Temp. } \\
\left({ }^{\circ} \mathrm{C}\right)\end{array}$} & \multicolumn{2}{|c|}{$\mathrm{pH}$} & \multicolumn{2}{|c|}{$\begin{array}{c}\mathrm{EC} \\
(\mu \mathrm{S} / \mathrm{cm})\end{array}$} & \multicolumn{2}{|c|}{$\begin{array}{l}\mathrm{Ca}^{2+} \\
(\mathrm{mg} / \mathrm{l})\end{array}$} & \multicolumn{2}{|c|}{$\begin{array}{c}\mathrm{Na}^{+} \\
(\mathrm{mg} / \mathrm{l})\end{array}$} & \multicolumn{2}{|c|}{$\begin{array}{c}\mathrm{K}^{+} \\
(\mathrm{mg} / \mathrm{l})\end{array}$} & \multicolumn{2}{|c|}{$\begin{array}{l}\mathrm{Mg}^{2+} \\
(\mathrm{mg} / \mathrm{l})\end{array}$} & \multicolumn{2}{|c|}{$\begin{array}{l}\mathrm{HCO}_{3}^{-} \\
(\mathrm{mg} / \mathrm{l})\end{array}$} & \multicolumn{2}{|c|}{$\begin{array}{c}\mathrm{Cl}^{-} \\
(\mathrm{mg} / \mathrm{l})\end{array}$} & \multicolumn{2}{|c|}{$\begin{array}{l}\mathrm{SO}^{2-} \\
(\mathrm{mg} / \mathrm{l})\end{array}$} & \multicolumn{2}{|c|}{$\begin{array}{l}\text { IB } \\
(\%)\end{array}$} \\
\hline & & 2014 & 2016 & 2014 & 2016 & 2014 & 2016 & 2014 & 2016 & 2014 & 2016 & 2014 & 2016 & 2014 & 2016 & 2014 & 2016 & 2014 & 2016 & 2014 & 2016 & 2014 & 2016 \\
\hline RN1-1 & 37.7 & 66.7 & 66.8 & 7.02 & 7.3 & 322 & 337 & 19.62 & 18.04 & 81.00 & 53.96 & 4.54 & 2.87 & 0.13 & 0.07 & 167.5 & 159.6 & 4.17 & 2.83 & 26.64 & 21.50 & -4.63 & -4.68 \\
\hline RN1-2 & 38.57 & 61.7 & 61.3 & 7.1 & 7.31 & 325 & 339 & 19.64 & 18.35 & 63.37 & 55.87 & 3.59 & 2.95 & 0.09 & 0.05 & 167.5 & 168 & 3.33 & 2.77 & 21.51 & 21.72 & -4.86 & -3.35 \\
\hline RN1-3 & 40.24 & 64 & 63.6 & 7.2 & 7.67 & 325 & 337 & 20.01 & 18.38 & 73.18 & 54.19 & 4.27 & 2.87 & 0.08 & 0.06 & 167.5 & 132 & 3.85 & 2.74 & 23.79 & 21.57 & -4.49 & -4.65 \\
\hline RN2 & 15.61 & 41.4 & 40.9 & 7.29 & 7.48 & 324 & 337 & 22.06 & 17.42 & 62.23 & 47.73 & 3.88 & 2.92 & 0.10 & 0.06 & 145.2 & 148.8 & 3.59 & 2.98 & 46.35 & 44.88 & -2.04 & 2.45 \\
\hline RN3 & 72.54 & 45.7 & 47.3 & 6.97 & 7.35 & 295 & 332 & 18.30 & 18.02 & 50.58 & 47.29 & 3.42 & 2.99 & 0.08 & 0.05 & 117.6 & 106.8 & 3.30 & 2.93 & 39.14 & 45.25 & -3.82 & -3.75 \\
\hline RN3-1 & 66.5 & - & 51.9 & - & 7.2 & - & 325 & - & 17.24 & - & 48.01 & - & 3.09 & - & 0.08 & - & 98.4 & - & 3.00 & - & 43.71 & - & -4.65 \\
\hline RN3-2 & 67.82 & - & 60.8 & - & 7.19 & - & 299 & - & 18.34 & - & 48.31 & - & 3.14 & - & 0.06 & - & 99.6 & - & 2.95 & - & 45.42 & - & -3.75 \\
\hline RN5 & 37.48 & 46 & 43.5 & 7.73 & 7.62 & 266 & 277 & 21.05 & 16.58 & 57.05 & 43.51 & 3.47 & 2.09 & 0.10 & 0.09 & 142.8 & 120 & 4.90 & 2.86 & 15.54 & 12.52 & -4.38 & -4.99 \\
\hline RN6-1 & 66.88 & 45.9 & 41.9 & 7.32 & 7.71 & 256 & 284 & 17.27 & 14.99 & 68.96 & 43.55 & 5.66 & 3.31 & 0.14 & 0.10 & 140.4 & 138 & 4.82 & 2.89 & 11.37 & 7.03 & -2.78 & -4.57 \\
\hline RN6-2 & 67.5 & 37.8 & 36 & 7.83 & 8.1 & 285 & 302 & 19.80 & 9.20 & 47.09 & 29.29 & 3.52 & 2.34 & 0.11 & 0.15 & - & 150 & 3.21 & 2.88 & 5.32 & 4.24 & - & -3.51 \\
\hline RN6-3 & 69 & 40 & 43.8 & 7.91 & 7.84 & 290 & 303 & - & 16.81 & - & 43.37 & - & 3.43 & - & 0.11 & - & 151.2 & - & 3.02 & - & 6.94 & - & -4.71 \\
\hline RN6-4 & 67.7 & - & 48.5 & - & 7.34 & - & 326 & - & 17.60 & - & 45.15 & - & 3.37 & - & 0.08 & - & 147.6 & - & 2.86 & - & 6.98 & - & -4.17 \\
\hline RN1-RV1 & - & 34.6 & - & 7.03 & - & - & - & 1.89 & - & 1.67 & - & 0.91 & - & 1.04 & - & 6 & - & 3.04 & - & 1.32 & - & -1.68 & - \\
\hline RN1-SW1 & 39.36 & 26.6 & 27.3 & 7.1 & 7.12 & 35.4 & 54.6 & 2.50 & 2.81 & 3.17 & 5.09 & 1.47 & 0.96 & 0.88 & 1.10 & 13.2 & 36 & 3.80 & 2.70 & 1.57 & 1.91 & 3.67 & 4.57 \\
\hline RN6-SW1 & 64 & 26.4 & 35.5 & 7.2 & 7.62 & 27 & 213 & 0.63 & 17.47 & 3.92 & 45.65 & 1.33 & 3.50 & 0.16 & 0.08 & 9 & 91.2 & 2.98 & 3.17 & 1.46 & 7.15 & 1.56 & -6.27 \\
\hline RN3-SW1 & - & 26.1 & 28.9 & 7.67 & 7.31 & 15.2 & 27.1 & 0.25 & 0.23 & 2.46 & 4.85 & 0.75 & 0.76 & 0.12 & 0.07 & 7.32 & 10.8 & 2.84 & 2.23 & 1.28 & 1.86 & 1.42 & 1.75 \\
\hline RN3-SW2 & - & 26 & 25.9 & 7.35 & 6.72 & 14.2 & 18.4 & 0.17 & 0.18 & 1.95 & 3.16 & 0.89 & 0.73 & 0.13 & 0.08 & 8.52 & 2.4 & 2.92 & 2.25 & 1.85 & 0.78 & 1.82 & -23.3 \\
\hline RNSW & 28.57 & - & - & - & 7.13 & - & - & - & 0.26 & - & 3.64 & - & 1.07 & - & 0.23 & - & 2.4 & - & 2.95 & - & 0.65 & - & -17.9 \\
\hline
\end{tabular}

IB; Ionic Balance (\%) 
Table 5-4: Major ion concentration in Ranong meteoric water.

\begin{tabular}{lcccccc}
\hline & $\begin{array}{c}\mathbf{C a}^{2+} \\
\mathrm{mg} / 1\end{array}$ & $\begin{array}{c}\mathbf{N a}^{+} \\
\mathrm{mg} / 1\end{array}$ & $\begin{array}{c}\mathbf{K}^{+} \\
\mathrm{mg} / 1\end{array}$ & $\begin{array}{c}\mathbf{M g}^{2+} \\
\mathrm{mg} / 1\end{array}$ & $\begin{array}{c}\mathbf{C l}^{-} \\
\mathrm{mg} / 1\end{array}$ & $\begin{array}{c}\mathbf{S O}_{4}{ }^{2-} \\
\mathrm{mg} / 1\end{array}$ \\
\hline RW_RN01 & 0.616 & 0.431 & 0.215 & 0.08 & 0.362 & 2.1 \\
RW_RN02 & 0.92 & 1.41 & 0.139 & 0.213 & 3.48 & 1.6 \\
RW_RN03 & 2.69 & 0.663 & 0.12 & 0.091 & 1.64 & 0.598 \\
RW_RN04 & $<0.05$ & $<0.05$ & 0.048 & $<0.05$ & 0.341 & 0.067 \\
RW_RN05 & 0.368 & 0.124 & 0.173 & $<0.05$ & 0.62 & 0.635 \\
RW_RN06 & 2.44 & 0.56 & 0.106 & 0.09 & 1.59 & 0.584 \\
RW_RN07 & 2.3 & 1.91 & 0.435 & 0.153 & 1.21 & 1.47 \\
\hline & 1.56 & 0.85 & 0.18 & 0.13 & 1.32 & 1.01 \\
\multicolumn{1}{c}{ average } & $<0.05$ & $<0.05$ & 0.05 & $<0.05$ & 0.34 & 0.07 \\
\multicolumn{1}{c}{ Maximum } & 2.69 & 1.91 & 0.44 & 0.21 & 3.48 & 2.10 \\
\hline Post-ET in Mae Chan & 10.81 & 7.68 & 1.77 & 0.84 & 13.99 & 8.44 \\
Post-ET in Ranong & 4.04 & 2.87 & 0.66 & 0.32 & 5.22 & 3.15 \\
\hline
\end{tabular}

\subsubsection{Radioactive and stable isotope analysis}

\subsubsection{Water isotopic characterization}

Stable isotopic ratios (deuterium: $\delta^{2} \mathrm{H}$ and oxygen 18: $\delta^{18} \mathrm{O}$ ) for the thermal and surface water samples were analyzed during both seasons (Table 5-5). The $\delta^{2} \mathrm{H}$ isotopic compositions of the surface waters in the post-monsoon season range from -31.05 to $-28.37 \%$, and $\delta^{18} \mathrm{O}$ range from -5.48 to $-5.22 \%$. During the pre-monsoon season, $\delta^{2} \mathrm{H}$ range from -29.49 to $-23.88 \%$ and $\delta^{18} \mathrm{O}$ range from -5.31 to $-4.40 \%$. The post-monsoon seasons are depleted in heavy isotope compared to pre-monsoon seasons. Nevertheless, the isotopic values of the thermal water measured in each sample during both seasons remained relatively constant, $\left(\delta^{2} \mathrm{H}\right.$ range between -32.86 and $-31.60 \%$ and $\delta^{18} \mathrm{O}$ range between -5.88 and $-5.55 \%$ ), with a $\delta^{2} \mathrm{H}$ isotopic variation from 0.56 to $1.23 \%$ and a $\delta^{18} \mathrm{O}$ variation from 0.02 to $0.25 \%$. 

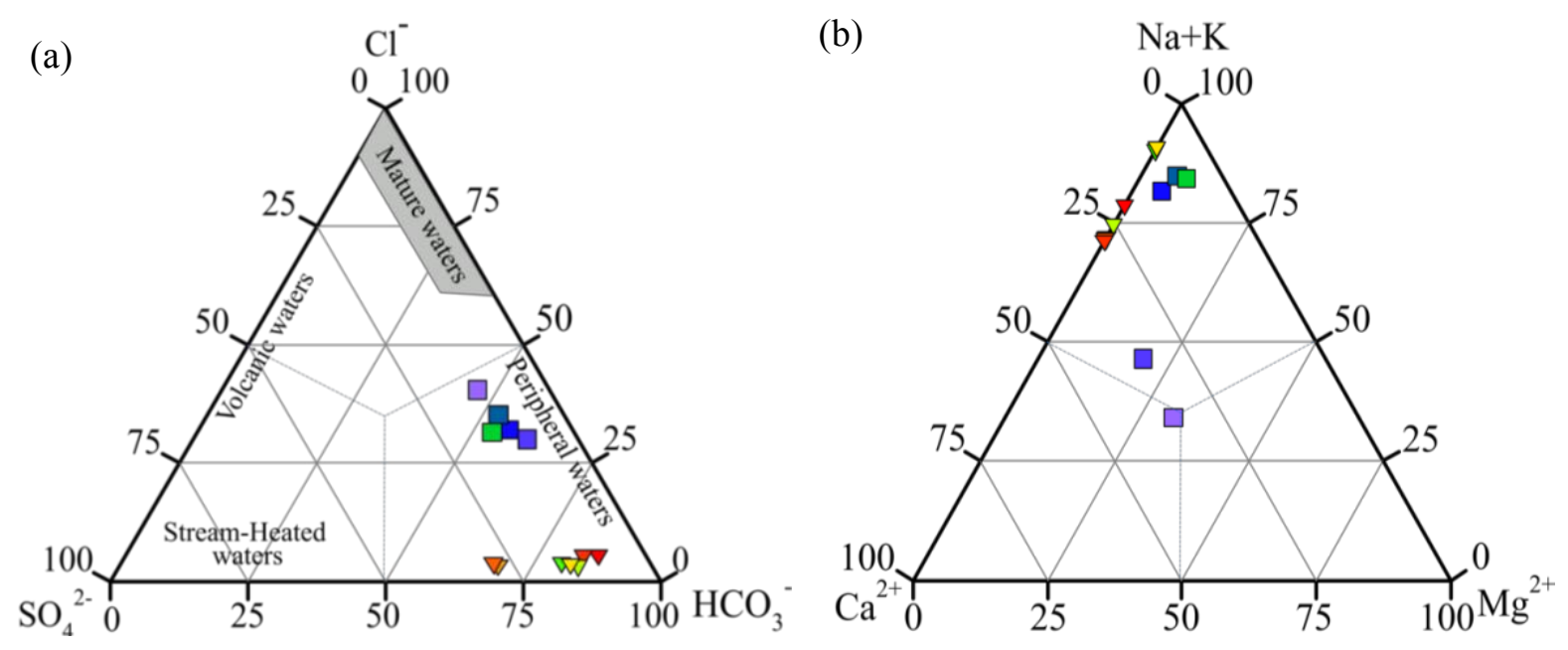

\begin{tabular}{|llllll|}
\hline$\square$ RN1-RV1 & $\square$ RN6-SWI & $\square$ RN3-SW2 & $\nabla_{\text {RN1-2 }}$ & $\nabla_{\text {RN2 }}$ & $\nabla_{\text {RN5 }}$ \\
$\square$ RN1-SW1 & $\square$ RN3-SW1 & $\nabla_{\text {RN1- }}$ & $\nabla_{\text {RN1-3 }}$ & $\nabla_{\text {RN3 }}$ & $\nabla_{\text {RN6-1 }}$ \\
\hline
\end{tabular}

Figure 5.2-1: Triangular diagram of (a) major anions (modified from Giggenbach, 1988) and (b) major cations in water samples in post-monsoon season (2014) in Ranong geothermal area.

(a)

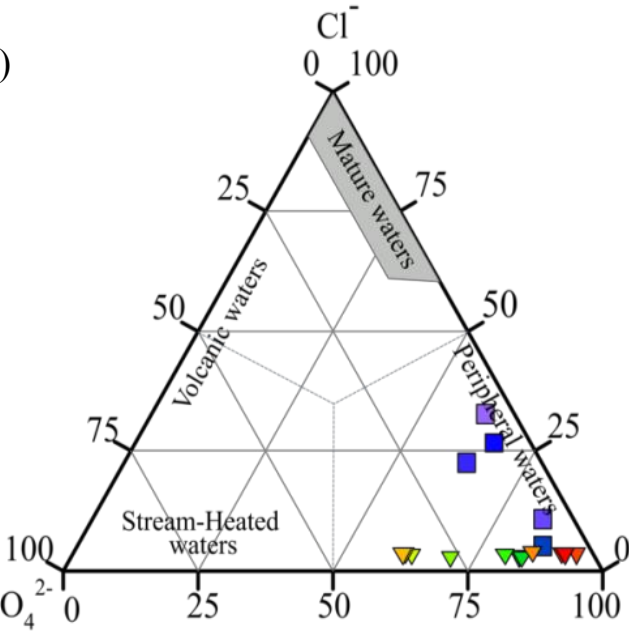

\begin{tabular}{|llllll|}
\hline RNSW & $\square_{\text {RN3-SW2 }}$ & $\nabla_{\text {RN1-2 }}$ & $\nabla_{\text {RN3 }}$ & $\nabla_{\text {RN5 }}$ & $\nabla_{\text {RN6-1 }}$ \\
$\square_{\text {RN1-SW1 }}$ & $\square_{\text {RN6-SW1 }}$ & $\nabla_{\text {RN1-3 }}$ & $\nabla_{\text {RN3-1 }}$ & $\nabla_{\text {RN6-3 }}$ & $\nabla_{\text {RN6-4 }}$ \\
$\square$ RN3-SW1 & $\nabla_{\text {RN1-1 }}$ & $\nabla_{\text {RN2 }}$ & $\nabla_{\text {RN3-2 }}$ & $\nabla_{\text {RN6-2 }}$ & \\
\hline
\end{tabular}

Figure 5.2-2: Triangular diagram of (a) major anions (modified from Giggenbach, 1988) and (b) major cations in water samples in pre-monsoon season (2016) in Ranong geothermal area. 
Table 5-5: Stable isotope results in thermal water and surface water samples in Ranong geothermal area from post-monsoon (December 2014) and pre-monsoon seasons (March 2016).

\begin{tabular}{|c|c|c|c|c|c|c|c|c|}
\hline \multirow{2}{*}{ Location } & \multicolumn{3}{|c|}{$\begin{array}{l}\text { post-monsoon season } \\
\text { (December 2014) }\end{array}$} & \multicolumn{5}{|c|}{$\begin{array}{c}\text { pre-monsoon seasons } \\
\text { (March 2016) }\end{array}$} \\
\hline & $\delta^{2} \mathrm{H}$ & $\delta^{18} \mathrm{O}$ & $D_{\text {excess }}$ & $\begin{array}{l}\delta^{18} \mathrm{O}- \\
\text { shift }\end{array}$ & $\delta^{2} \mathrm{H}$ & $\delta^{18} \mathrm{O}$ & $D_{\text {excess }}$ & $\begin{array}{l}\delta^{18} \mathrm{O}- \\
\text { shift }\end{array}$ \\
\hline RN1-1 & -32.19 & -5.61 & 12.67 & 0.13 & -31.63 & -5.55 & 12.79 & 0.12 \\
\hline RN1-2 & - & - & - & - & -32.05 & -5.61 & 12.86 & 0.11 \\
\hline RN1-3 & - & - & - & - & -31.90 & -5.61 & 13.00 & 0.09 \\
\hline RN2 & -32.53 & -5.79 & 13.77 & -0.01 & -32.49 & -5.77 & 13.64 & 0.01 \\
\hline RN3 & -32.86 & -5.79 & 13.49 & 0.03 & -32.48 & -5.79 & 13.82 & -0.01 \\
\hline RN3-1 & - & - & - & - & -31.71 & -5.69 & 13.84 & -0.01 \\
\hline RN3-2 & - & - & - & - & -32.08 & -5.71 & 13.57 & 0.02 \\
\hline RN5 & -32.62 & -5.84 & 14.06 & -0.05 & -32.45 & -5.75 & 13.58 & 0.02 \\
\hline RN6-1 & -31.90 & -5.73 & 13.94 & -0.03 & -32.14 & -5.68 & 13.29 & 0.05 \\
\hline RN6-2 & -32.84 & -5.78 & 13.41 & 0.04 & -31.60 & -5.55 & 12.76 & 0.12 \\
\hline RN6-3 & -31.88 & -5.63 & 13.13 & 0.07 & -32.65 & -5.88 & 14.39 & -0.08 \\
\hline RN6-4 & - & - & - & - & -32.59 & -5.81 & 13.91 & -0.02 \\
\hline RN1-SW1 & -31.05 & -5.48 & 12.76 & - & -25.47 & -4.93 & 13.98 & - \\
\hline RN3-SW1 & -29.24 & -5.31 & 13.23 & - & -23.98 & -4.52 & 12.17 & - \\
\hline RN3-SW2 & -28.59 & -5.34 & 14.12 & - & -23.88 & -4.40 & 11.29 & - \\
\hline RN6-SW1 & -28.37 & -5.27 & 13.79 & - & -29.49 & -5.31 & 12.99 & - \\
\hline RNSW & - & - & - & - & -26.83 & -5.00 & 13.19 & - \\
\hline RN1-RV1 & -29.73 & -5.22 & 12.00 & - & - & - & - & - \\
\hline
\end{tabular}

To determine the water sources and to understand the hydrologic cycle within the area, these stable isotopic ratios are plotted against the global meteoric water line (GMWL) and local meteoric water line (LMWL) (Figure5.2-3(a)). The LMWL was obtained from the stable isotopic data in daily precipitation samples $(n=338)$ from 2013 to 2015 at the Ranong monitoring station (Hydro and Agro Informatics Institute (HAII), 2016). This station, located in Tambon Bang Yai, Amphoe Kra Buri, Chang Wat Ranong, is the closest station to the Raksawarin hot spring about $40 \mathrm{~km}$ northeast, at $21 \mathrm{~m} \mathrm{AMSL}$ ). Moreover, these isotopic ratios are plotted compare with the magmatic water area according to Giggenbach, (1992) (Figure $5.2-3(b))$. 
According to the $\delta^{18} \mathrm{O}$ and $\delta^{2} \mathrm{H}$ diagrams during both seasons in Figure 5.2-3(a), the isotopic distribution in most thermal and surface water samples are located in the range of the isotopic data for daily precipitation, they plot closely above the LMWL. Most isotopic ratios of surface water samples in pre-monsoon season are more enriched than that in the post-monsoon season. Moreover, the cluster of thermal waters plot more negatively than the surface waters, and the cluster distribution in the pre-monsoon season is wider than that from the post-monsoon season. This isotopic variation of thermal water by season is lower than the uncertainty of the measurement $\left(\delta^{18} \mathrm{O}<0.2 \%\right.$ and $\delta^{2} \mathrm{H}<2 \%$ ) (Table 5-5), potentially indicating that that the thermal water, which derived from meteoric water, has no seasonal variation. For more detail, the model LMWL is created by following equation $\delta^{2} \mathrm{H}=7.97 \delta^{18} \mathrm{O}+13.4 \%$ (Figure 5.2-3), and further discussion in Chapter 5.3.1.1.

Deuterium excesses ( $D_{\text {Excess }}$ ) is a useful indicator for tracing the vapor sources that have been related to the meteorological condition in that area (Saravana Kumar et al., 2010). Hence, the DExcess values in thermal water and surface water should reflect the $\mathrm{D}_{\text {Excess }}$ of the meteoric water, calculated for each sampling site $\left(\mathrm{D}_{\text {excess }}=\delta^{2} \mathrm{H}-8 * \delta^{18} \mathrm{O}\right)$ (Saravana Kumar et al., 2010). The Dexcess values of thermal waters samples in the post-monsoon season are in the same range as in pre-monsoon season, all of which are between 12.69 and 14.39 (Table 5-5). Conversely, the Dexcess values of the surface water samples in the post-monsoon season (11.32 to 13.97\%o) are slightly lower than those in the pre-monsoon season (12.03 to $14.13 \%$ ).

$\delta^{18} \mathrm{O}$-shifted is an indicator for investigating water-rock interaction, calculated for each thermal water sample $\left(\delta^{18} \mathrm{O}\right.$-shifted $=\delta^{18} \mathrm{O}_{\text {thermal }}-\delta^{18} \mathrm{O}$ Model-LMwL $)$. All of the $\delta^{18} \mathrm{O}$-shifted results are lower than the analytical precision for $\delta^{18} \mathrm{O}(0.2 \%)$. The ranges of the $\delta^{18} \mathrm{O}$-shifted results for the post-monsoon season (-0.05 to $0.07 \%$ ) are narrower than that for the pre-monsoon season $(-0.08$ to $0.12 \%$ ) (Table $5-5)$ as well indicating that a small seasonal effect on the interaction between water and rock (water-rock interaction) is present. 
(a)

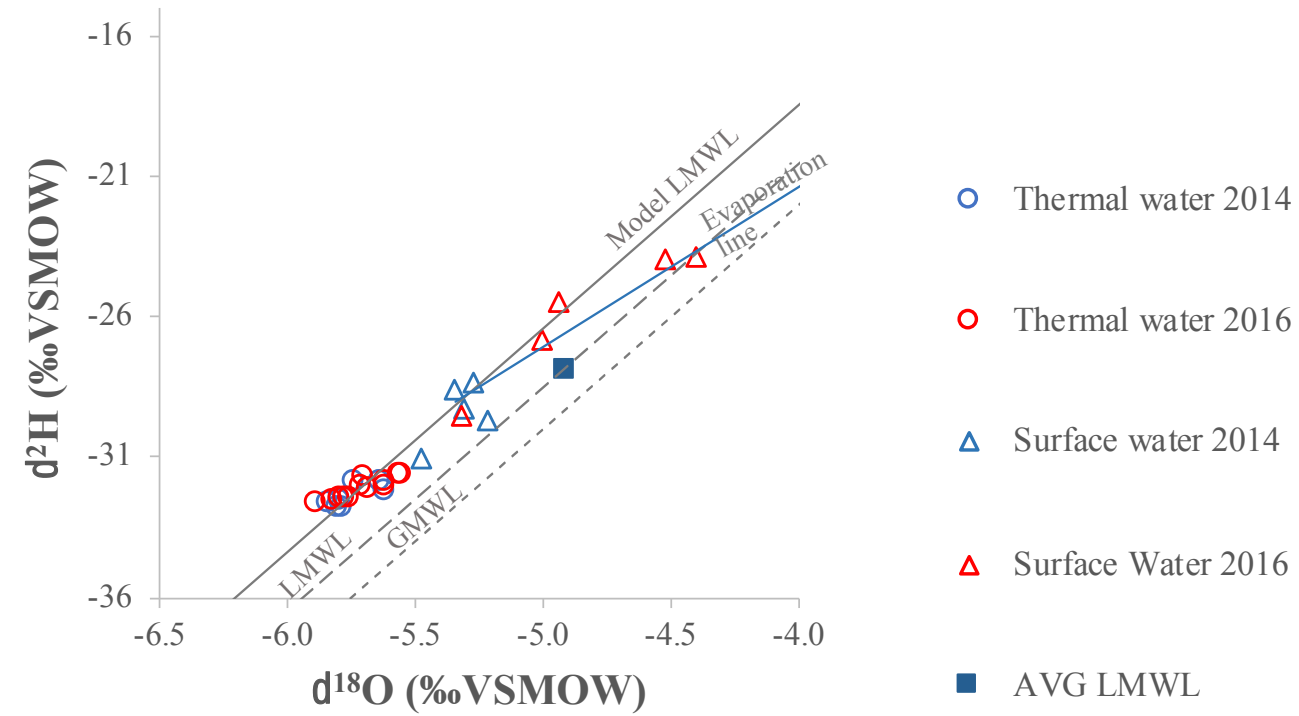

(b)

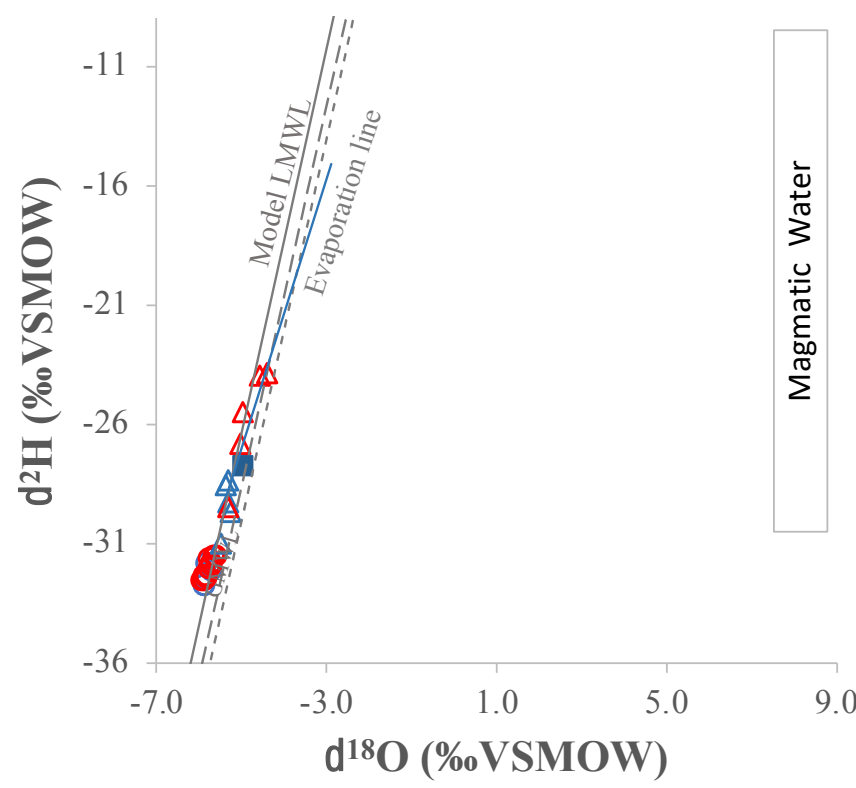

Figure 5.2-3: (a) Stable isotope results in thermal water and surface water samples from postmonsoon (December 2014) and pre-monsoon seasons (March 2016), compared with LMWLs from Ranong station. The navy blue-square symbol (AVG LMWL) represents the average rainfall from three-years of weighted mean data. The blue symbols represent the samples, collected in December 2014, while red symbols represent the samples, collected in March 2016. The gray line represents the linear model LMWL equation is the slope from the average LMWL (7.97) and the average Dexcess from thermal water (13.47\%). Two dot gray lines represent the linear from LMWL and GMWL equation. The blue line represents the evaporation line. (b) these results comparing with the magmatic water area was plotted according to Giggenbach, (1992). 


\subsubsection{Carbon stable isotope $\left(\delta^{13} \mathrm{C}\right)$, Radiocarbon $\left({ }^{14} \mathrm{C}\right)$ and Tritium $\left({ }^{3} \mathrm{H}\right)$}

The analytical results for $\delta^{13} \mathrm{C},{ }^{14} \mathrm{C}$, and ${ }^{3} \mathrm{H}$ in the thermal waters are shown in Table 5-6. The thermal water ${ }^{3} \mathrm{H}$ concentrations are below the detection limit $(<0.3 \mathrm{TU})$, while the surface water ${ }^{3} \mathrm{H}$ concentrations range from 1.5 to $2.2 \mathrm{TU}$. The results for $\delta^{13} \mathrm{C}$ range between -25.59 and $-23.55 \%$ PBD, and the ${ }^{14} \mathrm{C}$ concentrations vary between 54.70 and $61.94 \mathrm{pMC}$. The calculated fluid residence time from ${ }^{14} \mathrm{C}$ by Eq. (3.5), ranges from 3,850 to 4,850 BP.

As the $\delta^{13} \mathrm{C}$ and dissolved inorganic carbon (DIC) can identify the complex geochemical processes which disturbing the ${ }^{14} \mathrm{C}$. The alkalinity analysis (in chapter 5.2.1) indicates that the DIC in all of water are in the bicarbonate ion form $\left(\mathrm{HCO}_{3}^{-}\right)$, shown in Table 5-3. Therefore, these parameters are integrated with the ${ }^{14} \mathrm{C}$ to understand the geochemical processes of carbon and to improve the fluid residence time estimation in the Mae Chan thermal springs. The details are described in the further chapter (Chapter 5.3).

\subsubsection{Geothermometer estimation}

\subsubsection{Cation geothermometer}

The estimated reservoir temperatures from cation geothermometers range from 80 to $278{ }^{\circ} \mathrm{C}$, are shown in Table 5-7. Temperatures from Na-K-Ca geothermometer $\left(275-278^{\circ} \mathrm{C}\right)$ are higher than from $\mathrm{Na}-\mathrm{K}$ and $\mathrm{K}-\mathrm{Mg}$ geothermometers. Moreover, these temperature results from $\mathrm{K}-\mathrm{Mg}$ adiabatic cooling and $\mathrm{K}-\mathrm{Mg}$ conductive cooling geothermometers mostly have similar values, implying that the conductive cooling may not be occurring.

\subsubsection{Silica geothermometers}

The temperature results from the silica geothermometers in Ranong hot springs range from $100{ }^{\circ} \mathrm{C}$ to $135{ }^{\circ} \mathrm{C}$ (Table 5-8) and, consistent with previous results from Chaturongkawanich and Leevongchareon, (2000). Temperature results from the quartz geothermometer (99$139.4{ }^{\circ} \mathrm{C}$ ) are higher than those from chalcedony geothermometers $\left(83-112.4^{\circ} \mathrm{C}\right)$, while the quartz geothermometer results from maximum steam loss are similar to the results from no steam loss. 
Table 5-6: Tritium, stable isotope of carbon, and radiocarbon results in hot springs in Ranong area.

\begin{tabular}{|c|c|c|c|c|c|c|c|c|c|c|}
\hline \multirow[b]{2}{*}{ Location } & \multirow[b]{2}{*}{ Name } & \multicolumn{2}{|c|}{ Tritium } & \multirow{2}{*}{$\frac{\mathrm{DIC}^{*}}{\mathrm{mg} / \mathrm{l}}$} & \multicolumn{2}{|c|}{$\delta^{13} \mathrm{C}$} & \multicolumn{2}{|c|}{ Measured ${ }^{14} \mathrm{C}$} & \multicolumn{2}{|c|}{ Estimated resident times } \\
\hline & & $\mathrm{TU}$ & error & & $\begin{array}{c}\text { Permil } \\
(\%)\end{array}$ & error & $\mathrm{pMC}$ & error & $\mathrm{BP}$ & error \\
\hline RN1 & Raksawarin hot spring & 0 & 0.2 & 167.5 & -25.59 & 0.24 & 56.85 & 1.36 & 4,540 & 200 \\
\hline RN2 & Phu Lum Phi hot spring & 0.1 & 0.1 & 145.2 & -24.12 & 0.30 & n.d. & n.d. & n.d. & n.d. \\
\hline RN3 & Phorn Rung hot spring & 0.1 & 0.2 & 117.6 & -23.79 & 0.25 & 61.94 & 1.47 & 3,850 & 190 \\
\hline RN5 & Rattana Rangsan Hot spring & 0.1 & 0.1 & 142.8 & -23.55 & 0.30 & 54.70 & 1.31 & 4,850 & 200 \\
\hline RN6 & Hatyay Hot spring & 0.1 & 0.2 & 140.4 & -23.81 & 0.27 & 59.04 & 2.43 & 4,230 & 200 \\
\hline
\end{tabular}




\subsubsection{Rare earth elements within the water.}

The REE compositions in the water samples are given in Table 5-9. The $\Sigma$ REE contents in the surface water samples and the thermal water samples range from 0.43 to $4.54 \mu \mathrm{g} / \mathrm{l}$, and from 0.024 to $0.372 \mu \mathrm{g} / \mathrm{l}$, respectively. All of the water samples indicate the negative Eu anomalies with $\mathrm{Eu} / \mathrm{Eu}^{*}$ ranging from 0.02 to 0.49 , as well as positive $\mathrm{Ce}$ anomalies with $\mathrm{Ce} / \mathrm{Ce}$ * ranging from 2.50 to 12.67 . In contrast, RN1-RV1 indicates a positive Eu anomaly $\left(\mathrm{Eu} / \mathrm{Eu}^{*}=0.49\right)$ and positive $\mathrm{Ce}$ anomaly $\left(\mathrm{Ce} / \mathrm{Ce}^{*}=4.57\right)$.

The REE concentrations in water samples are normalized to the composition of chondrite (McDonough and Sun, 1995) and plotted for each location in Figure 5.2-4. There is considerably higher REE concentration pattern in the surface water than the thermal water. Most of the surface water samples are slightly enriched in LREE relative to HREE with negative Eu anomalies. In contrast, the RN3-SW1 sample depleted concentration pattern in LREE relative to the HREE with the most negative Eu anomaly measured. The REE concentration patterns from thermal water samples are relatively flat to slightly deplete in LREE. However, the patterns from the high-temperature thermal waters are depleted in LREE, indicated notably by the elements $\mathrm{Pr}, \mathrm{Nd}$, and Sm. The Eu anomalies are negative, less than the detection limit.

\subsubsection{Rb-Sr composition of the water}

The $\mathrm{Rb}$ contents, $\mathrm{Sr}$ contents and $\mathrm{Sr}$ isotopic ratios of the surface water and thermal water are shown in Table 5-10. The surface water has lower concentrations of both $\mathrm{Rb}$ and $\mathrm{Sr}$ than the thermal water. The surface water results range from 2.09 to $14.26 \mu \mathrm{gL}^{-1}$ for $\mathrm{Rb}$ and from 1.26 to $9.64 \mu \mathrm{gL}^{-1}$ for Sr. In thermal waters, Rb contents range between 23.86 and $35.95 \mu \mathrm{gL}^{-1}$ and Sr contents range between 47.66 and $99.22 \mu \mathrm{gL}^{-1}$. The measured ${ }^{87} \mathrm{Sr} /{ }^{86} \mathrm{Sr}$ ratios range between 0.73442 and 0.74494 in surface waters and between 0.73861 and 0.74909 in thermal waters. RN3-SW1 sample has the lowest ${ }^{87} \mathrm{Sr} /{ }^{86} \mathrm{Sr}$ ratio, while the highest ${ }^{87} \mathrm{Sr} /{ }^{86} \mathrm{Sr}$ ratio is in RN6-1. The ${ }^{87} \mathrm{Sr} /{ }^{86} \mathrm{Sr}$ ratio of feldspar minerals, surface water, and the thermal water from the Ranong geothermal area are plotted by local against geological map (Figure 5.2-5). In general, the ${ }^{87} \mathrm{Sr} /{ }^{86} \mathrm{Sr}$ ratio in the geothermal and surface water are significantly lower than the ${ }^{87} \mathrm{Sr} /{ }^{86} \mathrm{Sr}$ ratios from the granitic host rock samples. Moreover, the Sr concentrations of the surface water samples are significantly lower than those from geothermal water samples at the same location. 
Table 5-7: Temperature results of Cation geothermal estimations.

\begin{tabular}{|c|c|c|c|c|c|c|c|c|c|c|c|c|c|c|c|c|c|c|c|c|c|c|}
\hline \multirow[t]{2}{*}{ Location } & \multicolumn{2}{|c|}{$\begin{array}{l}\text { Fournier } \\
\text { (1979) }\end{array}$} & \multicolumn{2}{|c|}{$\begin{array}{l}\text { Arnorsson } \\
\text { (1983) }\end{array}$} & \multicolumn{2}{|c|}{$\begin{array}{c}\text { Arnorsson } \\
(1983) \text { et } \\
\text { al2 }\end{array}$} & \multicolumn{2}{|c|}{$\begin{array}{c}\text { Nieva \& } \\
\text { Nieva } \\
(1987)\end{array}$} & \multicolumn{2}{|c|}{$\begin{array}{l}\text { Giggenbach } \\
\text { (1988) }\end{array}$} & \multicolumn{2}{|c|}{$\begin{array}{l}\text { Arnorson } \\
(2000)\end{array}$} & \multicolumn{2}{|c|}{ Can 2002} & \multicolumn{2}{|c|}{$\begin{array}{l}\text { Fournier } \\
\text { (1991) }\end{array}$} & \multicolumn{2}{|c|}{$\begin{array}{c}\text { Giggenbach } \\
\text { (1988) } \\
\text { (Adiabatic } \\
\text { cooling) }\end{array}$} & \multicolumn{2}{|c|}{$\begin{array}{c}\text { Giggenbach } \\
\text { (1994) } \\
\text { (Conductive } \\
\text { cooling) }\end{array}$} & \multicolumn{2}{|c|}{$\begin{array}{c}\text { Na-K-Ca } \\
\text { Fournier } \\
\text { and } \\
\text { Truesdell } \\
\text { (1973) }\end{array}$} \\
\hline & $1 \mathrm{st}$ & 2nd & $1 \mathrm{st}$ & 2nd & $1 \mathrm{st}$ & 2nd & $1 \mathrm{st}$ & 2nd & $1 \mathrm{st}$ & $2 \mathrm{nd}$ & $1 \mathrm{st}$ & 2nd & $1 \mathrm{st}$ & 2nd & $1 \mathrm{st}$ & 2nd & $1 \mathrm{st}$ & 2nd & $1 \mathrm{st}$ & 2nd & $1 \mathrm{st}$ & $2 \mathrm{nd}$ \\
\hline RN1-1 & 179 & 175 & 143 & 138 & 174 & 170 & 160 & 156 & 190 & 186 & 197 & 193 & 164 & 161 & 180 & 170 & 101 & 97 & 100 & 97 & 275 & 250 \\
\hline RN1-2 & 180 & 175 & 143 & 138 & 175 & 170 & 160 & 156 & 191 & 186 & 198 & 192 & 164 & 160 & 177 & 180 & 100 & 101 & 99 & 100 & 258 & 250 \\
\hline RN1-3 & 182 & 175 & 146 & 138 & 176 & 170 & 162 & 156 & 193 & 186 & 201 & 192 & 166 & 160 & 193 & 177 & 105 & 100 & 105 & 99 & 277 & 250 \\
\hline RN2 & 187 & 186 & 151 & 150 & 181 & 180 & 167 & 166 & 197 & 196 & 207 & 205 & 170 & 169 & 176 & 175 & 99 & 99 & 99 & 99 & 263 & 258 \\
\hline RN3 & 194 & 188 & 158 & 153 & 187 & 182 & 173 & 168 & 203 & 198 & 214 & 208 & 176 & 171 & 175 & 181 & 99 & 101 & 99 & 101 & 267 & 260 \\
\hline RN3-1 & - & 190 & - & 154 & - & 183 & - & 169 & - & 199 & - & 210 & - & 172 & - & 170 & - & 97 & - & 97 & - & 262 \\
\hline RN3-2 & - & 190 & - & 155 & - & 184 & - & 170 & - & 200 & - & 211 & - & 173 & - & 181 & - & 101 & - & 101 & - & 262 \\
\hline RN5 & 186 & 168 & 149 & 131 & 179 & 164 & 166 & 149 & 196 & 180 & 205 & 185 & 169 & 155 & 170 & 138 & 97 & 85 & 97 & 85 & 260 & 239 \\
\hline RN6-1 & 209 & 203 & 176 & 168 & 201 & 195 & 188 & 182 & 217 & 211 & 234 & 226 & 190 & 184 & 193 & 166 & 105 & 96 & 105 & 95 & 291 & 274 \\
\hline RN6-2 & 201 & 207 & 167 & 173 & 194 & 199 & 180 & 186 & 210 & 215 & 224 & 231 & 183 & 187 & 167 & 129 & 96 & 81 & 96 & 82 & 271 & 274 \\
\hline RN6-3 & - & 206 & - & 172 & - & 198 & - & 185 & - & 214 & - & 230 & - & 187 & - & 164 & - & 95 & - & 95 & - & 276 \\
\hline RN6-4 & - & 201 & - & 167 & - & 194 & - & 181 & - & 210 & - & 224 & - & 183 & - & 177 & - & 100 & - & 99 & - & 272 \\
\hline
\end{tabular}


Table 5-8: Temperature results of silica geothermometer in Ranong area.

\begin{tabular}{|c|c|c|c|c|c|c|c|c|c|c|c|c|c|c|c|c|c|c|c|c|c|c|}
\hline \multirow[t]{2}{*}{ Location } & \multicolumn{2}{|c|}{$\begin{array}{c}\text { Surface } \\
\text { temperature } \\
{ }^{\circ} \mathrm{C}\end{array}$} & \multicolumn{2}{|c|}{$\mathrm{SiO}_{2}$} & \multicolumn{2}{|c|}{ Chalcedony } & \multicolumn{2}{|c|}{$\begin{array}{l}\text { Quartz } \\
\text { (no steam } \\
\text { loss) }\end{array}$} & \multicolumn{2}{|c|}{$\begin{array}{c}\text { Quartz } \\
\text { (max. steam } \\
\text { loss at } 100 \\
{ }^{\circ} \mathrm{C} \text { ) }\end{array}$} & \multicolumn{2}{|c|}{ Quartz } & \multicolumn{2}{|c|}{ Quartz $^{\mathrm{a}}$} & \multicolumn{2}{|c|}{ Chalcedony } & \multicolumn{2}{|c|}{ Quartz } & \multicolumn{2}{|c|}{ Quartz $^{\mathrm{a}}$} & \multicolumn{2}{|c|}{ Verma (2000) } \\
\hline & 1 st & 2nd & 1 st & 2 nd & 1 st & $2 \mathrm{nd}$ & 1 st & 2nd & 1 st & 2 nd & $1 \mathrm{st}$ & 2nd & 1 st & 2 nd & 1 st & 2nd & 1 st & $2 \mathrm{nd}$ & 1 st & 2 nd & 1 st & 2 nd \\
\hline RN1-1 & 67 & 67 & 99 & 85 & 110 & 101 & 137 & 128 & 132 & 125 & 137 & 128 & 134 & 126 & 109 & 100 & 125 & 116 & 122 & 114 & 134 & 125 \\
\hline RN1-2 & 62 & 61 & 96 & 84 & 108 & 100 & 135 & 128 & 131 & 125 & 135 & 128 & 132 & 126 & 107 & 100 & 123 & 115 & 120 & 114 & 133 & 125 \\
\hline RN1-3 & 64 & 64 & 104 & 87 & 113 & 102 & 139 & 129 & 135 & 126 & 139 & 129 & 136 & 127 & 111 & 101 & 127 & 117 & 124 & 115 & 137 & 126 \\
\hline RN2 & 41 & 41 & 90 & 87 & 104 & 102 & 132 & 130 & 128 & 126 & 132 & 130 & 129 & 127 & 103 & 101 & 119 & 117 & 117 & 115 & 129 & 127 \\
\hline RN3 & 46 & 47 & 85 & 81 & 100 & 98 & 128 & 126 & 125 & 123 & 128 & 126 & 126 & 124 & 100 & 97 & 116 & 113 & 114 & 112 & 125 & 122 \\
\hline RN3-1 & - & 52 & - & 85 & - & 101 & - & 128 & - & 125 & - & 129 & - & 126 & - & 100 & - & 116 & - & 114 & - & 125 \\
\hline RN3-2 & - & 61 & - & 86 & - & 102 & - & 129 & - & 126 & - & 129 & - & 127 & - & 101 & - & 117 & - & 115 & - & 126 \\
\hline RN5 & 46 & 44 & 81 & 73 & 98 & 92 & 126 & 120 & 123 & 119 & 126 & 121 & 124 & 119 & 98 & 92 & 113 & 107 & 112 & 107 & 123 & 116 \\
\hline RN6-1 & 46 & 42 & 88 & 91 & 103 & 105 & 130 & 132 & 127 & 128 & 131 & 132 & 128 & 129 & 102 & 104 & 118 & 119 & 116 & 117 & 127 & 129 \\
\hline RN6-2 & 38 & 67 & 95 & 99 & 108 & 83 & 135 & 112 & 131 & 112 & 135 & 113 & 132 & 112 & 106 & 84 & 122 & 99 & 120 & 99 & 132 & 108 \\
\hline RN6-3 & - & 62 & - & 100 & - & 111 & - & 137 & - & 133 & - & 138 & - & 134 & - & 109 & - & 125 & - & 122 & - & 135 \\
\hline RN6-4 & - & 64 & - & 95 & - & 107 & - & 134 & - & 130 & - & 135 & - & 132 & - & 106 & - & 122 & - & 120 & - & 132 \\
\hline
\end{tabular}


Table 5-9: Rare earth element in the water samples in Ranong area.

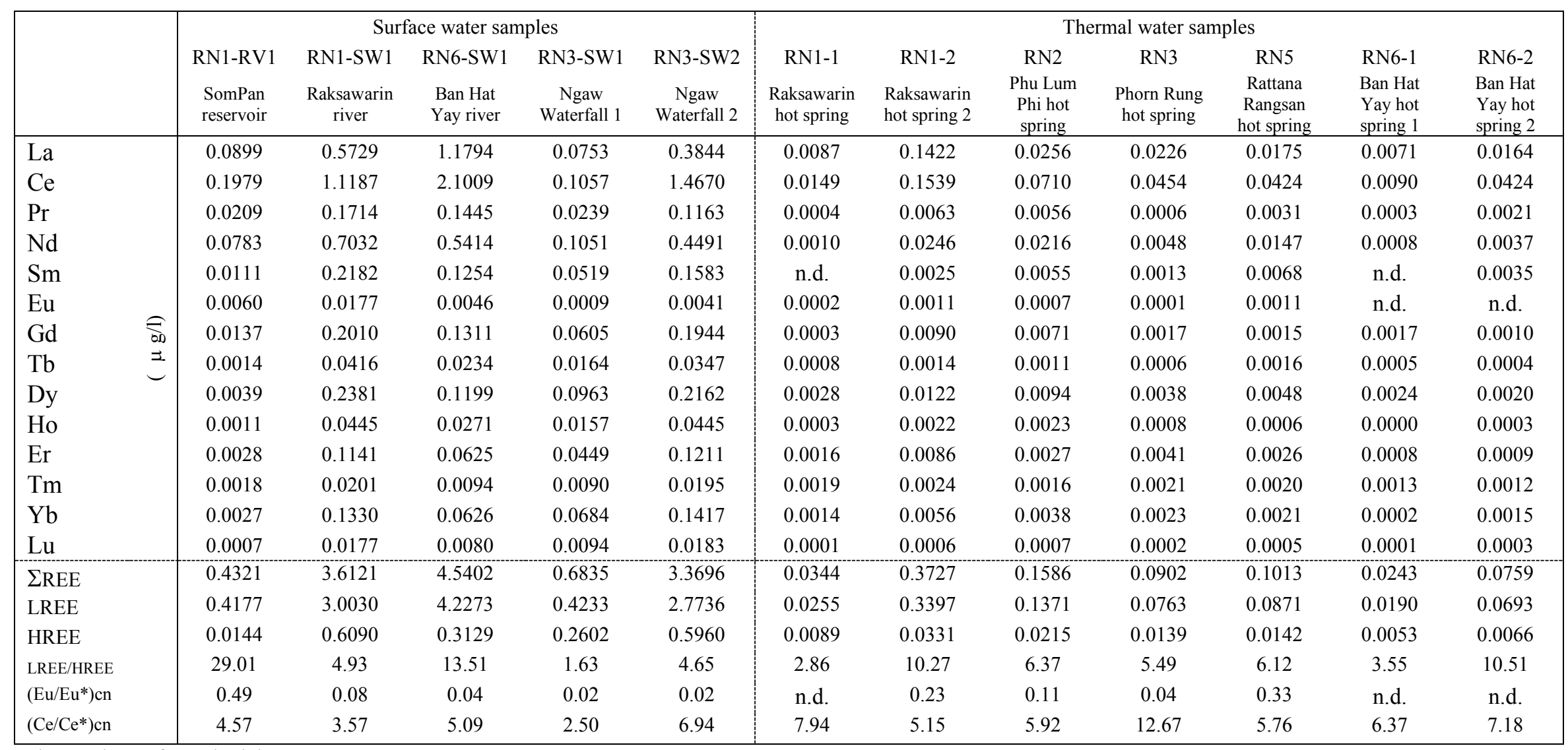

n.d.; not detect from the laboratory. 

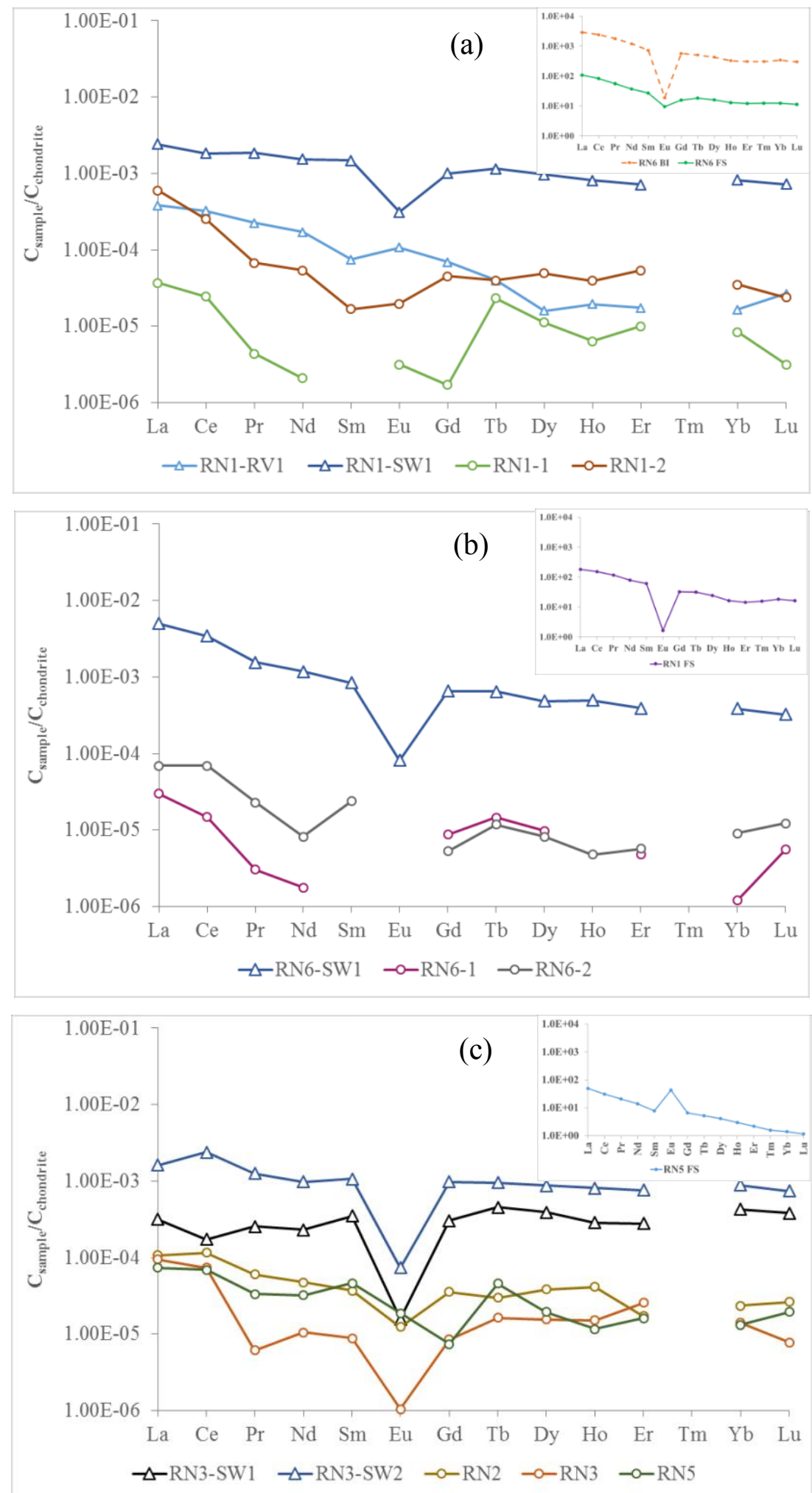

Figure 5.2-4: Chondrite-normalized REE patterns (McDonough and Sun, 1995) of surface and thermal water samples for location of RN1 (a), RN6 (b), and for RN2, RN3, and RN5 (c) comparing with the local rock. 
Table 5-10: Analytical results of $\mathrm{Rb}, \mathrm{Sr}$, and ${ }^{87} \mathrm{Sr} /{ }^{86} \mathrm{Sr}$ ratio in the water samples in Ranong geothermal area.

\begin{tabular}{|c|c|c|c|c|c|c|}
\hline \multirow{2}{*}{ Location } & \multirow{2}{*}{${ }^{87} \mathrm{Sr} /{ }^{86} \mathrm{Sr}$} & \multirow{2}{*}{ SD } & $\mathrm{Rb}$ & $\mathrm{Sr}$ & \multirow{2}{*}{$\mathrm{Rb} / \mathrm{Sr}$} & \multirow{2}{*}{$1 / \mathrm{Sr}$} \\
\hline & & & \multicolumn{2}{|c|}{$(\mu \mathrm{g} / \mathrm{l})$} & & \\
\hline RN1-1 & 0.74886 & 0.00002 & 35.15 & 71.60 & 0.491 & 0.014 \\
\hline RN1-2 & - & - & 34.86 & 73.78 & 0.472 & 0.014 \\
\hline RN2 & 0.73971 & 0.00002 & 35.95 & 99.22 & 0.362 & 0.010 \\
\hline RN3 & 0.73861 & 0.00004 & 33.86 & 82.33 & 0.411 & 0.012 \\
\hline RN5 & 0.74519 & 0.00001 & 23.62 & 53.89 & 0.438 & 0.019 \\
\hline RN6-1 & 0.74909 & 0.00001 & 27.66 & 44.00 & 0.629 & 0.023 \\
\hline RN6-2 & 0.74906 & 0.00006 & 28.84 & 47.66 & 0.605 & 0.021 \\
\hline RN1-RV1 & 0.74267 & 0.00002 & 2.09 & 9.64 & 0.217 & 0.104 \\
\hline RN1-SW1 & 0.74311 & 0.00002 & 7.56 & 7.87 & 0.960 & 0.127 \\
\hline RN6-SW1 & 0.74494 & 0.00002 & 14.26 & 3.25 & 4.381 & 0.307 \\
\hline RN3-SW1 & 0.73442 & 0.00002 & 12.14 & 1.26 & 9.652 & 0.795 \\
\hline RN3-SW2 & 0.73887 & 0.00026 & 12.83 & 1.65 & 7.758 & 0.605 \\
\hline
\end{tabular}




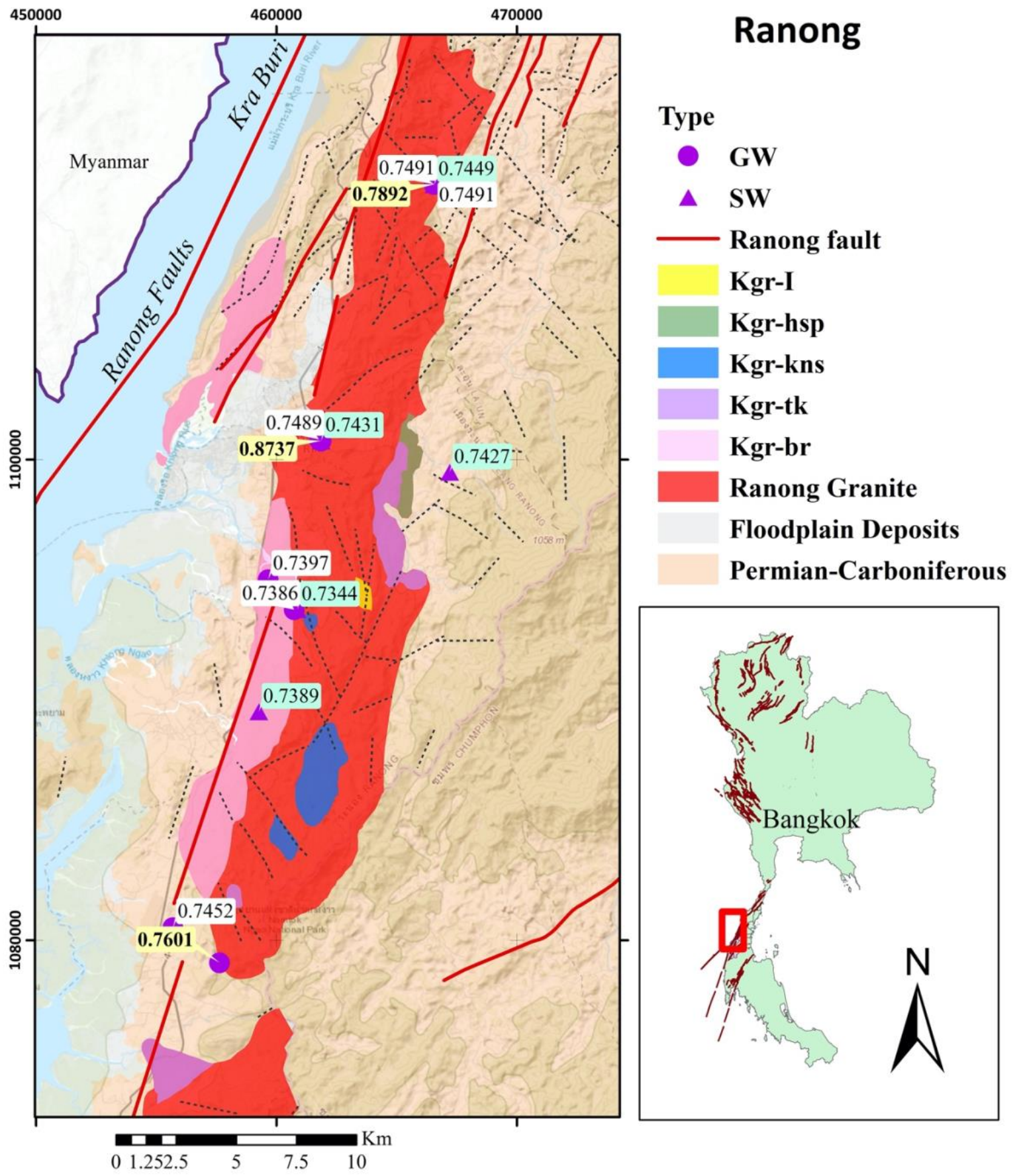

Figure 5.2-5: Spatial distribution of ${ }^{87} \mathrm{Sr} /{ }^{86} \mathrm{Sr}$ ratio in the feldspar mineral (yellow background), the surface water (blue background), and the thermal water samples (white background), are plotted with the Ranong geological map. 


\subsection{Interpretation}

\subsubsection{Hydro-geochemistry and origin of water}

\subsubsection{The origin of the thermal water}

In hydrological cycles, meteoric water is the primary source of geothermal water. The isotopic compositions of hydrogen and oxygen in thermal water reflect a combination of isotopic effects that occur in locally infiltrated meteoric water, for instance: temperature effects, altitude effects, continental effects, amount effects, and source effects (Dansgaard, 1964; Rozanski et al., 1993).

$\delta^{2} \mathrm{H}$ and $\delta^{18} \mathrm{O}$ results of Ranong thermal water and surface water samples, which plot close to and above the LMWL in the stable isotope relationship diagram (Figure5.2-3(a)), and has not correlation with the magmatic water area from Giggenbach, (1992) (Figure5.2-3(b)). Therefore, these can indicate that the main source of thermal and surface water is not conducted with the magmatic water, however, the location of thermal water in the graph does not support general isotopic theories. In fact, thermal water derived from rainwater transports and accumulates into the geothermal reservoirs before coming back to the land surface. Therefore, most thermal water retains the isotopic ratio of long-term precipitation and would therefore plot at or below the LMWL. This abnormal plotting location of thermal water (Figure 5.2-3(a)) may originate from three-year rainfall event in Ranong station.

According to HAII, (2016), the results of the average monthly precipitation amounts and $\delta^{18} \mathrm{O}$ at Ranong station between 2013 and 2015 are plotted as annual rainfall distributions by month (Figure 5.3-1). The overlap of peaks in the precipitation amount and $\delta^{18} \mathrm{O}$ in these graphs occur in July and September. These are in line with the rainfall event in this region from the Thailand Meteorological Department (TMD, 2012), the detailed of which are explained in Chapter 2. The amount-weighted monthly isotopic $\left(\delta^{18} \mathrm{O}\right)$ values and monthly mean precipitation amount in 2014 have large variabilities relative to other year. Moreover, $D_{\text {Excess }}$ of average LMWL in 2014 indicate lower value (7.67\%) relative to the Dexcess values from thermal waters (which range from 12.69 to $14.39 \%$ ) and from surface waters (which range from 11.32 to $14.13 \%$ ), suggesting that the precipitation event in 2014 provided a different isotopic composition of moisture relative to other years. 


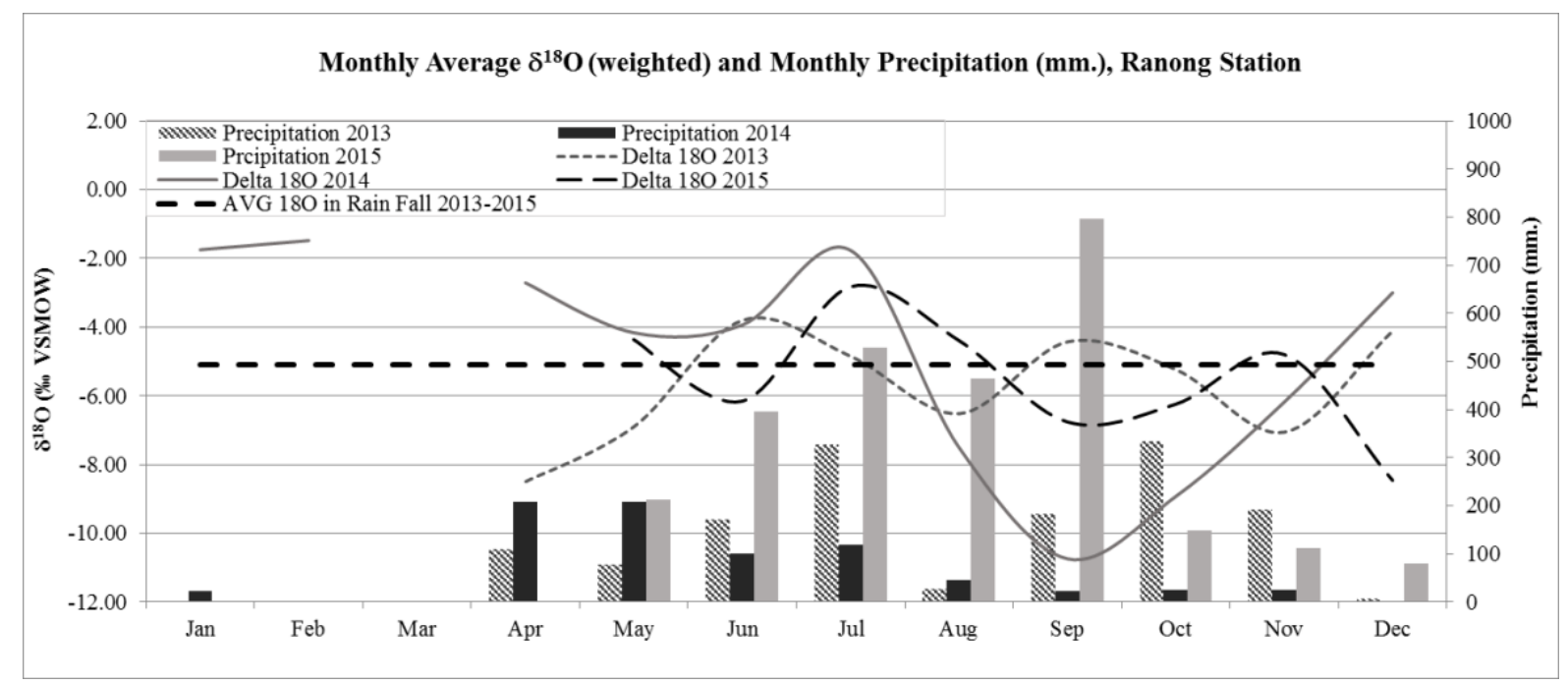

Figure 5.3-1: Seasonal variation of amount-weighted monthly isotopic $\left(\delta^{18} \mathrm{O}\right)$ values and monthly mean precipitation amount in the Ranong station in each year from 2013 to 2015. (modified after HAII, (2016)).

As proposed by previous studies (Kurita et al., 2009; Rozanski et al., 1993; Wei et al., 2018), the isotopic composition of precipitation in tropical regions is dominated by regional processes and varies through large-scale convection, moisture source, and the movement of the ITCZ. The results from back-trajectory simulations suggest that Indian Ocean moisture is the primary moisture source in this region (Wei et al., 2018). However, the percent contribution of Indian Ocean moisture in one-year mean in September 2005 (87\%) is significantly different than the multi-year mean from September 2003-2013 (75\%). This evidence points out that this region has a large yearly-variable in moisture contribution from the Indian Ocean (especially in 2005). In the same way, the sizeable variation of the isotopic composition and precipitation amount during 2014 may be associated with the Indian Ocean moisture contribution and possibly lowers the three-year LMWL to below the isotopic value of thermal water.

To investigate this phenomenon, the isotopic composition from the water samples were reinterpreted by drawing a modeled LMWL, using the slope from the average LMWL (7.97) and the y-intercept of the average Dexcess from thermal water $(13.47 \%$ ). This model LMWL is given by the following equation $\delta^{2} \mathrm{H}=7.97 \delta^{18} \mathrm{O}+13.4 \%$, (Figure 5.2-3). It passes through most of the isotopic ratio from thermal water (e.g., RN2, RN3, RN5, and RN6-1) and surface water samples (e.g., RN-SW1, RN3-SW1, RN3-SW2, and RN6-SW1).

Changing in the isotopic ratio of surface water samples typically indicate seasonal variation, since isotopic ratios are enriched in the pre-monsoon season and are depleted in the post- 
monsoon season (Figure 5.2-3). It should be noted that this isotopic ratio has the same trend as the monthly local meteoric data, which is also isotopically depleted in post-monsoon seasons and becomes remarkably enriched in pre-monsoon seasons (HAII, 2016). The seasonal variation is clearly demonstrated in the two samples from Ngaw waterfall (RN3-SW1 and RN3-SW2), which are probably influenced by the evaporation effect. The correlation line of these samples is modeled as: $\delta^{2} \mathrm{H}=5.68 \delta^{18} \mathrm{O}+1.4 \%$ (Figure 5.2-3).

The isotopic compositions of thermal waters are more depleted than the surface waters, as shown in Figure 5.2-3. The decrease in isotope values for precipitation varies according to a function of increasing elevation since isotopic fractionation occurs from cooling and condensation of water vapor as it rises over the mountain (Rowley et al., 2001; Rowley and Garzione, 2007). However, the altitude gradient of stable isotopes in this area has not been investigated in this study. Therefore, the recharge areas of thermal water are proposed to be located at the higher elevations and can be estimated by Eq. (3.4) and applying altitude- $\delta^{18} \mathrm{O}$ gradient in Thailand from Doi Inthanon reported, $-0.22 \%$ o $/ 100 \mathrm{~m}$ (TINT, 2012) as aforementioned in Chapter 3. The results of the recharge elevation estimation are ranging from 377.85 to $482.85 \mathrm{~m}$ AMSL and shown in Table 5-11.

Table 5-11: Results of recharge elevation estimation from stable isotope composition of thermal water.

\begin{tabular}{lccc}
\hline \multirow{2}{*}{ Location } & $\begin{array}{c}\text { Altitude } \\
\text { (m AMSL) }\end{array}$ & \multicolumn{2}{c}{$\begin{array}{c}\text { Recharge elevation } \\
\text { (m AMSL) }\end{array}$} \\
\cline { 2 - 4 } & & 1 st & 2nd \\
\hline RN1-1 & 37.70 & 409.83 & 377.85 \\
RN1-2 & 38.57 & - & 402.87 \\
RN1-3 & 39.85 & - & 395.73 \\
RN2 & 15.61 & 407.55 & 405.12 \\
RN3 & 72.54 & 482.85 & 461.13 \\
RN3-1 & 66.50 & - & 411.37 \\
RN3-2 & 67.82 & - & 433.81 \\
RN5 & 37.48 & 434.43 & 424.78 \\
RN6-1 & 66.88 & 422.70 & 436.56 \\
RN6-2 & 67.50 & 476.69 & 406.35 \\
RN6-3 & 69.00 & 423.87 & 467.65 \\
RN6-4 & 67.70 & - & 462.74 \\
\hline
\end{tabular}


The isotopic compositions of the thermal water samples exhibit lower seasonal changes compared to the isotopic compositions of the surface water. In Figure 5.3-2, the grouping of the thermal water samples in the pre-monsoon season features a wider distribution and higher deviation towards the LMWL than in the post-monsoon seasons. This result indicates that the seasonal variation has an effect on the isotopic ratio of thermal water samples. This conclusion is consistent with the conclusion from Rowley et al., (2001); Rowley and Garzione, (2007) that this isotopic signature from the unconfined aquifer can be retained from some seasonal effect in recharge.

The isotopic compositions of $\delta^{2} \mathrm{H}$ and $\delta^{18} \mathrm{O}$ in thermal water samples are likely correlated, given by the equation $\delta^{2} \mathrm{H}=3.47 \delta^{18} \mathrm{O}+12.3 \%\left(\mathrm{R}^{2}=0.72\right)$ and, shown in Figure $5.3-2$. The slope of this equation is lower than the slope of the evaporation line from surface water (Figure 5.2-3 (a)). Hence, this could suggest that this isotopic correlation line for thermal water is not derived from the evaporated surface water. It probably originated from the water-rock interaction.

The $\delta^{18} \mathrm{O}$-shifted values in the thermal water are estimated from the $\delta^{18} \mathrm{O}$ in model LMWL and shown in Table 5-5. All of the $\delta^{18} \mathrm{O}$-shifteds results are lower than the analytical precision of $\delta^{18} \mathrm{O}(0.2 \%)$. The ranges of the $\delta^{18} \mathrm{O}$-shifted results in the post-monsoon season are narrower than that for the pre-monsoon season. This would indicate that the water-rock interaction in the pre-monsoon season is higher than that from the post-monsoon season. Particularly, the seasonal variation of the $\delta^{18} \mathrm{O}$-shifted values in RN5 (ranging from -0.05 to $0.02 \%$ ) and RN6 (ranging from -0.02 to $0.12 \%$ ) are higher than from the other hot springs. This means that the variation of water-rock interaction in RN5 and RN6 hot springs are influenced by the seasons, which would reflect short water travel time in these systems.

The isotopic ratios of RN2 and RN3 thermal water samples, which are located in the middle of the study area, showing insignificant deviation from each other in both seasons with similar chemical concentrations. These thermal water samples are probably recharged at the same elevation and have a long residence time. 


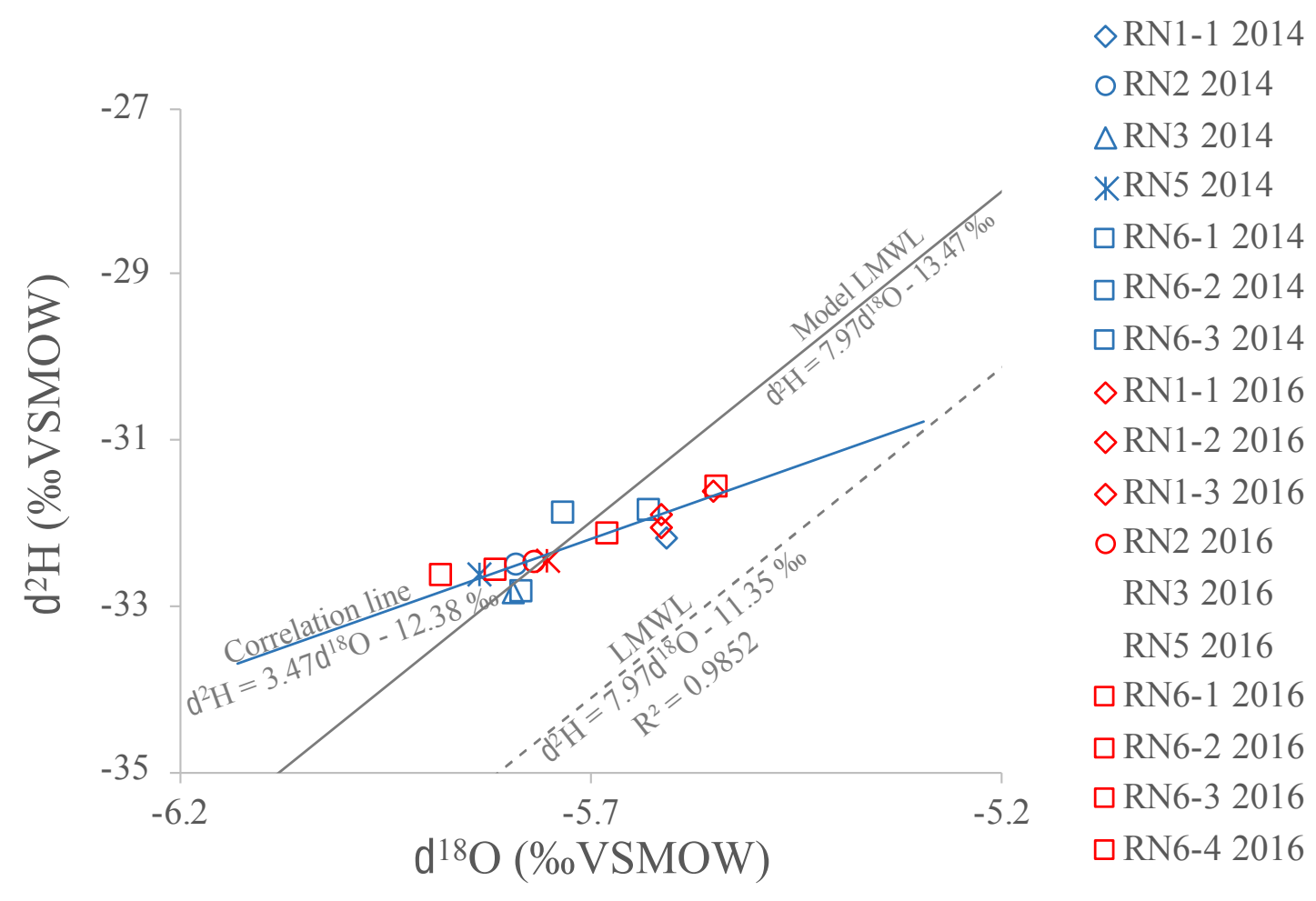

Figure 5.3-2: Stable isotope results in thermal water samples from December 2014 and March 2016, compare with LMWLs from Ranong station. The blue symbols represent the samples, collected in December 2014, while red symbols represent the samples collected in March 2016. The gray line represents the model LMWL equation which contains slope from the average LMWL (7.97) and a y-intercept of the average of Dexcess from thermal water (13.47\%o). The dotted gray lines represent the linear from the LMWL equation. The blue line represents the linear correlation of thermal water samples. 


\subsubsection{Geochemical processes.}

Groundwater geochemistry is controlled by the chemical and physical processes of subsurface systems such as cation exchange, dissolution of silicate minerals, and dissolution and/or precipitation of carbonates and gypsum (Cartwright and Morgenstern, 2012). In the Ranong geothermal area, the thermal waters provide a higher chemical concentration relative to surface water. From the triangular diagram, the water samples are dominated by $\mathrm{Na}-\mathrm{HCO}_{3}$ type commonly indicating the presence of a shallow condensate zone from the margins of the geothermal fields (Nicholson, 1993). Moreover, the isotopic composition in thermal water indicates the precipitation origin. These would reflect the developing of chemical concentration from rainwater and surface water to the subsurface geothermal system.

As aforementioned in Chapter 3.3, for visual identification of the geochemical processes, the analytical major-ion compositions in thermal waters samples and the major-ion compositions in Post-ET (Table 5-4) are plotted in the Schoeller's diagram in Figure 5.3-3.

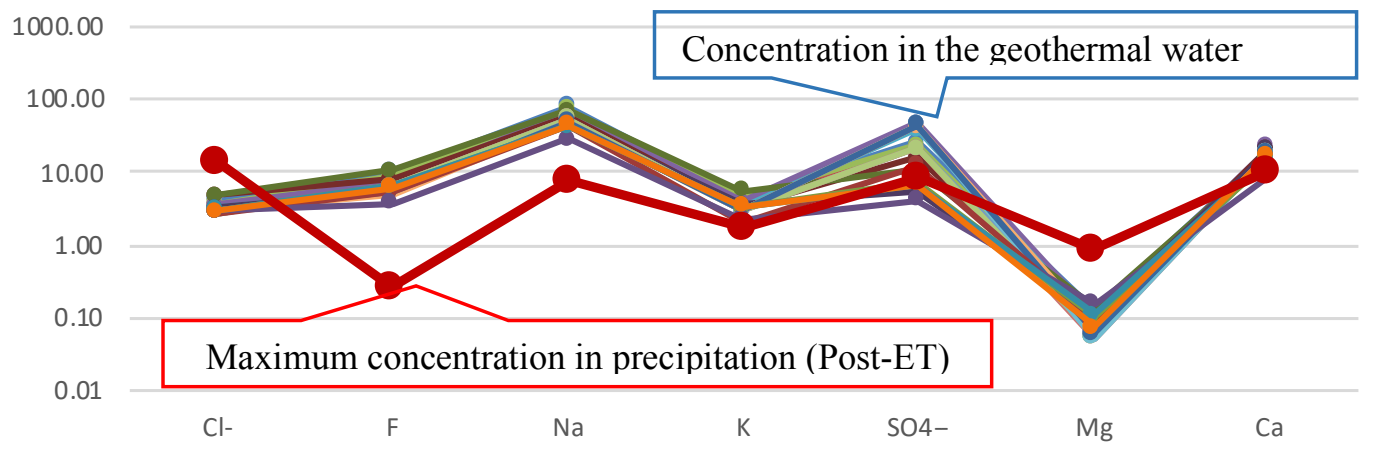

Figure 5.3-3: Schoeller's diagram of the major-ion concentration between the geothermal water versus Post-ET.

In Figure 5.3-3, most of the major-ion concentration in thermal water $\left(\mathrm{F}^{-}, \mathrm{Na}^{+}, \mathrm{K}^{+}, \mathrm{SO}_{4}^{-}\right.$and $\mathrm{Ca}^{2+}$ ) are increased from major-ion compositions in Post-ET. The geological setting of these thermal water is the granitic basement rock, mainly composed of plagioclase (Na-feldspar), Kfeldspar, and Biotite. These minerals can provide major-ion compositions to the water at the higher temperature and long residence time. This can suggest that the concentration of $\mathrm{F}^{-}, \mathrm{Na}^{+}$, $\mathrm{K}^{+}, \mathrm{SO}_{4}^{-}$and $\mathrm{Ca}^{2+}$ could be developed from the granitic minerals after the water flow through the undersaturated zone. 
In contrast, $\mathrm{Mg}^{2+}$ concentrations in thermal water are clearly lower than that in the precipitation. According to Nicholson, (1993), $\mathrm{Mg}^{2+}$ can precipitate in the form of carbonates, gypsum, or siliceous sinter at height temperature and is easily absorbed into these secondary alteration minerals; such as illite, montmorillonite, and chlorite. According to the petrology investigation, our granite samples demonstrated chloritized of biotite and minor sericitized of plagioclase. Therefore, these imply that $\mathrm{Mg}^{2+}$ may be decreased by precipitation processes after the water flow through the undersaturated zone which contains the altered minerals.

$\mathrm{Cl}^{-}$is a conservative element in the hydrological cycle, and is a useful chemical tracer for indicating sources, atmospheric input and the flow part of the subsurface. The main sources in the hydrological system are derived from marine salt, human activity, and rock (halite)(Clark, 2015; Nicholson, 1993; Petelet-Giraud et al., 2003). However, the $\mathrm{Cl}^{-}$concentrations in the thermal water samples are in a small range from 2.77 to $4.90 \mathrm{mg} / 1$ and is lower than the maximum $\mathrm{Cl}^{-}$concentration of the precipitation in Figure 5.3-3. These can be indicating that $\mathrm{Cl}^{-}$in thermal water was assigned to the precipitation origin.

From Figure 5.2-1 and Figure 5.2-2, the triangular diagram, The water samples are dominated by $\mathrm{Na}-\mathrm{HCO}_{3}$ type is commonly characterized in the shallow condensate zone from the margins of the geothermal fields (Petelet-Giraud et al., 2003).

\subsubsection{Source of dissolved carbon and residence time of thermal water}

Residence time is an important parameter for evaluating the quantity of water in the hydrological system. This study investigates the residence time of the Ranong hot springs through tritium and radiocarbon dating.

All samples of Ranong thermal water have low tritium content ranging between 0 and $0.1 \mathrm{TU}$, the values of which are lower than the standard deviation of the measurement. Therefore, it can imply that the residence time in thermal springs is older than 60 years.

For carbon sources and residence time estimation, the dissolved inorganic carbon concentration (DIC) from all water samples in the Ranong geothermal area are similar with respect to the bicarbonate ion form $\left(\mathrm{HCO}_{3}{ }^{-}\right)$at $\mathrm{pH} 6.72$ - 8.1, which is the most abundant anions. Ranong thermal waters have the depleted $\delta^{13} \mathrm{C}$ isotopic compositions (Table 5-6) ranging from -25.59 to -23.55 , are in agreement with the dissolved organic carbon (DOC) in groundwater (Clark, 2015; Hoefs, 2009) and in line with the $\delta^{13} \mathrm{C}$ of organic-rich land soil and river sediment on 
the southwestern coast of Thailand ranging from -27.8 to $-23.9 \%$ (Kuramoto and Minagawa, 2001).

This depleted $\delta^{13} \mathrm{C}$ ratio of the reaction product $\left(\mathrm{HCO}_{3}^{-}\right.$(aq) $)$in Ranong hot springs may associate with the silicate weathering from rapidly infiltration process (Han et al., (2012), Han and Plummer, (2016)). In this situation, the infiltrated water molecules react through the dissolution of $\mathrm{CO}_{2(\mathrm{aq})}$ from the soil, forming carbonic acid $\left(\mathrm{H}_{2} \mathrm{CO}_{3}(\mathrm{aq})\right)$. These molecules, which have $\delta^{13} \mathrm{C}$ from the soil gas, rapidly move into the silicate aquifer and weather the silica mineral in the basement rock without the interaction from the other carbon sources. This process may lead to an increase in $\mathrm{HCO}_{3}^{-}(\mathrm{aq}), \mathrm{Na}^{+}$, and $\mathrm{K}^{+}$in the water. Therefore, considering the geological setting of Ranong hot springs, we can imply that the thermal water rapidly recharges from the shallow soil layer and flows through the sinkhole/fracture of cretaceous regional granite where noncarbonate are.

In order to improve the radiocarbon age estimation, certain studies have attempted to adjust the analytical results of ${ }^{14} \mathrm{C}$ to be the initial radiocarbon amount $\left({ }^{14} \mathrm{C}_{0}\right)$ which is the value before being modified by the geochemical processes, but not radioactive decay. In the case of the fast infiltrating water and low $\delta^{13} \mathrm{C}$ values of Ranong hot springs, Pearson's model in Eq. (5.1) seem to be a suitable application to correct the initial radiocarbon $\left({ }^{14} \mathrm{C}_{0}\right)$ (Han and Plummer, 2016).

$$
{ }^{14} C_{0}=\frac{{ }^{14} C_{g}-{ }^{14} C_{s}}{\delta^{13} C_{g}-\delta^{13} C_{s}}\left(\delta^{13} C_{D I C}-\delta^{13} C_{s}\right)
$$

where ${ }^{14} \mathrm{C}_{\mathrm{s}}$ and ${ }^{13} \mathrm{C}_{\mathrm{s}}$ are Carbon isotopic composition of dissolved soil carbonate minerals assume to be ${ }^{14} \mathrm{C}_{\mathrm{s}}=0,{ }^{13} \mathrm{C}_{\mathrm{s}}=0,{ }^{14} \mathrm{C}_{\mathrm{g}}$ and ${ }^{13} \mathrm{C}_{\mathrm{g}}$ are Carbon isotopic composition of soil gas $\mathrm{CO}_{2}$, assumed to be ${ }^{14} \mathrm{C}_{\mathrm{g}}=100,{ }^{13} \mathrm{Cg}$ values are in the range of the previous $\delta^{13} \mathrm{C}$ value $(-27.8$ to 23.9\%o) in soil and river sediment (Han and Plummer, 2016), ${ }^{13} \mathrm{C}_{\mathrm{DIC}}$ is a carbon isotopic composition determined from the thermal water samples, The corrected results of initial radiocarbon $\left({ }^{14} \mathrm{C}_{0}\right)$ and age estimation in Ranong hot spring water where are shown in Table 512.

After the recalculation is completed, the fluid residence time results indicate a range of 2,675 to $5,235 \mathrm{BP}$, which appears to be around 600 to $1200 \mathrm{BP}$ when compared to the unadjusted residence time. The spring with the longest residence time is RN1 and the spring with the 
shortest is RN3. In addition, the long residence time results from ${ }^{14} \mathrm{C}$ are inconsistent with the tritium results, which have shown a residence time period for these hot springs of longer than $60 \mathrm{BP}$.

\subsubsection{Geothermal assessment, geothermometer application.}

Different geothermometers provide the different range of temperature results. However, if the system has not reached the water-rock equilibrium state and/or has been mixed with cooled water while rising to the surface, a straightforward temperature estimation from these geothermometers would not provide reliable temperature results. This study recognizes three graphical tools for validating these geothermometers in Ranong hot springs: the $\mathrm{Na}-\mathrm{K}-\mathrm{Mg}$ triangular diagram, the quartz/Na-K diagrams and quartz/Mg-K diagrams, and the silicaenthalpy mixing model.

\subsubsection{The Na-K-Mg triangular diagram.}

All of the Ranong thermal waters are located in the immature water regime of the $\mathrm{Na}-\mathrm{K}-\mathrm{Mg}$ triangular diagram (Figure 5.3-4). Apart from that, the RN3-2 hot spring closest to being partially equilibrated. This suggests that Ranong thermal waters are in the near-surface rockwater reactions. Therefore, the slow rock-water equilibrium reaction of the $\mathrm{Na}-\mathrm{K}$ geothermometer is not reliable to be applied in the Ranong area. 
Table 5-12: Corrected resident times period of hot springs in Ranong area.

\begin{tabular}{|c|c|c|c|c|c|c|c|c|}
\hline \multirow[t]{2}{*}{ Location } & \multirow[t]{2}{*}{ name } & \multirow{2}{*}{$\begin{array}{c}\text { Temp } \\
{ }^{\circ} \mathrm{C}\end{array}$} & \multicolumn{2}{|c|}{ Measured ${ }^{14} \mathrm{C}$} & \multicolumn{2}{|c|}{$\begin{array}{l}\text { Uncorrected } \\
\text { residence times }\end{array}$} & \multirow[t]{2}{*}{${ }^{14} \mathrm{C}_{\mathrm{DC}} /{ }^{14} \mathrm{C}_{0}$} & \multirow{2}{*}{$\begin{array}{c}\begin{array}{c}\text { Corrected } \\
\text { residence times }\end{array} \\
\text { BP }\end{array}$} \\
\hline & & & PMC & error & $\mathrm{BP}$ & error & & \\
\hline RN1 & Raksawarin hot spring & 66.70 & 56.85 & 1.36 & 4,540 & 200 & $0.53-0.62$ & $3,985-5,235$ \\
\hline RN2 & Phu Lum Phi hotspring & 41.40 & n.d. & n.d. & n.d. & n.d. & - & - \\
\hline RN3 & Phorn Rung hot spring & 45.70 & 61.94 & 1.47 & 3,850 & 190 & $0.62-0.72$ & $2,675-3,920$ \\
\hline RN5 & Rattana Rangsan hot spring & 46.00 & 54.70 & 1.31 & 4,850 & 200 & $0.56-0.65$ & $3,618-4,865$ \\
\hline RN6 & Had Yay hot spring & 45.90 & 59.04 & 2.43 & 4,230 & 200 & $0.59-0.69$ & $3,075-4,325$ \\
\hline
\end{tabular}




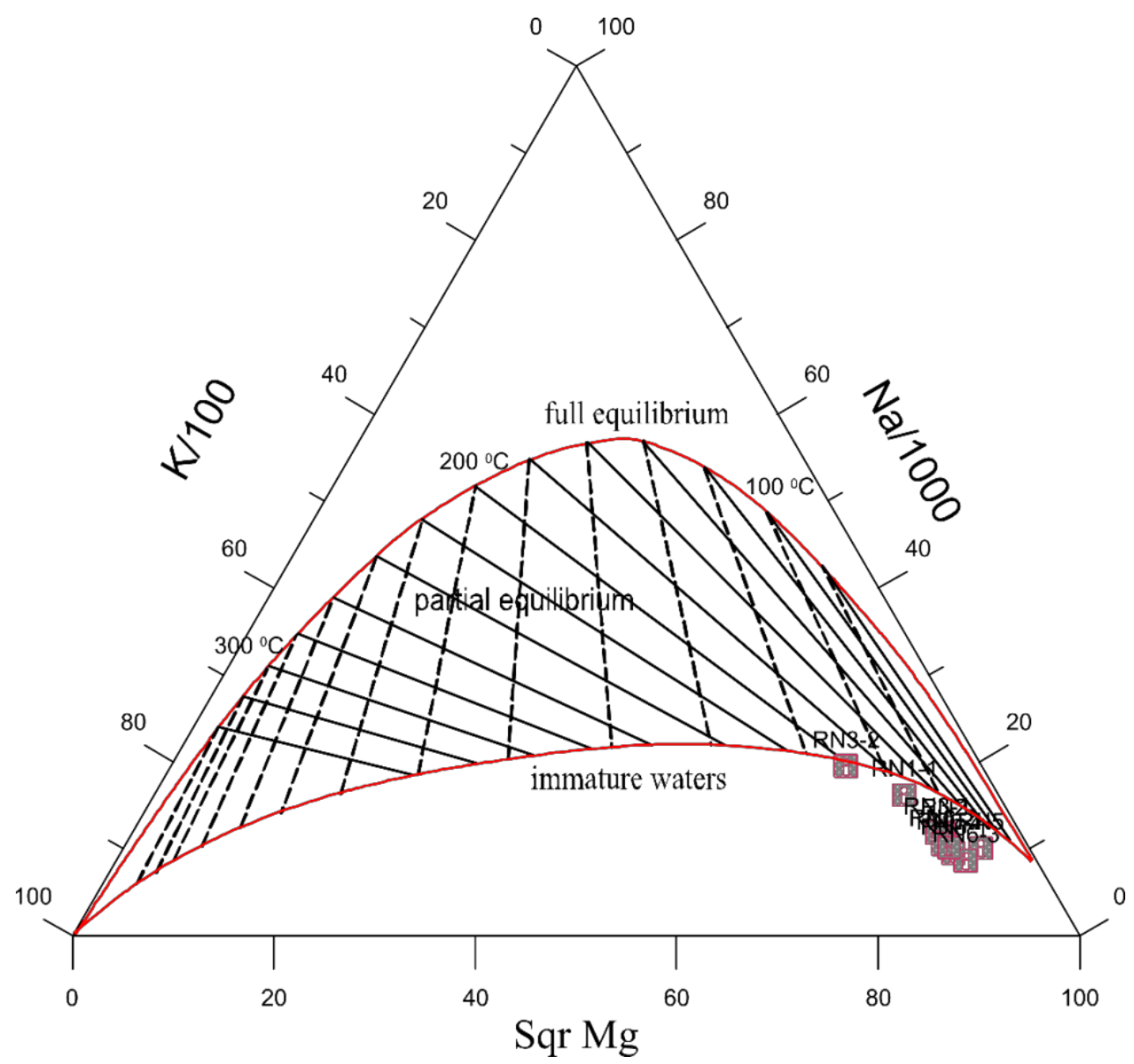

Figure 5.3-4: Na-K-Mg triangular diagram of the Ranong thermal water (Giggenbach, 1988).

\subsubsection{The Quartz/Na-K diagram and Quartz/Mg-K diagram}

The graphical correlation between the silica geothermometer and two cation geothermometers (Na-K and $\mathrm{Mg}-\mathrm{K}$ ) with the different rate of equilibrium reactions has been applied to check the validity of each aforementioned geothermometer.

The Quartz/Na-K diagram (Giggenbach, 1988) and the Quartz/ Mg-K diagram (Giggenbach et al., 1994) compare the logarithm of chemical concentration from hot springs and theoretical geothermometer lines (Figure 5.3-5(a), and 5.3-5(b), respectively).

In Figure 5.3-5(a), the Quartz/Na-K diagram results indicate that all of the thermal water are located below the theoretical line. For this reason, albite and K-feldspar minerals, (which are represented by $\mathrm{Na}$ and $\mathrm{K}$ ), are probably not present as hydrothermal minerals. Moreover, thermal waters have likely not reached equilibrium.

In Figure 5.3-5(b), the Quartz/ Mg-K diagram results indicate that all of the thermal waters are located close to the chalcedony line and the quartz conductive cooling line in the lower part of 
the graph. Remarkably, RN3-2 is closest to the quartz conductive cooling line, with an apparent equilibrium temperature of $114{ }^{\circ} \mathrm{C}$, and $\mathrm{RN}-1$ is at the chalcedony line, with an apparent equilibrium temperature of $99.6-100.9{ }^{\circ} \mathrm{C}$. Other samples demonstrate a slight disequilibrium between the K-Mg and Silica subsystems since the logarithm value of silica are located slightly above the chalcedony line. Therefore, Ranong thermal waters are reliable on the conservative $\mathrm{K}-\mathrm{Mg}$ and chalcedony subsystem, and these equilibrium temperatures are between 82 to $105^{\circ} \mathrm{C}$.
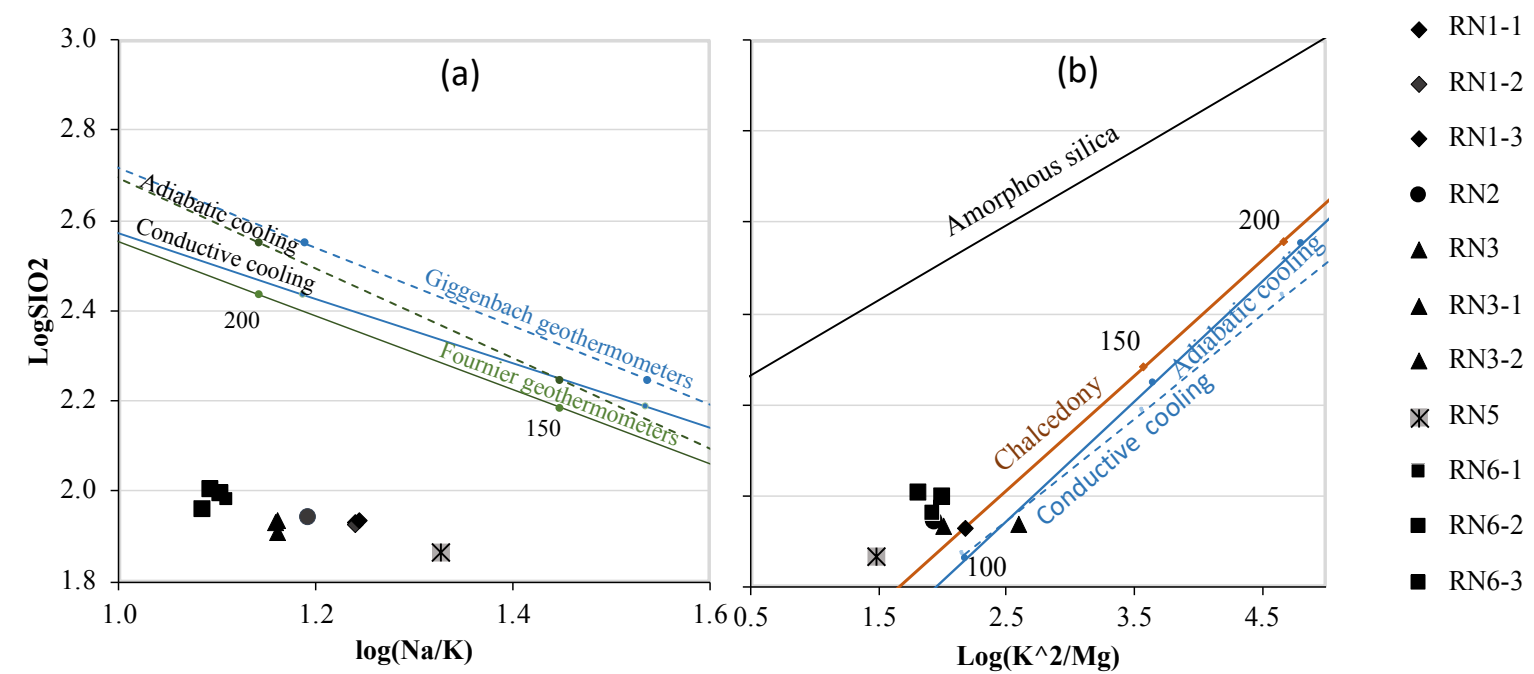

Figure 5.3-5: Quartz/Na-K diagram (modified from Giggenbach, 1988) and Quartz/Mg$\mathrm{K}$ diagram (modified from Giggenbach et al., 1994) for the considered thermal waters of Ranong area.

\subsubsection{The silica-enthalpy mixing model}

The chemical composition of the original thermal water can be modified by the chemical concentration of cold water. In this case, chemical geo-thermometers would probably obtain an incorrect estimated temperature result (mixed temperature).

The mixing model results from Ranong hot springs in pre- and post-monsoon seasons are shown in Figure 5.3-6(a) and 5.3-6(b), respectively. The results in the first scenario illustrated that both graphs can draw a mixing line converge on the Chalcedony solubility curve in the RN1, RN3 and RN5 samples. However, the enthalpy from the convergent point of RN3 and RN5 (point A) is higher than the limitation of the chalcedony geothermometer, ie., more than $1085.32 \mathrm{~J} / \mathrm{g}\left(\right.$ at $250^{\circ} \mathrm{C}$ ) (Arnórsson, 2000; Fournier, 1977). Therefore, it can be roughly implied that this model and the estimation of mixing ratio from the first scenario are only suitable for the RN1 hot spring (Table 5-13). The dilution ratios from enthalpy $(\mathrm{H})$ and $\mathrm{SiO}_{2}(\mathrm{~S})$ in $\mathrm{RN} 1$ 
indicate a slightly decreasing value from 0.83 to 0.79 , and the reservoir temperatures are from 194 to $229^{\circ} \mathrm{C}$.

In the second scenario, (Table 5-13), the results show that: the initial $\mathrm{SiO}_{2}$ concentrations range from 225 to $355 \mathrm{mg} / \mathrm{L}$, the corresponding reservoir temperatures range from 132 to $199{ }^{\circ} \mathrm{C}$, the enthalpy dilution ratios $(\mathrm{H})$ range from 0.80 to 0.93 , and the dilution ratio $\mathrm{SiO}_{2}(\mathrm{~S})$ range from 0.73 to 0.83 . Apart from that, the results in $\mathrm{RN} 1$ indicate lower value relative to the other hot springs.

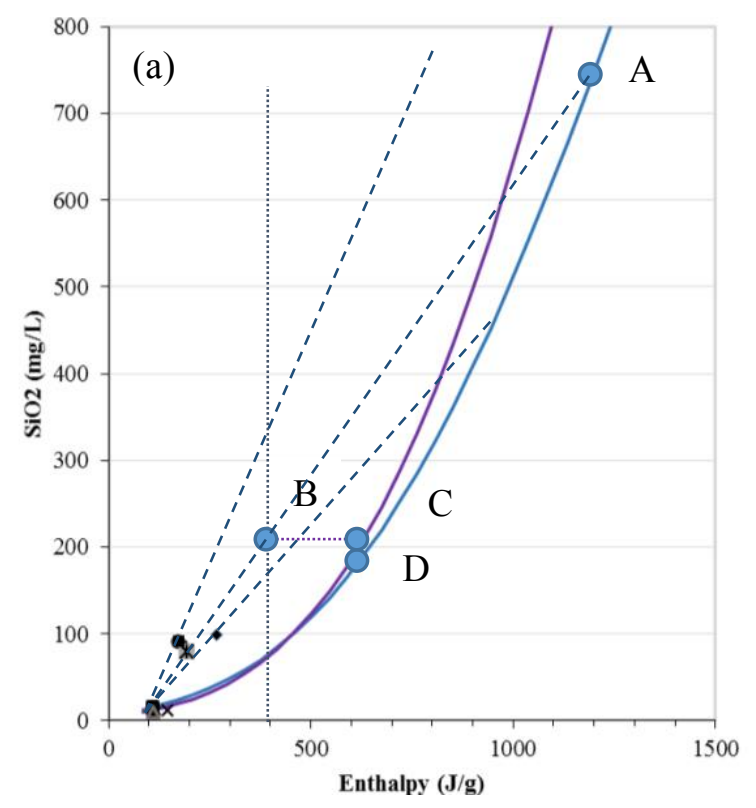

- RN1

* RN5

- RN1-SW1

$\Delta$ RN3-SW2

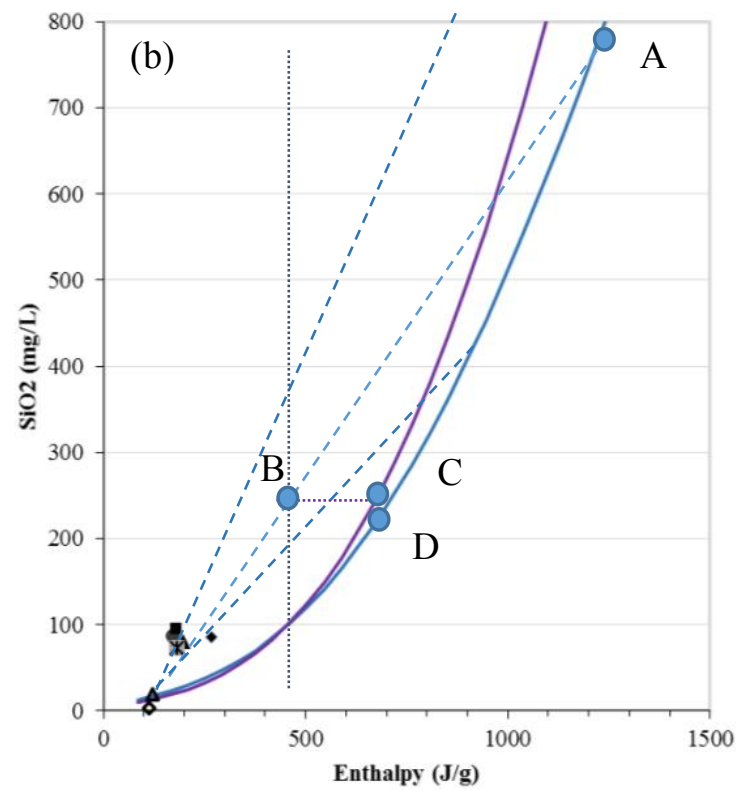

- RN2

- RN6

- RN6-SW1

- RNSW
A $\mathrm{RN} 3$

$\Delta \quad$ RN3-SW1

Chalcedony $\times$ RN1-RV1

\section{Chalcedony steam loss}

Figure 5.3-6: Silica-enthalpy mixing diagram of Ranong hot spring in post-monsoon season (a), and in pre-monsoon season (b). The results would compare with three theoretical reference lines; The first line (blue line) is the chalcedony solubility curve, and the second line (purple line) is the chalcedony maximum steam loss curve. Both curves estimated from the equation of chalcedony and chalcedony steam-loss geothermometer from Arnórsson et al., (1983). The third line (vertical gray line) refers to the boiling point of the water (at $100{ }^{\circ} \mathrm{C}$ ) which has been assumed equal to $419 \mathrm{~J} / \mathrm{g}$ of the enthalpy at saturation state (Wagner and Hans-Joachim, 2007).

This model shows that if thermal water has been mixed with cool water during the discharging processes, the geothermal reservoir would have high temperature approximately ranging from 130 to $199^{\circ} \mathrm{C}$. Most of the samples indicate stream-loss during ascension to the surface and are mixed with cool water from 70 to $90 \%$ by volume. 
Table 5-13: Estimated initial reservoir temperature and initial $\mathrm{SiO}_{2}$ concentration from the silica-enthalpy mixing diagram and mixing ratio results from $\mathrm{RN} 1$ hot spring in the premonsoon and post-monsoon seasons.

\begin{tabular}{|c|c|c|c|c|c|c|c|c|c|c|c|}
\hline & & \multicolumn{2}{|c|}{ RN1 } & \multicolumn{2}{|c|}{ RN2 } & \multicolumn{2}{|c|}{ RN3 } & \multicolumn{2}{|c|}{ RN5 } & \multicolumn{2}{|c|}{ RN6 } \\
\hline & & $1 \mathrm{st}$ & 2 nd & 1 st & 2 nd & $1 \mathrm{st}$ & 2nd & 1 st & 2nd & 1 st & $2 \mathrm{nd}$ \\
\hline \multirow{7}{*}{ 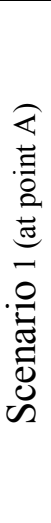 } & $\begin{array}{l}\text { Enthalpy at } \\
\text { sampling point* }\end{array}$ & 268.4 & 267.5 & 173.4 & 171.3 & 191.4 & 223.3 & 192.6 & 182.2 & 172.7 & 178.2 \\
\hline & $\mathrm{SiO}_{2}$ & 99.7 & 85.3 & 90.4 & 87.2 & 84.6 & 84.1 & 79.7 & 73.1 & 91.8 & 96.2 \\
\hline & $\begin{array}{l}\text { Enthalpy } \\
\text { (Point A) }\end{array}$ & 985 & 825 & - & - & - & - & - & - & - & - \\
\hline & $\mathrm{SiO}_{2}$ (Point A) & 482 & 340 & - & - & - & - & - & - & - & - \\
\hline & Temperature * & 229 & 194 & - & - & - & - & - & - & - & - \\
\hline & $\begin{array}{l}\text { Enthalpy Dilution } \\
\text { ratio }(\mathrm{H})\end{array}$ & 0.83 & 0.79 & - & - & - & - & - & - & - & - \\
\hline & $\begin{array}{l}\mathrm{SiO}_{2} \text { Dilution } \\
\text { Ratio (S) }\end{array}$ & 0.82 & 0.79 & - & - & - & - & - & - & - & - \\
\hline \multirow{6}{*}{ 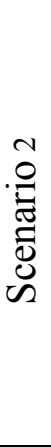 } & $\begin{array}{l}\text { Initial Enthalpy at } \\
\text { point } C\end{array}$ & 595 & 555 & 820 & 845 & 725 & 630 & 685 & 715 & 820 & 845 \\
\hline & $\mathrm{SiO}_{2}$ at point $\mathrm{C}$ & 183 & 155 & 395 & 425 & 297 & 210 & 255 & 285 & 395 & 425 \\
\hline & $\begin{array}{l}\text { Initial dissolved } \\
\mathrm{SiO}_{2} \text { at point } \mathrm{D}\end{array}$ & 170 & 145 & 332 & 355 & 255 & 190 & 225 & 280 & 332 & 355 \\
\hline & $\begin{array}{l}\text { Temperature at } \\
\text { point } \mathrm{C}\end{array}$ & 142 & 132 & 194 & 199 & 171 & 149 & 162 & 169 & 194 & 199 \\
\hline & $\begin{array}{l}\text { Enthalpy Dilution } \\
\text { ratio }(\mathrm{H})\end{array}$ & 0.68 & 0.67 & 0.92 & 0.93 & 0.88 & 0.80 & 0.87 & 0.90 & 0.92 & 0.92 \\
\hline & $\begin{array}{l}\mathrm{SiO}_{2} \text { Dilution } \\
\text { Ratio (S) }\end{array}$ & 0.49 & 0.51 & 0.80 & 0.83 & 0.75 & 0.66 & 0.73 & 0.79 & 0.79 & 0.81 \\
\hline
\end{tabular}

*Temperature and enthalpy of geothermal reservoir determined from international steam table at saturation state (Wagner and Hans-Joachim, 2007)

\subsubsection{The reservoir depth estimation.}

Identifying the fluid circulation depth is critical to understanding the dynamic behavior of the Ranong geothermal system. In natural geothermal systems, fluid circulates to great depth and is heated within the geothermal reservoir before ascending to the ground surface. The reservoir depth can be estimated by anomaly heat flow at hot springs, which is a site-specific variable. Even though the anomaly heat flow at hot springs in the Ranong area was not directly measured. Two reliable resources can be applied, the spatial distribution map of heat flow in south-eastern Asia (Hall, 2002) and drilling information from Phorn Rung hot spring.

The temperature gradient in the area can be estimated from the spatial distribution map of heat flow in south-east Asia through the simple heat transfer equation in Eq. (3.6).

The spatial distribution map of heat flow in southeastern Asia provides a heat flow value in the Ranong area ranging from 75 to $100 \mathrm{mWm}^{2}$ (Hall, 2002). The thermal conductivity of Ranong 
granite is assumed to be the same as the general thermal conductivity of granite ranging from 1.73 to $3.98 \mathrm{~W} / \mathrm{m}^{\circ} \mathrm{C}$ (The Natural Stone Institute, 2018). The estimated temperature gradient in the Ranong area ranges from 21.36 to $49.13{ }^{\circ} \mathrm{C} / \mathrm{km}$.

For geothermal reservoir depth estimation from spatial distribution map, the highest range of the temperature gradient value $\left(49.13{ }^{\circ} \mathrm{C} / \mathrm{km}\right)$ is representative of the anomaly heat flow at hot springs that changing temperature from the geothermal reservoir to the surface. Since, the geothermal assessment, most of these hot springs are reliable on the conservative $\mathrm{K}-\mathrm{Mg}$ and chalcedony subsystem. Therefore, the estimated depth of geothermal results in these thermal springs shown in Table 5-14.

For geothermal reservoir depth estimation from drilling information of Phorn Rung hot spring. The differences in altitude and water temperature of the hot springs in Phorn Rung location, comprised of two natural hot springs (RN-3, RN3-1) and a pumping well (RN3-2), reflect the temperature gradient of the Ranong geothermal area.

RN3 natural hot spring, which is covered by a circular concrete pool, discharge at an altitude 72.54 m AMSL from the east bank of Phorn Rung river. Water from RN3-1 seeps up to an altitude $66.5 \mathrm{~m}$ AMSL from the middle of the Phorn Rung river. The pumping well (RN3-2) is located at $67.82 \mathrm{~m}$ AMSL and the well bottom is $142 \mathrm{~m}$ below the ground surface (DAEDE, 2007).

From the field sampling data, the difference in temperature and altitude between RN3 and RN3-2 are 47.3-60.8 $=13.5^{\circ} \mathrm{C}$ and $72.54-67.82=4.72 \mathrm{~m}$ AMSL, respectively. The bottom of the RN3-2 is deeper than RN3 by $142+4.72=146.72 \mathrm{~m}$. Therefore, the estimated temperature gradient at Ponrunk hot springs is about $92.01{ }^{\circ} \mathrm{C} / \mathrm{km}$. This value is in good agreement with the high geothermal gradient $\left(\sim 87^{\circ} \mathrm{C} / \mathrm{km}\right)$ from an abandoned oil well in the Fang basin in the Northern-Thailand (Barr et al., 1979). 
Table 5-14: Estimated reservoir depth from spatial distribution map and from drilling information.

\begin{tabular}{|c|c|c|c|c|c|c|c|c|c|c|}
\hline \multirow{3}{*}{ Location } & \multirow{2}{*}{\multicolumn{2}{|c|}{$\begin{array}{c}\text { Water } \\
\text { temperature } \\
\left({ }^{\circ} \mathrm{C}\right)\end{array}$}} & \multicolumn{4}{|c|}{ Heat flow map } & \multicolumn{4}{|c|}{ Drilling information } \\
\hline & & & \multicolumn{2}{|c|}{$\begin{array}{c}\mathrm{Mg} / \mathrm{K} \\
(\mathrm{m})\end{array}$} & \multicolumn{2}{|c|}{$\begin{array}{c}\text { Chalcedony } \\
\text { (m) }\end{array}$} & \multicolumn{2}{|c|}{$\begin{array}{c}\mathrm{Mg} / \mathrm{K} \\
(\mathrm{m})\end{array}$} & \multicolumn{2}{|c|}{$\begin{array}{c}\text { Chalcedony } \\
(\mathrm{m})\end{array}$} \\
\hline & $1 \mathrm{st}$ & 2nd & $\min$ & $\max$ & $\min$ & $\max$ & $\min$ & $\max$ & $\min$ & $\max$ \\
\hline RN1-1 & 66.70 & 66.8 & 613 & 687 & 688 & 879 & 327 & 367 & 367 & 470 \\
\hline RN1-2 & 61.70 & 61.3 & 768 & 797 & 794 & 944 & 410 & 426 & 424 & 504 \\
\hline RN1-3 & 64.00 & 63.6 & 728 & 831 & 775 & 993 & 389 & 444 & 414 & 530 \\
\hline $\mathrm{RN} 2$ & 41.40 & 40.9 & 1,173 & 1,177 & 1,248 & 1,280 & 626 & 628 & 666 & 684 \\
\hline RN3 & 45.70 & 47.3 & 1,080 & 1,092 & 1,030 & 1,113 & 577 & 583 & 550 & 595 \\
\hline RN3-1 & - & 51.9 & - & 919 & - & 993 & - & 491 & - & 530 \\
\hline RN3-2 & - & 60.8 & - & 812 & - & 828 & - & 434 & - & 442 \\
\hline RN5 & 46.00 & 43.5 & 852 & 1,036 & 985 & 1,062 & 455 & 553 & 526 & 567 \\
\hline RN6-1 & 45.90 & 41.9 & 1,090 & 1,198 & 1,160 & 1,274 & 582 & 640 & 619 & 680 \\
\hline RN6-2 & 37.80 & 36 & 929 & 1,184 & 963 & 1,421 & 496 & 632 & 514 & 759 \\
\hline RN6-3 & 40.00 & 43.8 & - & 1,039 & - & 1,362 & - & 555 & - & 727 \\
\hline RN6-4 & - & 48.5 & - & 1,037 & - & 1,199 & - & 554 & - & 640 \\
\hline
\end{tabular}

As the geothermal assessment indicates that the $\mathrm{Mg} / \mathrm{K}$ geothermometers and chalcedony geothermometers are suitable for estimating the reservoir temperature of the Ranong hot springs. Therefore, the expected depths of these geothermal reservoirs are estimated from the temperature gradient value at the Ponrunk hot springs $\left(92.01{ }^{\circ} \mathrm{C} / \mathrm{km}\right)$ and the changing temperature from reservoir temperature to the surface, shown in Table 5-14.

The geothermal reservoir depth estimation from drilling information of Ponrunk hot spring (from 367 to $759 \mathrm{~m}$ depth) and heat transfer calculation at the high-temperature gradient (from 613 to $1421 \mathrm{~m}$ depth) are in good agreement with the Bouguer anomalies observation from Sanmuang, (2009), suggesting that the thickness of Cretaceous granite range in this area is 1 to $1.7 \mathrm{~km}$ depth and may be connected with the local rock. Moreover, the immature water results in the triangular equilibrium diagram (Giggenbach, 1988) indicate that these thermal waters are immature water that derided from the shallow system. The travel time is probably not long enough for equilibrium conditions with the host rock. Therefore, the results can conclude that the precipitation recharge to the fracture of the Cretaceous granite then flows down to the geothermal reservoir about 400 to $1,200 \mathrm{~m}$, increasing the water temperature to 
82-105 ${ }^{\circ} \mathrm{C}$ from the heat at 1 to $1.7 \mathrm{~km}$ depth. Afterward, the water turns up/rises up to the upper part of the subsurface without contamination of precipitation or cool water.

\subsubsection{Water-rock interaction}

\subsubsection{The REE in Ranong granite.}

In Figure 5.1-1., the distribution of REE results from feldspar minerals are in line with the REE pattern results from whole fresh Ranong granite (Imai et al., 2013). Moreover, the RN6 biotite mineral has a relatively high REE concentration with negative EU anomalies (3.0). The RN5 feldspar is relatively low in REE concentration but has a high slope with positive EU anomalies (6.07). These distributions from RN5 feldspar and RN6 biotite mineral are in line with the REE concentration pattern of feldspar (plagioclase + K-feldspar) and mica (biotite + muscovite) minerals in unaltered granite rock as stated by Alderton, (1980).

On the other hand, the REE distributions of RN1 and RN6 feldspar samples and the range of the REE concentration pattern of whole fresh granite from Haad Som Paen, Ranong tin field (Imai et al., 2013), both have high HREE concentration with negative EU anomalies. As proposed by Imai et al., (2013), the petrological evidence found points to the REE were potentially mobile during hydrothermal alteration, for instance, through chloritization and the sericitization. In sericitization, the feldspar minerals are replaced by muscovite and have the high negative EU anomalies. In the chloritization, the biotite and the feldspar minerals are replaced by chlorite, which can accommodate HREE released from the minerals. Therefore, these resulted in an increase in the size of the negative EU anomalies and an increase in HREE concentration in the hydrothermally altered feldspar. These can suggest that the degree of alteration in RN1 and RN6 feldspar minerals are stronger than that in RN5 feldspar mineral.

\subsubsection{REE in fluid phase}

According to the REE concentration, the geothermal fluids are derived from the dissolution and alteration of the accessory minerals in the host rocks. The variation in REE composition and pattern in water samples may be used as an indicator for understanding the fractionation mechanism during alteration of rock and fluid transport, the history of rock alteration, and the state of equilibrium in water-rock interaction.

The chondrite normalized REE patterns in Figure 5.2-4 show that the REE pattern in surface waters is similar to the REE pattern in the rock samples, however, the degree of enriched LREE pattern is less than that from the rock samples. Conversely, the thermal water results indicate 
completely different REE pattern and lower compositions relative to those of rocks and surface water. These results are generally consistent with the conceptual model states that REE in surface waters at atmospheric pressure would be leached from the host rock. After the water passes other permeable rock to the thermal system, the REE in thermal water is commonly regenerated by the rock minerals and is chemically reduced by increasing temperature and pressure (Migdisov et al., 2016; Möller, 2007).

Moreover, our results illustrate markedly depleted LREE patterns (especially in $\mathrm{Pr}, \mathrm{Nd}$, and Sm elements) relative to HREE in some samples (e.g., RN1-1, RN3, and RN6-1, shown in Figure 5.2-4). As proposed by Migdisov et al., (2016); Möller, (2007), this evidence points to chemical complexation of various strengths (e.g., $\mathrm{OH}^{-}, \mathrm{F}^{-}, \mathrm{HCO}^{3-}, \mathrm{H}_{2} \mathrm{PO}^{4-}$ ) which plays an important role in the behavior of REE in the hydrothermal system.

For more detail, the experimental data from Migdisov et al., (2016), points out that chloride $\left(\mathrm{Cl}^{-}\right)$and sulfate $\left(\mathrm{SO}_{4}{ }^{2-}\right)$ are the main ligands responsible for REE transportation, while Fluoride $\left(\mathrm{F}^{-}\right)$is the main ligand responsible for REE deposition. These ligands can be used to evaluate the REE behavior in the Ranong hydrothermal area. The chemical concentrations of these ligands are plotted against total REE concentrations in Figure 5.2-7.

These ligands likely indicate a negative correlation with total REE content. These total REE relationships with $\mathrm{Cl}^{-}$and with $\mathrm{SO}_{4}{ }^{2-}$ (Figure 5.3-7(a), and (b)) do not support the conclusion of Migdisov et al., (2016), who state that these ligands are REE vehicles, which increases the mobility of REE complexes. This would lead to the release of REE complexes to the discharge water.

Conversely, the high negative correlation between $\mathrm{F}^{-}$and total REE concentration (Figure 5.3$7(\mathrm{c}))$ is in line with the aforementioned conclusion. Leached fluoride in groundwater leads to the crystallization of solid REE-fluoride complexes along the flow path. The LREE-fluoride complexes, which have lower solubility relative to the HREE-fluoride complexes, precipitate in veinlets before discharging to the outflow. Therefore, these can indicate that the total REE concentration in the Ranong geothermal area is chemically controlled by the variation of $\mathrm{F}^{-}$ ions, and the depleted LREE patterns in thermal water are likely associated with the precipitation processes of LREE-fluoride complexes along the flow path.

Fluoride concentrations are controlled by the physiological condition of the rock geochemistry, e.g., decomposition, dissociation, and subsequent dissolution. In addition, analytical hydrochemistry in the thermal water characterized increasing fluoride concentration $\left(\mathrm{F}^{-}\right)$with 
increasing sodium $\left(\mathrm{Na}^{+}\right)$and potassium concentrations $\left(\mathrm{K}^{+}\right)$(shown in Figure 5.3-8(a), and (b), respectively). This evidence indicates the progressive dissolution of silicate minerals such as feldspar and biotite minerals. This supports our petrological findings that the alteration of fluorine-rich minerals, e.g., mica minerals (biotite + muscovite) altered into clay minerals (e.g., chlorite). This indicates that the fluoride concentration in the Ranong thermal water likely effectively originated from the dissolution of altered fluorine-rich minerals in the Ranong granite.

Besides leaching $\mathrm{F}^{-}$through the mica minerals dissolution, Chae et al., (2006) point out that calcium concentration plays an important role in $\mathrm{F}^{-}$precipitation in the groundwater system. In the case of high $\mathrm{Ca}^{2+}$, the $\mathrm{F}^{-}$concentrations are chemically precipitating with calcium in the form of the fluorite mineral $\left(\mathrm{CaF}_{2(\mathrm{~s})}\right)$, which lead to low fluoride concentrations. In contrast, in the case of low $\mathrm{Ca}^{2+}$ concentrations, the precipitation of the fluorite mineral $\left(\mathrm{CaF}_{2(\mathrm{~s})}\right)$ does not occur, indicating high fluoride concentrations. In addition, several geochemical processes reduced the $\mathrm{Ca}^{2+}$ concentration in the subsurface system, e.g., calcite precipitation, adsorption, and cation exchange.

The plotted correlation of chemical concentration comparing between precipitation and thermal water (Figure 5.3-3.) indicates that the $\mathrm{Ca}^{2+}$ concentrations in thermal water have similar value with that in precipitation water, while $\mathrm{F}^{-}$concentrations in thermal water is higher than that in the precipitation. These can imply that the $\mathrm{Ca}^{2+}$ in thermal waters remains the concentration from meteoric water without precipitation and mixing processes along the flow part. Therefore, these can suggest that fluoride concentrations in Ranong thermal water are not controlled by $\mathrm{Ca}^{2+}$ concentration variability and $\mathrm{F}^{-}$concentration is mainly leached from altered fluorine-rich minerals in Ranong granite. 


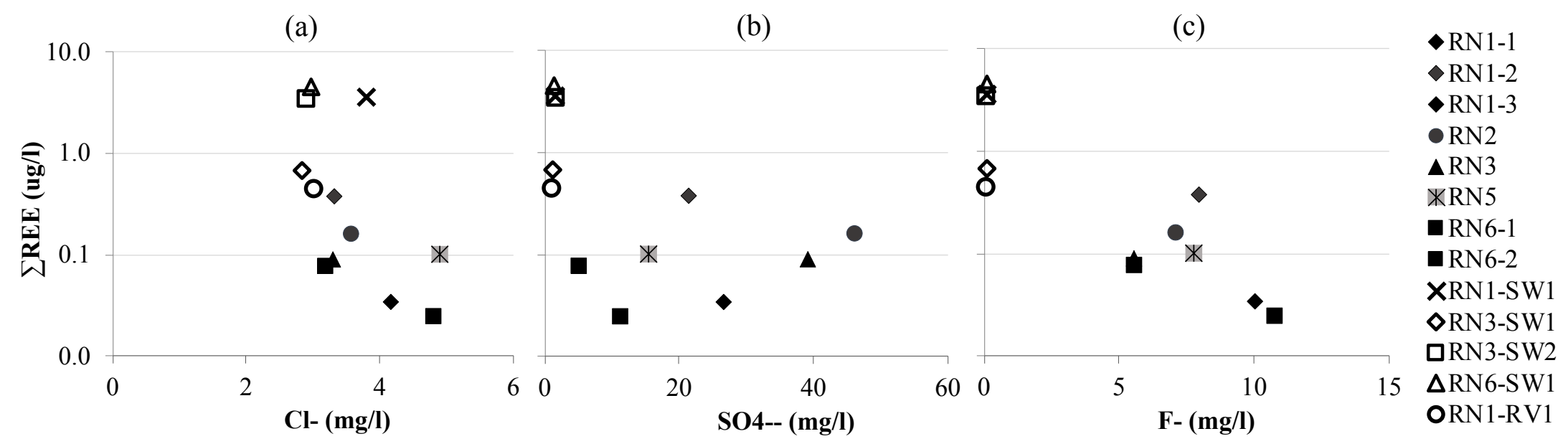

Figure 5.3-7: Correlation between three ligands for instance; chloride $\left(\mathrm{Cl}^{-}\right)(\mathrm{a})$, sulfate $\left(\mathrm{SO}_{4}{ }^{2-}\right)(\mathrm{b})$, and fluoride $\left(\mathrm{F}^{-}\right)$(a), along with total REE concentration.
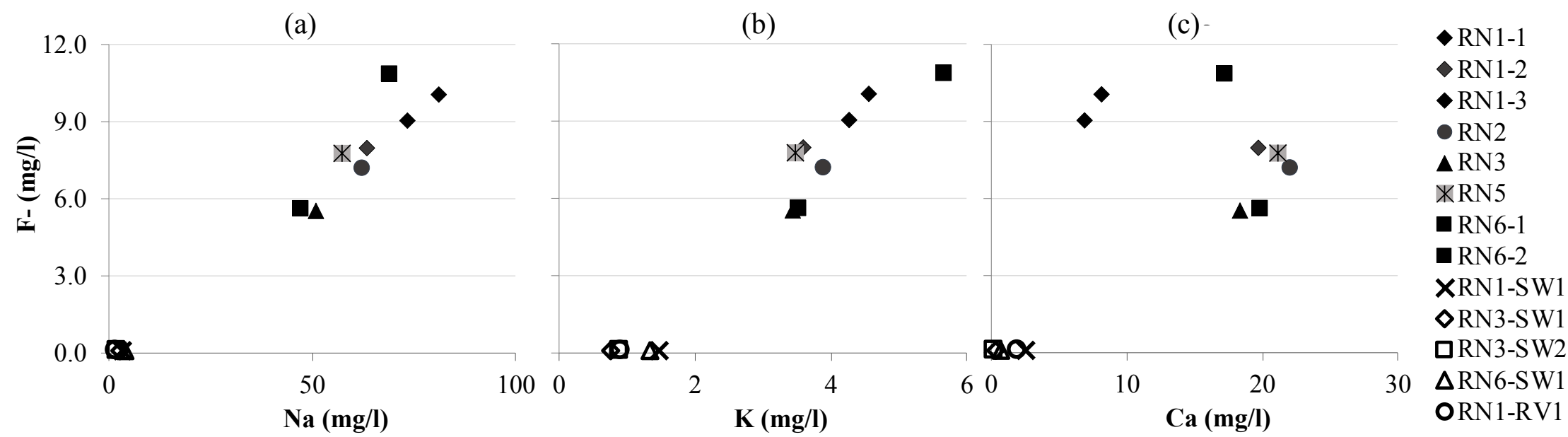

Figure 5.3-8: Correlation between fluoride $\left(\mathrm{F}^{-}\right)$and three major cation concentrations: sodium $\left(\mathrm{Na}^{+}\right)(\mathrm{a})$, potassium $\left(\mathrm{K}^{+}\right)(\mathrm{b})$, and calcium $\left(\mathrm{Ca}{ }^{2+}\right)$ (c). 
5.3.4.3 The strontium isotopic ratio and chemical concentrations in the solid phase.

According to DMR, (2014), the rock sampling locations in Cretaceous granite in the westernprovince granitic belt group (S-type) have high initial Sr isotopic ratios ranging between 0.708 and 0.745 . The mineralogical ${ }^{87} \mathrm{Sr} /{ }^{86} \mathrm{Sr}$ ratio results in RN6 and RN5 surface rock samples are in line with the range of ${ }^{87} \mathrm{Sr} /{ }^{86} \mathrm{Sr}$ ratio in whole granite rocks in Ranong province from Charusiri et al., 1992), ranging between 0.7721 and $0.8106(n=3,86.9$ Ma). Meanwhile, the highest feldspar ${ }^{87} \mathrm{Sr} /{ }^{86} \mathrm{Sr}$ ratio results are presented in the RN1 sample in the middle of Ranong granite (Figure 5.2-5.) and is significantly higher than the range of whole rock ${ }^{87} \mathrm{Sr} /{ }^{86} \mathrm{Sr}$ ratio from Ranong granitic rocks. This demonstrates that the Ranong granite has $\mathrm{Sr}$ isotopic heterogeneity and that the spatial distribution of ${ }^{87} \mathrm{Sr} /{ }^{86} \mathrm{Sr}$ ratios varies from the high value in the middle (RN1) to the lower value further south (RN5) and further north (RN6) of the Ranong pluton.

Theoretically, mineral crystallization and decay processes are responsible for the significant amount of $\mathrm{Rb}$ and $\mathrm{Sr}$ content in each mineral. Mica minerals (biotite and muscovite) have higher $\mathrm{Rb} / \mathrm{Sr}$ and higher ${ }^{87} \mathrm{Sr} /{ }^{86} \mathrm{Sr}$ ratio relative to feldspar minerals (plagioclase and potassium feldspars). Conversely, our granite analysis results indicate significantly low $\mathrm{Rb}$ content in the biotite as well as low $\mathrm{Sr}$ content in feldspar. These ${ }^{87} \mathrm{Sr} /{ }^{86} \mathrm{Sr}$ and $\mathrm{Rb} / \mathrm{Sr}$ ratio results for the granitic mineral samples are plotted in the $\mathrm{Rb} / \mathrm{Sr}$ isochron diagram in Figure 5.3-9. Remarkably, the most Rb/Sr depleted sample is the biotite in RN6 clearly correlating with the results of the RN6 thin-section profile. This can indicate completely chloritization and minor sericitization in this granitic rock. As proposed by (Glodny and Grauert, 2009), the evidence points to alteration-related mineralogical changes. During chloritization, the biotite is broken down in the alteration zone and loses $\mathrm{K}-\mathrm{Rb}$ elements to the fluid. Meanwhile, the plagioclase feldspar loses Ca-Sr elements to the fluid during sericitization. Therefore, the biotite minerals show low $\mathrm{Rb} / \mathrm{Sr}$ ratios and low radiogenic compositions, while the feldspar minerals show high $\mathrm{Rb} / \mathrm{Sr}$ ratios and radiogenic compositions. 


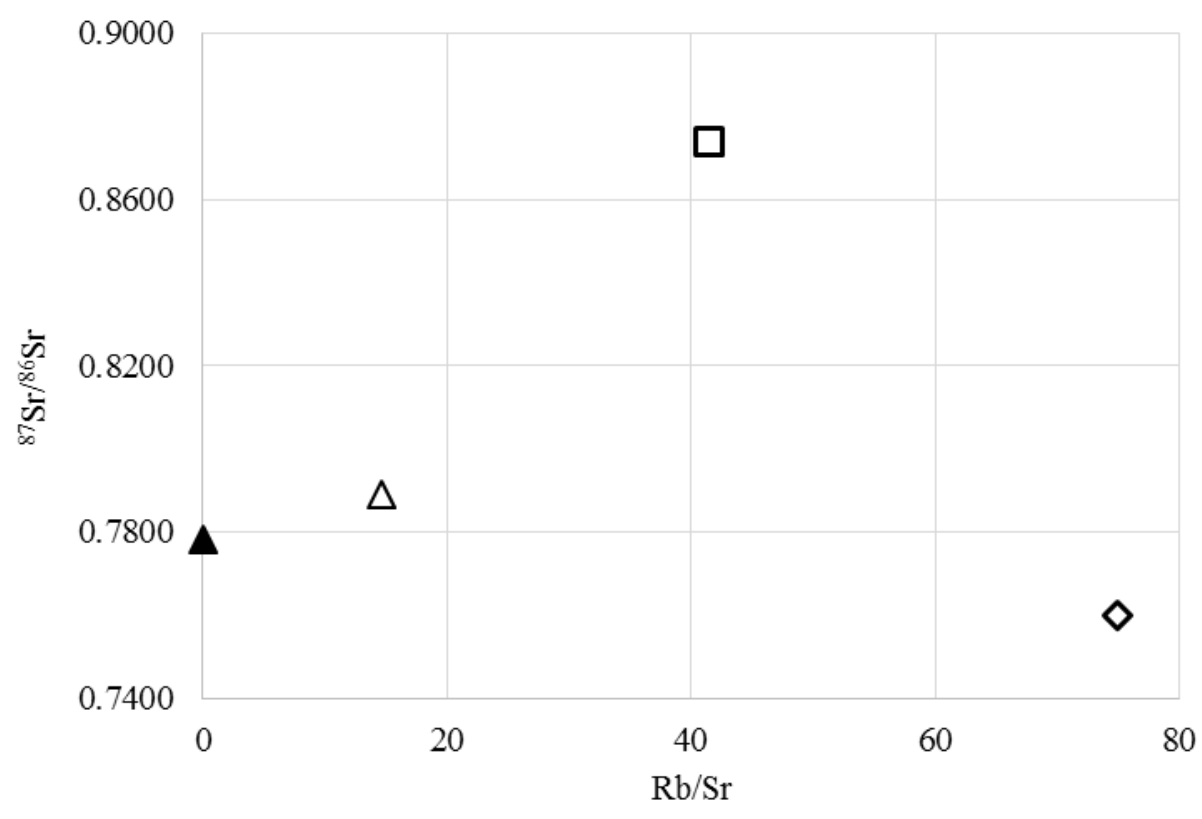

$\diamond \mathrm{RN}-5 \mathrm{FS} \quad \Delta \mathrm{RN}-6 \mathrm{Bi} \quad \Delta \mathrm{RN}-6 \mathrm{FS} \quad$ 口RN-1FS

Figure 5.3-9: Strontium isotopic composition of surface granite samples in Ranong geothermal area.

5.3.4.4 The strontium isotopic ratio and concentration in the fluid phase.

Dissolved $\mathrm{Sr}$ in natural waters is derived from different sources, which are generally the atmospheric inputs and weathering products from minerals and rocks. Sr isotopic ratios can provide information on the origin of these sources of solutes within the water.

The present study applies the mixing model from Wiegand, (2009) assuming that the mixing process between atmospheric inputs and weathering products at the steady-state condition (as aforementioned in Chapter 3)

The granite dissolution model (Négrel et al., 2001; Petelet-Giraud et al., 2003) in Eq. (3.13) is computed on the represent parent rock of the hot spring. For the reason that the granite cannot be sampled from every water sampling area, the calculation of the mixing model is computed from the most representative parent rock of thermal groundwater, as follows; The RN6 rock sample represents the parent rock from the RN6-1 and the RN6-2 hot springs. Remarkably, the rock sample from RN5 (Heo Lom waterfall) is the foliated granite that cannot identify the minerals composition. The RN1 rock sample represents the parent rock from the rest of the hot springs. The minerals composition of each parent rock from the petrology analysis and the granite dissolution model are shown in Table 5-15. The mixing model results are shown in Table 5-16. 
Table 5-15: Analytical results of $\mathrm{Rb}, \mathrm{Sr}$, and ${ }^{87} \mathrm{Sr} /{ }^{86} \mathrm{Sr}$ ratio in the rock samples in Ranong geothermal area.

\begin{tabular}{|c|c|c|c|c|c|c|c|}
\hline \multirow[b]{2}{*}{ Location } & \multirow[b]{2}{*}{ Rock Sample } & \multirow[b]{2}{*}{$\begin{array}{l}\text { Type of } \\
\text { Mineral }\end{array}$} & \multirow[b]{2}{*}{${ }^{87} \mathrm{Sr} /{ }^{86} \mathrm{Sr}$} & \multirow[b]{2}{*}{$\begin{array}{c}\mathrm{Sr} \\
\mathrm{mg} / \mathrm{kg}\end{array}$} & \multicolumn{3}{|c|}{ Model } \\
\hline & & & & & $\begin{array}{c}\text { minerals } \\
\text { composition }\end{array}$ & $\begin{array}{c}\mathrm{Sr} \\
\mathrm{mg} / \mathrm{kg}\end{array}$ & $\begin{array}{l}\text { Model } \\
{ }^{87} \mathrm{Sr} /{ }^{86} \mathrm{Sr}\end{array}$ \\
\hline \multirow{2}{*}{ RN6 } & \multirow{2}{*}{$\begin{array}{c}\text { Ban Hat Yay } \\
\text { hot spring }\end{array}$} & $\mathrm{Bi}$ & 0.7782 & 532 & 5 & \multirow{2}{*}{16.1} & \multirow{2}{*}{0.7846} \\
\hline & & FS & 0.7892 & 78 & $40+15$ & & \\
\hline \multirow{2}{*}{ RN1 } & \multirow{2}{*}{$\begin{array}{l}\text { Raksawarin } \\
\text { River }\end{array}$} & $\mathrm{Bi}$ & - & - & 5 & \multirow{2}{*}{9.8} & \multirow{2}{*}{0.8086} \\
\hline & & FS & 0.8737 & 32 & $35+15$ & & \\
\hline \multirow{2}{*}{ RN5 } & \multirow{2}{*}{$\begin{array}{l}\text { Heo Lom } \\
\text { waterfall }\end{array}$} & $\mathrm{Bi}$ & - & - & - & \multirow{2}{*}{7.3} & \multirow{2}{*}{0.7767} \\
\hline & & FS & 0.7601 & 5 & - & & \\
\hline
\end{tabular}

*FS $=$ Feldspar minerals that contains plagioclase and $\mathrm{K}$-feldspar, $\mathrm{Bi}=$ Biotite.

Table 5-16: Mixing model results of $\mathrm{Sr}$, and ${ }^{87} \mathrm{Sr} /{ }^{86} \mathrm{Sr}$ ratio in thermal water samples in Ranong geothermal area.

\begin{tabular}{lcccc}
\hline Location & ${ }^{87} \mathrm{Sr} /{ }^{86} \mathrm{Sr}$ & $\mathrm{Sr}$ & $\begin{array}{c}\text { Sr from } \\
\text { rock } \\
(\mu \mathrm{g} / \mathrm{L})\end{array}$ & $\begin{array}{c}\text { \% } \mathrm{Sr} \text { from } \\
\text { rock }\end{array}$ \\
\hline RN1-1 & 0.74886 & 71.6 & 62.36 & 87.09 \\
RN2 & 0.73971 & 99.22 & 86.81 & 87.50 \\
RN3 & 0.73861 & 82.33 & 71.25 & 86.54 \\
RN5 & 0.74519 & 53.89 & 47.59 & 88.31 \\
RN6-1 & 0.74909 & 44 & 37.93 & 86.21 \\
RN6-2 & 0.74906 & 47.66 & 41.43 & 86.92 \\
\hline
\end{tabular}

Table 5-16, the mixing model provides a narrow range of percent $\mathrm{Sr}$ from rock contribution between 86.21 and $88.31 \%$. Due to Figure 5.2-5, the spatial distribution of ${ }^{87} \mathrm{Sr} /{ }^{86} \mathrm{Sr}$ ratio in thermal water likely be variable on ${ }^{87} \mathrm{Sr} /{ }^{86} \mathrm{Sr}$ ratio in the feldspar minerals. This can suggest that these hot springs have similar water-rock interaction and are isotopically controlled by the granitic rock. 


\subsection{Discussion}

Geothermal fluids are generally controlled by the geological setting of the area and conduct with the surface hydrological system. Six hot springs in Ranong province manifest along the intrusive Cretaceous-granite batholith, which is featured mountainous topography and is contacted with the Ranong faults in the west of the province. This can imply that the faults system plays an important row in the hot springs (Sanmuang, 2009). Moreover, there are several NW-SE conjugate faults line with the NE-SW Ranong major fault and different direction of hundred fractures in the vicinity of the hot springs. These faults and fractures control the hot spring system (Chaturongkawanich and Leevongchareon, 2000).

The previous geophysical investigation from the gravity anomaly's results (Chaturongkawanich and Leevongchareon, 2000) demonstrate that the main heat sources probably originated from the deep granite mass or magmatic body ( 3.5 to $5 \mathrm{~km}$ depth) in the south-eastern part of Ranong Province, also transferring to the local granite through regional fractures and faults. As aforementioned, the geological setting in this area is complicated.

As the geochemical and isotopic composition results in thermal water are distinctively different from that of the surface water (in Chapter 5.2). The stable isotopic composition and $\mathrm{Cl}^{-}$ concentration results can clearly suggest that the local precipitations are the main recharge source of thermal water and surface water without magmatic contact. Moreover, the thermal water is recharged from the higher elevation compared with the surface water. The chemical concentration, temperature, and EC in geothermal water are higher than that in the surface water. The thermal fluid obtains the chemical composition along the flow part that is described in the $\mathrm{Na}-\mathrm{HCO}_{3}$ type. This can explain the regional conceptual model that the amount of precipitation infiltrates from faults and fractures of the granite with the attitude between 378 and $482 \mathrm{~m}$ AMSL into the underground, is heated at the reservoir depth between 327 and 640 $\mathrm{m}$ (-286 to $-612 \mathrm{~m}$ AMSL) before ascending to the surface (based on drilling information and $\mathrm{Mg} / \mathrm{k}$ geothermometer). The ${ }^{87} \mathrm{Sr} /{ }^{86} \mathrm{Sr}$ mixing model indicating that these hot springs have similar water-rock interaction.

For more specific interpretation, the surface flow direction (Figure 5.4-1), is estimated from a Digital Elevation Model (DEM) using the ASTER $30 \mathrm{~m}$ resolution dataset (USGS Earth Explorer, 2017) which was embedded in ArcGIS v.10.3 (ESRI C), 1999-2018), can hydrologically explain that the precipitation accumulates and flows from the high mountainous 
area to the lower elevation. The water mostly outflows to the sea on the west side of the study area.

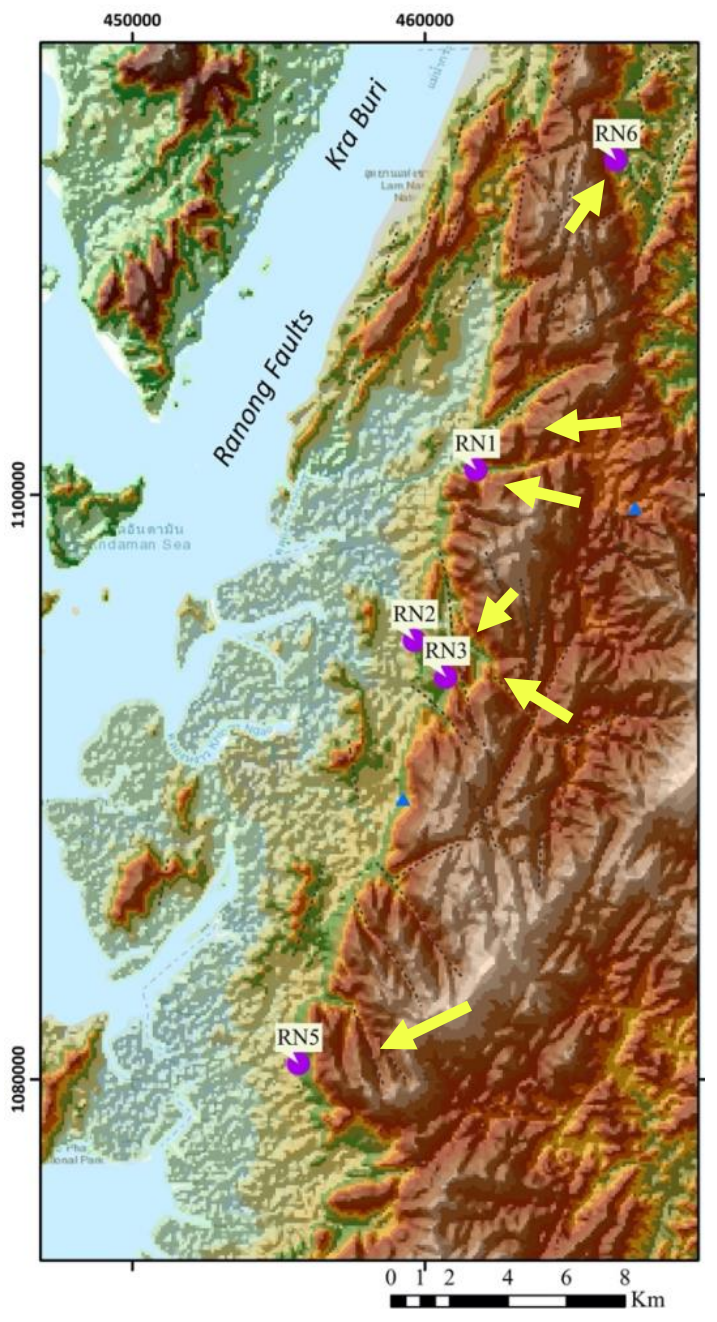

Figure 5.4-1: Topographic map along with sample location points of the study area. The yellow arrows represent the surface flow direction of each area.

Therefore, for future water resources assessment, four conceptual models in these geothermal hot springs are established by considering the surface flow direction from the topographic map, the previous geophysical investigation, and our results, 1) RN6, 2) RN1, 3) RN2 and RN3, 4) RN5. 


\section{1) RN6}

The surface water in this hot spring area flows from the high mountainous area in the west and the south to the lower elevation in the central and runoff to the sea in the north direction of the map (Figure 5.4-1). Due to the isotopic composition results in thermal water indicate the estimated elevations of the recharge area are between 400 and $480 \mathrm{~m}$ AMSL. This elevation results match with the NW-SE conjugate faults adjacent to the hot spring's location (Figure 5.4-2. (a)).

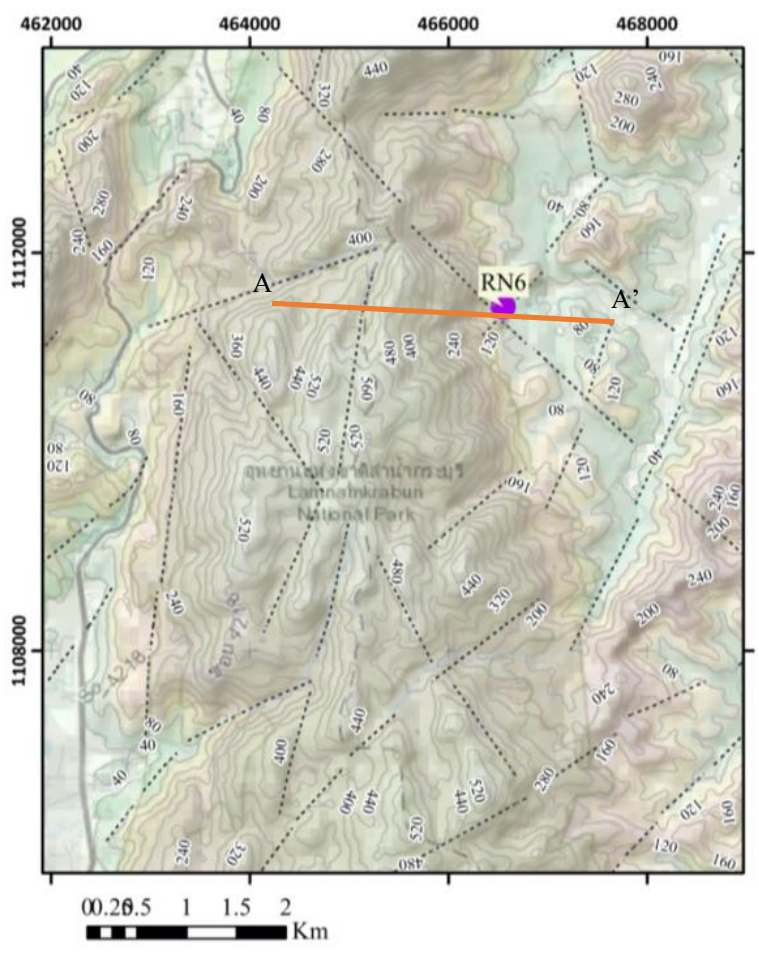

(a)

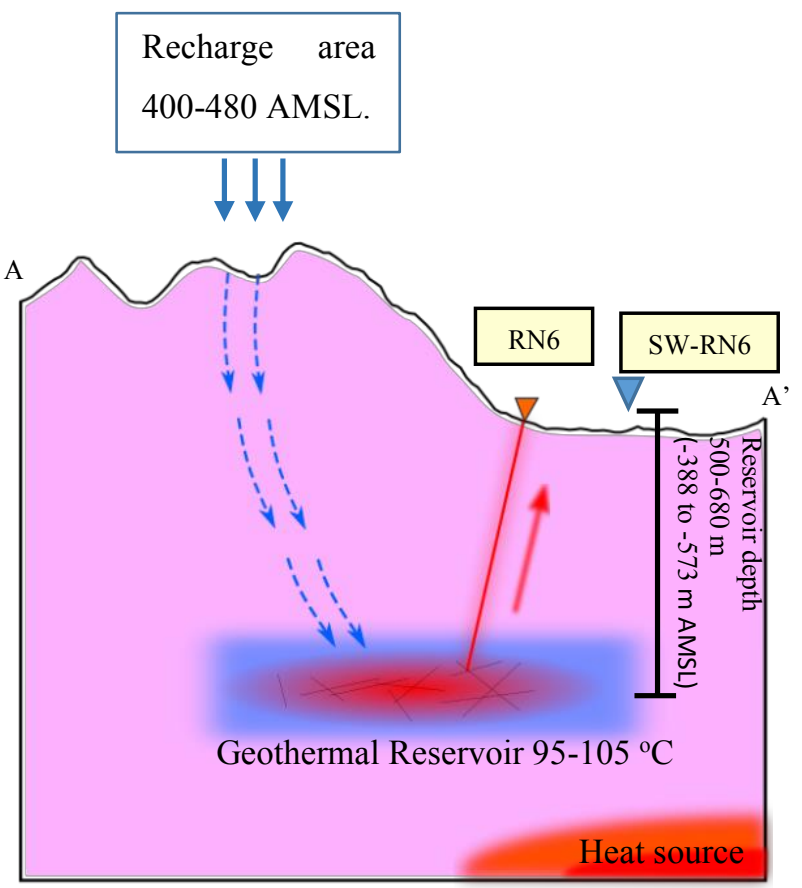

(b)

Figure 5.4-2: Topographic map with major and local faults structures (a) and conceptual model (b) of Ban Hat Yay hot spring (RN6). The purple circle represents the water sample location. The black dot lines represent local faults and fractures drawn according to a recent survey (Sanmuang, 2009). The orange line (cross-section line; A-A') represents the location of the conceptual model. The conceptual model is generated from our geochemical and isotopic investigation, and geoinformation from previous study.

Our results can suggest that the precipitation water infiltered from the high mountainous area (400 to $480 \mathrm{~m}$ AMSL) at NW-SE conjugate faults to the geothermal reservoir at 455 to $640 \mathrm{~m}$ depth (-388 to $-573 \mathrm{~m}$ AMSL). The heat source of the system is transferred from the great depth of the granitic batholith and warmed the fluid until 80 to $105^{\circ} \mathrm{C}$. Then, the thermal fluid rises 
up to the surface along the conjugate fault's direction which has the travel time period more than 3,075 to 4,325 BP. The conceptual model of RN6 hot spring shown in Figure 5.4-2. (b).

Moreover, RN6-SW1 contains the anomaly highest value of field parameters and chemical concentration in surface water (EC: $213 \mu \mathrm{S} / \mathrm{cm}$, temperature: $35.5^{\circ} \mathrm{C}, \mathrm{pH}: 7.6$, and chemical concentration: $>10 \mathrm{mg} / \mathrm{l}$ ). This anomaly probably derived from the mixing between hot water and surface water. The simple binary mixing model from silica concentration indicates that the RN6-SW1 is mixed with $61 \%$ hot water.

2) RN1

The surface water in this hot spring area flows from the high mountainous area in the east to the lower elevation in the west and outflows to the sea on the west side of the study area (Figure 5.4-3(a)). Our results can suggest that the precipitation water infiltered from the high mountainous area (375 to $410 \mathrm{~m}$ AMSL) at NW-SE conjugate faults to the geothermal reservoir at 325 to $445 \mathrm{~m}$ depth (-286 to $-406 \mathrm{~m}$ AMSL). The heat source of the system should be from the great depth of the granitic batholith and heated the fluid until 97 to $105^{\circ} \mathrm{C}$. Then, the thermal fluid rises up to the surface along the fault's core direction which has the travel time period more than 3,985 to 5,235 BP. The thermal fluid obtains the chemical composition along the flow part that is described in the $\mathrm{Na}-\mathrm{HCO}_{3}$ type. The conceptual model of $\mathrm{RN} 1$ hot spring shown in Figure 5.4-3(b). 


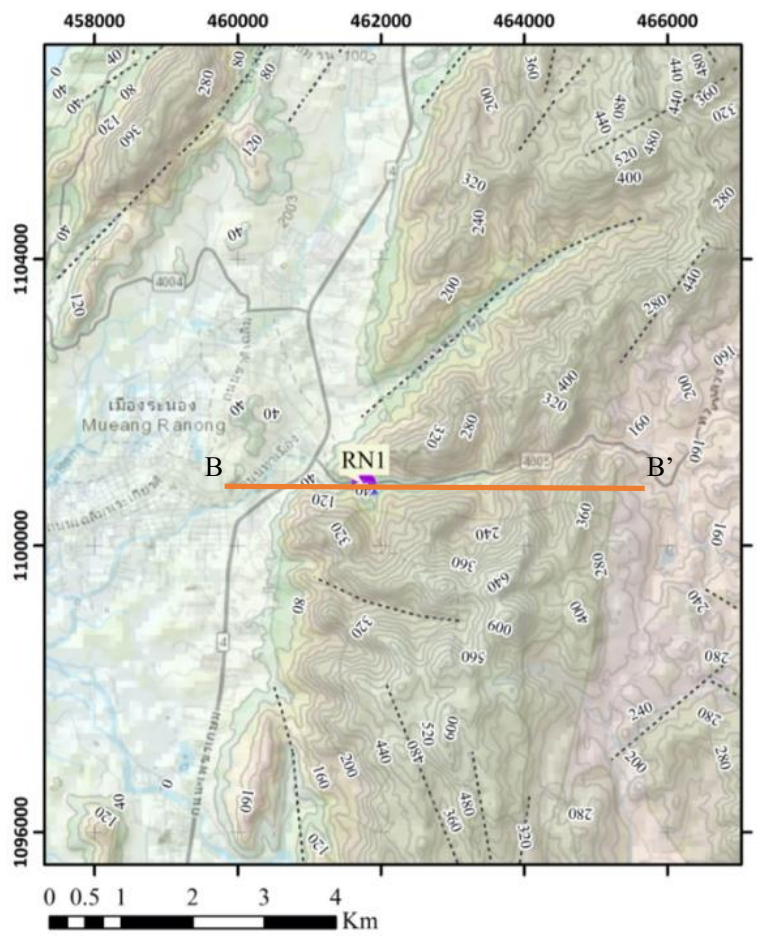

(a)

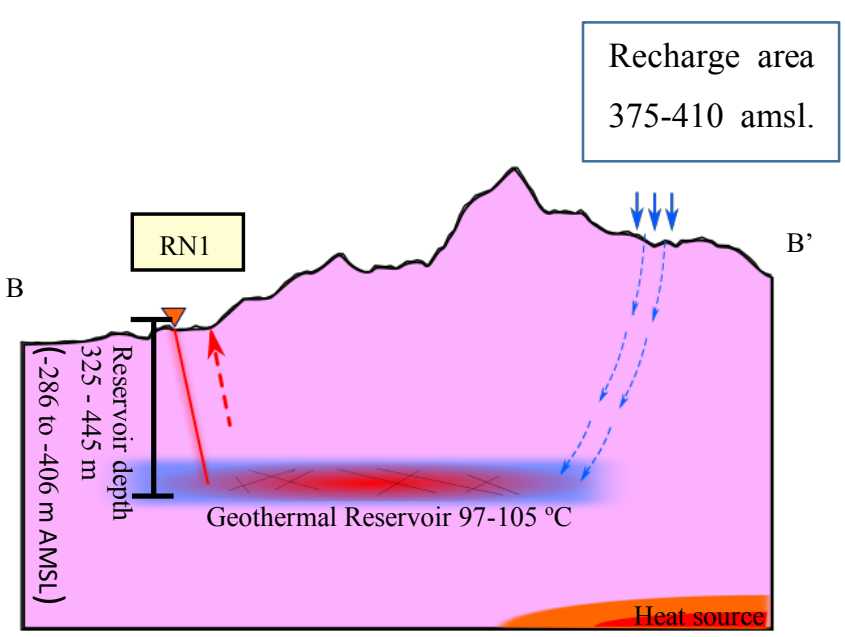

(b)

Figure 5.4-3: Topographic map with major and local faults structures (a) and conceptual model (b) of Raksawarin hot spring (RN1). The purple circle represents the water sample location. The black dot lines represent local faults and fractures drawn according to a recent survey (Chaturongkawanich and Leevongchareon, 2000). The orange line (cross-section line; B-B') represents the location of the conceptual model. (b) The conceptual model is generated from our geochemical and isotopic investigation and geoinformation from previous study.

\section{3) RN2 and RN3}

These hot springs likely are in the same surface flow system that flows from the high mountainous area in the east to the lower elevation in the west and outflows to the sea on the west side of the study area (Figure 5.4-4(a)). Moreover, the analyses of hydro-geochemical and isotopic compositions illustrate the similarity in each parameter. These can suggest that these hot springs ascend from the same systems. The conceptual model of RN2 and RN3 hot springs shown in Figure 5.4-4 and explain below.

Stable isotope results in these hot springs can suggest that the precipitation water infiltered from the high mountainous area (405 to $483 \mathrm{~m} \mathrm{AMSL}$ ) and infiltered towards a geothermal reservoir at 577 to $628 \mathrm{~m}$ depth (-485 to $-612 \mathrm{~m} \mathrm{AMSL}$ ). The heat source of the system heated the fluid until $100{ }^{\circ} \mathrm{C}$. Then, the thermal fluid rises up to the surface along the fault or fracture 
direction which has the travel time period from 2,675 to 3,920 BP. The thermal fluid obtains the chemical composition along the flow part that is described in the $\mathrm{Na}-\mathrm{HCO}_{3}$ type. The conceptual model of RN2 and RN3 hot springs shown in Figure 5.4-4(b).

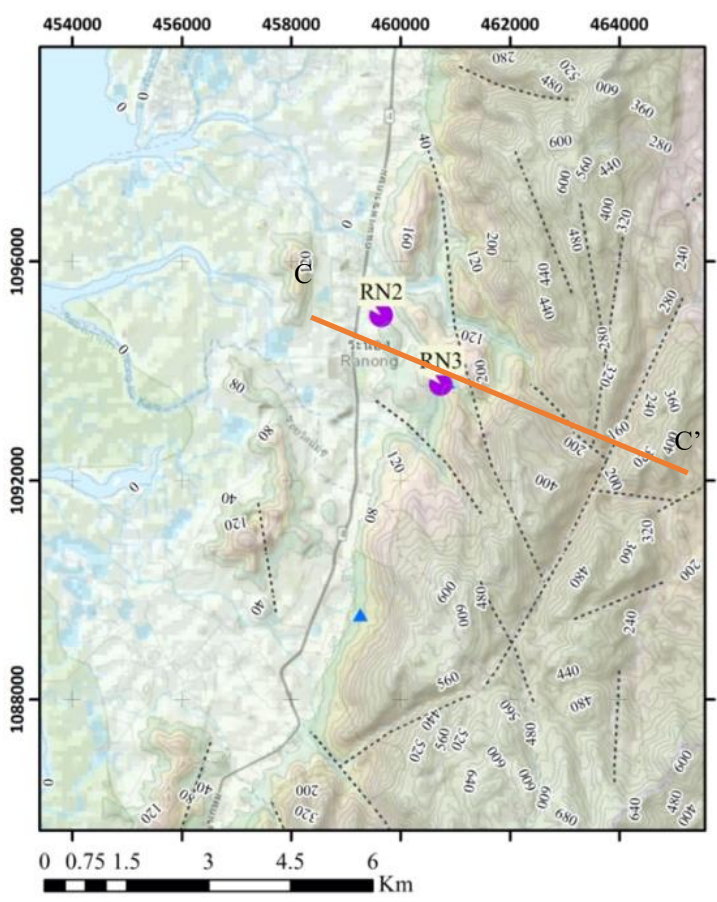

(a)

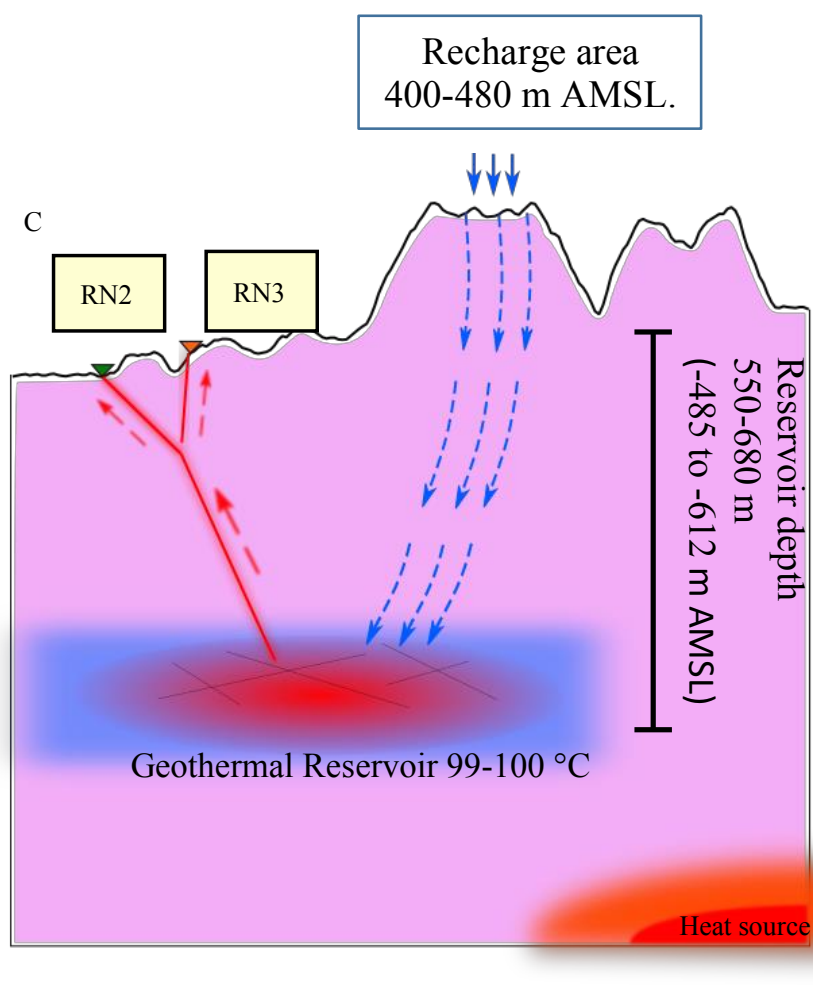

(b)

Figure 5.4-4: Topographic map with major and local faults structures (a) and conceptual model (b) of the Phu Lum Phi and Phorn Rung hot springs (RN2 and RN3). The purple circles represent the water sample locations. The black dot lines represent local faults and fractures drawn according to a recent survey (Chaturongkawanich and Leevongchareon, 2000). The orange line (cross-section line; C-C') represents the location of the conceptual model. The conceptual model is generated from our geochemical and isotopic investigation and geoinformation from the previous study. 


\section{4) RN5}

The surface water in this hot spring area flows from the high mountainous area in the east to the lower elevation in the west and outflows to the sea on the west side of the study area (Figure 5.4-5(a)). Our results can suggest that the precipitation water infiltered from the high mountainous area (455 to $425 \mathrm{~m}$ AMSL) to the geothermal reservoir at 445 to $533 \mathrm{~m}$ depth (407 to $-495 \mathrm{~m}$ AMSL). The heat source of the system should be from the great depth of the granitic batholith in the south of the map and heated the fluid until 85 to $97{ }^{\circ} \mathrm{C}$. Then, the thermal fluid rises up to the surface along the fault's core direction which has the travel time period more than 3,618 to 4,865 BP. The thermal fluid obtains the chemical composition along the flow part that is described in the $\mathrm{Na}-\mathrm{HCO}_{3}$ type. The conceptual model of RN5 hot spring shown in Figure 5.4-5(b).

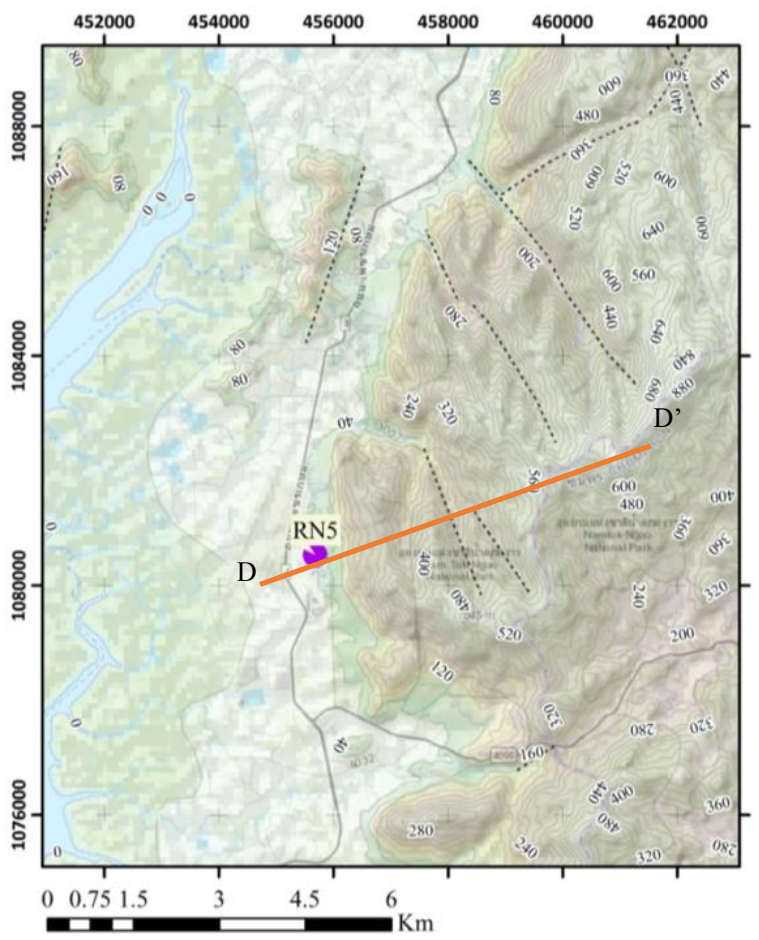

(a)

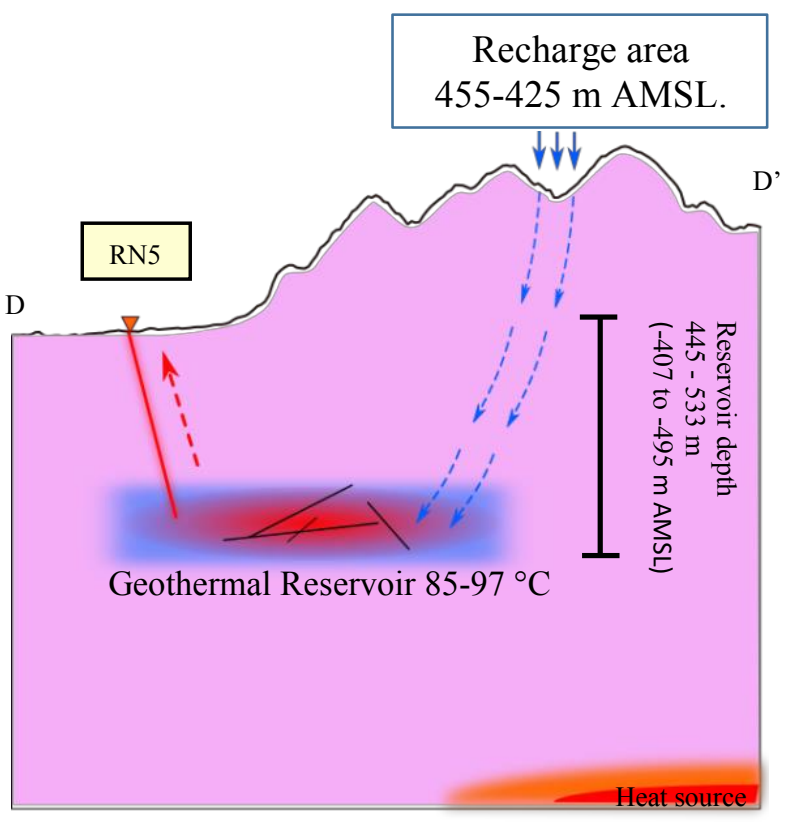

(b)

Figure 5.4-5: Topographic map with major and local faults structures (a) and conceptual model (b) of the Rattana Rangsan hot spring (RN5). The purple circle represents the water sample location. The black dot lines represent local faults and fractures drawn according to a recent survey (Chaturongkawanich and Leevongchareon, 2000). The orange line (cross-section line; D-D') represents the location of the conceptual model. (b) The conceptual model is generated from our geochemical and isotopic investigation and geoinformation from the previous study. 


\subsection{Conclusion}

The low enthalpy hot springs in Ranong Province in the southern part of Thailand are manifested along the Cretaceous granite basement rock and have become local tourist destinations in the southern part of the country. A comprehensive understanding of the natural hydrodynamic system is required for an evaluation of the availability and sustainability of groundwater resources. Analyses of the hydro-geochemical and isotopic composition of the thermal water indicate that:

- The seasonal variation in isotopic and chemical compositions is more pronounced in surface water, while the thermal water demonstrates remain stable compositions during seasonal changes.

- These waters are classified as sodium bicarbonate water type (Na- $\mathrm{HCO}_{3}$ type) which commonly indicates shallow condensate zones along the margins of the geothermal fields and identify the weathering of silicate system in the area. Most of the chemical concentrations $\left(\mathrm{F}^{-}\right.$, $\mathrm{Na}^{+}, \mathrm{K}^{+}, \mathrm{SO}_{4}{ }^{-}$and $\mathrm{Ca}^{2+}$ ) in thermal water could be developed from the Cretaceous granite basement rock of the geothermal fields. Apart from that, $\mathrm{Mg}^{2+}$ concentration may be decreased by precipitation processes after the water flow through the undersaturated zone which contains the altered minerals. The $\mathrm{Cl}^{-}$in thermal water is derived from precipitation.

- The stable isotope compositions of thermal water are located unusually above the LMWL. This derives from the high variation of meteoric water in this region as well as the collection of water depleted heavy isotopes during large precipitation events. A modeled LMWL is drawn for interpretation, is given by the following equation $\delta^{2} \mathrm{H}=7.97 \delta^{18} \mathrm{O}+$ $13.4 \%$. These can suggest that both thermal and surface water are originated from local meteoric water without magmatic origin. The thermal water is recharged from the high elevation of the mountainous area ranging from 378 to $483 \mathrm{~m}$ AMSL.

- Although the $\delta^{18} \mathrm{O}$-shifted values in thermal water are lower than the analytical precision of $\delta^{18} \mathrm{O}(<0.2 \%)$, the seasonal variation in $\delta^{18} \mathrm{O}$-shifted values are found in some hot springs (RN5 and RN6) reflecting the shallow-circulating system.

- The depleted $\delta^{13} \mathrm{C}$ ratio of the thermal water (ranging from -25.59 to $-23.55 \%$ ) is derived from organic-rich soil and river sediment from the southwestern coast of Thailand (Kuramoto and Minagawa, 2001). The water rapidly infiltrates to the shallow soil layers and flows into the silicate aquifer (Cretaceous regional granite), weathering the silica mineral in 
the basement rock. The corrected residence time from the ${ }^{14} \mathrm{C}$ dating by Pearson's model ranges from 2,675 to $5,235 \mathrm{BP}$. This consistent with the residence time from tritium results that indicate more than $60 \mathrm{BP}$.

- The geothermometer application provides a different range of temperature results. The verification of the geothermometry application suggests that the Ranong geothermal area derives from near-surface rock-water reactions (shallow system) and is reliable on the conservative $\mathrm{K}-\mathrm{Mg}$ and chalcedony subsystems, which state equilibrium temperatures ranging from 82 to $105{ }^{\circ} \mathrm{C}$. Based on drilling information and $\mathrm{Mg} / \mathrm{k}$ geothermometer, the estimated reservoir depth is in the range from 327 and $640 \mathrm{~m}$ (-286 to $-612 \mathrm{~m}$ AMSL). Moreover, if thermal water sample has been mixed with cold water in the silica-enthalpy mixing diagram, the geothermal reservoir would have high temperature approximately ranging from 130 to $199{ }^{\circ} \mathrm{C}$ and most of the samples have stream-loss during ascending to the surface and mixed with cool water from 70 to $90 \%$ by volume.

- The water-rock interaction in the Ranong geothermal area is evaluated by applying the REE and strontium isotopic compositions in minerals of surface rock and thermal water.

- The petrology results indicate mineral alteration, e.g., chloritization and the sericitization in the granitic rocks in Ranong.

- The REE concentration pattern results are generally accepted that REE in surface waters would be leached from the host rock. After the water passes the local permeable rock to the thermal system, total REE concentrations are chemically reduced by increasing temperature and pressure. Moreover, the results suggest that the $\mathrm{F}^{-}$concentration from altered fluorine-rich minerals (biotite and muscovite) predominantly control the precipitation processes of LREE-fluoride complex during flow path in this system. This contributes to the LREE depletion in thermal water.

- The mixing model of ${ }^{87} \mathrm{Sr} /{ }^{86} \mathrm{Sr}$ isotopic ratio and strontium composition in thermal water provides a narrow range of $\mathrm{Sr}$ from rock contribution from 86.21 to $88.31 \%$. This can suggest that these hot springs have similar water-rock interaction and are isotopically controlled by the granitic rock.

- Theses environment chemical and isotopic results in Ranong geothermal hot springs can establish four conceptual models by considering the surface flow direction from the 
topographic map, the previous geophysical investigation, and our results, for instance; 1) RN6, 2) RN1, 3) RN2 and RN3, 4) RN5. 
Chapter 6 


\section{Comparison of Mae Chan and Ranong geothermal area.}

Mae Chan and Ranong geothermal areas are located in different regions and have different topography. The isotopic and chemistry results show similarities in the origin of thermal water, water type, the evolution of REE pattern, and water-rock interaction as described below.

- The geothermal water in both areas comes from a shallow system in granitic rock, it is originated from meteoric water and chemically classified in $\mathrm{Na}-\mathrm{HCO}_{3}$ type.

- The mineral alteration, e.g., chloritization and sericitization in the granitic rocks are identified in both areas. The alteration changes the concentration of $\mathrm{Sr}$ and REE concentration, and ${ }^{87} \mathrm{Sr} /{ }^{86} \mathrm{Sr}$ ratio in the minerals.

- The REE in thermal waters are modified by host rocks and predominantly controlled by $\mathrm{F}^{-}$concentration.

The differences in each parameter and geothermal processes between the two areas are found and summarized in Table 6-1. 
Table 6-1: Comparison of the geothermal parameters and processes between two study areas.

\begin{tabular}{|c|c|c|}
\hline & Mae Chan & Ranong \\
\hline Granitic host rock & Triassic (?) granite & Cretaceous granite \\
\hline Surface temperatures & 50 to $92{ }^{\circ} \mathrm{C}$ & 41 to $66^{\circ} \mathrm{C}$ \\
\hline Chemical concentration & High & Low \\
\hline Chemical precipitation & $\mathrm{Mg}^{2+}$ and $\mathrm{Ca}^{2+}$ & - \\
\hline $\begin{array}{l}{ }^{87} \mathrm{Sr} /{ }^{86} \mathrm{Sr} \text { in the feldspar } \\
\text { minerals }\end{array}$ & $0.7230-0.7418$ & $0.7601-0.8737$ \\
\hline $\begin{array}{l}{ }^{87} \mathrm{Sr} /{ }^{86} \mathrm{Sr} \text { in the biotite } \\
\text { minerals }\end{array}$ & $0.7710-1.2520$ & 0.7892 \\
\hline Recharge elevation & 740 - 1,200 m AMSL. & 378 to 483 m AMSL. \\
\hline $\begin{array}{l}\text { Sources of dissolved } \\
\text { carbon }\end{array}$ & $\begin{array}{l}\text { dissolved inorganic carbon } \\
\text { (DIC) }\end{array}$ & $\begin{array}{l}\text { dissolved organic carbon } \\
\text { (DOC) }\end{array}$ \\
\hline Residence time period & 12,760 to $18,120 \mathrm{BP}$ & 2,675 to $5,235 \mathrm{BP}$ \\
\hline $\begin{array}{l}\text { Reservoir temperatures by } \\
\text { Mg and chalcedony }\end{array}$ & 98 to $139^{\circ} \mathrm{C}$ & 82 to $105^{\circ} \mathrm{C}$ \\
\hline Reservoir depth & $\begin{array}{c}353 \text { to } 814 \mathrm{~m} \\
(-405 \text { and } 150 \mathrm{~m} \text { AMSL) }\end{array}$ & $\begin{array}{c}327 \text { and } 640 \mathrm{~m} \\
\text { (-286 to }-612 \mathrm{~m} \text { AMSL) }\end{array}$ \\
\hline $\begin{array}{l}\text { Mixing model in thermal } \\
\text { water indicate } \mathrm{Sr} \text { from } \\
\text { rock contribution }\end{array}$ & $\begin{array}{c}\text { Short distance from the } \\
\text { faults has rock contribution } \\
\text { ranging from } 73.11 \text { to } \\
75.10 \% \\
\text { Long distance from the } \\
\text { faults has rock contribution } \\
\text { ranging from } 82.50 \text { to } \\
86.31 \%\end{array}$ & $\begin{array}{c}\text { Similar range from } 86.21 \text { to } \\
88.31 \%\end{array}$ \\
\hline
\end{tabular}


Chapter 7 


\section{Conclusion and outlook}

\section{Conclusion}

The medium enthalpy hot springs in the Mae Chan area in the northern part of Thailand are found along the Triassic (?) granite basement rock and the low enthalpy hot springs in Ranong Province in the southern part of Thailand are found along the Cretaceous granite basement rock.

To evaluate and improve the understanding of these hydrothermal systems. This Ph.D. dissertation integrated the applications of natural hydrogeochemical and isotopic composition in water and rock minerals as follows;

- Due to the major ions composition $\left(\mathrm{Ca}^{2+}, \mathrm{Mg}^{2+}, \mathrm{Na}^{+}, \mathrm{K}^{+}, \mathrm{HCO}_{3}{ }^{-}, \mathrm{CO}_{3}^{2-}, \mathrm{SO}_{4}{ }^{2-}\right.$, and $\left.\mathrm{Cl}^{-}\right)$, the hydrothermal systems can be characterized as $\mathrm{Na}-\mathrm{HCO}_{3}$ type which is the shallow system.

- The geothermometer applications provide the ranges of reservoir temperatures. Based on the verification, the conservative $\mathrm{K}-\mathrm{Mg}$ and chalcedony geothermometers, are considered as two reliable geothermometer applications, state equilibrium temperatures ranging from 82 to $139{ }^{\circ} \mathrm{C}$. These results combine with the local geothermal gradient to estimate the reservoir depth ranging from 400 to $1,200 \mathrm{~m}$ for the Ranong area and ranging from 353 to $814 \mathrm{~m}$ (-405 and $150 \mathrm{~m}$ AMSL) for the Mae Chan area.

- The stable isotope of water $\left(\delta^{2} \mathrm{H}, \delta^{18} \mathrm{O}\right)$ can provide the information about source and altitude of the recharge area. The thermal water from these hydrothermal systems is from meteoric water and is recharged from the high elevation of the mountainous area.

- The carbon stable isotope result $\left(\delta^{13} \mathrm{C}\right)$ indicates that the carbon compositions in Ranong thermal water are originated from the dissolved organic carbon (DOC), while the carbon composition in Mae Chan thermal water are mostly originated from the dissolved inorganic carbon (DIC). It also indicates the contamination from local geologic gases and the biological carbon in Mae Chan area.

- Tritium $\left({ }^{3} \mathrm{H}\right)$ analysis shows the residence time period in both areas is longer than 60 BP.

- Radiocarbon $\left({ }^{14} \mathrm{C}\right)$ analysis indicates longer residence time period as compared to Tritium $\left({ }^{3} \mathrm{H}\right)$ analysis. Moreover, the evidence of carbon contamination from geologic gases and from biological carbon in Mae Chan area can interrupted the residence time periods of thermal water, therefore, the residence time periods of these groups are not 
reliable. The residence time period in Mae Chan area (in case of without external carbon contamination) ranges from 12,760 to $18,000 \mathrm{BP}$ and in Ranong area ranges from 2,675 to $5,235 \mathrm{BP}$.

- Rare earth elements (REE) in minerals and water provide the water-rock interaction that the REE in these thermal waters are chemically reduced by increasing temperature and pressure which has the fluoride concentration predominantly control the precipitation processes of LREE-fluoride complex during flow path in this system.

- Strontium isotope $\left({ }^{87} \mathrm{Sr} /{ }^{86} \mathrm{Sr}\right)$ in minerals and water are investigated by using the strontium mixing model and granite dissolution model to investigate the water-rock interaction. The results reveal that the distance between fault core and the hot springs influences the percent dissolved $\mathrm{Sr}$ from the rock.

- The differences in the hydrogeochemical and isotopic composition in these hot springs can be explained by multi, small reservoirs, rather than by single, large scale reservoirs. For more specific interpretation, five conceptual models for Mae Chan geothermal water and four conceptual models for Ranong geothermal water are built by integrating our result, the geological data, and topographic data. These models will be helpful for future water resources assessment and sustainable geothermal water management.

\section{Outlook}

- According to the hydro-chemical and isotopic results, these geothermal areas can be characterized as the shallow system, which is heavily influenced by seasonal variation. A better understanding of seasonal effect improves the investigation of shallow systems. Therefore, the sampling in future studies should be more frequent and the duration should be longer than this study.

- As the south of Thailand has a large yearly-variable in moisture contribution from the Indian Ocean, this directly affects the shifted LMWL. Therefore, the future investigation in this area should continually monitor isotopic composition in meteoric water in the long-term period for reducing the error from the yearly-variation and improving the LMWL.

- As various processes occur in the geothermal system, the trace element concentration in water and minerals are controlled by the chemical reaction and mobility of that trace element. Therefore, analyzing of other trace elements in water and minerals would provide a further understanding of the water-rock interaction in these geothermal systems. 
- To fill the gap of the carbon source in the system, the concentration and isotopic composition of the carbon dioxide gas, methane from the thermal water, and the dissolved organic carbon in the soil need to be investigated. This could clarify the mixing processes of carbon source of the system.

- The chemical and isotopic composition in granitic minerals in the reservoirs and surface sinter should be investigated. This would provide more water-rock interaction details, hydrothermal alteration, and precipitation processes for the understanding of the geothermal reservoir in systems. 
Chapter 8 


\section{References}

Alderton, D.H.M., 1980. Rare earth elament mobility during granite alteration: Evidence from southwest England 49, 149-165.

Amatyakul, P., Boonchaisuk, S., Rung-arunwan, T., 2016. Geothermics Exploring the shallow geothermal fluid reservoir of Fang geothermal system, Thailand via a 3-D magnetotelluric survey. Geothermics 64, 516-526.

Amatyakul, P., Rung-arunwan, T., Siripunvaraporn, W., 2015. Geothermics A pilot magnetotelluric survey for geothermal exploration in Mae Chan region, northern Thailand. Geothermics 55, 31-38.

Apollaro, C., Vespasiano, G., De Rosa, R., Marini, L., 2015. Use of mean residence time and flowrate of thermal waters to evaluate the volume of reservoir water contributing to the natural discharge and the related geothermal reservoir volume. Application to Northern Thailand hot springs. Geothermics 58, 62-74.

Arnórsson, S., 2000. Isotopic and Chemical Techiques In Geothermal Exploration.

Arnórsson, S., Gunnlaugsson, E., Svavarsson, H., 1983. The chemistry of geothermal waters in Iceland. III. Chemical geothermometry in geothermal investigations. Geochim. Cosmochim. Acta 47, 567-577.

Battistel, M., Hurwitz, S., Evans, W.C., Barbieri, M., 2016. The chemistry and isotopic composition of waters in the low-enthalpy geothermal system of Cimino-Vico Volcanic District, Italy. J. Volcanol. Geotherm. Res. 328, 222-229.

Cartwright, I., Fifield, L.K., Morgenstern, U., 2013. Using3H and14C to constrain the degree of closed-system dissolution of calcite in groundwater. Appl. Geochemistry 32, 118-128.

Cartwright, I., Morgenstern, U., 2012. Constraining groundwater recharge and the rate of geochemical processes using tritium and major ion geochemistry: Ovens catchment, southeast Australia. J. Hydrol. 475, 137-149.

Chae, G.T., Yun, S.T., Kim, K., Mayer, B., 2006. Hydrogeochemistry of sodium-bicarbonate type bedrock groundwater in the Pocheon spa area, South Korea: water-rock interaction and hydrologic mixing. J. Hydrol. 321, 326-343.

Charusiri, P., Kosuwan, S., Tuteechin, W., Khantaprab, C., 1994. Rare-Earth Element 
Geochemistry of Some Granitoid Rocks in Thailand: Implication for Future Exploration. Prince of Songkla University (in Thai language), Had Yai.

Charusiri, P., Pongsapich, W., Daorerk, V., Khantaprab, C., 1992. Granitoid Belts in Thailand :

New Evidence from 40Ar/43Ar Geochronological and Isotopic Syntheses. J. Sci. Res. Chulalongkorn Univ. 17, 99-116.

Chaturongkawanich, S., Leevongchareon, S., 2000. The geothermal resources of changwat Ranong southern Thailand. In: Proceedings World Geothermal Congress. KyushuTohoku, Japan, pp. 1049-1052.

Chen, G., Wang, G., Sun, Z., Liu, J., 2010. The Isotopic and Chemical Characteristics of Geothermal Fluids from Two Selected Hot Spring Areas in Jiangxi Province, SE-China AND ISOTOPIC 25-29.

Clark, I., 2015. Groundwater Geochemistry and Isotopes. CRC Press, London, New York.

Clow, D.W., Mast, M.A., Bullen, T.D., Turk, J.T., 1997. Strontium 87/strontium 86 as a tracer of mineral weathering reactions and calcium sources in an alpine/subalpine watershed, Loch Vale, Colorado. Water Resour. Res. 33, 1335-1351.

Dansgaard, W., 1964. Stable isotopes in precipitation. Tellus 16, 436-468.

De Baar, H.J.W., Bacon, M.P., Brewer, P.G., Bruland, K.W., 1985. Rare earth elements in the Pacific and Atlantic Oceans. Geochim. Cosmochim. Acta 49, 1943-1959.

Department of Alternative Energy Developtment and Efficeincy, 2007a. Potential Assessment of Hot Springs in Thailand Executive Summary Report. Bangkok, Thailand.

Department of Alternative Energy Developtment and Efficeincy, 2007b. Potential Assessment of Hot Springs in Thailand [WWW Document]. URL http://www2.dede.go.th/geothermal_gis/website/ (accessed 8.16.16).

Department of Mineral Resources, 2007. The boundary classification for manage geology and mineral resource in Ranong province. Bangkok, Thailand.

DGR, 2017a. Final report: The study and Investigation of Hot Spring Sources for Promoting Geothermal Energy Generation and Local Industries in Thailand. Bangkok, Thailand.

DGR, 2017b. Executive summary report: The study and Investigation of Hot Spring Sources for Promoting Geothermal Energy Generation and Local Industries in Thailand. Bangkok, 
Thailand.

DMR, 2014. Geology of Thailand, First edit. ed. Bureau of Geological Survey Department of Mineral Resources, Bangkok, Thailand, Bangkok, Thailand.

Dotsika, E., Poutoukis, D., Kloppmann, W., Guerrot, C., Voutsa, D., Kouimtzis, T.H., 2010. The use of $\mathrm{O}, \mathrm{H}, \mathrm{B}, \mathrm{Sr}$ and $\mathrm{S}$ isotopes for tracing the origin of dissolved boron in groundwater in Central Macedonia, Greece. Appl. Geochemistry 25, 1783-1796.

F. Ridd, M., J. Barber, A., J.Crow, M. (Eds.), 2011. The Geology of Thailand. The Geological Society London.

Fenton, C.H., Charusiri, P., Wood, S.H., 2003. Recent paleoseismic investigations in Northern and Western Thailand. Ann. Geophys. 46, 957-981.

Fournier, R.O., 1977. Chemical geothermometers and mixing models for geothermal systems. Geothermics 5, 41-50.

Fournier, R.O., Rowe, J. j., 1977. The solubility of amorphous silica in water at high temperatures and high pressures. Am. Mineral. 62, 1052-1056.

Gat, J.R., Mook, W.G., Meijer, a. J., 2001. Environmental isotopes in the hydrological cycle Volume II Atmospheric water. IHP-V, Tech. Doc. 2, 1-113.

Geothermica Italiana Slr., 1984. Geothermal reconnaissance survey of northern Thailand: UNDP final report. PISA.

Giggenbach, W., Sheppard, D., Robinson, B., Stewart, M., Lyon, G., 1994. Geochemical structure and position of the Waiotapu geothermal field, New Zealand. Geothermics 23, $599-644$.

Giggenbach, W.F., 1988. Geothermal solute equilibria. Derivation of Na-K-Mg-Ca geoindicators. Geochim. Cosmochim. Acta 52, 2749-2765.

Giggenbach, W.F., 1992. Isotopic shifts in waters from geothermal and volcanic systems along convergent plate boundaries and their origin. Earth Planet. Sci. Lett. 113, 495-510.

Hall, R., 2002. SE Asian Heatflow: call for new data. SEAPEX Press.

Han, L.F., Plummer, L.N., 2016. A review of single-sample-based models and other approaches for radiocarbon dating of dissolved inorganic carbon in groundwater. EarthScience Rev. 152, 119-142. 
Han, L.F., Plummer, L.N., Aggarwal, P., 2012. A graphical method to evaluate predominant geochemical processes occurring in groundwater systems for radiocarbon dating. Chem. Geol. 318-319, 88-112.

Herschy, R.W., 1998. Water resources: water resourcessurface and groundwaterSurface and groundwater. In: Encyclopedia of Hydrology and Lakes. Springer Netherlands, Dordrecht, pp. $757-762$.

Hoefs, J., 2009. Stable Isotope Geochemistry, sixth. ed. Springer Berlin Heidelberg, Berlin, Heidelberg.

Hydro and Agro Informatics Institute (HAII), 2016. Database of stable isotope in surface water, Precipitation and humidity for water cycle studies in Thailand project. Bangkok, Thailand.

Imai, A., Yonezu, K., Sanematsu, K., Ikuno, T., Ishida, S., Watanabe, K., Pisutha-Arnond, V., Nakapadungrat, S., Boosayasak, J., 2013. Rare Earth Elements in Hydrothermally Altered Granitic Rocks in the Ranong and Takua Pa Tin-Field, Southern Thailand. Resour. Geol. $63,84-98$.

Imsamut, S., Krawchan, V., 2005. The Geology of Amphor Fang Quadrangle (4848IV). Bangkok, Thailand.

International Atomic Energy Agency, 1993. Isotope and geochemical techniques applied to geothermal investigations. Proc. Final Res. Co-ord. Meet. Appl. Isot. Geochemical Tech. to Geotherm. Explor. Middle East, Asia, Pacific Africa 12-15.

International Atomic Energy Agency, 2010. Sampling Procedures for Isotope Hydrology. Water Resour. Program. 8.

Jongatchariyakul, S., Chaikam, A., 2013. Exploration and Evaluation of Geological in Chiang Rai Province. Lampang, Thailand.

Kendall, C., Snyder, D., Caldwell, E., 2004. USGS -- Isotope Tracers -- Resources [WWW Document]. URL https://wwwrcamnl.wr.usgs.gov/isoig/period/h_iig.html (accessed 2.7.17).

Khoonphunnarai, P., 2009. Interpretation of Airborne Geophysical Data of Ranong Geothermal Area. Prince of Songkla University.

Kita, I., Nagao, K., Takashima, I., Honda, S., Ratanasthien, B., 1990. Preliminary Study on the 
Chemical and Isotopicin Northern Thailand.pdf. MASS Spectrosc. 38.

Klaus, J.S., Hansen, B.T., Buapeng, S., 2007. 87Sr/86Sr ratio: A natural tracer to monitor groundwater flow paths during artificial recharge in the Bangkok area, Thailand. Hydrogeol. J. 15, 745-758.

Korjedee, T., 2002. Geothermal exploration and development in Thailand. World Geotherm. Congr. 2000 11, 56-66.

Kosuwan, S., Nakapadungrat, S., 1991. The Geology of Changwat Ranong Quadrangle; Geological Map of Thailand Series 1:50,000. Bangkok, Thailand.

Kosuwan, S., Nakapadungrat, S., 1992. The Geology of Changwat Ranong Quadrangle (4728IV), Amphoe Phato Quadrangle (4728I) and Bansai Dang Quadrangle (4729III). Bangkok, Thailand.

Kuramoto, T., Minagawa, M., 2001. Stable Carbon and Nitrogen Isotopic Characterization of Organic Matter in a Mangrove Ecosystem on the Southwestern Coast of Thailand. J. Oceanogr. 57, 421-431.

Lasaga, A.C., 1984. Chemical kinetics of water-rock interactions. J. Geophys. Res. Solid Earth $89,4009-4025$.

McDonough, W.F., Sun, S., 1995. The composition of the Earth. Chem. Geol. 120, 223-253.

Migdisov, A., Williams-Jones, A.E., Brugger, J., Caporuscio, F.A., 2016. Hydrothermal transport, deposition, and fractionation of the REE: Experimental data and thermodynamic calculations. Chem. Geol. 439, 13-42.

Mitchell, T.M., Faulkner, D.R., 2012. Towards quantifying the matrix permeability of fault damage zones in low porosity rocks. Earth Planet. Sci. Lett. 339-340, 24-31.

Möller, P., 2007. Rare earth elements and yttrium in geothermal fluids. Potsdam.

Mook, W.G., Bommerson, J.C., Staverman, W.H., 1974. Carbon isotope fractionation between dissolved bicarbonate and gaseous carbon dioxide. Earth Planet. Sci. Lett. 22, 169-176.

Morley, C.K., Charusiri, P., Watkinson, I., 2011. Structural geology of Thailand during the cenozoic. In: The Geology of Thailand. pp. 273-334.

Myrttinen, A., Becker, V., Barth, J.A.C., 2012. A review of methods used for equilibrium isotope fractionation investigations between dissolved inorganic carbon and $\mathrm{CO} 2$. Earth- 
Science Rev. 115, 192-199.

Négrel, P., Casanova, J., Aranyossy, J.F., 2001. Strontium isotope systematics used to decipher the origin of groundwaters sampled from granitoids: The Vienne Case (France). Chem. Geol. 177, 287-308.

Négrel, P., Giraud, E.P., 2011. Geochemistry , isotopic composition ( delta O-18 , delta of French Guiana as indicators of their origin, interrelations $G^{\prime}$ eochimie et compositions isotopiques eaux souterraines de Guyane comme indicateurs de leur origine et interrelations To cite this $342,786-795$.

Nicholson, K., 1993. Geothermal Fluids: Chemistry and Exploration Techniques, 1st ed. Springer Berlin Heidelberg.

Office of Development Tourism, 2006. The Natural hot spring [WWW Document]. URL http://61.19.236.142/hotspring/about.php (accessed 8.16.16).

Office of Natural Resources and Environmental Policy and Planning, 2014. Preparation and protection project for climate change which may affect to eco and environment system [WWW Document]. URL http://www.onep.go.th/thailandnaturalsites/index.php (accessed 8.16.16).

Petelet-Giraud, E., Négrel, P., Casanova, J., 2003. Variability of $87 \mathrm{Sr} / 86 \mathrm{Sr}$ in water draining granite revealed after a double correction for atmospheric and anthropogenic inputs. Hydrol. Sci. J. 48, 729-742.

Petrini, R., Italiano, F., Ponton, M., Slejko, F.F., Aviani, U., Zini, L., 2013. Geochemistry and isotope geochemistry of the Monfalcone thermal waters (northern Italy): inference on the deep geothermal reservoirGéochimie et géochimie isotopique des eaux thermales de Monfalcone (Italie du Nord): interférence avec le réservoir géotherm. Hydrogeol. J. 21, $1275-1287$.

Pirajno, F., 2009. Hydrothermal processes and mineral systems / Franco Pirajno. Springer/Geological Survey of Western Australia, Dordrecht; London.

Raksaskulwong, M., 2004. GEOTHERMAL DIRECT - USE IN SOUTHERN THAILAND. 6th Asian Geotherm. Symp. 6 th, 33-37.

Raksaskulwong, M., 2008. Thailand geothermal energy: development history and current status. Proc. 8th Asian Geotherm. Symp. 39-46. 
Raksaskulwong, M., 2011. FOUR DECADES OF GEOTHERMAL RESEARCH AND DEVELOPMENT IN. In: Proceedings of the 9th Asian Asian Geothermal Symposium. pp. 7-9.

Raksaskulwong, M., 2015. Update on geothermal development in Thailand. Proc. World Geotherm. Congr. 1, 337-340.

Ramingwong, T., Lertsrimongkol, S., Asnachinda, P., Praserdvigai, S., 2000. Update on Thailand geothermal energy research and development. World Geotherm. Congr. 2000 2, $377-386$.

Ratanasthein, B., Ramingwong, T., Tunsakul, L., 1988. The origin of Northern Thailand geothermal systems as indicated by isotopic hydrogeology. Japan Int. Geotherm. Symp.

Rowley, D.B., Garzione, N.C., 2007. Stable Isotope-Based Paleoaltimetry. J. Orthomol. Psychiatry 13, 193-196.

Rowley, D.B., Pierrehumbert, R.T., Currie, B.S., 2001. A new approach to stable isotope-based paleoaltimetry: Implications for paleoaltimetry and paleohypsometry of the High Himalaya since the late Miocene. Earth Planet. Sci. Lett. 188, 253-268.

Saad, D.A., Thorstenson, D.C., 1998. Flow and geochemistry along shallow ground-water flowpaths in an agricultural area in southeastern Wisconsin. Water-Resources Investig. U. S. Geol. Surv. 62.

Sanmuang, E., 2009. Gravity Anomaly of Ranong Geothermal area. Prince of Songkla University (in Thai language).

Saravana Kumar, U., Kumar, B., Rai, S.P., Sharma, S., 2010. Stable isotope ratios in precipitation and their relationship with meteorological conditions in the Kumaon Himalayas, India. J. Hydrol. 391, 1-8.

Singharajwarapan, F.S., Wood, S.H., Prommakorn, N., Owens, L., 2012. Northern Thailand Geothermal Resources and Development: A Review and 2012 Update. Geotherm. Resouces Counc. Boise State Univ. 36, 787-791.

Stute, M., 1989. on Deep Groundwater Circulation Systems 31.

Subtavewung, P., Raksaskulwong, M., Tulyatid, J., 2005. The Characteristic and Classification of Hot Springs in Thailand. In: World Geothermal Congress 2005. pp. 24-29. 
Szaran, J., 1998. Carbon isotope fractionation between dissolved and gaseous carbon dioxide. Chem. Geol. 150, 331-337.

Thailand Meteorological Department (TMD), 2012. Climate and weather of Ranong province. Bangkok, Thailand.

Thailand Meterological Department, 2011. Climatological Data for the period 1981-2010. Bangkok, Thailand.

The Natural Stone Institute, 2018. R-Value for Natural Stone [WWW Document]. URL https://www.naturalstoneinstitute.org/stoneprofessionals/technical-bulletins/rvalue/

Thomas, M.A., 2018. Chemical and Isotopic Characteristics of Methane in Groundwater of Ohio , 2016 Scientific Investigations Report 2018 - 5097.

TINT, 2012. The investigation of stable isotope effect at Doi Inthanonin Chiang Mai, Thailand. Ongkarak.

Tulyatid, D., Jitrattana, R., Worakanok, S., Lertnok, A., Chaisen, W., 2014. Excursion guide book Chiang Mai Thailand. In: 62nd CCOP STEERING COMMITTEE MEETING. CHIANGMAI THAILAND.

U.S. Geological Survey, 2019. Specific conductance: U.S. Geological Survey Techniques and Methods. In: Handbooks for Water-Resources Investigations. p. 15 p.

Ueno, K., 2003. The Permian fusulinoidean faunas of the Sibumasu and Baoshan blocks: Their implications for the paleogeographic and paleoclimatologic reconstruction of the Cimmerian Continent. Palaeogeogr. Palaeoclimatol. Palaeoecol. 193, 1-24.

USGS Earth Explorer, 2017. ASTER Digital Elevation Model (DEM) 30 m resolution [WWW Document]. URL http://earthexplorer.usgs.gov. (accessed 7.1.17).

Uttamo, W., Elders, C., Nichols, G., 2003. Relationships between Cenozoic strike-slip faulting and basin opening in northern Thailand. Geol. Soc. London, Spec. Publ. 210, 89-108.

Wagner, W., Hans-Joachim, K., 2007. International Steam Tables, Secound Ed. ed.

Wanakasem, S., Takabut, K., 1987. Present status of fang geothermal project, thailand. Geothermics 15, 583-587.

Wang, X., Lu, G., Hu, B.X., 2018. Hydrogeochemical Characteristics and Geothermometry Applications of Thermal Waters in Coastal Xinzhou and Shenzao Geothermal Fields, 
Guangdong, China. Geofluids 2018.

Watkinson, I., Elders, C., Batt, G., Jourdan, F., Hall, R., Mcnaughton, N.J., 2011. The timing of strike - slip shear along the Ranong and Khlong Marui faults , Thailand 116, 1-26.

Wei, Z., Lee, X., Liu, Z., Seeboonruang, U., Koike, M., Yoshimura, K., 2018. Influences of large-scale convection and moisture source on monthly precipitation isotope ratios observed in Thailand, Southeast Asia. Earth Planet. Sci. Lett. 488, 181-192.

Wiegand, B.A., 2009. Tracing effects of decalcification on solute sources in a shallow groundwater aquifer, NW Germany. J. Hydrol. 378, 62-71.

Wood, S.H., Kaewsomwang, P., Singharajwarapan, F.S., 2018. Geologic framework of the Fang Hot Springs area with emphasis on structure, hydrology, and geothermal development, Chiang Mai Province, northern Thailand, Geothermal Energy. Springer Berlin Heidelberg.

Wood, S.H., Singharajwarapan, F.S., 2015. Geothermal systems of northern Thailand and their association with faults active during the Quaternary. GRC Trans. 38.

Wood, S.H., Singharajwarapan, F.S., Bundarnsin, T., Rothwell, E., 2004. Mae Sai Basin and Wiang Nong Lom : Radiocarbon Dating and Relation to the Active Strike-Slip Mae Chan Fault, Northern Thailand. In: International Conference on Applied Geophysics. Chiang Mai, Thailand.

Yongprawat, M., Kamdee, K., Noipow, N., 2012. Tritium content in rainfall for mornitoring effect from Fulkushima Accident at Ongkharak raindall station in Thailand. In: Environmental and Safety Technology. TIChE International Conference 2012, Nakornratchasima, Thailand.

Zuddas, P., Seimbille, F., Michard, G., 1995. Granite-fluid interaction at near-equilibrium conditions: Experimental and theoretical constraints from $\mathrm{Sr}$ contents and isotopic ratios. Chem. Geol. 121, 145-154. 
Chapter 9 


\section{Appendix.}

9.1 Appendix 1: The data from previous investigation are involved in the study

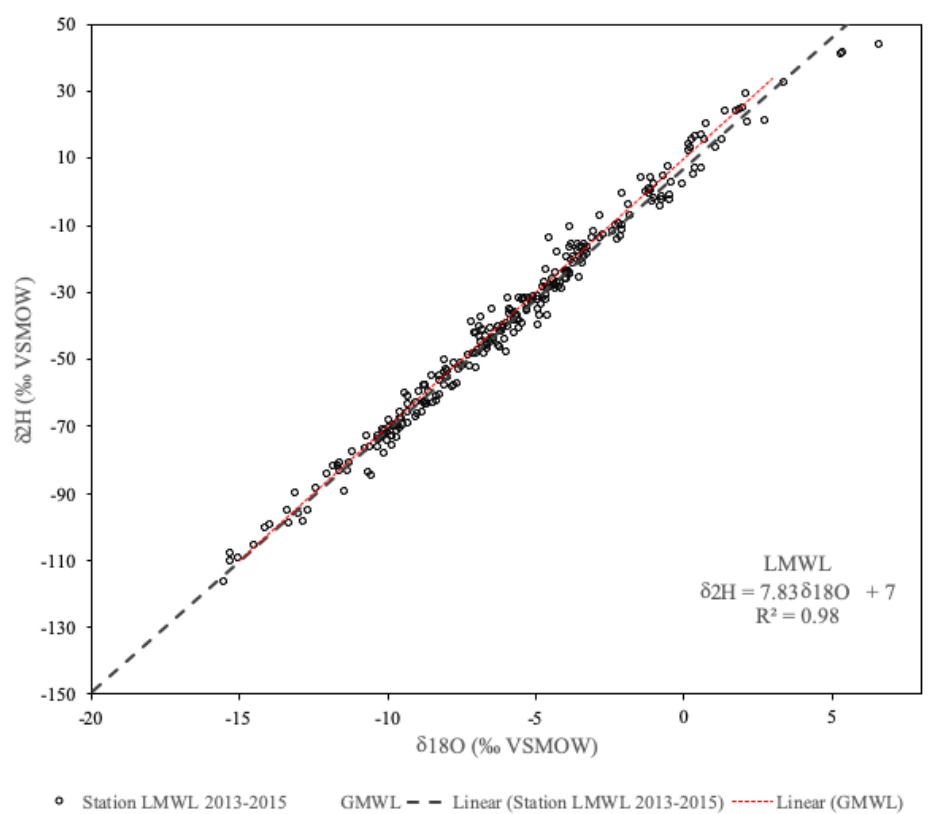

Figure 9.1-1: Local meteoric water line in Chiang Rai station, Thailand, based on precipitation data $(\mathrm{n}=263 \mathrm{~F})$ from 2013 to 2015 (HAII, 2016).

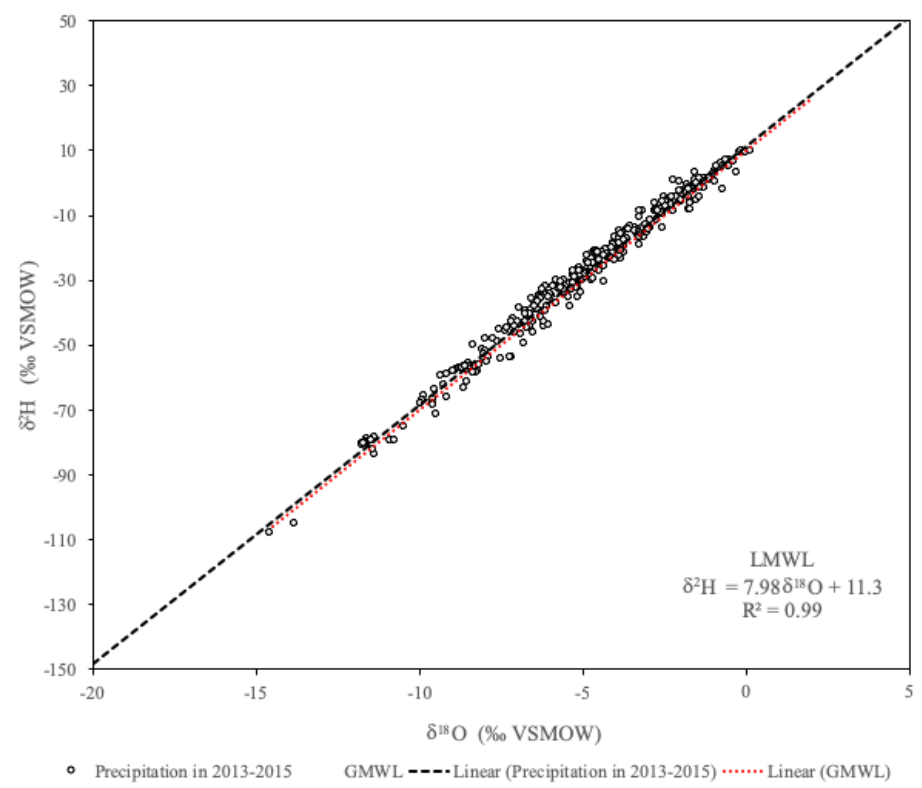

Figure 9.1-2: Local meteoric water line in Ranong station, Thailand, based on precipitation data $(\mathrm{n}=338)$ from 2013 to 2015 (HAII, 2016). 


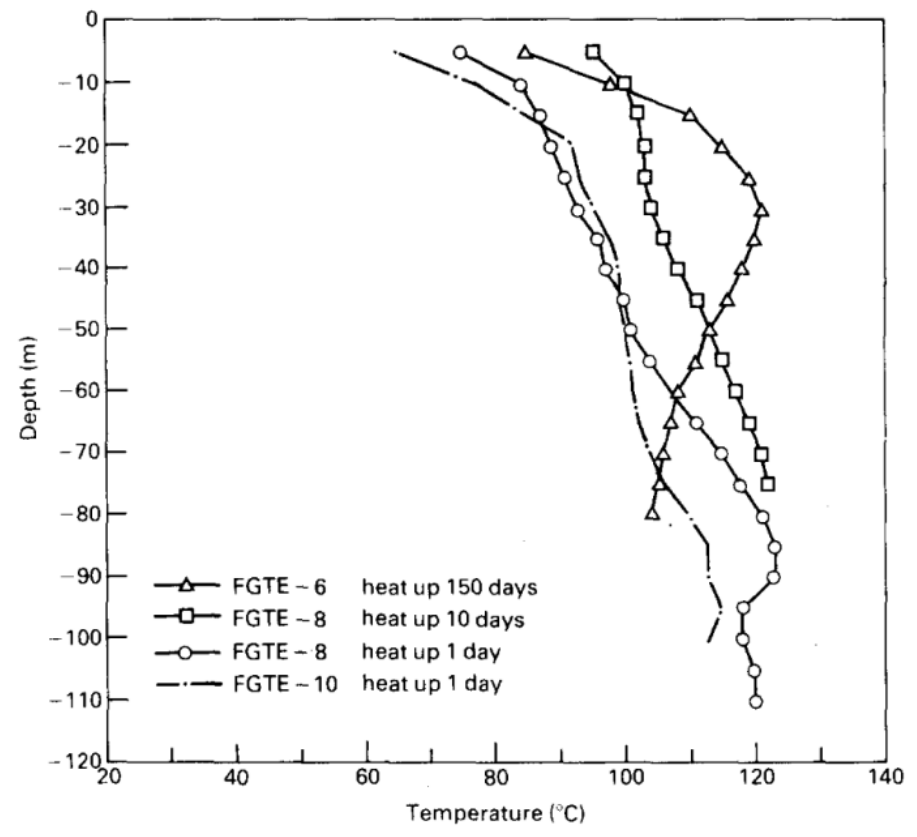

Figure 9.1-3: Temperature profiles from drilling well in the Fang shallow geothermal area (Wanakasem and Takabut, 1987). 
9.2 Appendix 2: The petrology results of the study.
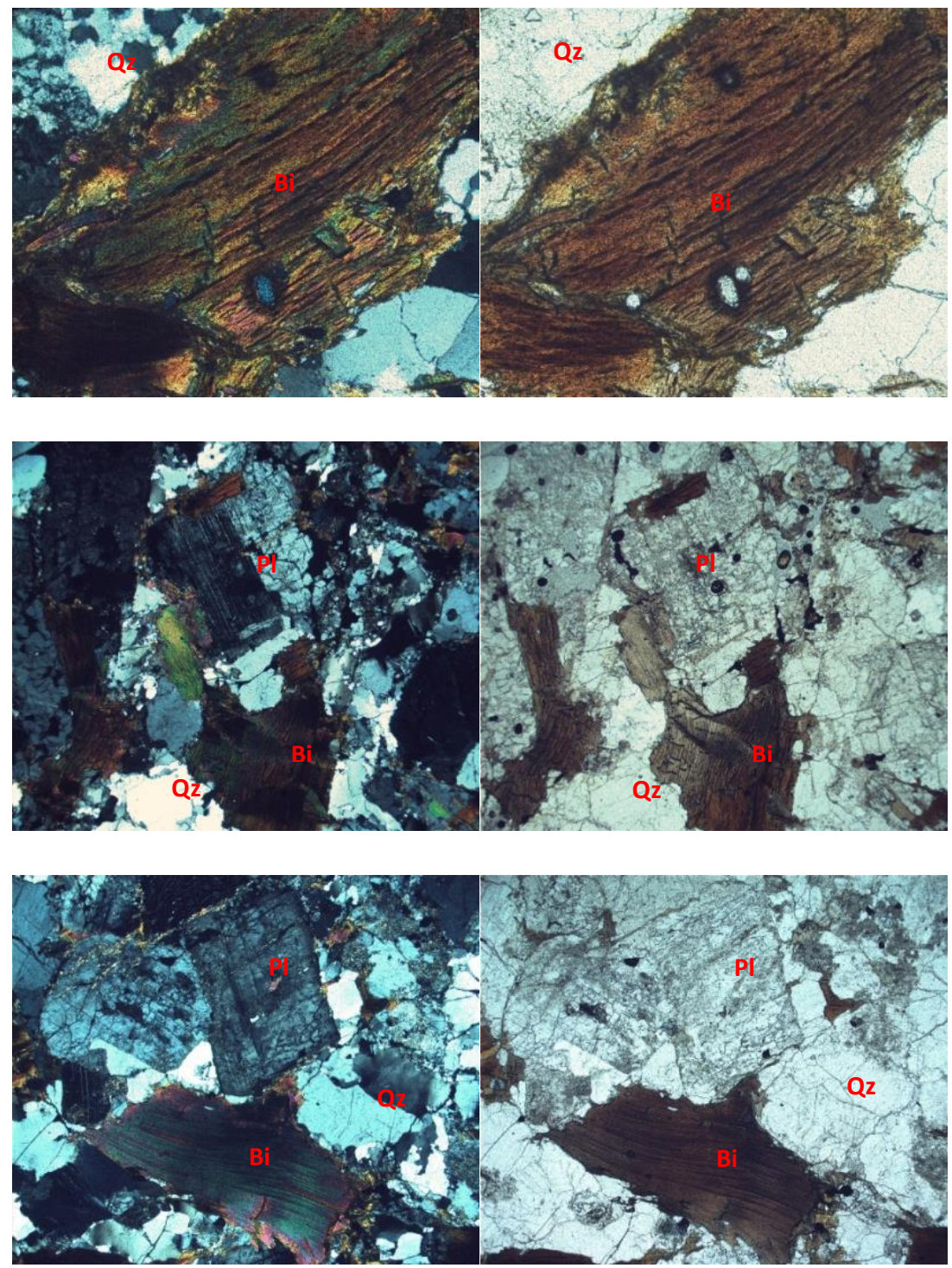

(PL)

(TL)

Figure 9.2-1: Polarized light (PL) and transmitted light (Tl) microscopic analysis of thinsection and petrography in the surface granite from the Mulika hot springs (CM-16). Abbreviations: Qz: Quartz, Kfs: K-feldspar (alkali-feldspar), Pl: plagioclase, Bi: Biotite, and Mc: Muscovite. 

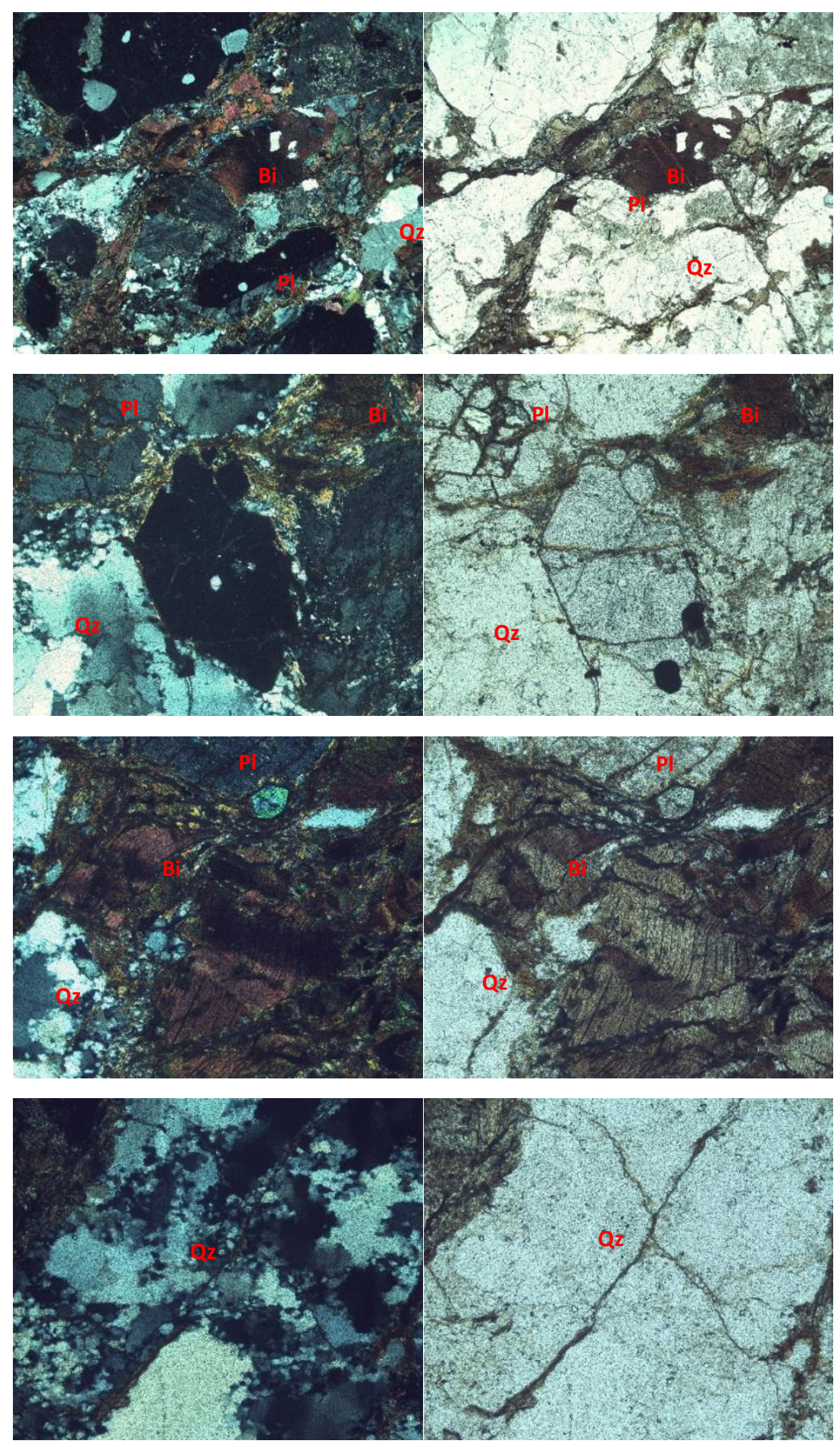

(PL)

(TL)

Figure 9.2-2: Polarized light (PL) and transmitted light (Tl) microscopic analysis of thinsection and petrography in the surface granite from the CR-Near Malika (CM-16-2). Abbreviations: Qz: Quartz, Kfs: K-feldspar (alkali-feldspar), P1: plagioclase, Bi: Biotite, and Mc: Muscovite. 

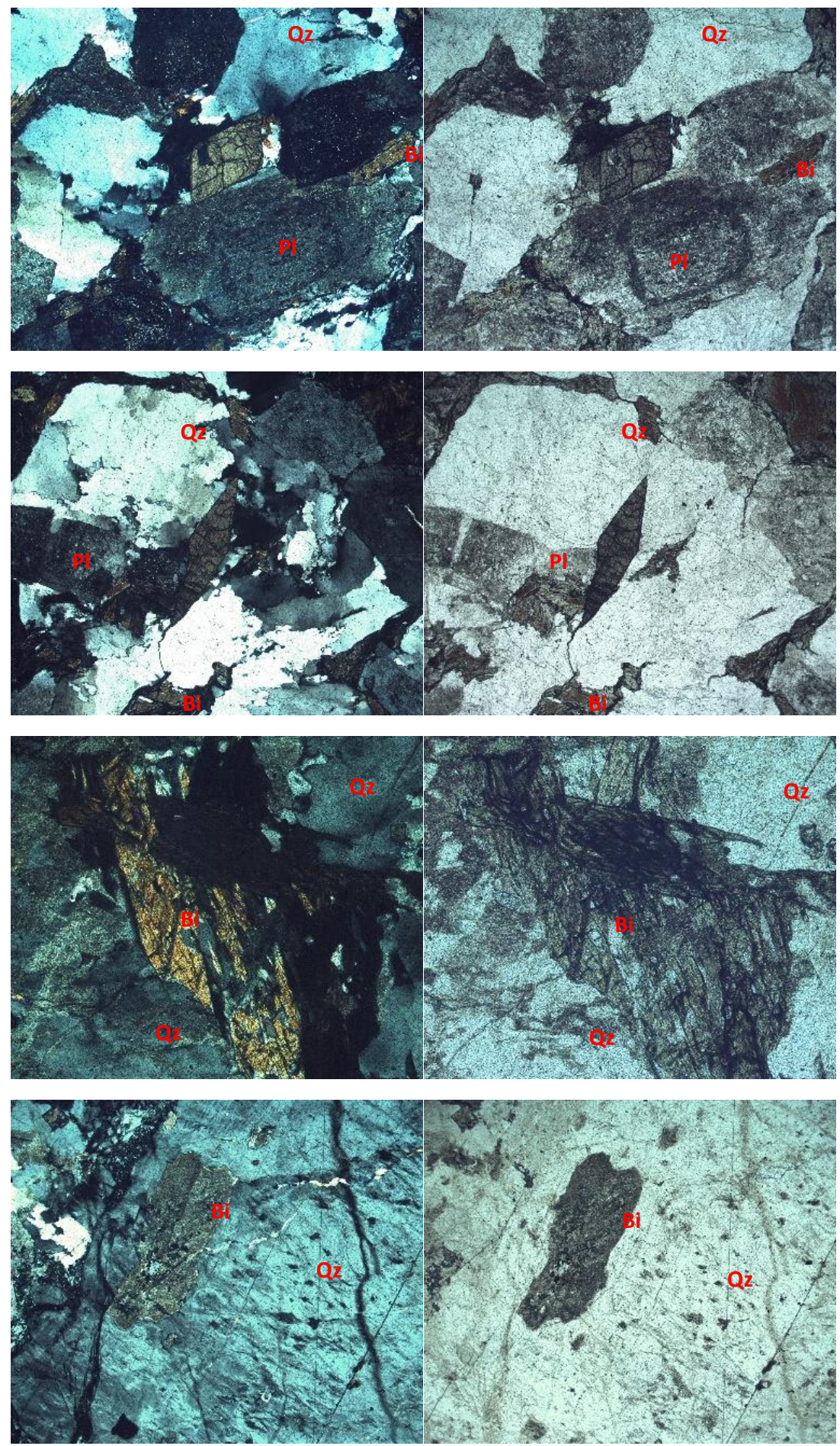

(PL)

(TL)

Figure 9.2-3: Polarized light (PL) and transmitted light (Tl) microscopic analysis of thinsection and petrography in the surface granite from the CR-Mae Chan (CM-04). Abbreviations: Qz: Quartz, Kfs: K-feldspar (alkali-feldspar), Pl: plagioclase, Bi: Biotite, and Mc: Muscovite. 

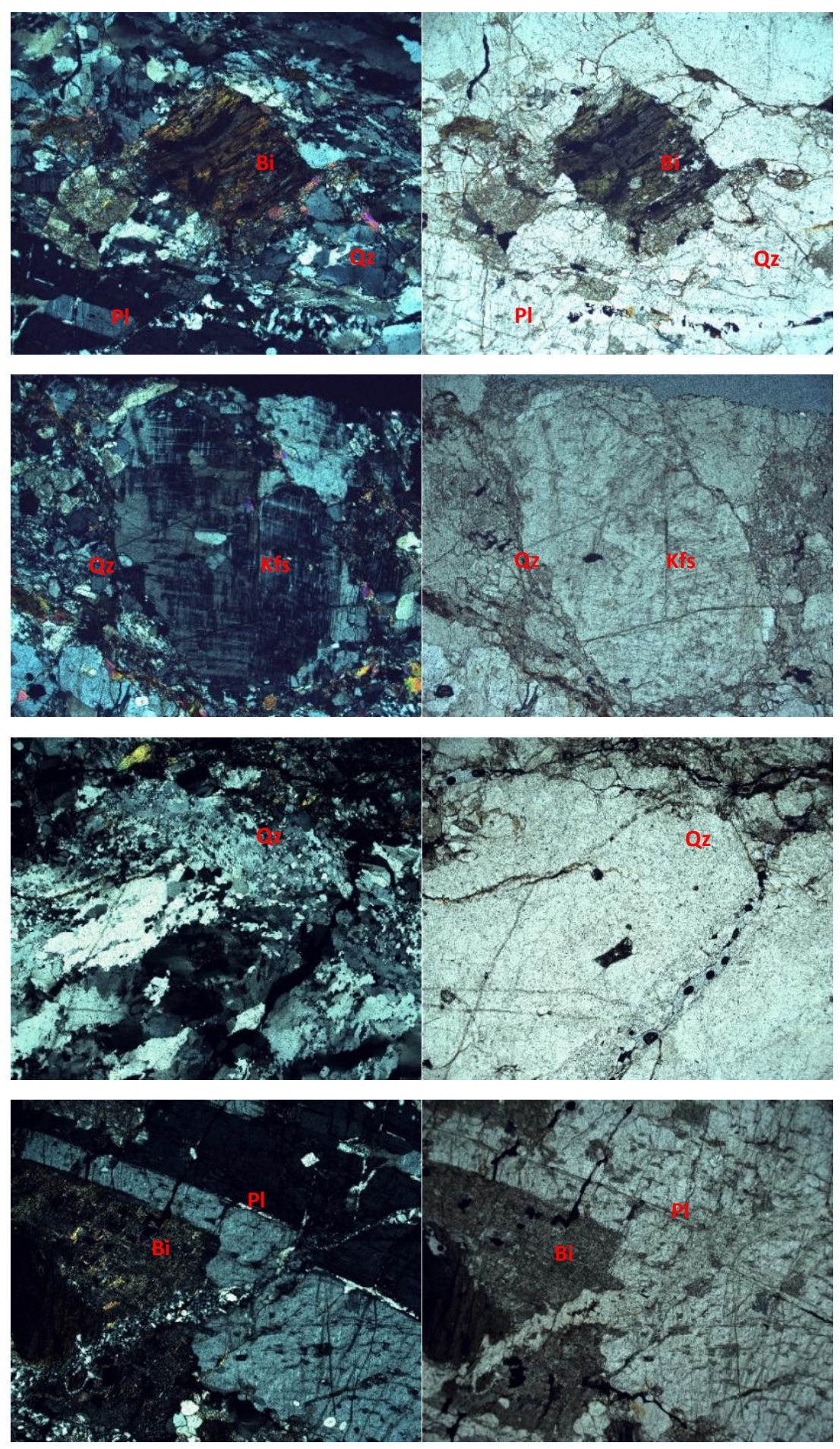

(PL)

(TL)

Figure 9.2-4: Polarized light (PL) and transmitted light (Tl) microscopic analysis of thinsection and petrography in the surface granite from the CR-Huay Mae Jai (CM-03). Abbreviations: Qz: Quartz, Kfs: K-feldspar (alkali-feldspar), Pl: plagioclase, Bi: Biotite, and Mc: Muscovite. 

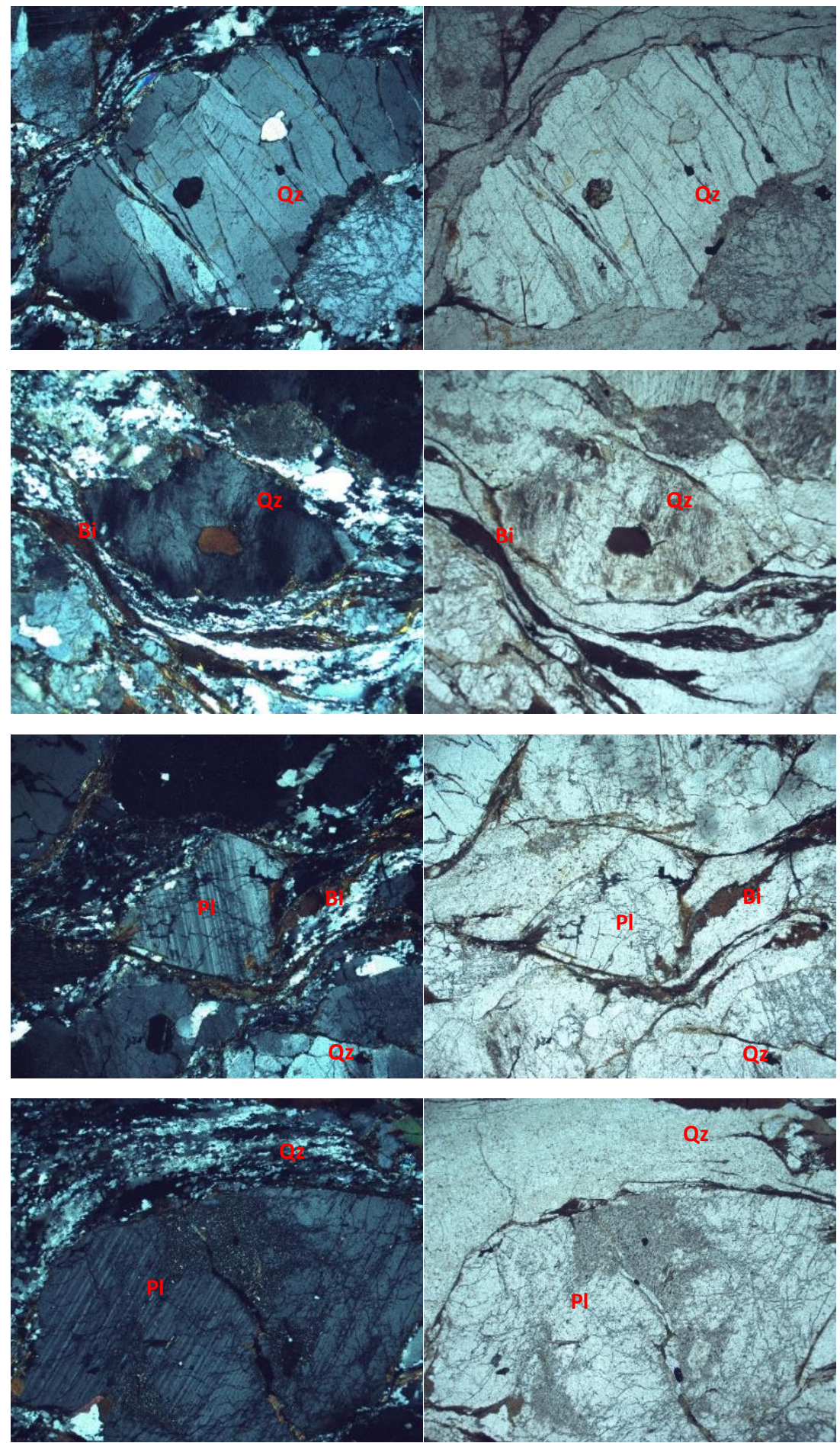

(PL)

(TL)

Figure 9.2-5: Polarized light (PL) and transmitted light (Tl) microscopic analysis of thinsection and petrography in the surface granite from the Ratchagrude hot spring (RN-5). Abbreviations: Qz: Quartz, Kfs: K-feldspar (alkali-feldspar), Pl: plagioclase, Bi: Biotite, and Mc: Muscovite. 

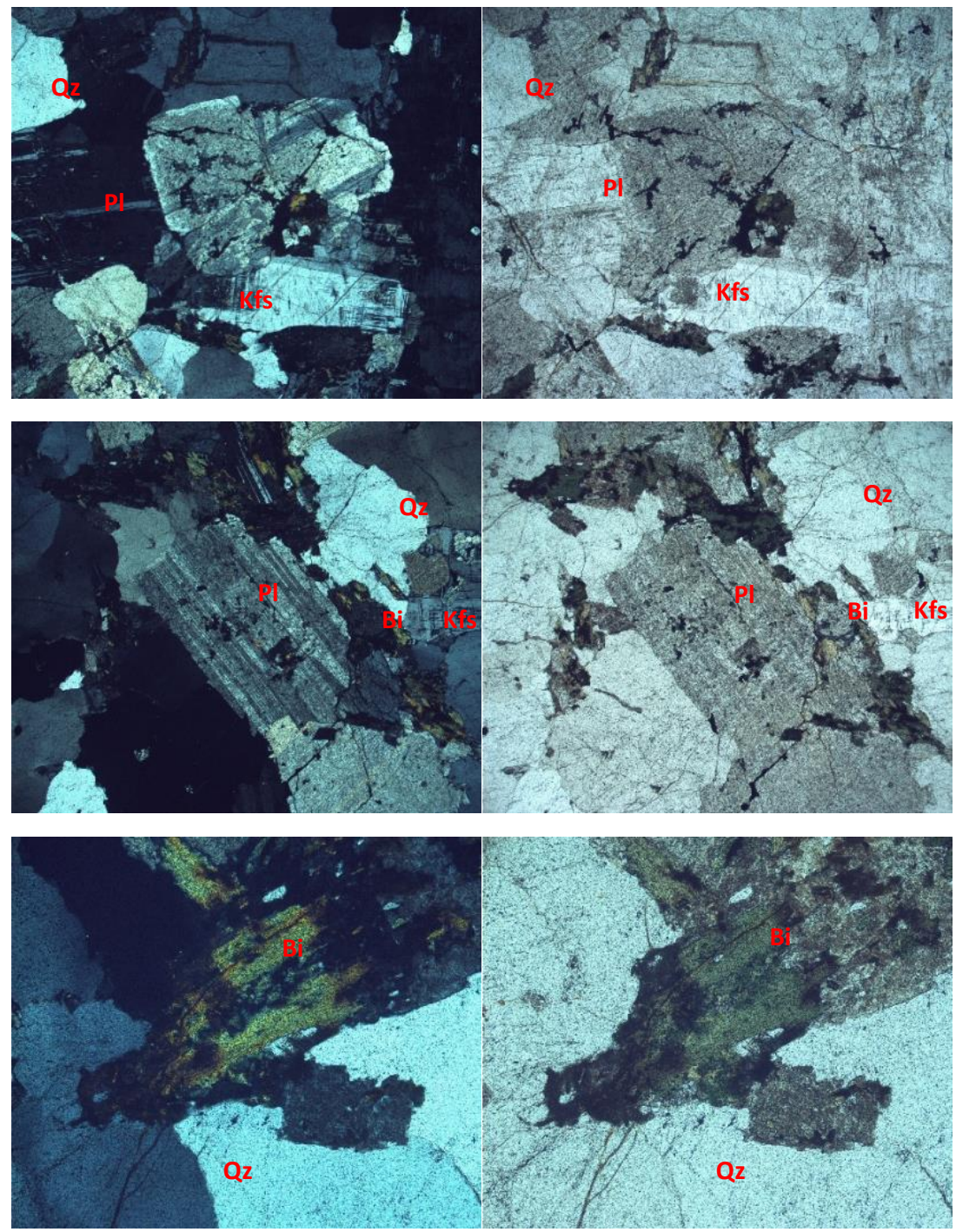

(PL)

(TL)

Figure 9.2-6: Polarized light (PL) and transmitted light ( $\mathrm{Tl})$ microscopic analysis of thinsection and petrography in the first granite sample from Ban Hat Yay hot spring (RN-6). Abbreviations: Qz: Quartz, Kfs: K-feldspar (alkali-feldspar), Pl: plagioclase, Bi: Biotite, and Mc: Muscovite. 

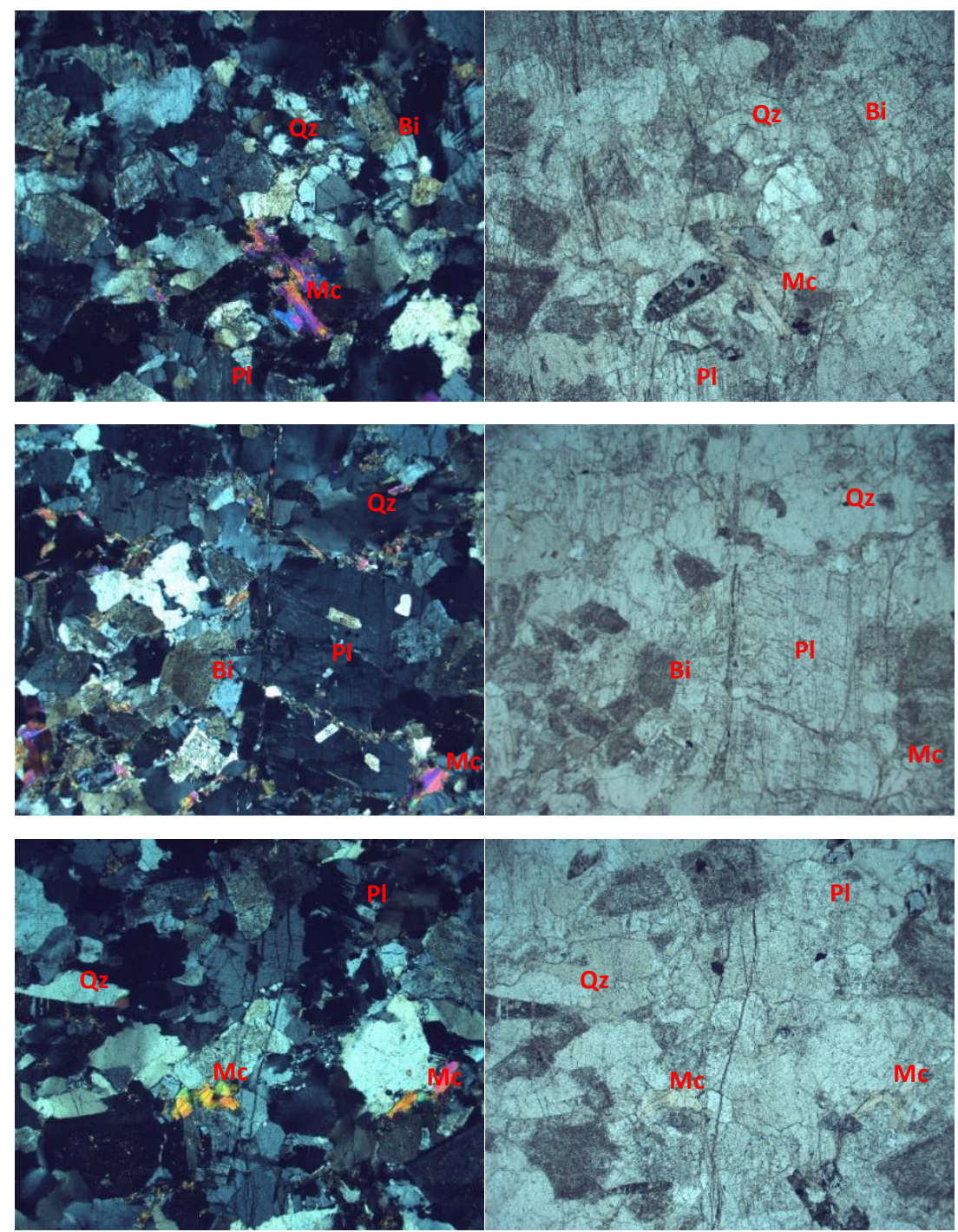

(PL)

(TL)

Figure 9.2-7: Polarized light (PL) and transmitted light $(\mathrm{Tl})$ microscopic analysis of thinsection and petrography of the second granite sample from Raksawarin hot springs (RN-1). Abbreviations: Qz: Quartz, Kfs: K-feldspar (alkali-feldspar), Pl: plagioclase, Bi: Biotite, and Mc: Muscovite. 


\section{List of publications within this study}

\section{Conference Proceeding:}

Yongprawat M., Kamdee K., Wiegand B., Sauter M. (2017) Application of natural isotope tracers to geothermal research in the Mae Chan fault zone (N Thailand). Geophysical research abstract. Vol. 19, EGU2017-14412-2, 2017. Poster presentation. EGU General Assembly 2017. April 8-13, 2017.

Yongprawat M., Wiegand B., Sauter M. (2018) Application of natural isotope tracers to geothermal research in Ranong fault zone (S-Thailand). Developments in Geothermal Energy I Posters, Poster presentation. American Geophysical Union (AGU), Fall Meeting 2018, abstract \#H11Q-1678. December 10-14, 2018 